\title{
The 2015 edition of the GEISA spectroscopic database
}

\author{
N. Jacquinet-Husson ${ }^{1 *}$, R. Armante ${ }^{2}$, N.A. Scott ${ }^{2}$, A. Chédin ${ }^{2}$, L. Crépeau ${ }^{2}$, \\ C. Boutammine ${ }^{2}$, A. Bouhdaoui ${ }^{2}$, C. Crevoisier ${ }^{2}$, V. Capelle ${ }^{2}$, C. Boonne ${ }^{3}$, \\ N. Poulet-Crovisier ${ }^{3}$, A. Barbe ${ }^{4}$, D. Chris Benner ${ }^{5}$, V. Boudon ${ }^{6}$
}

L.R. Brown ${ }^{7}$, J. Buldyreva ${ }^{8}$, A. Campargue ${ }^{9,10}$, L.H. Coudert ${ }^{11}$, V.M. Devi ${ }^{5}$, M.J. Down ${ }^{12}$, B.J. Drouin ${ }^{7}$, A. Fayt ${ }^{13}$, C. Fittschen ${ }^{14}$, J.-M Flaud ${ }^{11}$, R.R. Gamache ${ }^{15}$, J. J. Harrison ${ }^{16,17}$, C. Hill ${ }^{12}, \varnothing$. Hodnebrog ${ }^{18}, \mathrm{~S} .-\mathrm{M} \mathrm{Hu}{ }^{19}$, D. Jacquemart ${ }^{20}$, A. Jolly ${ }^{11}$, E. Jiménez ${ }^{21}$, N.N. Lavrentieva ${ }^{22}$, A.-W. Liu ${ }^{19}$, L. Lodi ${ }^{12}$, O.M. Lyulin ${ }^{22}$, S.T. Massie ${ }^{23}$, S. Mikhailenko ${ }^{24}$, H.S.P. Müller ${ }^{25}$, O.V. Naumenko ${ }^{22}$, A. Nikitin ${ }^{22}$, C.J. Nielsen ${ }^{26}$, J. Orphal $^{27}$, V.I Perevalov ${ }^{22}$, A. Perrin ${ }^{11}$, E. Polovtseva ${ }^{22}$, A. Predoi-Cross ${ }^{28}$, M. Rotger ${ }^{4}$, A. A. Ruth ${ }^{29}$, S.S Yu ${ }^{7}$, K. Sung ${ }^{7}$, S.A. Tashkun ${ }^{22}$, J. Tennyson ${ }^{12}$, Vl.G. Tyuterev ${ }^{4}$, J. Vander Auwera ${ }^{30}$, B.A. Voronin ${ }^{22}$, and A. Makie.

${ }^{1}$ Laboratoire de Météorologie Dynamique/IPSL, CNRS, UPMC Univ. Paris 06, Sorbonne Universités, 75252, Paris, France

${ }^{2}$ Laboratoire de Météorologie Dynamique/IPSL, CNRS, Ecole Polytechnique, Université Paris-Saclay, 91128, Palaiseau, France

${ }^{3}$ Institut Pierre Simon Laplace, Université Pierre et Marie Curie, 75252 Paris, France

${ }^{4}$ Université de Reims-Champagne-Ardenne, Groupe de Spectrométrie Moléculaire et Atmosphérique, 51062 Reims, France

${ }^{5}$ The College of William and Mary, Department of Physics, Williamsburg, VA 23187, USA

${ }^{6}$ Laboratoire Interdisciplinaire Carnot de Bourgogne, UMR 6303 CNRS-Univ. Bourgogne

Franche-Comté, 9 Avenue Alain Savary, BP 47 870, F-21078 DIJON Cedex, France

${ }^{7}$ Jet Propulsion Laboratory, California Institute of Technology, Pasadena, CA 91109, USA

${ }^{8}$ Institut UTINAM, UMR 6213 CNRS-Université fédérale Bourgogne Franche-Comté, 16 Route de Gray, F-25030 Besançon cedex, France

${ }^{9}$ Université Grenoble Alpes, LIPhy, F-38000 Grenoble, France;

${ }^{10}$ CNRS, LIPhy, F-38000 Grenoble, France

${ }^{11}$ CNRS et Universités Paris EST et Paris 7, Laboratoire Inter-Universitaire des Systèmes Atmosphériques, 94010 Créteil, France

${ }^{12}$ Department of Physics and Astronomy, University College London, London WC1E 6BT, United Kingdom

${ }^{13}$ Université Catholique de Louvain, Chemin du cyclotron 2, boîte L7.01.07, B-1348 Louvain-la-Neuve, Belgium

${ }^{14}$ Université Lille, CNRS, UMR 8522, PC2A, Physicochimie des Processus de Combustion et de l'Atmosphère, F 59000 Lille, France

${ }^{15}$ University of Massachusetts Lowell, Department of Environmental Earth and Atmospheric Sciences, Lowell, MA 01854, USA

${ }^{16}$ Department of Physics and Astronomy, University of Leicester, University Road, Leicester LE1 7RH, United Kingdom

${ }^{17}$ National Centre for Earth Observation, University of Leicester, University Road, LeicesterLE1 7RH, United Kingdom

${ }^{18}$ Center for International Climate and Environmental Research-Oslo (CICERO), P.O. Box 1129 Blindern, NO-0318 Oslo, Norway

${ }^{19}$ Hefei National Laboratory for Physical Sciences at Microscale, University of Science and Technology of China, Hefei, 230026 China

${ }^{20}$ Sorbonne Universités, UPMC Univ Paris 06, CNRS, UMR 8233, MONARIS, Université

Pierre et Marie Curie, 4 place Jussieu, F-75005, Paris, France 
${ }^{21}$ Department of Physical Chemistry, Faculty of Chemical Sciences and Technology, University of Castilla-La Mancha, ES-13071 Ciudad Real, Spain

${ }^{22}$ V.E. Zuev Institute of Atmospheric Optics, SB, Russian Academy of Sciences, Academician Zuev square, 634055, Tomsk, Russia

${ }^{23}$ Laboratory for Atmospheric and Space Physics, University of Colorado, Boulder, CO, 80303, USA

${ }^{24}$ V.E. Zuev Institute of Atmospheric Optics, SB, Russian Academy of Science, Akademician Zuev square, 634021, Tomsk, Russia and Mathematical Physics Department, Tomsk

Polytechnic University, 30, Lenin av., 634050, Tomsk, Russia

${ }^{25}$ I. Physikalisches Institut, Universität zu Köln, 50937 Köln, Germany

${ }^{26}$ Department of chemistry, University of Oslo, Blindern, NO-0315, Norway

${ }^{27}$ Institute for Meteorology and Climate Research Centre Karlsruhe/University of Karlsruhe (KIT), 76021 Karlsruhe, Germany

${ }^{28}$ Department of Physics and Astronomy, University of Lethbridge, Lethbridge, AB,

T1K 3M4, Canada

${ }^{29}$ Physics Department and Environmental Research Institute, University College Cork, Cork, Ireland

${ }^{30}$ Service de Chimie Quantique et Photophysique, C.P. 160/09, Université Libre de Bruxelles, 50 avenue F.D. Roosevelt, B-1050 Brussels, Belgium

* Corresponding author. Tel: +33169335162; fax: +33169335218

E-mail address: nicole.jacquinet@1md.polytechnique.fr

Number of pages for text:

Number of pages for references

Number of Tables

Number of figures

\section{Corresponding author}

Dr. Nicole Jacquinet

Phone: +33169335162 Fax: +33169335218

E-mail: nicole.jacquinet@1md.polytechnique.fr 


\section{ABSTRACT}

The GEISA database (Gestion et Etude des Informations Spectroscopiques Atmosphériques: Management and Study of Atmospheric Spectroscopic Information) has been developed and maintained by the $\underline{\operatorname{ARA} / \mathrm{ABC}(\mathrm{t})}$ group at $\underline{\mathrm{LMD}}$ since 1974. GEISA is constantly evolving, taking into account the best available spectroscopic data. This paper presents the 2015 release of GEISA (GEISA-2015), which updates the last edition of 2011 and celebrates the $40^{\text {th }}$ anniversary of the database. Significant updates and additions have been implemented in the three following independent databases of GEISA.

The "line parameters database" contains 52 molecular species (113 isotopologues) and transitions in the spectral range from $10^{-6}$ to $35,877.031 \mathrm{~cm}^{-1}$, representing 5,059,777 entries, against 3,794,297 in GEISA-2011. Among the previously existing molecules, 20 molecular species have been updated. A new molecule $\left(\mathrm{SO}_{3}\right)$ has been added. HDO, isotopologue of $\mathrm{H}_{2} \mathrm{O}$, is now identified as an independent molecular species. Six new isotopologues have been added to the GEISA-2015 database.

The "cross section sub-database" has been enriched by the addition of 43 new molecular species in its infrared part, 4 molecules (ethane, propane, acetone, acetonitrile) are also updated; they represent $3 \%$ of the update. A new section is added, in the near-infrared spectral region, involving 7 molecular species: $\mathrm{CH}_{3} \mathrm{CN}, \mathrm{CH}_{3} \mathrm{I}, \mathrm{CH}_{3} \mathrm{O}_{2}, \mathrm{H}_{2} \mathrm{CO}, \mathrm{HO}_{2}, \mathrm{HONO}$, $\mathrm{NH}_{3}$.

The "microphysical and optical properties of atmospheric aerosols sub-database" has been updated for the first time since 2003. It contains more than 40 species originating from NCAR and 20 from the ARIA archive of Oxford University.

As for the previous versions, this new release of GEISA and associated management software facilities are implemented and freely accessible on the AERIS/ESPRI atmospheric chemistry data center website.

Key words: molecular spectroscopic database, line parameters, cross sections, aerosols, earth and planetary radiative transfer 


\section{Introduction 1 :}

At the start of the second half of the 20th century, several technologies matured, initiating noTable progress in the development of molecular spectroscopy. The progress in the Hamiltonian mechanics led theoreticians to demand more precision and detail spectra, obtained from laboratory or planetary observations [1]. From the mid 1960's, various scientific communities (Astrophysics, Atmospheric Physics, Metrology and soon after, Climate and Chemistry) required access to databases detailing the spectral characteristics of atmospheric molecular absorption and atmospheric diffusion. As a result, the first standardized spectroscopic database, the so-called "AFGL tape", oriented towards the Earth's atmosphere, was initiated in 1973, at the Air Force Geophysics Laboratory USA (McClatchey et al. [2] and Garing and McClatchey [3]). This early contribution was dedicated to a few molecules $\left(\mathrm{H}_{2} \mathrm{O}, \mathrm{CO}_{2}, \mathrm{O}_{3}, \mathrm{~N}_{2} \mathrm{O}, \mathrm{CO}, \mathrm{CH}_{4}\right.$, and $\left.\mathrm{O}_{2}\right)$ important in the terrestrial atmosphere and in the infrared spectral domain. It contained approximately 100,000 transitions.

For its own applications related to the radiative transfer in the Earth and planetary atmospheres, the $\mathrm{ARA} / \mathrm{ABC}(\mathrm{t})$ group at LMD initiated a similar effort that was to lead in the early 1970's to the creation of GEISA (Gestion et Etude des Informations Spectroscopiques Atmosphériques: Management and Study of Atmospheric Spectroscopic Information), see Chédin et al. [4,5], Husson et al. [6,7], Jacquinet-Husson et al. [8,9,10,11]. Pioneering user friendly management software was an important part of the first issue of GEISA.

At that time, the GEISA archive included major atmospheric absorbers $\left(\mathrm{H}_{2} \mathrm{O}, \mathrm{CO}_{2}, \mathrm{O}_{3}\right.$, $\mathrm{N}_{2} \mathrm{O}, \mathrm{CO}, \mathrm{CH}_{4}, \mathrm{O}_{2}$ ) as well as complementary species (e.g.: $\mathrm{NH}_{3}, \mathrm{PH}_{3}, \mathrm{C}_{2} \mathrm{H}_{4}, \mathrm{GeH}_{4}, \mathrm{C}_{3} \mathrm{H}_{8}$, $\mathrm{C}_{2} \mathrm{H}_{2}, \mathrm{HC}_{3} \mathrm{~N}, \mathrm{HCOOH}, \mathrm{C}_{3} \mathrm{H}_{4}, \mathrm{NO}, \mathrm{SO}_{2}, \mathrm{NO}_{2}$ ). Some molecules, mainly related to planetary atmospheres (especially those found in the giant planets) like $\mathrm{GeH}_{4}, \mathrm{C}_{3} \mathrm{H}_{8}, \mathrm{C}_{2} \mathrm{~N}_{2}, \mathrm{C}_{3} \mathrm{H}_{4}, \mathrm{HNC}$, $\mathrm{C}_{6} \mathrm{H}_{6}$, and $\mathrm{C}_{2} \mathrm{HD}$ were also included. Since then, GEISA has been constantly updated to meet the needs of researchers as well as international space agencies, by collecting, archiving and distributing the most accurate, validated available spectroscopic information. One of the features of GEISA, in comparison with other databases such as HITRAN (the descendent of the "AFGL tape" for atmospheric and planetary remote sensing (Rothman et al. $[\mathbf{1 2 , 1 3 , 1 4 ] )}$, has been to consider, since its first edition, any isotopologue of a species having symmetry

\footnotetext{
1 Acronyms used in the text are documented in Appendix A
} 
properties different from that of the main isotopologue (e. g. $\mathrm{CH}_{3} \mathrm{D}$ and $\mathrm{CH}_{4}, \mathrm{C}_{2} \mathrm{HD}$ and $\mathrm{C}_{2} \mathrm{H}_{2}$ ) as an independent molecular species (considered as isotopologues of $\mathrm{CH}_{4}$ and $\mathrm{C}_{2} \mathrm{H}_{2}$ in HITRAN, respectively).

The comprehensive GEISA database can be compared to a number of other spectroscopic databases, such as:

- $\quad$ HITRAN [14]

- MIPAS specifically tied to satellite experiments in the Earth's atmosphere [15];

- the JPL Catalog $[\mathbf{1 6 , 1 7 ]}$ of microwave to sub-millimeter transitions which mainly contains rotational transitions for a few hundred molecules which can or may be observed in the atmospheres of the Earth or other planets, or in the interstellar- or circum-stellar medium. A small, but increasing number of entries contain infrared transitions;

- the CDMS catalog $[\mathbf{1 8 , 1 9 ]}$ which mostly contains rotational transitions of molecules, on a similar basis as the JPL catalog, related to interstellar medium studies. Some of the molecules are also of relevance for Earth's atmosphere or that of other planets. Furthermore, a number of entries deal with infrared transitions of such molecules.

Certain molecules, mainly related to planetary atmospheres (especially those of the giant planets) are specific to GEISA; these include $\mathrm{GeH}_{4}, \mathrm{C}_{3} \mathrm{H}_{8}, \mathrm{C}_{2} \mathrm{~N}_{2}, \mathrm{C}_{3} \mathrm{H}_{4}, \mathrm{HNC}, \mathrm{C}_{6} \mathrm{H}_{6}$. However, GEISA does not include species like $\mathrm{HOBr}, \mathrm{O}, \mathrm{H}_{2}$ and $\mathrm{CS}$, which are considered in HITRAN. Since the beginning, our focus has been on undertaking evaluations of relevance appropriateness and efficiency of introducing or replacing data. The rapidly evolving capacity of space-borne, ground-based or laboratory observations to deliver more and more detailed, accurate and sTable observed spectra, as well as the constant improvement of radiative transfer models, opens the way to reinforced tests for these evaluations. For example, since the launch of the high spectral resolution infrared sounders AIRS/Aqua and IASI/Metop, in 2003 and in 2006 respectively, an efficient approach has been designed for the validation of GEISA: this is performed interactively through comparisons between forward radiative transfer simulations (e.g. made by the STRANSAC or the 4A models (Scott [20], Scott and Chédin [21]) and observations of spectra made from various sounders collocated over thousands of well-characterized atmospheric and surface situations. Averaging the resulting 'calculated-observed spectra' residuals minimizes the random errors coming from both the observations and the imperfect description of the atmospheric state. This efficient approach has also proved capability of evaluating spectroscopic parameters: the resulting SPARTE 
(Spectroscopic Parameters And Radiative Transfer Evaluation) chain and related results concerning TIR, SWIR and NIR are presented by Armante et al. [22]. Armante et al. use a few representative examples to also demonstrate the relevance of the SPARTE approach to interactively refining spectroscopic parameters

Based on the valuable and sustained support of the international community of spectroscopists concomitant with this validation strategy, the $\mathrm{ARA} / \mathrm{ABC}(\mathrm{t})$ group continues to extend, maintain and update the GEISA content to incorporate the best available spectroscopic data. Since the launch of Metop-A (24 October 2006), GEISA has been the official reference spectroscopic database used by the international working group (ISSWG) in charge of IASI. GEISA is also involved in the definition of 3 future space missions such as $\underline{\text { IASI-NG }}$ (Crevoisier et al. [23]), $\underline{\text { MERLIN and MicroCarb. }}$

GEISA and its associated management software facilities are implemented and distributed (in the same way as GEISA-2011) via AERIS/ESPRI atmospheric chemistry data center website. It is used on-line by more than 350 laboratories working in domains which include atmospheric physics, planetary science, astronomy, astrophysics.

This paper describes the latest 2015 GEISA release (hereafter referred to as GEISA2015) with reference to the GEISA-2011 release and to other similar databases. It provides a detailed description of the newly implemented or corrected data, for each of the three distinct, however complementary, sub-databases: (i) line parameter in Section 2, (ii) infrared, nearinfrared and ultraviolet absorption cross-sections in Section 3, (iii) microphysical and optical properties of atmospheric aerosols in Section 4.

\section{GEISA-2015 Line parameters database description}

\subsection{General Overview}

The GEISA-2015 line parameters database contains the spectral properties of 52 molecular species (113 isotopologues) corresponding to a total of 5,049,777 entries in the spectral range from $10^{-6}$ to $35,877.031 \mathrm{~cm}^{-1}\left(10^{10}\right.$ to $\left.0.28 \mu \mathrm{m}\right)$. The reference temperature is $296 \mathrm{~K}$.

The spectroscopic line parameters of 22 of the 50 molecules included in GEISA-2011 have been updated These updates are summarized in Table 1 which gives (i) the GEISA-2015 molecule names; (ii) the corresponding GEISA codes; (iii) the name of the main contributors. 
The parameters of 30 molecules, i.e.: $\mathrm{N}_{2} \mathrm{O}, \mathrm{CO}, \mathrm{NO}, \mathrm{NO}_{2}, \mathrm{PH}_{3}, \mathrm{OH}, \mathrm{HF}, \mathrm{HCl}, \mathrm{HBr}$, HI, CLO, OCS, $\mathrm{GeH}_{4}, \mathrm{C}_{3} \mathrm{H}_{8}, \mathrm{HC}_{3} \mathrm{~N}, \mathrm{HOCl}, \mathrm{N}_{2}, \mathrm{H}_{2} \mathrm{O}_{2}, \mathrm{HCOOH}, \mathrm{COF}_{2}, \mathrm{SF}_{6}, \mathrm{C}_{3} \mathrm{H}_{4}, \mathrm{HO}_{2}$, $\mathrm{ClONO}_{2}, \mathrm{CH}_{3} \mathrm{OH}, \mathrm{NO}+, \mathrm{C}_{6} \mathrm{H}_{6}, \mathrm{C}_{2} \mathrm{HD}, \mathrm{CF}_{4}, \mathrm{CH}_{3} \mathrm{CN}$, are unchanged from GEISA-2011 with the exception that certain duplicated entries have been removed following technical validations.

Due to the fact that, for atmospheric applications, $\mathrm{H}_{2} \mathrm{O}$ and $\mathrm{HDO}$ have to be taken into account separately in the radiative transfer modeling (different vertical concentration may occur), and also considering their different symmetry properties, it has been decided to consider HDO as an independent molecular species in GEISA-2015. This option was already our choice for $\mathrm{C}_{2} \mathrm{HD}$ and $\mathrm{CH}_{3} \mathrm{D}$. The new identification code for HDO is " 51 ".

$\mathrm{SO}_{3}$ is a newly added molecular species. The identification code of $\mathrm{SO}_{3}$ is " 52 ". Details of these different updates are given in paragraphs 2.2.1 to 2.2.22. 
Table 1

Updated molecular species in the GEISA-2015 edition

\begin{tabular}{|c|c|c|}
\hline $\begin{array}{l}\text { Molecular } \\
\text { Species }\end{array}$ & ID & Contributors \\
\hline $\mathrm{H}_{2} \mathrm{O}$ & 1 & $\begin{array}{c}\text { L. Coudert, } \\
\text { J. Tennyson, } \\
\text { A. Campargue, S. Mikhailenko, } \\
\text { O.V. Naumenko, J. Orphal, A. Ruth, } \\
\text { R.R. Gamache }\end{array}$ \\
\hline $\mathrm{CO}_{2}$ & 2 & V.I. Perevalov, S. Tashkun, R.R. Gamache \\
\hline $\mathbf{O}_{3}$ & 3 & A. Barbe, S. Mikhailenko, Vl.G. Tyuterev \\
\hline $\mathrm{CH}_{4}$ & 6 & $\begin{array}{l}\text { V. Boudon, L.R. Brown, A.Campargue, } \\
\text { D.C. Benner }\end{array}$ \\
\hline $\mathbf{O}_{2}$ & 7 & S. Yu, B. Drouin \\
\hline $\mathrm{SO}_{2}$ & 9 & D. Jacquemart, H.S.P. Müller \\
\hline $\mathrm{NH}_{3}$ & 11 & M. Down, J. Tennyson, L.R. Brown \\
\hline $\mathrm{HNO}_{3}$ & 13 & A. Perrin \\
\hline $\mathrm{H}_{2} \mathrm{CO}$ & 21 & D. Jacquemart, H.S.P. Müller \\
\hline $\mathbf{C}_{2} \mathbf{H}_{6}$ & 22 & L.R. Brown, K.Y. Sung \\
\hline $\mathrm{CH}_{3} \mathrm{D}$ & 23 & L.R. Brown, A. Campargue. \\
\hline $\mathrm{C}_{2} \mathrm{H}_{2}$ & 24 & D. Jacquemart \\
\hline $\mathrm{C}_{2} \mathbf{H}_{4}$ & 25 & J.-M. Flaud \\
\hline HCN & 27 & J. Tennyson \\
\hline $\mathbf{C}_{2} \mathbf{N}_{2}$ & 29 & A. Jolly, A. Fayt \\
\hline $\mathbf{C}_{4} \mathbf{H}_{2}$ & 30 & A. Jolly, A. Fayt \\
\hline $\mathrm{CH}_{3} \mathrm{Cl}$ & 34 & D. Jacquemart, A. Nikitin, J. Buldyreva, N. Lavrentieva \\
\hline $\mathbf{H}_{2} \mathbf{S}$ & 36 & O.V. Naumenko, L.R. Brown \\
\hline $\mathrm{CH}_{3} \mathbf{B r}$ & 43 & D. Jacquemart. \\
\hline HNC & 46 & J. Tennyson \\
\hline HDO (NEW) & 51 & $\begin{array}{c}\text { A. Campargue, S. Mikhailenko, O.V. Naumenko, } \\
\text { R.R. Gamache }\end{array}$ \\
\hline $\mathrm{SO}_{3}(\mathrm{NEW})$ & 52 & J. Tennyson, D.S. Underwood \\
\hline
\end{tabular}


Table 2 summarizes the evolution, since GEISA-2011, of each of the 50 molecular species in the GEISA-2015 line parameters database in term of: (i) spectral range $\left(\mathrm{cm}^{-1}\right)$; (ii) the number of lines; (iii) the minimum and maximum of the intensities $\left(\mathrm{cm}\right.$ molecule ${ }^{-1}$ at 296 $\mathrm{K})$, expressed in terms of maximum and minimum values of the intensity exponent. Columns 3 to 6 correspond to GEISA-2011 and columns 7 to 10 to GEISA-2015. The molecule names and identification numbers are in the 2 first columns, and the references of their updates in the last column.

\section{Table 2}

Contents of the GEISA-2015 line parameters database. Details per molecule of the evolution of GEISA contents since its 2011 edition. Reference temperature is $296 \mathrm{~K}$.

\begin{tabular}{|c|c|c|c|c|c|c|c|c|c|c|}
\hline \multirow{3}{*}{ Mol.. } & \multirow{3}{*}{ ID } & \multicolumn{4}{|c|}{ GEISA-2011 } & \multicolumn{4}{|c|}{ GEISA-2015 } & \multirow[t]{3}{*}{ Refs } \\
\hline & & \multirow[t]{2}{*}{$\begin{array}{l}\text { Spectral range } \\
\left(\mathrm{cm}^{-1}\right)\end{array}$} & \multirow[t]{2}{*}{ \# lines } & \multicolumn{2}{|c|}{$\begin{array}{l}\text { Exponent of the } \\
\text { intensity } \\
\left(\mathrm{cm} \text { molecule }^{-1}\right) \\
\text { at } 296 \mathrm{~K} . \\
\end{array}$} & \multirow[t]{2}{*}{$\begin{array}{l}\text { Spectral range } \\
\left(\mathrm{cm}^{-1}\right)\end{array}$} & \multirow[t]{2}{*}{ \# lines } & \multicolumn{2}{|c|}{$\begin{array}{c}\text { Exponent of } \\
\text { the intensity } \\
\left(\mathrm{cm} \text { molecule }^{-1}\right) \\
\text { at } 296 \mathrm{~K} \text {. }\end{array}$} & \\
\hline & & & & Max. & Min. & & & Max. & Min. & \\
\hline $\mathrm{H}_{2} \mathrm{O}$ & 1 & $0.007-25232.004$ & 67789 & -18 & -33 & $0.052-25336.949$ & 191846 & -18 & -36 & {$[24-83]$} \\
\hline $\mathrm{CO}_{2}$ & 2 & $5.891-12784.053$ & 413619 & -18 & -42 & $5.890-14075.298$ & 534227 & -18 & -30 & [84-105] \\
\hline $\mathrm{O}_{3}$ & 3 & $0.026-6395.379$ & 389378 & -20 & -31 & $0.026-6996.681$ & 405919 & -20 & -31 & [106-131] \\
\hline $\mathrm{N}_{2} \mathrm{O}$ & 4 & $0.838-7796.633$ & 50633 & -17 & -25 & $0.838-7796.633$ & 50633 & -17 & -25 & No Update \\
\hline $\mathrm{CO}$ & 5 & $3.414-8464.882$ & 13515 & -18 & -77 & $3.414-8464.882$ & 13515 & -18 & -77 & No Update \\
\hline $\mathrm{CH}_{4}$ & 6 & $0.001-9199.284$ & 240991 & -19 & -39 & $0.001-11501.877$ & 421811 & -19 & -39 & [132-162] \\
\hline $\mathrm{O}_{2}$ & 7 & $10^{-6}-15927.230$ & 6428 & -24 & -51 & $10-6-15927.804$ & 16197 & -24 & -54 & [163-174] \\
\hline $\mathrm{NO}$ & 8 & $10^{-6}-9273.214$ & 105079 & -19 & -94 & $10-6-9273.214$ & 105079 & -19 & -94 & No Update \\
\hline $\mathrm{SO}_{2}$ & 9 & $0.017-4092.948$ & 68728 & -20 & -28 & $0.017-4092.948$ & 83668 & -20 & -30 & [175-182] \\
\hline $\mathrm{NO}_{2}$ & 10 & $0.498-3074.152$ & 104223 & -18 & -27 & $0.498-3074.152$ & 104223 & -18 & -27 & No Update \\
\hline $\mathrm{NH}_{3}$ & 11 & $0.058-5294.501$ & 29082 & -19 & -39 & $0.058-6999.429$ & 46414 & -19 & -39 & [183-192] \\
\hline $\mathrm{PH}_{3}$ & 12 & $17.805-3601.652$ & 20364 & -18 & -27 & $17.805-3601.652$ & 20364 & -18 & -27 & No Update \\
\hline $\mathrm{HNO}_{3}$ & 13 & $0.012-1769.982$ & 669988 & -20 & -28 & $0.012-1769.982$ & 691161 & -20 & -28 & [193-197] \\
\hline $\mathrm{OH}$ & 14 & $0.005-35877.031$ & 42866 & -16 & -84 & $0.005-35877.031$ & 42866 & -16 & -84 & No Update \\
\hline $\mathrm{HF}$ & 15 & $41.111-11535.570$ & 107 & -16 & -25 & $41.111-11535.570$ & 107 & -16 & -25 & No Update \\
\hline $\mathrm{HCl}$ & 16 & $20.240-13457.841$ & 533 & -18 & -25 & $20.240-13457.841$ & 533 & -18 & -25 & No Update \\
\hline $\mathrm{HBr}$ & 17 & $16.231-9758.564$ & 1293 & -18 & -32 & $16.231-9758.564$ & 1293 & -18 & -32 & No Update \\
\hline $\mathrm{HI}$ & 18 & $12.509-8487.305$ & 806 & -19 & -29 & $12.509-8487.305$ & 806 & -19 & -29 & No Update \\
\hline $\mathrm{ClO}$ & 19 & $0.015-1207.639$ & 7230 & -20 & -29 & $0.015-1207.639$ & 7230 & -20 & -29 & No Update \\
\hline OCS & 20 & $0.381-4199.671$ & 33809 & -17 & -27 & $0.381-4199.671$ & 33809 & -17 & -27 & No Update \\
\hline $\mathrm{H}_{2} \mathrm{CO}$ & 21 & $3 \times 10^{-6}-3099.958$ & 37050 & -20 & -38 & $0.000-3099.958$ & 44611 & -20 & -39 & [198-206] \\
\hline $\mathrm{C}_{2} \mathrm{H}_{6}$ & 22 & $706.601-3000.486$ & 27644 & -20 & -29 & $706.601-3070.971$ & 53803 & -20 & -29 & {$[207-218$} \\
\hline $\mathrm{CH}_{3} \mathrm{D}$ & 23 & $7.7602-6510.326$ & 49237 & -23 & -30 & $7.760-6510.324$ & 58763 & -23 & -30 & [219-223] \\
\hline $\mathrm{C}_{2} \mathrm{H}_{2}$ & 24 & $604.774-9889.038$ & 11340 & -18 & -28 & $604.774-9889.038$ & 12969 & -18 & -28 & [224-227] \\
\hline $\mathrm{C}_{2} \mathrm{H}_{4}$ & 25 & $701.203-3242.172$ & 18378 & -20 & -37 & $614.740-3242.172$ & 53227 & -20 & -37 & [228-231] \\
\hline $\mathrm{GeH}_{4}$ & 26 & $1937.371-224.570$ & 824 & -18 & -21 & $1937.371-224.570$ & 824 & -18 & -21 & No Update \\
\hline $\mathrm{HCN}$ & 27 & $0.006-17581.010$ & 82042 & -19 & -34 & $0.018-17581.009$ & 138103 & -19 & -32 & [232-236] \\
\hline $\mathrm{C}_{3} \mathrm{H}_{8}$ & 28 & $700.015-799.930$ & 8983 & -21 & -23 & $700.015-799.930$ & 8983 & -21 & -23 & No Update \\
\hline $\mathrm{C}_{2} \mathrm{~N}_{2}$ & 29 & $203.955-2181.690$ & 2577 & -20 & -24 & $200.817-2181.690$ & 71954 & -20 & -24 & [237-240] \\
\hline $\mathrm{C}_{4} \mathrm{H}_{2}$ & 30 & $191.635-730.235$ & 119480 & -19 & -24 & $189.422-1302.217$ & 417540 & -19 & -24 & [241-247] \\
\hline $\mathrm{HC}_{3} \mathrm{~N}$ & 31 & $463.604-759.989$ & 179347 & -19 & -23 & $463.604-759.989$ & 179347 & -19 & -23 & No Update \\
\hline $\mathrm{HOCl}$ & 32 & $0.0236-3799.682$ & 17862 & -19 & -27 & $0.0236-3799.682$ & 17862 & -19 & -27 & No Update \\
\hline
\end{tabular}




\begin{tabular}{|c|c|c|c|c|c|c|c|c|c|c|}
\hline \multirow{3}{*}{ Mol.. } & \multirow{3}{*}{ ID } & \multicolumn{4}{|c|}{ GEISA-2011 } & \multicolumn{4}{|c|}{ GEISA-2015 } & \multirow[t]{3}{*}{ Refs } \\
\hline & & \multirow[t]{2}{*}{$\begin{array}{c}\text { Spectral range } \\
\left(\mathrm{cm}^{-1}\right)\end{array}$} & \multirow[t]{2}{*}{ \# lines } & \multicolumn{2}{|c|}{$\begin{array}{l}\text { Exponent of the } \\
\text { intensity } \\
\left(\text { cm molecule } \text { - }^{-1}\right) \\
\text { at } 296 \mathrm{~K} .\end{array}$} & \multirow[t]{2}{*}{$\begin{array}{c}\text { Spectral range } \\
\left(\mathrm{cm}^{-1}\right)\end{array}$} & \multirow[t]{2}{*}{ \# lines } & \multicolumn{2}{|c|}{$\begin{array}{c}\text { Exponent of } \\
\text { the intensity } \\
\left(\mathrm{cm} \text { molecule }^{-1}\right) \\
\text { at } 296 \mathrm{~K} .\end{array}$} & \\
\hline & & & & Max. & Min. & & & Max. & Min. & \\
\hline $\mathrm{N}_{2}$ & 33 & $1992.63-2625.497$ & 120 & -27 & -33 & $1992.63-2625.497$ & 120 & -27 & -33 & No Update \\
\hline $\mathrm{CH}_{3} \mathrm{Cl}$ & 34 & $674.143-3172.927$ & 18344 & -20 & -32 & $0.872-3197.961$ & 83043 & -21 & -32 & [248-264] \\
\hline $\mathrm{H}_{2} \mathrm{O}_{2}$ & 35 & $0.043-1730.371$ & 126983 & -19 & -28 & $0.043-1730.371$ & 126983 & -19 & -28 & No Update \\
\hline $\mathrm{H}_{2} \mathrm{~S}$ & 36 & $2.985-4256.547$ & 20788 & -19 & -26 & $\begin{array}{lll}1.030 & -1329.780\end{array}$ & 58650 & -19 & -30 & {$[265-278]$} \\
\hline $\mathrm{HCOOH}$ & 37 & $10.018-1889.334$ & 62684 & -19 & -25 & $10.018-1889.334$ & 62684 & -19 & -25 & No Update \\
\hline $\mathrm{COF}_{2}$ & 38 & $725.005-2001.348$ & 70904 & -19 & -23 & $725.005-2001.348$ & 70904 & -19 & -23 & No Update \\
\hline $\mathrm{SF}_{6}$ & 39 & $588.488-975.787$ & 92398 & -19 & -23 & $588.488-975.787$ & 92398 & -19 & -23 & No Update \\
\hline $\mathrm{C}_{3} \mathrm{H}_{4}$ & 40 & $288.913-673.479$ & 19001 & -19 & -23 & $288.913-673.479$ & 19001 & -19 & -23 & No Update \\
\hline $\mathrm{HO}_{2}$ & 41 & $0.173-3675.819$ & 38804 & -19 & -25 & $0.173-3675.819$ & 38804 & -19 & -25 & No Update \\
\hline $\mathrm{ClONO}_{2}$ & 42 & $0.636-797.741$ & 356899 & -21 & -27 & $0.636-797.741$ & 356899 & -21 & -27 & No Update \\
\hline $\mathrm{CH}_{3} \mathrm{Br}$ & 43 & $794.403-1705.612$ & 36911 & -21 & -27 & $794.403-1705.612$ & 36911 & -21 & -27 & [279] \\
\hline $\mathrm{CH}_{3} \mathrm{OH}$ & 44 & $0.019-1407.206$ & 19897 & -19 & -34 & $0.019-1407.206$ & 19897 & -19 & -34 & No Update \\
\hline $\mathrm{NO}^{+}$ & 45 & $1634.83-2530.462$ & 1206 & -18 & -80 & $1634.83-2530.462$ & 1206 & -18 & -80 & No Update \\
\hline HNC & 46 & $0.217-4814.904$ & 5619 & -18 & -25 & $0.145-4692.098$ & 75554 & -18 & -30 & [280-281] \\
\hline $\mathrm{C}_{6} \mathrm{H}_{6}$ & 47 & $642.427-705.262$ & 9797 & -20 & -23 & $642.427-705.262$ & 9797 & -20 & -23 & No Update \\
\hline $\mathrm{C}_{2} \mathrm{HD}$ & 48 & $416.785-34264$ & 15512 & -22 & -28 & $416.785-3421.864$ & 15512 & -22 & -28 & No Update \\
\hline $\mathrm{CF}_{4}$ & 49 & $594.581-1312.647$ & 60033 & -19 & -23 & $594.581-1312.647$ & 60033 & -19 & -23 & No Update \\
\hline $\mathrm{CH}_{3} \mathrm{CN}$ & 50 & $890.052-1650.000$ & 17172 & -19 & -37 & $890.052-1650.000$ & 17172 & -19 & -37 & No Update \\
\hline HDO & 51 & - & - & - & - & $0.007-17080.098$ & 63641 & -22 & -33 & [282-293] \\
\hline $\mathrm{SO}_{3}$ & 52 & - & - & - & - & $0.477-2824.347$ & 10881 & -19 & -31 & [294-302] \\
\hline \multicolumn{6}{|c|}{ Total \# lines: } & \multicolumn{5}{|c|}{ Total \# lines } \\
\hline \multicolumn{6}{|c|}{$3,794,297$} & \multicolumn{5}{|c|}{$5,049,777$} \\
\hline
\end{tabular}

Notes: "No Update" in the "Refs." column indicates that only minor technical corrections were made for the given molecule between GEISA-2011 to GEISA-2015.

(-) Missing data.

Table 3 summarizes, for each individual molecular species implemented in the GEISA-2015 line parameters database, information on each of its associated isotopologues. It is organized as follows: (i) individual GEISA-2015 molecular species names ("Mol.”); (ii) molecular species corresponding identification codes (“ID” codes, defined for the GEISA management software), (iii) each molecule ID associated isotopologue identification codes "Isot ID" (See Appendix $\mathrm{C}$ for corresponding this identifier); (iv) to (viii) the number of lines with associated minimum and maximum wave numbers $\left(\mathrm{cm}^{-1}\right)$ and intensities (in cm molecule ${ }^{-1}$ at 296 K). 


\section{Table 3}

The GEISA-2015 line parameters database. Spectral and intensity ranges per molecule and per isotopologue. The third column "Isot ID" indicates the isotopologue identification. The notation used for GEISA in described in the Appendix C

\begin{tabular}{|c|c|c|c|c|c|c|c|}
\hline Mol. & ID & $\begin{array}{l}\text { Isot. } \\
\text { ID. }\end{array}$ & \# lines & $\begin{array}{c}\text { Minimum } \\
\text { Wave } \\
\text { number } \\
\left(\mathrm{cm}^{-1}\right)\end{array}$ & $\begin{array}{c}\text { Maximum } \\
\text { Wave } \\
\text { number } \\
\left(\mathrm{cm}^{-1}\right)\end{array}$ & $\begin{array}{c}\text { Minimum } \\
\text { Intensity } \\
\left(\mathrm{cm} \text { molecule }^{-1}\right) \\
\text { at } 296 \mathrm{~K} \\
\end{array}$ & $\begin{array}{c}\text { Maximum } \\
\text { Intensity } \\
\left(\mathrm{cm} \text { molecule }^{-1}\right) \\
\text { at } 296 \mathrm{~K} \\
\end{array}$ \\
\hline \multirow[t]{5}{*}{$\mathrm{H}_{2} \mathrm{O}$} & \multirow[t]{5}{*}{1} & 161 & 119885 & 0.400560 & 25336.948790 & $1.070 \times 10^{-30}$ & $2.656 \times 10^{-18}$ \\
\hline & & 181 & 39613 & 0.052583 & 19917.617846 & $8.470 \times 10^{-36}$ & $5.270 \times 10^{-21}$ \\
\hline & & 171 & 26215 & 0.451497 & 19945.257171 & $4.857 \times 10^{-35}$ & $9.860 \times 10^{-22}$ \\
\hline & & 262 & 5971 & 5.060500 & 7979.071900 & $7.310 \times 10^{-33}$ & $1.751 \times 10^{-26}$ \\
\hline & & 282 & 162 & 6328.068400 & 6637.658200 & $1.530 \times 10^{-35}$ & $5.640 \times 10^{-34}$ \\
\hline \multirow[t]{12}{*}{$\mathrm{CO}_{2}$} & \multirow[t]{12}{*}{2} & 626 & 170846 & 345.935822 & 14075.298241 & $1.000 \times 10^{-30}$ & $3.551 \times 10^{-18}$ \\
\hline & & 636 & 70462 & 408.380298 & 13734.963032 & $1.000 \times 10^{-30}$ & $3.741 \times 10^{-20}$ \\
\hline & & 628 & 115942 & 5.890710 & 12677.181338 & $1.000 \times 10^{-30}$ & $6.800 \times 10^{-21}$ \\
\hline & & 627 & 72120 & 10.599802 & 12726.561843 & $1.000 \times 10^{-30}$ & $1.263 \times 10^{-21}$ \\
\hline & & 638 & 40143 & 461.995234 & 9212.608647 & $1.000 \times 10^{-30}$ & $7.964 \times 10^{-23}$ \\
\hline & & 637 & 23901 & 493.881436 & 8061.740848 & $1.000 \times 10^{-30}$ & $1.388 \times 10^{-23}$ \\
\hline & & 828 & 10593 & 482.813154 & 8162.742864 & $1.000 \times 10^{-30}$ & $1.317 \times 10^{-23}$ \\
\hline & & 728 & 15206 & 498.616897 & 8193.172140 & $1.000 \times 10^{-30}$ & $2.529 \times 10^{-24}$ \\
\hline & & 838 & 3111 & 539.626449 & 6687.643142 & $1.002 \times 10^{-30}$ & $1.413 \times 10^{-25}$ \\
\hline & & 727 & 6623 & 535.357499 & 6932.953775 & $1.001 \times 10^{-30}$ & $2.858 \times 10^{-25}$ \\
\hline & & 738 & 3621 & 555.753837 & 4915.047803 & $1.000 \times 10^{-30}$ & $2.706 \times 10^{-26}$ \\
\hline & & 737 & 1659 & 575.852870 & 4822.770500 & $1.004 \times 10^{-30}$ & $3.014 \times 10^{-27}$ \\
\hline \multirow[t]{5}{*}{$\mathrm{O}_{3}$} & \multirow[t]{5}{*}{3} & 666 & 249673 & 0.026300 & 6996.680800 & $3.904 \times 10^{-29}$ & $4.060 \times 10^{-20}$ \\
\hline & & 668 & 44302 & 0.920900 & 2767.874110 & $4.692 \times 10^{-28}$ & $7.760 \times 10^{-23}$ \\
\hline & & 686 & 24886 & 1.176800 & 2739.289270 & $9.970 \times 10^{-29}$ & $7.560 \times 10^{-23}$ \\
\hline & & 667 & 58171 & 0.289037 & 820.380127 & $5.135 \times 10^{-31}$ & $5.356 \times 10^{-25}$ \\
\hline & & 676 & 28887 & 0.212814 & 822.795105 & $1.433 \times 10^{-31}$ & $5.827 \times 10^{-25}$ \\
\hline \multirow[t]{8}{*}{$\mathrm{N}_{2} \mathrm{O}$} & \multirow[t]{8}{*}{4} & 446 & 34468 & 0.838022 & 7796.633112 & $4.650 \times 10^{-26}$ & $1.003 \times 10^{-18}$ \\
\hline & & 456 & 4466 & 5.028000 & 5088.905757 & $5.220 \times 10^{-26}$ & $3.423 \times 10^{-21}$ \\
\hline & & 546 & 4841 & 4.858000 & 4992.236153 & $4.720 \times 10^{-26}$ & $3.513 \times 10^{-21}$ \\
\hline & & 448 & 4412 & 541.341626 & 4672.579499 & $1.614 \times 10^{-25}$ & $1.930 \times 10^{-21}$ \\
\hline & & 447 & 1778 & 549.366695 & 4429.961520 & $1.614 \times 10^{-25}$ & $4.017 \times 10^{-22}$ \\
\hline & & 458 & 105 & 2121.769638 & 2203.982901 & $1.673 \times 10^{-25}$ & $6.637 \times 10^{-24}$ \\
\hline & & 548 & 108 & 2144.997413 & 2226.290105 & $1.675 \times 10^{-25}$ & $7.631 \times 10^{-24}$ \\
\hline & & 556 & 455 & 1226.535927 & 3415.767844 & $1.642 \times 10^{-25}$ & $1.210 \times 10^{-23}$ \\
\hline \multirow[t]{6}{*}{$\mathrm{CO}$} & \multirow[t]{6}{*}{5} & 26 & 5908 & 3.530098 & 8464.881965 & $7.880 \times 10^{-78}$ & $4.460 \times 10^{-19}$ \\
\hline & & 36 & 4768 & 3.414267 & 8180.218750 & $3.610 \times 10^{-73}$ & $4.690 \times 10^{-21}$ \\
\hline & & 27 & 748 & 3.714216 & 6338.061200 & $8.190 \times 10^{-40}$ & $1.600 \times 10^{-22}$ \\
\hline & & 28 & 770 & 3.629408 & 6266.577400 & $7.610 \times 10^{-39}$ & $8.320 \times 10^{-22}$ \\
\hline & & 37 & 580 & 1807.870900 & 6196.551100 & $1.030 \times 10^{-36}$ & $1.680 \times 10^{-24}$ \\
\hline & & 38 & 741 & 3.462498 & 6123.294200 & $2.580 \times 10^{-40}$ & $8.700 \times 10^{-24}$ \\
\hline \multirow[t]{2}{*}{$\mathrm{CH}_{4}$} & \multirow[t]{2}{*}{6} & 211 & 315765 & 0.001063 & 11501.877400 & $1.030 \times 10^{-39}$ & $2.114 \times 10^{-19}$ \\
\hline & & 311 & 106046 & 0.001063 & 11318.549800 & $1.172 \times 10^{-39}$ & $2.362 \times 10^{-21}$ \\
\hline \multirow[t]{3}{*}{$\mathrm{O}_{2}$} & \multirow[t]{3}{*}{7} & 66 & 1902 & 0.000001 & 15927.804099 & $7.233 \times 10^{-51}$ & $8.797 \times 10^{-24}$ \\
\hline & & 67 & 13392 & 0.000001 & 14537.832826 & $1.960 \times 10^{-54}$ & $3.437 \times 10^{-27}$ \\
\hline & & 68 & 903 & 1.572090 & 15852.677413 & $1.186 \times 10^{-35}$ & $1.675 \times 10^{-26}$ \\
\hline \multirow[t]{3}{*}{$\mathrm{NO}$} & \multirow[t]{3}{*}{8} & 46 & 103701 & 0.000001 & 9273.214340 & $1.451 \times 10^{-95}$ & $2.322 \times 10^{-20}$ \\
\hline & & 48 & 679 & 1601.909400 & 2038.846100 & $4.190 \times 10^{-28}$ & $1.390 \times 10^{-22}$ \\
\hline & & 56 & 699 & 1609.585400 & 2060.462500 & $4.430 \times 10^{-28}$ & $2.550 \times 10^{-22}$ \\
\hline
\end{tabular}




\begin{tabular}{|c|c|c|c|c|c|c|c|}
\hline Mol. & ID & $\begin{array}{l}\text { Isot. } \\
\text { ID. }\end{array}$ & \# lines & $\begin{array}{c}\text { Minimum } \\
\text { Wave } \\
\text { number } \\
\left(\mathrm{cm}^{-1}\right)\end{array}$ & $\begin{array}{c}\text { Maximum } \\
\text { Wave } \\
\text { number } \\
\left(\mathrm{cm}^{-1}\right)\end{array}$ & $\begin{array}{c}\text { Minimum } \\
\text { Intensity } \\
\left(\mathrm{cm} \text { molecule }^{-1}\right) \\
\text { at } 296 \mathrm{~K}\end{array}$ & $\begin{array}{c}\text { Maximum } \\
\text { Intensity } \\
\left(\text { cm molecule } \text { m }^{-1}\right) \\
\text { at } 296 \mathrm{~K}\end{array}$ \\
\hline \multirow[t]{2}{*}{$\mathrm{SO}_{2}$} & \multirow[t]{2}{*}{9} & 626 & 72903 & 0.017394 & 4092.948220 & $2.864 \times 10^{-30}$ & $4.851 \times 10^{-20}$ \\
\hline & & 646 & 10765 & 1060.195581 & 2500.400420 & $4.980 \times 10^{-24}$ & $2.100 \times 10^{-21}$ \\
\hline $\mathrm{NO}_{2}$ & 10 & 646 & 104223 & 0.497999 & 3074.152650 & $4.240 \times 10^{-28}$ & $1.302 \times 10^{-19}$ \\
\hline \multirow[t]{2}{*}{$\mathrm{NH}_{3}$} & \multirow[t]{2}{*}{11} & 411 & 45324 & 0.058210 & 6999.428900 & $2.115 \times 10^{-39}$ & $5.493 \times 10^{-19}$ \\
\hline & & 511 & 1090 & 0.374789 & 5179.785600 & $5.460 \times 10^{-29}$ & $1.992 \times 10^{-21}$ \\
\hline $\mathrm{PH}_{3}$ & 12 & 131 & 20364 & 8.904310 & 3601.652010 & $1.849 \times 10^{-28}$ & $2.520 \times 10^{-19}$ \\
\hline \multirow[t]{2}{*}{ HNO3 } & \multirow[t]{2}{*}{13} & 146 & 669988 & 0.011922 & 1769.982240 & $3.590 \times 10^{-28}$ & $3.130 \times 10^{-20}$ \\
\hline & & 156 & 21173 & 830.370600 & 922.931350 & $3.000 \times 10^{-25}$ & $3.300 \times 10^{-23}$ \\
\hline \multirow[t]{3}{*}{$\mathrm{OH}$} & \multirow[t]{3}{*}{14} & 61 & 42711 & 0.004620 & 35877.030506 & $1.500 \times 10^{-85}$ & $6.450 \times 10^{-17}$ \\
\hline & & 62 & 90 & 0.009943 & 1.824065 & $2.090 \times 10^{-31}$ & $5.780 \times 10^{-29}$ \\
\hline & & 81 & 65 & 0.052846 & 6.325014 & $1.200 \times 10^{-30}$ & $1.200 \times 10^{-26}$ \\
\hline $\mathrm{HF}$ & 15 & 19 & 107 & 41.110982 & 11535.570000 & $1.110 \times 10^{-26}$ & $1.440 \times 10^{-17}$ \\
\hline \multirow[t]{2}{*}{$\mathrm{HCl}$} & \multirow[t]{2}{*}{16} & 15 & 284 & 20.270297 & 13457.840907 & $1.090 \times 10^{-26}$ & $5.030 \times 10^{-19}$ \\
\hline & & 17 & 249 & 20.240304 & 10994.721087 & $1.010 \times 10^{-26}$ & $1.610 \times 10^{-19}$ \\
\hline \multirow[t]{2}{*}{$\mathrm{HBr}$} & \multirow[t]{2}{*}{17} & 11 & 642 & 16.231550 & 9757.189365 & $1.528 \times 10^{-32}$ & $1.178 \times 10^{-19}$ \\
\hline & & 19 & 651 & 16.236523 & 9758.311660 & $9.450 \times 10^{-33}$ & $1.211 \times 10^{-19}$ \\
\hline $\mathrm{HI}$ & 18 & 17 & 806 & 12.509418 & 8487.304744 & $1.644 \times 10^{-30}$ & $3.423 \times 10^{-20}$ \\
\hline \multirow[t]{2}{*}{$\mathrm{ClO}$} & \multirow[t]{2}{*}{19} & 56 & 3599 & 0.027699 & 1207.639162 & $1.520 \times 10^{-29}$ & $3.240 \times 10^{-21}$ \\
\hline & & 76 & 3631 & 0.014605 & 1199.839726 & $5.090 \times 10^{-30}$ & $1.030 \times 10^{-21}$ \\
\hline \multirow[t]{6}{*}{ OCS } & \multirow[t]{6}{*}{20} & 622 & 19130 & 0.405713 & 4199.671388 & $4.398 \times 10^{-26}$ & $1.220 \times 10^{-18}$ \\
\hline & & 624 & 6665 & 0.395798 & 4165.233004 & $6.400 \times 10^{-27}$ & $4.720 \times 10^{-20}$ \\
\hline & & 632 & 3243 & 0.404408 & 4055.089955 & $1.720 \times 10^{-27}$ & $1.200 \times 10^{-20}$ \\
\hline & & 623 & 2788 & 509.006700 & 4163.068691 & $4.678 \times 10^{-26}$ & $8.430 \times 10^{-21}$ \\
\hline & & 822 & 1626 & 0.380587 & 4045.602054 & $2.620 \times 10^{-28}$ & $2.090 \times 10^{-21}$ \\
\hline & & 634 & 357 & 1972.188480 & 2032.038820 & $1.010 \times 10^{-23}$ & $5.240 \times 10^{-22}$ \\
\hline \multirow[t]{3}{*}{$\mathrm{H}_{2} \mathrm{CO}$} & \multirow[t]{3}{*}{21} & 126 & 40680 & 0.000000 & 3099.958130 & $3.955 \times 10^{-39}$ & $7.436 \times 10^{-20}$ \\
\hline & & 128 & 1622 & 0.000016 & 100.054366 & $8.054 \times 10^{-36}$ & $1.089 \times 10^{-22}$ \\
\hline & & 136 & 2309 & 0.000019 & 116.701949 & $3.566 \times 10^{-35}$ & $6.314 \times 10^{-22}$ \\
\hline \multirow[t]{2}{*}{$\mathrm{C}_{2} \mathrm{H}_{6}$} & \multirow[t]{2}{*}{22} & 226 & 47766 & 706.601510 & 3070.971230 & $4.609 \times 10^{-29}$ & $1.873 \times 10^{-20}$ \\
\hline & & 236 & 6037 & 725.602722 & 918.717163 & $1.130 \times 10^{-28}$ & $1.515 \times 10^{-23}$ \\
\hline $\mathrm{CH}_{3} \mathrm{D}$ & 23 & 212 & 54550 & 7.760179 & 6510.324200 & $3.528 \times 10^{-30}$ & $5.714 \times 10^{-23}$ \\
\hline & & 312 & 4213 & 959.393990 & 1694.123380 & $2.768 \times 10^{-29}$ & $1.398 \times 10^{-25}$ \\
\hline $\mathrm{C}_{2} \mathrm{H}_{2}$ & 24 & 221 & 12684 & 604.774170 & 9889.037680 & $4.425 \times 10^{-28}$ & $1.187 \times 10^{-18}$ \\
\hline & & 231 & 285 & 613.536460 & 6588.934700 & $3.820 \times 10^{-26}$ & $1.577 \times 10^{-20}$ \\
\hline $\mathrm{C}_{2} \mathrm{H}_{4}$ & 25 & 211 & 35132 & 701.202696 & 3242.172128 & $2.764 \times 10^{-37}$ & $8.412 \times 10^{-20}$ \\
\hline & & 311 & 18095 & 614.740436 & 3180.238042 & $4.852 \times 10^{-24}$ & $5.512 \times 10^{-20}$ \\
\hline $\mathrm{GeH}_{4}$ & 26 & 411 & 824 & 1937.371090 & 2224.570070 & $1.96010^{-22}$ & $3.680 \times 10^{-19}$ \\
\hline $\mathrm{HCN}$ & 27 & 124 & 136018 & 0.018640 & 17581.009367 & $1.000 \times 10^{-30}$ & $7.038 \times 10^{-19}$ \\
\hline & & 125 & 791 & 2.870485 & 3550.842326 & $5.156 \times 10^{-32}$ & $2.468 \times 10^{-21}$ \\
\hline & & 134 & 791 & 2.879990 & 3532.251747 & $1.431 \times 10^{-31}$ & $7.568 \times 10^{-21}$ \\
\hline & & 224 & 503 & 2.415494 & 2725.191923 & $1.801 \times 10^{-30}$ & $7.317 \times 10^{-23}$ \\
\hline $\mathrm{C}_{3} \mathrm{H}_{8}$ & 28 & 221 & 8983 & 700.014648 & 799.929688 & $1.583 \times 10^{-24}$ & $1.810 \times 10^{-22}$ \\
\hline $\mathrm{C}_{2} \mathrm{~N}_{2}$ & 29 & 224 & 71954 & 200.817750 & 2181.689940 & $1.009 \times 10^{-24}$ & $2.478 \times 10^{-20}$ \\
\hline $\mathrm{C}_{4} \mathrm{H}_{2}$ & 30 & 211 & 417540 & 189.422800 & 1302.216600 & $1.003 \times 10^{-24}$ & $1.074 \times 10^{-19}$ \\
\hline $\mathrm{HC}_{3} \mathrm{~N}$ & 31 & 124 & 179347 & 463.604500 & 759.988800 & $1.052 \times 10^{-24}$ & $4.041 \times 10^{-20}$ \\
\hline $\mathrm{HOCl}$ & 32 & 165 & 9293 & 0.023599 & 3799.249000 & $1.650 \times 10^{-27}$ & $3.590 \times 10^{-20}$ \\
\hline & & 167 & 8569 & 0.349154 & 3799.681900 & $7.220 \times 10^{-28}$ & $1.140 \times 10^{-20}$ \\
\hline $\mathrm{N}_{2}$ & 33 & 44 & 120 & 1992.627702 & 2625.497436 & $1.590 \times 10^{-34}$ & $3.548 \times 10^{-28}$ \\
\hline $\mathrm{CH}_{3} \mathrm{Cl}$ & 34 & 215 & 40941 & 0.886304 & 3197.758930 & $9.051 \times 10^{-32}$ & $7.152 \times 10^{-21}$ \\
\hline & & 217 & 42102 & 0.872753 & 3197.961060 & $2.177 \times 10^{-27}$ & $2.326 \times 10^{-21}$ \\
\hline
\end{tabular}




\begin{tabular}{|c|c|c|c|c|c|c|c|}
\hline Mol. & ID & $\begin{array}{l}\text { Isot. } \\
\text { ID. }\end{array}$ & \# lines & $\begin{array}{l}\text { Minimum } \\
\text { Wave } \\
\text { number } \\
\left(\mathrm{cm}^{-1}\right)\end{array}$ & $\begin{array}{c}\text { Maximum } \\
\text { Wave } \\
\text { number } \\
\left(\mathrm{cm}^{-1}\right)\end{array}$ & $\begin{array}{c}\text { Minimum } \\
\text { Intensity } \\
\left(\mathrm{cm} \text { molecule }^{-1}\right) \\
\text { at } 296 \mathrm{~K}\end{array}$ & $\begin{array}{c}\text { Maximum } \\
\text { Intensity } \\
\left(\mathrm{cm} \text { molecule }^{-1}\right) \\
\text { at } 296 \mathrm{~K}\end{array}$ \\
\hline $\mathrm{H}_{2} \mathrm{O}_{2}$ & 35 & 166 & 126983 & 0.043110 & 1730.370600 & $5.064 \times 10^{-29}$ & $5.582 \times 10^{-20}$ \\
\hline \multirow[t]{3}{*}{$\mathrm{H}_{2} \mathrm{~S}$} & \multirow[t]{3}{*}{36} & 121 & 38139 & 1.168413 & 11329.779860 & $9.823 \times 10^{-30}$ & $1.377 \times 10^{-19}$ \\
\hline & & 131 & 12193 & 1.097191 & 11226.586550 & $1.002 \times 10^{-29}$ & $1.080 \times 10^{-21}$ \\
\hline & & 141 & 8318 & 1.030566 & 11071.420170 & $1.006 \times 10^{-29}$ & $5.990 \times 10^{-21}$ \\
\hline $\mathrm{HCOOH}$ & 37 & 261 & 62684 & 10.018282 & 1889.333730 & $3.966 \times 10^{-26}$ & $5.068 \times 10^{-20}$ \\
\hline $\mathrm{COF}_{2}$ & 38 & 269 & 70904 & 725.005500 & 2001.347800 & $4.740 \times 10^{-24}$ & $3.940 \times 10^{-20}$ \\
\hline $\mathrm{SF}_{6}$ & 39 & 29 & 92398 & 588.488352 & 975.787491 & $1.001 \times 10^{-24}$ & $1.453 \times 10^{-20}$ \\
\hline $\mathrm{C}_{3} \mathrm{H}_{4}$ & 40 & 341 & 19001 & 288.912585 & 673.478839 & $4.230 \times 10^{-24}$ & $1.550 \times 10^{-20}$ \\
\hline $\mathrm{HO}_{2}$ & 41 & 166 & 38804 & 0.172756 & 3675.818586 & $1.001 \times 10^{-26}$ & $2.744 \times 10^{-20}$ \\
\hline \multirow[t]{2}{*}{$\mathrm{ClONO}_{2}$} & \multirow[t]{2}{*}{42} & 564 & 206861 & 0.635822 & 797.741040 & $7.547 \times 10^{-28}$ & $3.850 \times 10^{-22}$ \\
\hline & & 764 & 150038 & 0.928373 & 790.805380 & $7.519 \times 10^{-28}$ & $1.260 \times 10^{-22}$ \\
\hline \multirow[t]{2}{*}{$\mathrm{CH}_{3} \mathrm{Br}$} & \multirow[t]{2}{*}{43} & 79 & 18692 & 794.403140 & 1705.611680 & $9.970 \times 10^{-27}$ & $2.580 \times 10^{-21}$ \\
\hline & & 81 & 18219 & 795.083120 & 1696.895670 & $1.000 \times 10^{-26}$ & $2.530 \times 10^{-21}$ \\
\hline $\mathrm{CH}_{3} \mathrm{OH}$ & 44 & 216 & 19897 & 0.019265 & 1407.205540 & $8.826 \times 10^{-35}$ & $3.771 \times 10^{-20}$ \\
\hline $\mathrm{NO}^{+}$ & 45 & 46 & 1206 & 1634.831153 & 2530.462136 & $6.121 \times 10^{-81}$ & $1.186 \times 10^{-19}$ \\
\hline $\mathrm{HNC}$ & 46 & 142 & 75554 & 0.145590 & 4692.098100 & $1.000 \times 10^{-30}$ & $1.262 \times 10^{-18}$ \\
\hline $\mathrm{C}_{6} \mathrm{H}_{6}$ & 47 & 266 & 9797 & 642.427000 & 705.262000 & $4.070 \times 10^{-24}$ & $9.490 \times 10^{-21}$ \\
\hline $\mathrm{C}_{2} \mathrm{HD}$ & 48 & 122 & 15512 & 416.784700 & 3421.864100 & $5.195 \times 10^{-29}$ & $9.802 \times 10^{-23}$ \\
\hline $\mathrm{CF}_{4}$ & 49 & 291 & 60033 & 594.580718 & 1312.647564 & $7.912 \times 10^{-24}$ & $4.718 \times 10^{-20}$ \\
\hline $\mathrm{CH}_{3} \mathrm{CN}$ & 50 & 234 & 17172 & 890.051655 & 1650.000000 & $1.200 \times 10^{-38}$ & $3.824 \times 10^{-20}$ \\
\hline \multirow[t]{3}{*}{ HDO } & \multirow[t]{3}{*}{51} & 162 & 53706 & 0.007002 & 17080.098180 & $1.240 \times 10^{-32}$ & $2.700 \times 10^{-22}$ \\
\hline & & 172 & 175 & 1234.234730 & 1598.765470 & $2.033 \times 10^{-27}$ & $9.319 \times 10^{-27}$ \\
\hline & & 182 & 9760 & 0.196882 & 8748.128100 & $3.734 \times 10^{-33}$ & $5.646 \times 10^{-25}$ \\
\hline $\mathrm{SO}_{3}$ & 52 & 26 & 10881 & 0.477672 & 2824.347247 & $1.636 \times 10^{-31}$ & $1.266 \times 10^{-19}$ \\
\hline
\end{tabular}

The parameters for each spectral line (or molecular vibrational-rotational transition) of GEISA-2015 are stored in ASCII, in the "standard format" as previously defined for GEISA2011. Each entry in GEISA describes the 31 spectroscopic line parameters on a 252 character length record: a detailed description of these entries (identification, format, record length, etc is given in Appendix B and Table 15 herein).

Some modifications have been made to the GEISA-2011 format. The standard default values for fields $« \mathrm{O}$ ’», « $\mathrm{T} »$ and $\langle\mathrm{T}$ ’ $»$, (respectively estimated accuracy on the air pressure-shift of the line transition, self-pressure-shift of the line transition and estimated accuracy on the self-pressureshift of the line transition) have been changed and set to "zero". This modification was made to avoid potential misunderstanding and thus improper use of these parameters in some applications especially related to forward radiative transfer.

\subsection{Description of GEISA-2015 updates per individual molecular species}


This description is given below, in sub-sections 2.2.1 to 2.2.22, for each molecular species identified by its formula associated with its identification code in GEISA. It should be noted that, in the following, wave numbers may be displayed with all their decimal places - as in the database itself - or truncated when such a high detailed information is not required.

\subsection{1 $\quad \mathrm{H}_{2} \mathrm{O}($ molecule 1$)$}

\subsubsection{GEISA-2015 $\mathrm{H}_{2} \mathrm{O}$ update overview}

$\mathrm{H}_{2} \mathrm{O}$ is significantly updated in this 2015 edition of GEISA, with important additions across the whole spectral range (67,789 lines in GEISA-2011 have become 191,846 in GEISA-2015). This significant increase of the total number of transitions originates mainly in the inclusion of empirical lists in the GEISA-2015.

The new line lists for $\mathrm{H}_{2} \mathrm{O}$ in this 2015 edition of GEISA originate from results of 8 participating institutions (in alphabetic order):

- V.E. Zuev Institute of Atmospheric Optics, Russian Federation

- Karlsruhe Institute of Technology, Germany

- Laboratoire Inter-Universitaire des Systèmes Atmosphériques, France

- Laboratoire Interdisciplinaire de Physique, France

- Netherlands Institute for Space Research, Netherlands

- University College Cork, Ireland

- University College London, UK

- University of Massachusetts, USA

Five isotopologues, i.e., $\mathrm{H}_{2}{ }^{16} \mathrm{O}, \mathrm{H}_{2}{ }^{17} \mathrm{O}, \mathrm{H}_{2}{ }^{18} \mathrm{O}, \mathrm{D}_{2}{ }^{16} \mathrm{O}, \mathrm{D}_{2}{ }^{18} \mathrm{O}$, are updated in the 2015 release, as summarized in Table 4. This Table lists GEISA-2015 entries that have totally replaced entries of GEISA-2011. They represent 172,680 entries. Their names are listed in the first column of this Table with associated identification codes (see Appendix C). Each line list spectral range, minimum and maximum wave numbers $\left(\mathrm{cm}^{-1}\right)$, the number of transitions, the mean (Moy.I) and the maximum (Max.I) of the line intensities (cm molecule ${ }^{-1}$ at $296 \mathrm{~K}$ ), and the origin of the data are given in columns 2 to 7 of this Table, respectively. The process used to update each isotopologue is described in the sections below. 
Table 4

General overview of the $\mathrm{H}_{2} \mathrm{O}$ update in GEISA-2015

\begin{tabular}{|c|c|c|c|c|c|c|}
\hline $\begin{array}{l}\text { Isot. } \\
\text { ID }\end{array}$ & $\begin{array}{l}\text { Wavenb. min } \\
\quad\left(\mathrm{cm}^{-1}\right)\end{array}$ & $\begin{array}{l}\text { Wavenb. max } \\
\quad\left(\mathrm{cm}^{-1}\right)\end{array}$ & \#lines & $\begin{array}{c}\begin{array}{c}\text { Moy. I } \\
\left(\mathrm{cm} \text { molecule }^{-1}\right) \\
\text { at } 296 \mathrm{~K}\end{array} \\
\end{array}$ & $\begin{array}{c}\text { Max. I } \\
(\mathrm{cm} \text { molecule } \\
\text { at } 296 \mathrm{~K}\end{array}$ & Origin \\
\hline $\begin{array}{l}\mathrm{H}_{2}{ }^{16} \mathrm{O} \\
161\end{array}$ & $\begin{array}{l}10.714930 \\
5850.059600\end{array}$ & $\begin{array}{l}5098.661059 \\
7920.315400\end{array}$ & $\begin{array}{l}12520 \\
18757\end{array}$ & $\begin{array}{l}9.9741 \times 10^{-30} \\
1.001 \times 10^{-29}\end{array}$ & $\begin{array}{l}2.651 \times 10^{-18} \\
1.856 \times 10^{-20}\end{array}$ & $\begin{array}{l}\text { LISA, IAO } \\
\text { LIPhy, IAO } \\
\text { UMASS }\end{array}$ \\
\hline $\begin{array}{l}\mathrm{H}_{2}{ }^{17} \mathrm{O} \\
171\end{array}$ & $\begin{array}{l}0.451497 \\
5850.241200 \\
4174.108380\end{array}$ & $\begin{array}{l}19945.257171 \\
7905.615600 \\
4299.793100\end{array}$ & $\begin{array}{l}27547 \\
3659 \\
24\end{array}$ & $\begin{array}{l}4.857 \times 10^{-35} \\
1.002 \times 10^{-29} \\
6.46 \times 10^{-28}\end{array}$ & $\begin{array}{l}9.860 \times 10^{-22} \\
6.939 \times 10^{-24} \\
4.393 \times 10^{-26}\end{array}$ & $\begin{array}{l}\text { UCL } \\
\text { LIPhy, IAO } \\
\text { SRON, UMASS }\end{array}$ \\
\hline $\begin{array}{l}\mathrm{H}_{2}{ }^{18} \mathrm{O} \\
181\end{array}$ & $\begin{array}{l}893.551335 \\
0.052583 \\
4177.931920 \\
5855.542000\end{array}$ & $\begin{array}{l}1996.530386 \\
19917.617846 \\
4298.236000 \\
7919.033200\end{array}$ & $\begin{array}{l}974 \\
39918 \\
47 \\
6641\end{array}$ & $\begin{array}{l}9.9741 \times 10^{-30} \\
8.47 \times 10^{-36} \\
2.93 \times 10^{-26} \\
1.001 \times 10^{-29}\end{array}$ & $\begin{array}{l}2.651 \times 10^{-18} \\
5.270 \times 10^{-21} \\
2.440 \times 10^{-25} \\
3.647 \times 10^{-23}\end{array}$ & $\begin{array}{l}\text { LISA } \\
\text { UCL } \\
\text { SRON } \\
\text { LIPhy, IAO } \\
\text { UMASS }\end{array}$ \\
\hline $\begin{array}{l}\mathrm{D}_{2}{ }^{16} \mathrm{O} \\
\text { (new) } \\
262\end{array}$ & $\begin{array}{l}6378.9189 \\
5.060500\end{array}$ & $\begin{array}{l}6676.1465 \\
7979.071900\end{array}$ & $\begin{array}{l}225 \\
5746\end{array}$ & $\begin{array}{l}7.31 \times 10^{-33} \\
1.76 \times 10^{-28}\end{array}$ & $\begin{array}{l}2.640 \times 10^{-31} \\
1.75 \times 10^{-26}\end{array}$ & $\begin{array}{l}\text { UCC, KIT } \\
\text { IAO } \\
\text { UMASS }\end{array}$ \\
\hline $\begin{array}{l}\mathrm{D}_{2}{ }^{18} \mathrm{O} \\
\text { (new) } \\
282\end{array}$ & 6328.068400 & 6637.658200 & 162 & $9.41 \times 10^{-35}$ & $5.41 \times 10^{-34}$ & $\begin{array}{l}\text { UCC, KIT } \\
\text { UMASS }\end{array}$ \\
\hline
\end{tabular}

\subsubsection{2 $\quad \mathrm{H}_{2}{ }^{16} \mathrm{O}$ update process}

The revised line list built using contributions from IAO, LISA and LIPhy was processed in two steps: first, the $\mathrm{H}_{2}{ }^{16} \mathrm{O}$ entries in GEISA-2011 were updated with the new data; then, the resulting line list was evaluated against so called "reference" spectra or "empirical" line lists [24] (see below) before implementation in GEISA-2015. In the spectral range 10.719-5098.661 $\mathrm{cm}^{-1}$, the previous $\mathrm{H}_{2}{ }^{16} \mathrm{O}$ data were replaced by 12520 lines of Coudert [25], computed from line position and line intensity analysis of two large data sets involving vibrational states up to the second triad. Both analyses were carried out with the Bending-Rotation approach [26]. The reader is referred to Ref. [25] for further information.

For $\mathrm{H}_{2}{ }^{16} \mathrm{O}$ transitions up to the (010) vibrational state, with wavenumbers smaller than $2000 \mathrm{~cm}^{-1}$, a comparison between $S$, the intensity in the line list built in Ref. [25], and $S_{\text {Hitran }}$ that from HITRAN-2012 [14] is presented on Fig. 1, The figure compares \% intensity difference $\left(S-S_{\text {Hitran }}\right) / S$ for the 3937 transitions common to both line lists. For a line intensity larger than $10^{-24} \mathrm{~cm}$ molecule $\mathrm{e}^{-1}$ both sets of intensities agree to better than $10 \%$. 


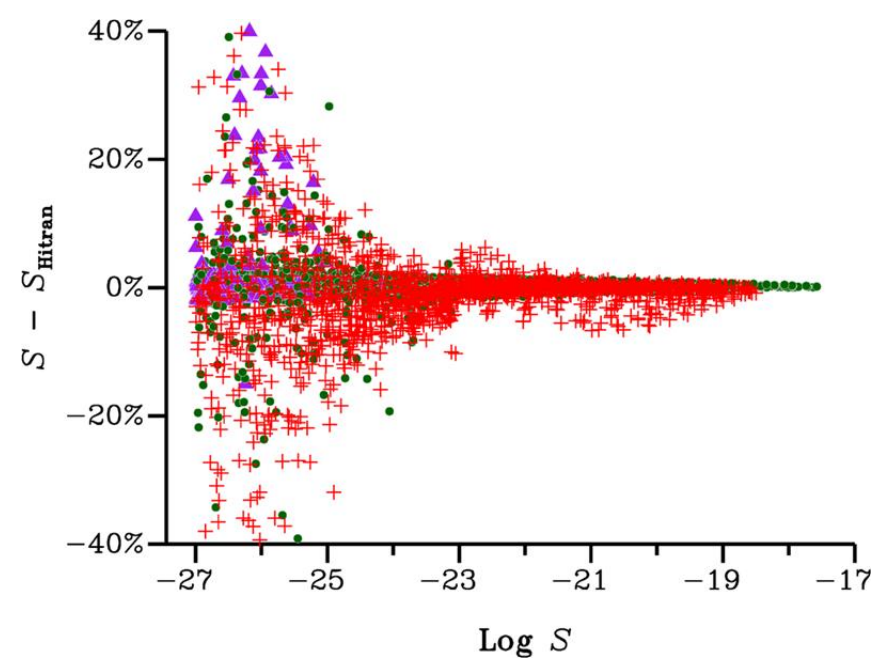

Fig. 1. Comparison $\left(S-S_{\text {Hitran }}\right)$ between $S$, the intensity in the line list built in Ref. [25] and adopted in GEISA-2015, and $S_{\text {Hitran }}$ from HITRAN-2012 [14]. The intensity difference $S-S_{\text {Hitran }}$ in $\%$ of the average intensity $\left(S+S_{\text {Hitran }}\right) / 2$ is plotted as a function of the base 10 logarithm of $S_{\text {Hitran }}$ in cm molecule $^{-1}$ at $296 \mathrm{~K}$. Plus signs (+) correspond to the 1514 transitions belonging to the $v_{2}$ band; full circles to the 1623 pure rotational transitions within the ground vibrational state; and full triangles to the 800 pure rotational transitions within the (010) vibrational state. $v_{2}$ band transitions in HITRAN2012 come from Refs. $[\mathbf{2 5 , 4 0 ]}$. The 5\% agreement observed in many cases stems from the fact that the results of reference [25] were also used in GEISA-2015.

In the 5850-7920 $\mathrm{cm}^{-1}$ region, the GEISA-2015 list for $\mathrm{H}_{2}{ }^{16} \mathrm{O}$ (and for $\mathrm{H}_{2}{ }^{17} \mathrm{O}$ and $\mathrm{H}_{2}{ }^{18} \mathrm{O}$ as well, see below) uses the empirical line list described in Mikhaillenko et al. [27], from a joint participation of IAO and LIPhy. This GEISA update list, involving 18757 lines in the spectral range 5850.060-7920.315 $\mathrm{cm}^{-1}$ was obtained by gathering separate line lists recently obtained from spectra recorded using high sensitivity CW-CRDS of natural water [28-32] and is completed with literature data obtained by FTS for the strongest lines by Toth [33]. It has to be noted that there is a large literature suggesting that the intensities of the strong lines from [33] might be seriously in error especially above $8000 \mathrm{~cm}^{-1}$ and around $4000 \mathrm{~cm}^{-1}$; this is not the case in the 5850-8000 $\mathrm{cm}^{-1}$ spectral region considered in GEISA-2015.

The spectral sensitivity of the CW-CRDS recordings $\left(\min \sim 10^{-11}-10^{-10} \mathrm{~cm}^{-1}\right)$ allowed the detection of lines with intensities down to the $10^{-29} \mathrm{~cm}$ molecule ${ }^{-1}$. The list was made mostly complete by including a large number of weak lines with positions calculated using experimentally determined energy levels and intensities computed by S.A. Tashkun [34] using the results of the variational calculations by Schwenke and Partridge [35]. After this first update step, the whole GEISA-2015 $\mathrm{H}_{2}{ }^{16} \mathrm{O}$ line list was processed as follows.

New experimental results of Regalia et al. [36] (3867 transitions in total) have replaced the former GEISA-2011 positions and intensities in the $7924-9393 \mathrm{~cm}^{-1}$ region. The line positions from [37] between 9500 and $14500 \mathrm{~cm}^{-1}$ were recalculated using the calibration 
factor of 0.99999989 proposed by Tennyson et al. [38]. Then positions and intensities of all new and former $\mathrm{H}_{2}{ }^{16} \mathrm{O}$ data were checked against "reference" spectrum or "empirical" line list in which the positions are obtained from the energy levels derived by Tennyson et al. [38] with the additional inclusion of new experimental data from Refs. [27,30-32,36], and intensities available from variational calculations of Barber et al. [39]. As a consequence of this validation process, the following replacements or additions were made:

1. positions and intensities of about 900 incorrectly assigned lines, mostly coming from the previous GEISA editions, were corrected;

2. positions of all lines which deviated from the empirical data by more than $0.01 \mathrm{~cm}^{-1}$ were corrected;

3. simulated intensities data originating from Toth [40] were replaced by those of Barber et al. [39], mostly for the weakest lines.

Finally all empirical lines [24] with intensities larger than $10^{-29} \mathrm{~cm}$ molecule ${ }^{-1}$ at $296 \mathrm{~K}$, missing in the initial line list, were added in the spectral region $0-26000 \mathrm{~cm}^{-1}$.

The final $\mathrm{H}_{2}{ }^{16} \mathrm{O}$ GEISA-2015 line list has been supplemented by data from the empirical list generated by Naumenko [24]. GEISA-2015 contains 119,885 entries for the isotopologue $\mathrm{H}_{2}{ }^{16} \mathrm{O}$ compared to 40,920 in GEISA-2011.

A graphical overview of the GEISA-2015 line intensities for $\mathrm{H}_{2}{ }^{16} \mathrm{O}$ is shown on Fig. 2. The new intensity values cover the spectral regions: $10-5098 \mathrm{~cm}^{-1}$ [25], 5850-7920 $\mathrm{cm}^{-1}$ [27], and 7924-9392 $\mathrm{cm}^{-1}$ [38]. Above $9500 \mathrm{~cm}^{-1}$ and, partly, between 1200 and $8000 \mathrm{~cm}^{-1}$ the line intensities from GEISA-2011 were retained, these include data from Refs. [40, 41]. 


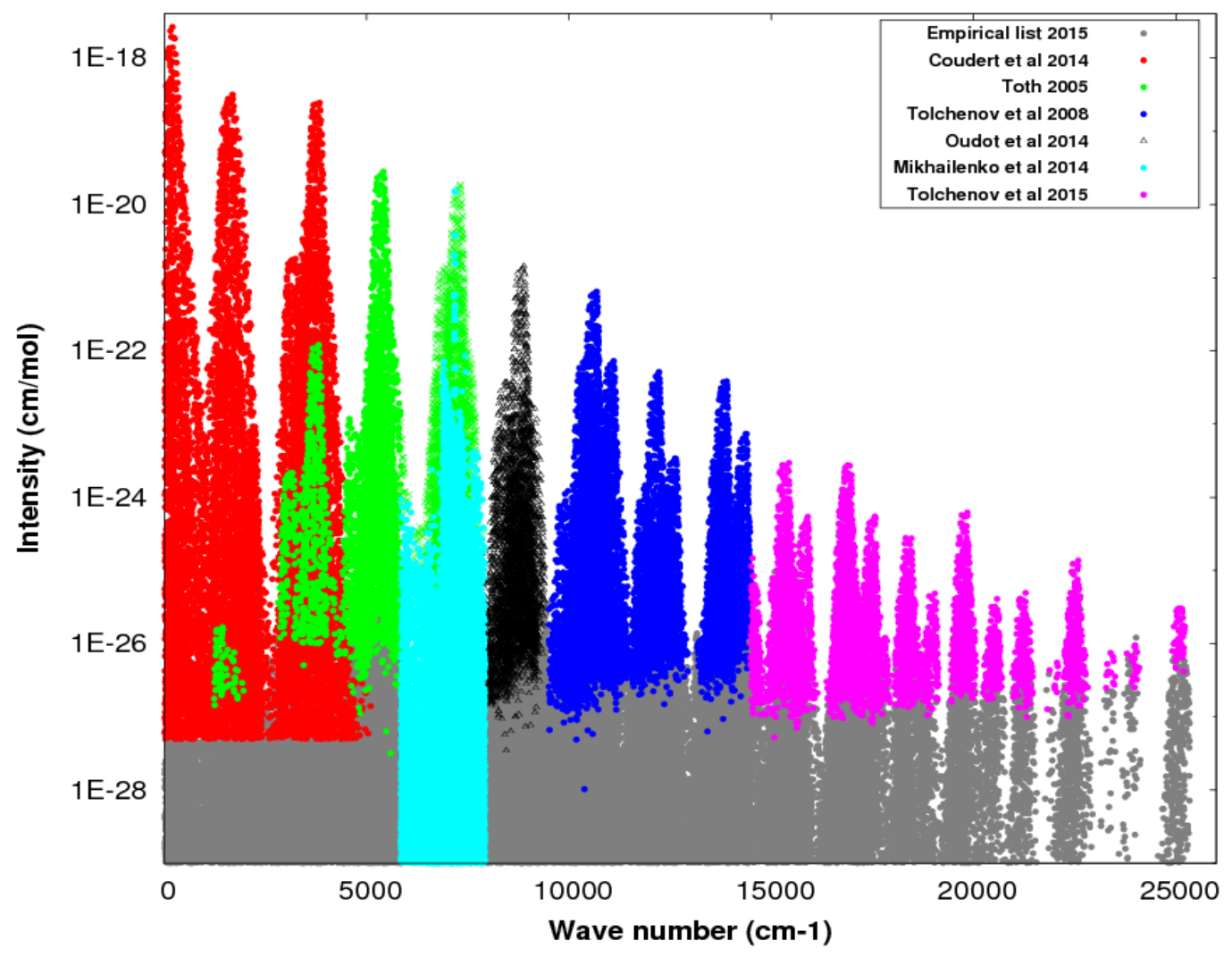

Fig. 2 Log scale graphical display of transition intensities (cm molecule ${ }^{-1}$ at $296 \mathrm{~K}$ ) included in GEISA-2015 for $\mathrm{H}_{2}{ }^{16} \mathrm{O}$.

\subsubsection{3 $\quad \mathrm{H}_{2}{ }^{17} \mathrm{O}$ and $\mathrm{H}_{2}{ }^{18} \mathrm{O}$ update process}

New line lists provided by UCL, SRON, LIPhy and IAO, have been included in GEISA-2015 update for both $\mathrm{H}_{2}{ }^{17} \mathrm{O}$ and $\mathrm{H}_{2}{ }^{18} \mathrm{O}$ isotopologues. New data from LISA for $\mathrm{H}_{2}{ }^{18} \mathrm{O}$ have been included, as well.

Line positions and intensities of $\mathrm{H}_{2}{ }^{17} \mathrm{O}$ and $\mathrm{H}_{2}{ }^{18} \mathrm{O}$, from UCL, were taken from the line lists of Lodi and Tennyson [42], and provided new data in the spectral ranges 0.451$19945.257 \mathrm{~cm}^{-1}$ (22508 lines) and 0.052-19917.618 $\mathrm{cm}^{-1}$ (31,926 lines), for $\mathrm{H}_{2}{ }^{17} \mathrm{O}$ and $\mathrm{H}_{2}{ }^{18} \mathrm{O}$ respectively. This study is based on two developments:

- First the work on an IUPAC-TG on water spectroscopy [43] which adopted the MARVEL procedure $[\mathbf{4 4 , 4 5}]$, to determine precise empirical values for the energy levels of $\mathrm{H}_{2}{ }^{17} \mathrm{O}$ and $\mathrm{H}_{2}{ }^{18} \mathrm{O}$ [46]. These energy levels were used to generate a list of transition frequencies which encompasses all the measured frequencies validated by the IUPAC-TG, and all those other allowed transitions between known energy levels. 
- Then, line intensities were computed using the high accuracy, ab-initio dipole moment function of Lodi et al. [47] and wave functions generated from a spectroscopicallydetermined potential energy surface [48]. Lodi and Tennyson developed a procedure for determining the uncertainty in these intensities and, for a few cases where the calculated intensities were deemed unreliable, the empirical ones were retained.

It should be noticed that:

- Regalia et al. [36] performed a comprehensive comparison of water absorption in the 6450 to $9400 \mathrm{~cm}^{-1}$ region based on a new experimental study. While their comparisons identified a significant number of issues with the spectroscopic data available in current compilations, the agreement with the $\mathrm{H}_{2}{ }^{18} \mathrm{O}$ and $\mathrm{H}_{2}{ }^{17} \mathrm{O}$ line lists of Lodi and Tennyson was, in general, excellent;

- the recent work by Polyansky et al. [49] allows us to significantly increase the number of $\mathrm{H}_{2}{ }^{18} \mathrm{O}$ and $\mathrm{H}_{2}{ }^{17} \mathrm{O}$ energy levels known to experimental accuracy by exploiting the much more extensive list of known $\mathrm{H}_{2}{ }^{16} \mathrm{O}$ levels. This work will be used to further enhance the line lists for the $\mathrm{H}_{2}{ }^{18} \mathrm{O}$ and $\mathrm{H}_{2}{ }^{17} \mathrm{O}$ isotopologues in future editions.

SRON provided updates in the $2.3 \mu \mathrm{m}$ windows wavelength range which covers the windows used for the retrieval of $\mathrm{H}_{2} \mathrm{O}$ and the ratio $\mathrm{HDO} / \mathrm{H}_{2} \mathrm{O}$, by the SCIAMACHY instrument, on board ENVISAT. However, the spectroscopy of water lines in this region remained a large source of uncertainty for these retrievals. Consequently, Scheepmaker et al. [50] updated the spectroscopic line parameters of $\mathrm{H}_{2}{ }^{17} \mathrm{O}$ and $\mathrm{H}_{2}{ }^{18} \mathrm{O}$ in the 4175.123-4298.302 $\mathrm{cm}^{-1}$ spectral range, taking the results of Jenouvrier et al. [51] as the a priori input in their new line list processing method. These additional data have been retained for implementation in GEISA-2015 because they represent an improved spectroscopic dataset which has been tested on a series of ground based high resolution FTS spectra as well as on SCIAMACHY retrievals of $\mathrm{H}_{2} \mathrm{O}$ and on the ratio $\mathrm{HDO} / \mathrm{H}_{2} \mathrm{O}$. This improved spectroscopy has led to lower residuals in the FTS spectra compared to alternate available spectroscopic sources and the retrievals have become more robust against changes in the retrieval window. As a result, a total of 71 lines for isotopologues $\mathrm{H}_{2}{ }^{17} \mathrm{O}$ (24 lines) and $\mathrm{H}_{2}{ }^{18} \mathrm{O}$ (47 lines), were included in GEISA-2015, from the supplementary material available in [50].

In the 5850-7920 $\mathrm{cm}^{-1}$ spectral region, the GEISA-2015 list for $\mathrm{H}_{2}{ }^{17} \mathrm{O}$ and $\mathrm{H}_{2}{ }^{18} \mathrm{O}$ uses the empirical line list, from LIPhy and IAO, described in Mikhaïlenko et al. [27]. Two new series of entries, covering respectively, for $\mathrm{H}_{2}{ }^{17} \mathrm{O}$ and $\mathrm{H}_{2}{ }^{18} \mathrm{O}$, the spectral ranges 5850.241- 
$7905.616 \mathrm{~cm}^{-1}$ (3659 lines) and 5855.542-7919.033 $\mathrm{cm}^{-1}$ (6641 lines) have been implemented in GEISA-2015.

In the 20-2000 $\mathrm{cm}^{-1}$ spectral range, line parameters of $\mathrm{H}_{2}{ }^{18} \mathrm{O}$ were updated based on the line position and line intensity analyses carried out in LISA by Coudert and Chelin [52] using the Bending-Rotation approach [26]. In the line position analysis of Ref. [53], using 173 parameters, the data from Refs [54-60] were fitted up to $J=17, K a=17$, and to the first Triad; they were reproduced with a dimensionless standard deviation of 1.2. The line parameters of $\mathrm{H}_{2}{ }^{18} \mathrm{O}$ were updated fitting the limited line intensity data set of Refs. [60,61] involving the ground and (010) states only. 1760 line intensities were reproduced with a unit-less standard deviation of 1.5 using 18 parameters and a line list containing pure rotational and $v_{2}$ band transitions was built. An abundance-weighted intensity cut-off of $10^{-27} \mathrm{~cm}^{-}$molecule ${ }^{-1}$ at $296 \mathrm{~K}$ was used assuming an isotopic abundance of $0.199983 \%$. Fig. 3 compares the intensities in this line list and those in HITRAN-2012 [14] for transitions belonging to the $v_{2}$ band of $\mathrm{H}_{2}{ }^{18} \mathrm{O}$. For this band, the intensity values in HITRAN-2012 were set to ab-initio calculated values given in Ref. [42]. A negative bias, more pronounced for strong lines, can easily be seen $(-2.3 \%)$. For strong lines with a intensity larger than $10^{-23} \mathrm{~cm}$ molecule ${ }^{-1}$, the bias could reach $-3.4 \%$. The RMS value of the intensity differences is $3.2 \%$. We have retained this line list because, as discussed in Ref. [52], this work both reproduces more accurately the experimental intensities from Refs. [60,61] than the line list of HITRAN-2012 [14] (example of the $v_{2}$ band of $\mathrm{H}_{2}{ }^{18} \mathrm{O}$ where the intensity values in HITRAN-2012 were retrieved through $a b$-initio calculations (see Lodi and Tennyson [42]).

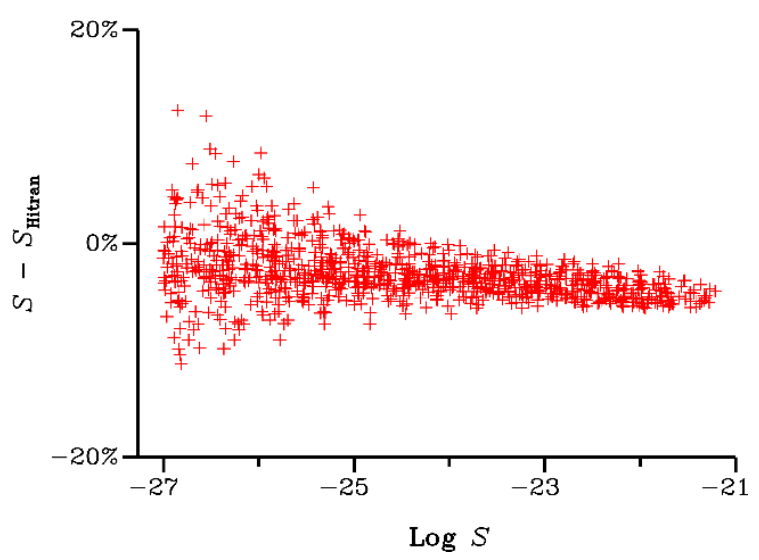

Fig. 3. A comparison between the intensity $S$ of $v_{2}$ band transitions comprising the GEISA-2015 updated $\mathrm{H}_{2}{ }^{18} \mathrm{O}$ line list and $\left(\mathrm{S}_{\text {Hitran }}\right)$ those from HITRAN-2012 [14] for the 971 transitions in both line lists with a wave number smaller than $2000 \mathrm{~cm}^{-1}$. The intensity difference $S-S_{\text {Hitran }}$ in $\%$ of the average intensity $\left(S+S_{\text {Hitran }}\right) / 2$ is plotted as a function of the base 10 logarithm of $S_{\text {Hitran }}$ in cm molecule ${ }^{-1}$. 
Finally, most of the previous data on $\mathrm{H}_{2}{ }^{16} \mathrm{O}, \mathrm{H}_{2}{ }^{17} \mathrm{O}, \mathrm{H}_{2}{ }^{18} \mathrm{O}$, in the $5850-7920 \mathrm{~cm}^{-1}$ spectral region, were replaced by the new line list (more than 29000 vibration-rotation transitions) of Mikhaïlenko et al. [27]. The advantages of this list, which incorporates all available experimental information, are discussed in [27]. An illustration of this new data set is given, in Fig. 4, by the base 10 logarithm graphical display of intensities ( $\mathrm{cm}$ molecule ${ }^{-1}$ ) for $\mathrm{H}_{2}{ }^{16} \mathrm{O}, \mathrm{H}_{2}{ }^{17} \mathrm{O}, \mathrm{H}_{2}{ }^{18} \mathrm{O}$ (Y-Axis) in the spectral range $5850-7920 \mathrm{~cm}^{-1}$ (X-abscissa).

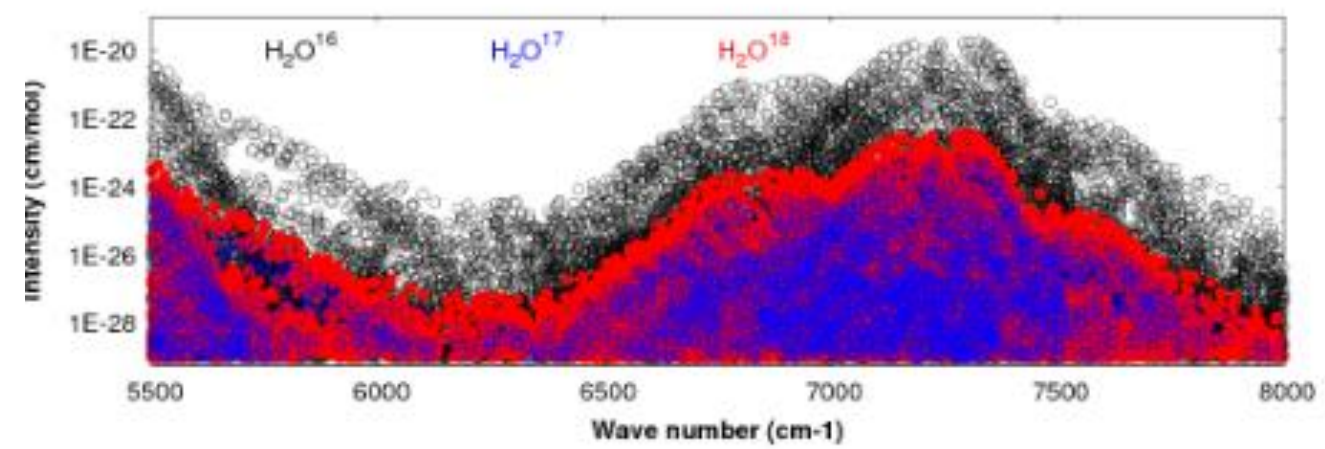

Fig. 4. Overview of line intensities (at $296 \mathrm{~K}$, in logarithmic scale) in the GEISA-2015 line parameter database for water isotopologues, $\mathrm{H}_{2}{ }^{16} \mathrm{O}, \mathrm{H}_{2}{ }^{17} \mathrm{O}, \mathrm{H}_{2}{ }^{18} \mathrm{O}$, between 5850 and $7920 \mathrm{~cm}^{-1}$. The contribution of the different isotopologues is highlighted: $\mathrm{H}_{2}{ }^{16} \mathrm{O}$-black, $\mathrm{H}_{2}{ }^{17} \mathrm{O}$-blue, $\mathrm{H}_{2}{ }^{18} \mathrm{O}$-red).

\subsubsection{Implementation of two new isotopologues: $\mathrm{D}_{2}{ }^{16} \mathrm{O}$ and $\mathrm{D}_{2}{ }^{18} \mathrm{O}$ in GEISA-2015}

The data for $\mathrm{D}_{2}{ }^{16} \mathrm{O}$ and $\mathrm{D}_{2}{ }^{18} \mathrm{O}$ were originally based on a high resolution $\left(0.02 \mathrm{~cm}^{-1}\right)$ absorption spectrum recorded by Orphal and Ruth [53] for a mixture of $\mathrm{D}_{2}{ }^{16} \mathrm{O}$ and $\mathrm{H}_{2}{ }^{18} \mathrm{O}$ gases and designed to maximise the presence of $\mathrm{HD}^{18} \mathrm{O}$. Significant quantities of the isotopologues $\mathrm{H}_{2}{ }^{18} \mathrm{O}(\sim 29 \%), \mathrm{HD}^{16} \mathrm{O}(\sim 22.5 \%), \mathrm{H}_{2}{ }^{16} \mathrm{O}(\sim 14.5 \%), \mathrm{D}_{2}{ }^{18} \mathrm{O}(\sim 9.3 \%)$ and $\mathrm{D}_{2}{ }^{16} \mathrm{O}$ $(\sim 6.3 \%)$ were observed [52] and are at the origin of line lists of two new isotopologues, $\mathrm{D}_{2}{ }^{16} \mathrm{O}$ and $\mathrm{D}_{2}{ }^{18} \mathrm{O}$, implemented in GEISA-2015.

However several (some unpublished), variational line lists and experimental lower level data exist for $\mathrm{D}_{2}{ }^{16} \mathrm{O}[63-67]$ and $\mathrm{D}_{2}{ }^{18} \mathrm{O}[63],[68],[69]$. The IUPAC group have recently completed their analysis of $\mathrm{D}_{2} \mathrm{O}$ isotopologues [70] and these data will be used in a future update. 


\subsubsection{1 $\mathrm{D}_{2}{ }^{16} \mathrm{O}$ :}

The new $\mathrm{D}_{2}{ }^{16} \mathrm{O}$ transitions have been implemented in GEISA-2015 in two spectral regions:

- The region 6378.92-6676.15 $\mathrm{cm}^{-1}$ where all observed $\mathrm{D}_{2}{ }^{16} \mathrm{O}$ transitions agree with assignments by Ormsby et al. [64]. 295 lines were included in the analysis, of which 265 were assigned directly to observations including 40 blended lines. Most of the lines belong to the $v_{1}+v_{2}+v_{3}$ combination band and calculations agreed with observation within the spectral resolution of $0.02 \mathrm{~cm}^{-1}$. The experimental spectral resolution does not limit the precision of line positions except in the case of blended lines. Hence, for the current GEISA-2015 edition, all blended lines have been deleted from the datasets.

- The region between 5 and $7980 \mathrm{~cm}^{-1}$ contains a list of empirical line positions completed by variational line intensities. The line positions were calculated using the empirical energy levels recommended by an IUPAC task group [70]. Calculated line intensities, available at http://spectra.iao.ru/1366x647/en/mol/survey/1/ and based on the results of Partridge and Schwenke [71].

The list includes 5746 transitions of 18 vibration-rotation bands with maximum values of rotational numbers $J$ and $K_{a}$ equal to 24 and 14, respectively. This list corresponds to a cut-off of $1 \times 10^{-30} \mathrm{~cm} /$ molecule at $296 \mathrm{~K}$ taking into account a natural abundance of $2.4197 \times 10^{-8}$ for $\mathrm{D}_{2}{ }^{16} \mathrm{O}$.

\subsubsection{2 $\mathrm{D}_{2}{ }^{18} \mathrm{O}$ :}

The $\mathrm{D}_{2}{ }^{18} \mathrm{O}$ transitions between 6328 and $6638 \mathrm{~cm}^{-1}$ were recorded and identified in Down et al. [62] based on variational line list. A set of lower energy levels from $\mathrm{Ni}$ et al. [69] was used to determine the upper energy levels. The accuracy of line positions is estimated to be of $0.002-0.004 \mathrm{~cm}-1$. About $150 \mathrm{D}_{2}{ }^{18} \mathrm{O}$ transitions from [62] approved by the IUPAC analysis [70] are implemented in GEISA-2015. These transitions belong, mostly, to (111)(000) and (210)-(000) vibrational bands.

\subsubsection{Line shape parameters}


Line shape parameters for water vapor; the air-broadened half-widths, $\gamma_{\text {air }}$, its temperature dependence, $n_{\text {air }}$, the air-induced line shifts, $\delta_{\text {air }}$, and the self-broadened halfwidths, $\gamma_{\text {self }}$, are added to the GEISA-2015 database from a number of sources.

For the three most abundant isotopologues of water, $\mathrm{H}_{2}{ }^{16} \mathrm{O}, \mathrm{H}_{2}{ }^{18} \mathrm{O}$, and $\mathrm{H}_{2}{ }^{17} \mathrm{O}$, the airbroadened half-widths, line shifts and self-broadened half-widths were added using a sophisticated scheme explained by Gordon et al. [72] that determines and eliminates the experimental outliers and then either uses their averages, if they exist, or the experimental values, or theoretical values calculated using the CRB method (see for instance Refs. [73],[74]), or if no experimental or theoretical value exists, semi-empirical values from Jacquemart et al. [75]. When none of the above data are available, the half-width data are obtained from J-dependent polynomials [76]. The temperature dependence of the half-width is taken from measured values, if no data exist the data are obtained from a polynomial in J" that was developed by Gamache [77] using the data of Birk and Wagner [78] smoothened and extrapolated to $J "=50$. Note, when there are no data available for $\mathrm{H}_{2}{ }^{18} \mathrm{O}$ or $\mathrm{H}_{2}{ }^{17} \mathrm{O}$, the corresponding data for $\mathrm{H}_{2}{ }^{16} \mathrm{O}$ are used (if they exist).

For the air- $\mathrm{D}_{2} \mathrm{O}$ collision system, measured half-widths and line shifts are available [79-82] for a small number of transitions in the $v_{2}, 2 v_{2}-v_{2}$, and $v_{3}$ bands. From these data a set of air-broadened half-widths as a function of rotational quantum numbers was made and these data were added to the database neglecting vibrational dependence. To augment the measurement database, the half-width data were taken and the average half-width as a function of $\mathrm{J}$ " determined. These data were extrapolated to $\mathrm{J} "=50$ and fit to a polynomial. These data were used for lines for which there are no measured data or rotational transition data. The error in the averaged data was taken to be $50 \%$ of the averaged value. There are no measured data on the temperature dependence of the half-width or on coefficient $n$. The HITRAN $\mathrm{H}_{2}{ }^{16} \mathrm{O}$-air $\mathrm{n}$ values were used for $\mathrm{D}_{2}{ }^{16} \mathrm{O}$-air with the error set to $50 \%$.

For the $\mathrm{D}_{2} \mathrm{O}-\mathrm{D}_{2} \mathrm{O}$ collision system, the half-width, its temperature dependence, and the line shift (rotation band only) data are from the MCRB calculations of Gamache et al. [83]. Again vibrational dependence is assumed negligible for the half-width and its temperature dependence. For transitions for which MCRB calculations are not available, the MCRB data were averaged as a function of $\mathrm{J}$ " and extrapolated to $\mathrm{J} "=50$. The average values were then used for transitions for which there were no half-width data. The error in the averaged halfwidths was set to $50 \%$. 


\subsubsection{Line list update description}

The GEISA-2011 carbon dioxide line list is replaced by the current version of CDSD296 databank [84] which forms the new GEISA-2015 CO 2 line list. The CDSD-296 databank contains calculated line parameters (positions, intensities, air- and self-broadened half-widths, coefficients of temperature dependence of air-broadened half-widths and air pressure-induced line shifts) for twelve sTable isotopic species of $\mathrm{CO}_{2}$ (See Table 5 below). This databank was generated for a reference temperature $296 \mathrm{~K}$ and an intensity cut-off of $10^{-30} \mathrm{~cm}$ molecule ${ }^{-1}$. It contains 534,227 lines covering the $6-14,075 \mathrm{~cm}^{-1}$ spectral range. The line positions and intensities were calculated using the method of effective operators and are based on global weighted fits of the effective Hamiltonian and effective dipole moment parameters to the observed data collected from the literature. The fitted sets of the effective Hamiltonian parameters on average reproduce the observed line positions with the residuals about twice the experimental uncertainties. The fitted sets of effective dipole moment parameters reproduce most of the observed line intensities within their experimental uncertainties. Each isotopologue has been considered separately. The sets of the effective dipole moment parameters of the principal isotopologue were used to calculate the line intensities of the minor isotopologues. The isotopologue composition of the current version of CDSD-296, and consequently in GEISA-2015, is presented in Table 5. The isotopologue Identification Codes (ID), respectively in CDSD, HITRAN-2012 and GEISA-2015, are listed in columns 1 to 3; column 4 and 5 detail the chemical formula and the natural abundance corresponding to each isotopologue; the number of lines reported for each species is in column 6. Compared to GEISA-2011, the current version GEISA-2015 includes the spectral line parameters for three additional isotopologues: ${ }^{17} \mathrm{O}^{12} \mathrm{C}^{17} \mathrm{O},{ }^{17} \mathrm{O}^{13} \mathrm{C}^{18} \mathrm{O}$ and ${ }^{17} \mathrm{O}^{13} \mathrm{C}^{17} \mathrm{O}$. The line parameters for other minor isotopologues are considerably improved and the spectral ranges extended. These improvements are possible due to the extensive measurements of line parameters of the minor isotopologues performed in Paris [85], Grenoble [89-91], Hefei [86,92-94] and Brussels [95]. The stated errors for the line positions and intensities rely on the measurement errors and on the rough estimates performed for the extrapolated values.

Very recently Polyansky et al. computed an ab-initio dipole moment surface which has been used for the prediction of $\mathrm{CO}_{2}$ intensities below $8000 \mathrm{~cm}^{-1}$ with very high accuracy 
[96]. This has been combined with energy levels from CDSD-296 to give a new line list for $\mathrm{CO}_{2}$ [97] which will be considered as part of a future update. 
Table 5

$\mathrm{CO}_{2}$ isotopologues in GEISA-2015 (from Tashkun et al. [84])

\begin{tabular}{|c|c|c|c|c|c|}
\hline CDSD ID & $\begin{array}{c}\text { HITRAN-2012 } \\
\text { ID }\end{array}$ & $\begin{array}{c}\text { GEISA-2015 } \\
\text { ID }\end{array}$ & $\begin{array}{c}\text { Molecular } \\
\text { species }\end{array}$ & Abundance & \#lines \\
\hline 1 & 1 & 626 & ${ }^{12} \mathrm{C}^{16} \mathrm{O}_{2}$ & 0.9842 & 170846 \\
\hline 2 & 2 & 636 & ${ }^{13} \mathrm{C}^{16} \mathrm{O}_{2}$ & $1.106 \times 10^{-2}$ & 70462 \\
\hline 3 & 3 & 628 & ${ }^{16} \mathrm{O}^{12} \mathrm{C}^{18} \mathrm{O}$ & $3.947 \times 10^{-3}$ & 115942 \\
\hline 4 & 4 & 627 & ${ }^{16} \mathrm{O}^{12} \mathrm{C}^{17} \mathrm{O}$ & $7.339 \times 10^{-4}$ & 72120 \\
\hline 5 & 5 & 638 & ${ }^{16} \mathrm{O}^{13} \mathrm{C}^{18} \mathrm{O}$ & $4.434 \times 10^{-5}$ & 40143 \\
\hline 6 & 6 & 637 & ${ }^{16} \mathrm{O}^{13} \mathrm{C}^{17} \mathrm{O}$ & $8.246 \times 10^{-6}$ & 23901 \\
\hline 7 & 7 & 828 & ${ }^{18} \mathrm{O}^{12} \mathrm{C}^{18} \mathrm{O}$ & $3.957 \times 10^{-6}$ & 10593 \\
\hline 8 & 8 & 728 & ${ }^{17} \mathrm{O}^{12} \mathrm{C}^{18} \mathrm{O}$ & $1.472 \times 10^{-6}$ & 15206 \\
\hline 9 & 9 & $727(\mathrm{New})$ & ${ }^{17} \mathrm{O}^{12} \mathrm{C}^{17} \mathrm{O}$ & $1.430 \times 10^{-7}$ & 6623 \\
\hline 10 & 0 & 838 & ${ }^{18} \mathrm{O}^{13} \mathrm{C}^{18} \mathrm{O}$ & $4.446 \times 10^{-8}$ & 3111 \\
\hline 11 & Abs & $738(\mathrm{New})$ & ${ }^{17} \mathrm{O}^{13} \mathrm{C}^{18} \mathrm{O}$ & $1.654 \times 10^{-8}$ & 3621 \\
\hline 12 & Abs & $737($ New $)$ & ${ }^{13} \mathrm{C}^{17} \mathrm{O}_{2}$ & $1.55 \times 10^{-9}$ & 1659 \\
\hline
\end{tabular}

\subsubsection{Line shape parameters:}

The algorithm to add $\mathrm{CO}_{2}$ line shape parameters to the GEISA-2015 line list uses data from the measurement database [98]. The database values were filtered and outliers removed. However, most of the data in the algorithm rely on recent CRB calculations of the line shape parameters for $\mathrm{CO}_{2}$ broadened by $\mathrm{N}_{2}, \mathrm{O}_{2}$, air, and $\mathrm{CO}_{2}$ [99-101]. These calculations show excellent agreement with measurement; average differences of a fraction of a percent and standard deviations of 1-3\%. The CRB calculations allowed the study of the dependence of the line shape parameters on J" values, temperatures, and vibrational bands that are yet to be measured. A study of the vibrational dependence of the half-width and line shift, and the temperature dependence of these parameters was recently completed by Gamache and Lamouroux [102]. From this study they developed an algorithm based on a generalization of the method of Gamache and Hartmann [103] that can predict the line shape parameters for $\mathrm{CO}_{2}$ in collision with $\mathrm{N}_{2}, \mathrm{O}_{2}$, air, and $\mathrm{CO}_{2}$ [104]. $\mathrm{CRB}$ calculations were used to produce data up to $\mathrm{J} "=160$ and these data were extrapolated to $\mathrm{J}=200$. The prediction algorithm determines the half-width and the line shift for any vibrational transition with $\mathrm{J} " \leq 200$ for temperatures in the range 150-2000 K. The accuracy of the algorithm is discussed in Ref. [104]. 
The prediction algorithm uses the rotational and vibrational quantum numbers and temperature as inputs and returns the half-width and line shift for the particular transition at the specified temperature. Given the line shape data at a number of temperatures, the temperature dependence of these parameters can be determined using the power law model

$$
(T)=\left(T_{0}\right)\left[\frac{T_{o}}{T}\right]^{n} .
$$

It is known that the temperature exponent, $n$, is strongly dependent on the temperature range chosen [101]. Here the temperature dependence of the air- and self-broadened half-width were determined using the prediction algorithm data for the temperature range 200-350 K (Earth). For applications to other atmospheres, different values should be used. For example the NASA Ames $\mathrm{CO}_{2}$ database [105] contains temperature exponents for 4 temperature ranges corresponding to applications to Mars (150-296 K), Earth (200-350 K), Venus (296-700 K), and high temperature applications (700-2000 K).

Using the algorithm, the half-width, its temperature dependence, and the line shift for both air- and self-broadening of $\mathrm{CO}_{2}$, and the corresponding errors in these parameters were added to the GEISA-2015 $\mathrm{CO}_{2}$ transitions. 


\subsection{3 $\quad \mathrm{O}_{3}$ (molecule 3)}

Forty-six bands of the main ozone isotopologue, ${ }^{16} \mathrm{O}_{3}$, in the $3266-6997 \mathrm{~cm}^{-1}$ spectral region are newly included in the GEISA-2015 database, as summarized in Table 6. A graphical intensity overview of the new data is shown on Fig. 5.

\section{Table 6}

Ozone bands newly included or updated in GEISA-2015 line parameter database. Upper and lower state vibrational band identifiers $\left(\mathrm{v}_{\mathrm{i}}(\mathrm{i}=1,2,3)\right)$ are given in column 1 , with associated number of archived lines, spectral region in $\mathrm{cm}^{-1}$, total intensity in $\mathrm{cm}$ molecule ${ }^{-1}$ at $296 \mathrm{~K}$, and source references, in columns 2 to 5 , respectively.

\begin{tabular}{|c|c|c|c|c|}
\hline Band & \# lines & $\begin{array}{l}\text { Spectral region } \\
\left(\mathrm{cm}^{-1}\right)\end{array}$ & $\begin{array}{c}S_{V} \\
\text { (cm molecule }^{-1} \\
\text { at } 296 \mathrm{~K})\end{array}$ & Refs. \\
\hline $022-000$ & $2616^{\mathrm{a}}$ & $3266.51-3488.18$ & $1.111 \times 10^{-22}$ & [106] \\
\hline $121-000$ & $2210^{a}$ & $3373.90-3487.30$ & $6.329 \times 10^{-22}$ & {$[106]$} \\
\hline $220-000$ & $684^{\mathrm{a}}$ & $3488.15-3627.87$ & $2.500 \times 10^{-23}$ & [106] \\
\hline $311-100$ & 729 & $3739.97-3826.22$ & $2.398 \times 10^{-23}$ & [107] \\
\hline $005-100$ & 508 & $3742.91-3726.13$ & $1.660 \times 10^{-23}$ & [107] \\
\hline $104-100$ & 51 & $3752.69-3863.55$ & $8.192 \times 10^{-25}$ & [107] \\
\hline $005-001$ & 278 & $3807.31-3917.54$ & $9.849 \times 10^{-24}$ & [107] \\
\hline $311-001$ & 436 & $3810.30-3946.73$ & $9.846 \times 10^{-24}$ & [107] \\
\hline $104-001$ & 950 & $3820.17-3894.94$ & $2.218 \times 10^{-22}$ & [107] \\
\hline $123-010$ & 783 & $4531.73-4599.39$ & $6.534 \times 10^{-23}$ & [108] \\
\hline $330-010$ & 47 & $4554.65-4601.97$ & $1.830 \times 10^{-24}$ & [108] \\
\hline $104-000$ & 1093 & $4802.98-4978.61$ & $7.789 \times 10^{-23}$ & [107] \\
\hline $005-000$ & 1514 & $4806.33-4938.21$ & $5.300 \times 10^{-22}$ & [107] \\
\hline $311-000$ & 1053 & $4827.65-4928.49$ & $3.450 \times 10^{-22}$ & [107] \\
\hline $203-000$ & 1086 & $4997.30-5085.47$ & $1.263 \times 10^{-22}$ & [109] \\
\hline $132-000$ & 27 & $5028.06-5085.33$ & $1.396 \times 10^{-24}$ & [109] \\
\hline $123-000$ & 784 & $5216.76-5300.21$ & $5.902 \times 10^{-23}$ & [108] \\
\hline $401-000$ & 896 & $5244.80-5319.26$ & $8.153 \times 10^{-23}$ & [108] \\
\hline $330-000$ & 43 & $5252.48-4302.26$ & $1.514 \times 10^{-24}$ & [108] \\
\hline $024-000$ & 2 & $5271.73-5316.28$ & $6.791 \times 10^{-26}$ & [108] \\
\hline $015-000$ & 622 & $5625.97-5704.62$ & $3.465 \times 10^{-23}$ & [108] \\
\hline $420-000$ & 10 & $5663.20-5706.33$ & $3.065 \times 10^{-25}$ & [108] \\
\hline $105 \_1-000^{\mathrm{c}}$ & 730 & $5708.95-5790.90$ & $4.943 \times 10^{-23}$ & [111] \\
\hline $312-000$ & 14 & $5753.33-5786.12$ & $4.336 \times 10^{-25}$ & [111] \\
\hline $421-010$ & 303 & $5815.58-5873.74$ & $3.570 \times 10^{-25}$ & [114] \\
\hline $133-000$ & 702 & $5852.44-5931.22$ & $4.718 \times 10^{-24}$ & [114] \\
\hline $411-000$ & 444 & $5895.17-5956.76$ & $1.379 \times 10^{-24}$ & [114] \\
\hline $233 \_1-000^{\mathrm{c}}$ & 528 & $5941.73-6021.44$ & $7.950 \times 10^{-25}$ & [115] \\
\hline $034-000$ & 264 & $5956.88-6078.00$ & $8.529 \times 10^{-25}$ & [112] \\
\hline $105 \_2-000^{\mathrm{c}}$ & 678 & $5983.44-6071.43$ & $2.097 \times 10^{-24}$ & {$[112]$} \\
\hline $124 \_1-000^{\mathrm{c}}$ & 999 & $6019.98-6201.30$ & $2.934 \times 10^{-24}$ & [112] \\
\hline $223 \_1-000^{\mathrm{c}}$ & 954 & $6031.75-6130.78$ & $1.179 \times 10^{-23}$ & [112] \\
\hline $510-000$ & 39 & $6067.96-6136.40$ & $1.275 \times 10^{-25}$ & [112] \\
\hline $331-000$ & 168 & $6163.49-6207.75$ & $1.371 \times 10^{-25}$ & {$[112]$} \\
\hline $025-000$ & 1003 & $6225.12-6311.46$ & $7.702 \times 10^{-24}$ & [113] \\
\hline
\end{tabular}




\begin{tabular}{|c|c|c|c|c|}
\hline Band & \# lines & $\begin{array}{c}\text { Spectral region } \\
\left(\mathbf{c m}^{-\mathbf{1}}\right)\end{array}$ & $\begin{array}{c}\boldsymbol{S}_{V} \\
(\mathbf{c m} \text { molecule } \\
\text { at 296 K) }\end{array}$ & Refs. \\
\hline $124 \_2-000^{\mathrm{c}}$ & 78 & $6246.40-6363.42$ & $3.445 \times 10^{-25}$ & {$[\mathbf{1 1 3}]$} \\
\hline $430-000$ & 111 & $6284.63-6395.38$ & $3.115 \times 10^{-25}$ & {$[\mathbf{1 1 3}]$} \\
\hline $501-000$ & 749 & $6301.80-6365.48$ & $6.370 \times 10^{-24}$ & {$[\mathbf{1 1 3}]$} \\
\hline $223 \_2-000^{\mathrm{c}}$ & 777 & $6318.03-6393.74$ & $6.790 \times 10^{-24}$ & {$[\mathbf{1 1 3}]$} \\
\hline $421-000$ & 409 & $6503.67-6574.40$ & $8.695 \times 10^{-25}$ & {$[\mathbf{1 1 4}]$} \\
\hline $205 \_1-000^{\mathrm{c}}$ & 570 & $6525.82-6593.61$ & $1.966 \times 10^{-24}$ & {$[\mathbf{1 1 4}]$} \\
\hline $242-000$ & 457 & $6665.49-6822.32$ & $2.914 \times 10^{-25}$ & {$[\mathbf{1 1 5}]$} \\
\hline $233 \_1-000^{\mathrm{c}}$ & 754 & $6641.08-6722.18$ & $1.583 \times 10^{-24}$ & {$[\mathbf{1 1 5}]$} \\
\hline $520-000$ & 33 & $6677.10-6771.82$ & $2.158 \times 10^{-26}$ & {$[\mathbf{1 1 5}]$} \\
\hline $511-000$ & $317^{\mathrm{b}}$ & $6945.09-6989.76$ & $2.423 \times 10^{-25}$ & {$[\mathbf{1 1 4}]$} \\
\hline $233 \_2-000^{\mathrm{c}}$ & 417 & $6950.18-6996.68$ & $4.506 \times 10^{-25}$ & {$[\mathbf{1 1 4}]$} \\
\hline
\end{tabular}

Notes: ${ }^{a, b)}$ The number of transitions is not the same as that given in the S\&MPO databank [116] due to use of a cut-off of respectively $3 \times 10^{-27}$ instead of $2 \times 10^{-26}$ and $1 \times 10^{-28}$ instead of $2 \times 10^{-28}$ (in cm molecule ${ }^{-1}$ ).

${ }^{c)}$ For these bands the additional ranking number is given to distinguish the upper states which could have the same principal normal mode contributions as discussed in [118]; $S_{V}$ is the integrated band intensity computed as a sum of vibration-rotation line intensities with the $I_{\min }$ and $J_{\max }$ cut-off specified for each band in original publications cited in the last column.

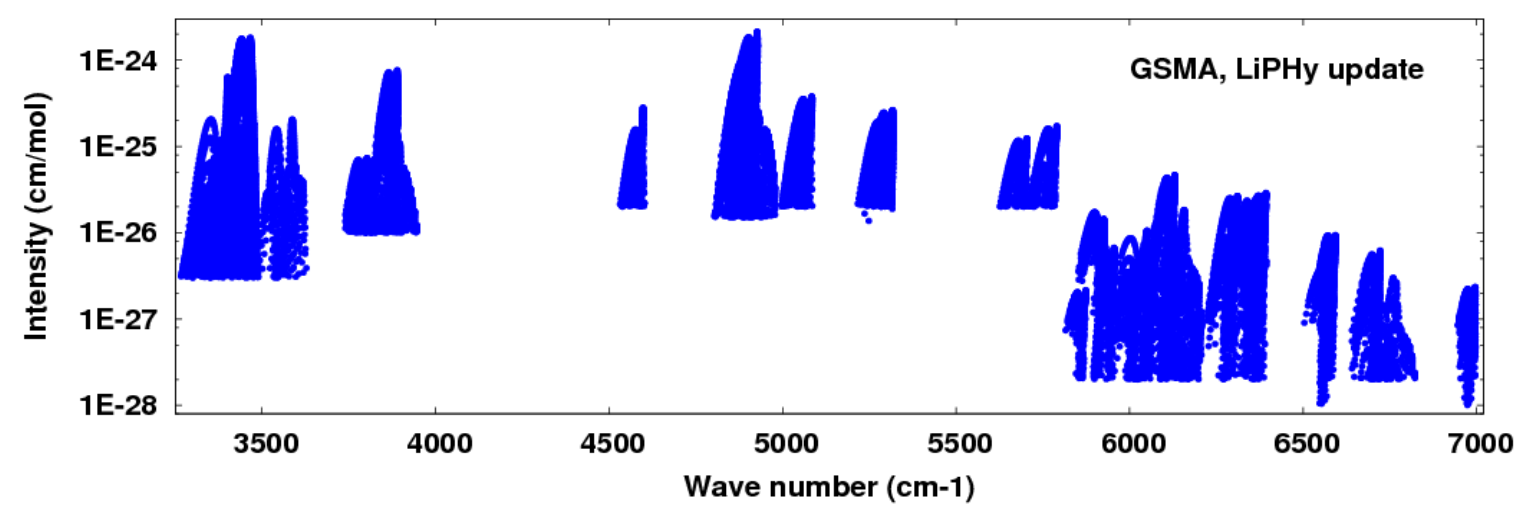

Fig. 5. Overview of line intensities of the supplementary ozone data included in GEISA-2015 in the 3266$6997 \mathrm{~cm}^{-1}$ spectral region. The intensity cut-off is much lower above $5800 \mathrm{~cm}^{-1}$ because the laser CRDS measurements in this range were more sensitive resulting in the detection and assignments of much weaker lines [113-115].

The twenty-four bands up to $5800 \mathrm{~cm}^{-1}$ were obtained from the analysis of FTS recorded in GSMA laboratory of Reims University [106-111,116], while the twenty two other bands were recorded by CW-CRDS in LIPhy laboratory of Grenoble University [112-115]. This new dataset, beginning at $3266 \mathrm{~cm}^{-1}$, was based on results of previous work by Mikhailenko et al. [117] included in GEISA-2011 which covered the spectral range below $3000 \mathrm{~cm}^{-1}$. All these data are implemented 
in the S\&MPO databank (Babikov et al. [116]), jointly developed and maintained by the Institute of Atmospheric Optics (Tomsk) and Reims University. Relevant details about experimental accuracies for each of the analyzed bands, theoretical models and rovibrational assignments can be found in Refs. [106,111-118].

In GEISA-2011, the highest included ozone bands corresponded to FTS data in the 4400$4800 \mathrm{~cm}^{-1}$ wavenumber range analyzed in Refs. [119,121] and to CRDS data up to $6394 \mathrm{~cm}^{-1}$ [112,113]. In GEISA-2015 the ozone line list is considerably extended and is now almost complete up to nearly $7000 \mathrm{~cm}^{-1}$. The higher-frequency CRDS measurement have been described by Campargue et al. $[\mathbf{1 1 4}, \mathbf{1 1 5}]$, while the assignment and analyses of both FTS and CRDS spectra have been reviewed by Barbe et al. [118].

In particular, the previously missing spectral interval between 4850 and $5800 \mathrm{~cm}^{-1}$ is now covered. For the $5 v_{3}, v_{1}+4 v_{3}$ and $3 v_{1}+v_{2}+v_{3}$ bands $\left(4800-4930 \mathrm{~cm}^{-1}\right)$, results of a recent unpublished analysis [107] have been included improving the results of Ref. [121]. The motivation for including new data sets is twofold. On one hand, knowledge of highly excited vibration-rotation ozone states and transition probabilities is important for the modeling of molecular fragmentation and recombination processes. It has been recently shown that this information is important for the understanding of the properties of the ozone transition state towards the dissociation [122]. On the other hand, radiative processes involving high-energy ro-vibrational states of ozone are also required for a detailed description of non-LTE processes in the upper atmosphere $[\mathbf{1 2 3 , 1 2 4 ]}$ and in turn for better interpretation of ozone emission in satellite measurements [125].

The multiple vibrational labels appearing in Table 6 for high energy bands deserve a comment. The vibrational assignments rely on normal mode decomposition of effective wave functions following the method described in [126]. The assignments of highly excited vibrations become ambiguous for some states [117] because of the absence of a dominant normal mode contribution in the vibrational eigen-functions. This occurs when the normal modes are strongly mixed due to anharmonic resonance interactions including inter-polyad couplings. For this reason the vibrational labelling could change with an improved potential function. At present we apply the vibrational assignment deduced from recent accurate ab-initio potential energy surface of Tyuterev et al. [127] that was used for spectral analyses in the high energy range approaching the dissociation threshold [122]. The vibrational assignment of some bands in Table 6 has evolved since the earlier publications (see the review [118] for more details): the $2 v_{1}+v_{2}+3 v_{3}$ band of Ref. [110] is now labeled as $v_{2}+5 v_{3}$ and the $v_{1}+5 v_{3}$ band of Ref. [111] is labeled as $v_{1}+5 v_{3_{-}} 1$. In the latter case, as is also for some bands in Table 6, an additional ranking number is given to distinguish the upper states which could have the same principal normal mode contributions as discussed in [118]. 
The accuracy of line lists depends strongly on the wavenumber range. In the range of fundamental, low overtones and combination bands, the accuracy on line positions reaches $\sim 10^{-4}$ $\mathrm{cm}^{-1}$ with relative precision on experimental intensity determination of $\sim 2-3 \%$ for strong isolated lines [118]. With increasing upper state energies the spectra are more and more crowded, and become dominated by numerous overlapping weak bands making the retrieval of line parameters using line profile fit [128] less accurate. Moreover, the data reduction using effective Hamiltonians and effective transition moment operators introduces a supplementary uncertainty due to multiple resonance interactions and "dark" state perturbations: in the range of bands with five or six vibrational quanta $(\Delta V=5$ or $\Delta V=6$ ), the root mean square fit error reaches value of the order of 0.002-0.004 $\mathrm{cm}^{-1}$ [106]. An accurate description of $B$-type bands represents a particular challenge for the analysis. While in the FTS range below $5800 \mathrm{~cm}^{-1}$, the line positions were calculated using respective effective Hamiltonian models [106-110, 111], in the CRDS range above $5800 \mathrm{~cm}^{-1}$, empirical corrections in calculated line positions have been introduced as described in Refs. [112115,118 ] to reduce the error to experimental accuracy, which is of the order of $0.0015 \mathrm{~cm}^{-1}$.

In GEISA-2015, along with other data, the bands with $\Delta V=5$ to $\Delta V=8$ (Table 6 , figure 5) are included; these give rise to congested ozone spectra involving numerous superimposed weak lines. In these circumstances only a selected set of unblended, relatively isolated lines (with best strengths measurements accurate to $\sim 5-10 \%$ ) could be involved in the determination of the band transition moment parameters, which have then been used for the generation of line lists. At high wavenumber ranges the corresponding synthetic spectra result in a qualitative description [109-118] of ozone absorption except for some extremely weak or yet unassigned transitions. Because of remaining inconsistencies between IR and UV intensity measurements which only agree within about $4 \%$ as discussed in $[\mathbf{1 1 8 , 1 2 9 , 1 3 0 ]}$, it has to be noted that in general the question of absolute accuracy of ozone line strengths is a controversial issue which requires further investigation.

Fig. 6 exhibits the difference of ozone absorption between 3397.3 and $3404.7 \mathrm{~cm}^{-1}$ using GEISA-2011 (upper panel A) and GEISA-2015 (lower panel B). On each panel, the upper part displays the experimental (in blue) and simulated (in olive) transmission spectra in \%. The lower part displays the difference (in \%) between the experimental (“OBS") and simulated transmission based on GEISA-2011 (panel A) and GEISA-2015 (panel B). The sum of the squares of differences between observed and simulated spectra $\left(\right.$ Diff $=\sum_{i=1}^{n}\left(T_{i}^{\text {Obs }}-T_{i}^{\text {Simul }}\right)^{2}, n-$ number of spectrum points, $T$ - transmission) are 0.560 and 0.064 for GEISA-2011 and GEISA-2015 respectively. The strongest lines correspond to the $R_{P}$ and $R_{R}$ branches of the $2 v_{2}+2 v_{3}$ band of ozone. Blue solid line corresponds to experimental absorption (room temperature, absorption path $3616 \mathrm{~cm}$, total pressure 
53.9 torr $\left(\mathrm{O}_{3}-79.404 \%, \mathrm{O}_{2}-20.408 \%, \mathrm{CO}_{2}-0.091 \%, \mathrm{H}_{2} \mathrm{O}-0.083 \%, \mathrm{CO}-0.01 \%, \mathrm{~N}_{2} \mathrm{O}-\right.$ $0.004 \%)$ ). The olive (panel A) and red (panel (B) lines correspond to calculated transmission. The new line list (GEISA-2015) was generated using results reported by Barbe et al.[106].
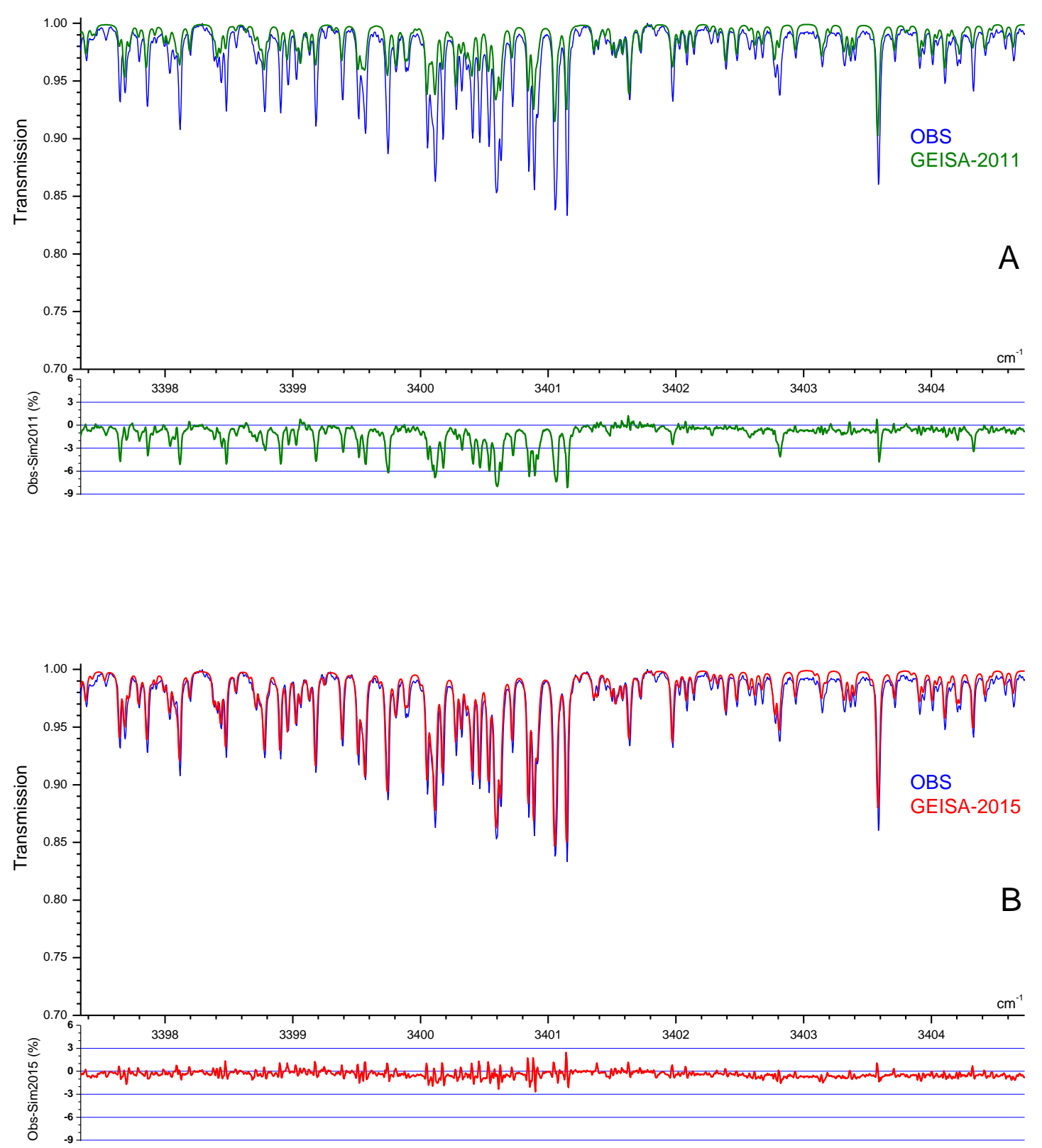

Fig.6. Differences between ozone absorption simulations using GEISA-2011 (upper panel A) and GEISA2015 (lower panel B) for the $v_{1}+2 v_{2}+v_{3}$ and $2 v_{2}+2 v_{3}$ bands near $3400 \mathrm{~cm}^{-1}$.

The user accuracy requirements for ozone data also depend on wavenumber range and vary according to specific applications. In the high energy range, knowledge of the most important 
absorption features and their trend with upper state energy are essential for non-LTE modeling or for global understanding of ozone spectroscopic properties and dynamics,. The present release includes a significant portion of the relevant data, up to $\sim 82 \%$ of the dissociation threshold (estimated as $\mathrm{D}_{0} \sim 8500 \mathrm{~cm}^{-1}[\mathbf{1 3 1}]$ ), which corresponds to recent progress in ozone spectral assignments [109-118]. These data could also be useful for validation of ab-initio calculations in this high energy range.

\subsection{4 $\mathrm{CH}_{4}$ (molecule 6)}

Part of the GEISA-2015 methane update is based on the latest global fits of line-by-line assignments (for both line positions and line intensities). The global analysis up to the Tetradecad region [132] was used for ${ }^{12} \mathrm{CH}_{4}$, while a global fit up to the Octad region [133] was used for ${ }^{13} \mathrm{CH}_{4}$. The line list was generated by computing semi-empirical upper state energy levels. These levels are calculated from averages over several transitions sharing the same upper state; all line positions are then recomputed using these upper states. This method is the same as the one used for the HITRAN-2012 methane update described in Ref. [134]. Since this last paper, some problems, however, have been detected especially concerning some hot band lines like those of the OctadDyad and Octad-Pentad regions. As a consequence, in the case of ${ }^{12} \mathrm{CH}_{4}$, the calculated lines of Octad-Dyad resulting from these global fits are discarded in the present GEISA update, while Octad-Pentad lines are included with an intensity cut-off limited to $10^{-26} \mathrm{~cm}^{-1} /$ molecule $\mathrm{cm}^{-2}$. Moreover, after a careful validation process based on a method described in Armante et al. [22] (this issue), it appeared that the new spectroscopic parameters of the Octad-GS lines for ${ }^{12} \mathrm{CH}_{4}$ and ${ }^{13} \mathrm{CH}_{4}$, and the Dyad-GS lines for ${ }^{13} \mathrm{CH}_{4}$, were less precise than the previous ones in GEISA-2011 [11]; these have, consequently, been retained in GEISA-2015.

The present calculated data were recently used to estimate the spectroscopic uncertainties for methane retrievals associated with the set-up and instrumentation of the future Earth-observing satellite Sentinel-5 [135].

It should also be mentioned that the problems concerning hot bands in the global fits, discussed above have very recently been solved. A new ${ }^{12} \mathrm{CH}_{4}$ study using high-temperature emission data which includes highly excited rovibrational levels (up to $\mathrm{J}=30$ in some regions) between 1000 and $1500 \mathrm{~cm}^{-1}$ has been performed and included in a global fit of the 0 to $6300 \mathrm{~cm}^{-1}$ range [136]. Many new hot band lines could be assigned and their intensity is now reliably modeled. These new data are not included in GEISA-2015, but will be used in a future update, in conjunction with other ongoing studies. Finally, two new line-broadening studies in the Tetradecad region will also be included in the database in the near future $[\mathbf{1 3 7 , 1 3 8 ]}$. 
The near infrared line list for methane above $5850 \mathrm{~cm}^{-1}$ has been considerably updated on the basis of new measurements. While methane molecular line parameters are mostly calculated values below $5000 \mathrm{~cm}^{-1}$, above this value, line positions and line intensities take empirical values directly retrieved from experimental spectra recorded at room temperature. In particular, the GEISA-2011 list above $4900 \mathrm{~cm}^{-1}$ relied almost exclusively on empirical spectroscopic parameters obtained by Brown using an FTS with path lengths up to 433 meters [139]. The overwhelming majority of the absorption lines were included without rovibrational assignment and with a lower state energy default value of $999.9900 \mathrm{~cm}^{-1}$ as recommended by the author of the data [140]. In the recent years, considerable progress has been achieved using new measurements with increased sensitivity and extended spectral coverage. The major changes are summarized below and illustrated in the overview comparison of the GEISA-2011 and GEISA-2015 line lists presented in Fig.7.

The methane list in the $5850-7918.9 \mathrm{~cm}^{-1}$ region is essentially the room temperature WKLMC empirical list [141] constructed in Grenoble from natural methane spectra recorded by differential DAS laser and high sensitivity CRDS. The positions and intensities were retrieved from spectra recorded at room temperature and at $80 \mathrm{~K}$ by DAS in the strong absorption regions in the $2 v_{3}$ region of the Tetradecad [142-145] and in the Icosad [146-148], and CRDS in the $1.58 \mu \mathrm{m} \mathrm{[149-151]}$ and $1.28 \mu \mathrm{m}$ transparency windows [152]. Two WKLMC empirical lists for methane in "natural" abundance were constructed as described in Refs. [134,141]. The GEISA-2015 list reproduces the WKLMC list at $296 \mathrm{~K}$ while the WKLMC list at $80 \mathrm{~K}$ has fulfilled important needs for the analysis of the near infrared spectra of various planetary objects [153-155], in particular Titan [149,156]. Transitions of the ${ }^{13} \mathrm{CH}_{4}$ and $\mathrm{CH}_{3} \mathrm{D}$ isotopologues present in "natural" methane were identified by comparison with DAS spectra of "pure" ${ }^{13} \mathrm{CH}_{4}$ and $\mathrm{CH}_{3} \mathrm{D}$ recorded at $80 \mathrm{~K}$ and $296 \mathrm{~K}$. The combined $80 \mathrm{~K}$ and room temperature intensities facilitated the application of the so-called "two Temperature-method" which allows the empirical lower state energy level, $E_{\text {emp }}$, of a given transition to be determined from the ratio of the intensities of the corresponding line measured at two temperatures $[\mathbf{1 5 7 , 1 5 8 ]}$. In this way, although most of the lines lack full rovibrational assignments, the derived $E_{\text {emp }}$ values allow the temperature dependence of most of the absorption in the region to be accounted for satisfactorily. When available and validated using the $E_{\text {emp }}$ values, the rovibrational assignments were attached to the WKLMC line parameters and included in the GEISA-2015 list. Rovibrational assignments were transferred from three sources: $(i)$ the GOSAT empirical list [159] provided $~ 2000$ rovibrational assignments in the 5855-6204.6 $\mathrm{cm}^{-1}$, region, (ii) the $6350-6500 \mathrm{~cm}^{-1}$, interval corresponding to the $5 v_{4}$ and $v_{2}+4 v_{4}$ bands in the Icosad system which were assigned by Nikitin et al. [150], (iii) about 70 lines of the $v_{2}+2 v_{3}$ band near $7510 \mathrm{~cm}^{-1}$ are assigned. In figure 7, the WKLMC lines with full rovibrational assignments or $E_{\text {emp }}$ values have been highlighted. 


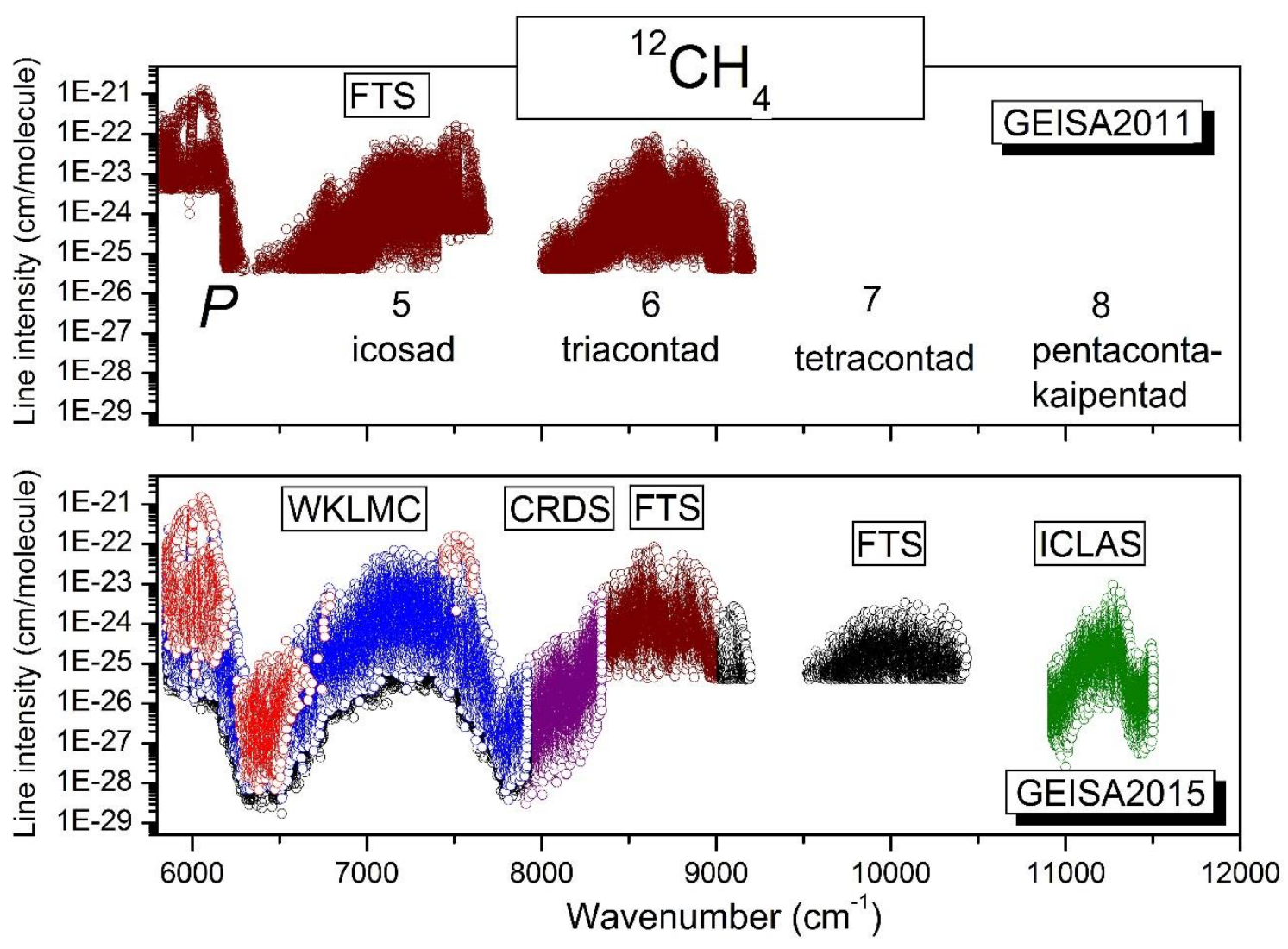

Fig. 7. Line intensity overview comparison of the GEISA list of ${ }^{12} \mathrm{CH}_{4}$ in the 2011 and 2015 editions of GEISA above $5850 \mathrm{~cm}^{-1}$ In this region, line parameters all are of empirical origin: the WKLMC list up to $7920 \mathrm{~cm}^{-1}$ [141], CRDS between 7920 and $8345 \mathrm{~cm}^{-1}$ [160], FTS by Brown in the $8345-9028 \mathrm{~cm}^{-1}$ interval [139] and by Béguier et al. in the $9028-10923 \mathrm{~cm}^{-1}$ interval [161], and ICLAS between 11000 and $11500 \mathrm{~cm}^{-1}$ [162]. The different polyad and corresponding numbers, $P$, are indicated. (The polyad number $P$ is equal to $2\left(V_{l}+V_{3}\right)+V_{2}+V_{4}$, where $V_{i}$ are the normal mode vibrational quantum numbers). The WKLMC lines with full rovibrational assignments or $E_{\text {emp }}$ values have been highlighted with red and blue symbols, respectively.

\subsection{5 $\quad \mathrm{O}_{2}$ (molecule 7)}

Our update has started from the $\mathrm{O}_{2}$ line list as given in HITRAN-2012 [14], which represents a substantial extension to previous versions of GEISA and HITRAN, with updates largely based on Gordon et al. [163,164], Leshchishina et al. [165,166] and Long et al. [167-169]. The line positions and lower states energies were updated with the results from an updated isotopically invariant Dunham fit published by Yu et al. in 2014 [170]. The other line parameters, such as line intensities and broadening, remain unchanged, and finally the number of lines also stays the same. The updated isotopically invariant Dunham fit [170] was obtained by adding new measurements in the microwave [171] and in the infrared [172] to the first global analysis of $\mathrm{O}_{2}$ by Yu et al. in 2012 [173] that simultaneously fits spectra involving the $X^{\mathbf{3}} \Sigma_{g}^{-}, a^{\mathbf{1}} \Delta_{g}$ and ${ }^{b^{\mathbf{1}} \Sigma_{g}^{+}}$states of all six $\mathrm{O}_{2}$ isotopologues. The new microwave work [171] measured 324 rotational transitions in 
the $a^{a^{1} \Delta_{g}} \mathrm{v}=0$ and 1 states of the six $\mathrm{O}_{2}$ isotopologues with experimental accuracy of 50-200 kHz, which helped determine two more hyperfine parameters, the electric quadrupole interaction $e Q q$ and the nuclear spin-rotation interaction $C_{I}$. The new infrared work [172] reported 1644 transition frequencies in the $b^{1} \Sigma_{g}^{+}-X^{3} \Sigma_{g}^{-}$system of six $\mathrm{O}_{2}$ isotopologues and the experimental accuracy ranged from 0.0004 to $0.006 \mathrm{~cm}^{-1}$. The new infrared study [172] revealed a $0.2 \mathrm{~cm}^{-1}$ calibration error in the ${ }^{17} \mathrm{O}^{18} \mathrm{O} \mathrm{v}^{\prime}-\mathrm{v}^{\prime \prime}=1-0$ Raman data of Edwards et al. [174], resolved discrepancies in the Raman data for ${ }^{16} \mathrm{O}^{17} \mathrm{O},{ }^{17} \mathrm{O}{ }^{17} \mathrm{O}$, and ${ }^{17} \mathrm{O}^{18} \mathrm{O}$, and improved the vibrational parameterization of the ground electronic state.

Note that the absolute zero energy of each isotopologue is set to the allowed lowest rotational level in $X^{3} \Sigma_{g}^{-}$of that isotopologue, i.e., the absolute zero energy is set to the level of $N=1$ and $J=0$ for ${ }^{16} \mathrm{O}^{16} \mathrm{O}$, to the level of $N=0$ and $J=1$ for ${ }^{16} \mathrm{O}^{18} \mathrm{O}$ and to the level of $N=0, J=1$ and $F=3.5$ for ${ }^{16} \mathrm{O}^{17} \mathrm{O}$. For ${ }^{16} \mathrm{O}^{17} \mathrm{O}$, the microwave transitions have nuclear hyperfine structures while the $a^{\mathbf{1}} \Delta_{g}-X^{3} \Sigma_{g}^{-}$and $b^{\mathbf{1}} \Sigma_{g}^{+}-X^{\mathbf{3}} \Sigma_{g}^{-}$electronic transitions have no nuclear hyperfine structures. The ${ }^{16} \mathrm{O}^{17} \mathrm{O}$ microwave transitions were directly updated using the results of the updated Dunham fit while its electronic transitions were updated with "hyperfine-free" energies calculated with the nuclear hyperfine parameters set to zero. In this case, the absolute zero energy is set to the level of $N=0$ and $J=1$ for ${ }^{16} \mathrm{O}^{17} \mathrm{O}$.

When compared to HITRAN-2012, line positions differences up to $0.015 \mathrm{~cm}^{-1}$ were found for the ${ }^{16} \mathrm{O}^{16} \mathrm{O} a-X$ system, up to $0.05 \mathrm{~cm}-1$ for ${ }^{16} \mathrm{O}^{16} \mathrm{O} b-X$, up to $0.05 \mathrm{~cm}^{-1}$ for ${ }^{16} \mathrm{O}^{17} \mathrm{O} a-X$, up to $0.025 \mathrm{~cm}^{-1}$ for ${ }^{16} \mathrm{O}^{17} \mathrm{O} b-X$, up to $0.003 \mathrm{~cm}^{-1}$ for ${ }^{16} \mathrm{O}^{18} \mathrm{O} a-X$ system, and up to $0.09 \mathrm{~cm}^{-1}$ for ${ }^{16} \mathrm{O}^{18} \mathrm{O} b-X$. Fig. 8 presents a comparison of the ${ }^{16} \mathrm{O}^{17} \mathrm{O} a-X\left(\mathrm{v}^{\prime}, \mathrm{v}^{\prime \prime}\right)=(0,0)$ band position with experiment, which indicates a systematic error in the line positions of this band in HITRAN-2012 which has been corrected in GEISA-2015.

It was found that in HITRAN-2012, the quantum numbers for the $\triangle N \Delta J=P O$ branch of the ${ }^{16} \mathrm{O}^{16} \mathrm{O} a-X\left(\mathrm{v}^{\prime}, \mathrm{v}^{\prime \prime}\right)=(0,0)$ band were incorrectly labeled, i.e., the $7875.6 \mathrm{~cm}^{-1}$ transition with a lower state energy of $16.4 \mathrm{~cm}^{-1}$ was labeled as $P 1 O 2$. A $P 1 O 2$ line has $N^{\prime \prime}=1, J^{\prime \prime}=2, N^{\prime}=0$ and $J^{\prime}=0$, but the rotational level of $N^{\prime}=0$ and $J^{\prime}=0$ does not exist in the ${ }^{a^{\mathbf{1}} \Delta_{g}}$ state. The correct assignment for this line is $\mathrm{P} 3 \mathrm{O} 4$. Other lines in the same $P O$ branch were also incorrectly labeled with the same shift of two in quantum numbers. This error is corrected in the updated GEISA-2015 line list. 


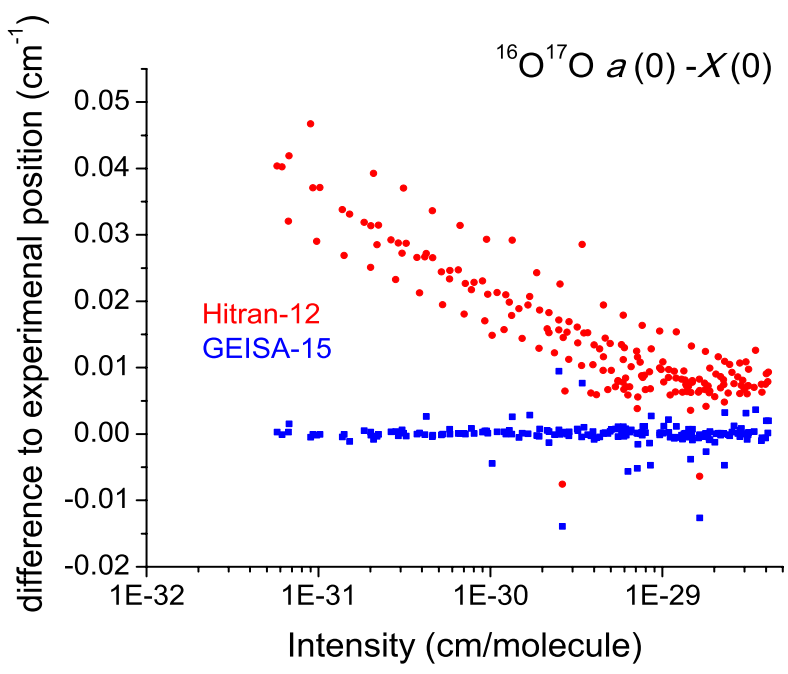

Fig. 8. Comparisons of the ${ }^{16} \mathrm{O}^{17} \mathrm{O} \boldsymbol{a}^{\mathbf{1}} \boldsymbol{\Delta}_{\boldsymbol{g}}-\boldsymbol{X}^{\mathbf{3}} \boldsymbol{\Sigma}_{\boldsymbol{g}}^{-}\left(\mathrm{v}^{\prime}, \mathrm{v}^{\prime \prime}\right)=(0,0)$ band positions in HITRAN-2012 (red) and GEISA-2015 (blue) as a function of the intensity.

As commented in the GEISA-2011 [11] $\mathrm{SO}_{2}$ update description, "It is worthwhile mentioning that the CDMS catalog $\left[\mathbf{1 8 , 1 9 ]}\right.$ provides an entry for $v_{2}$ which is based on extensive rotational transitions in its $\mathrm{v}_{2}=0$ and 1 states [175] along with previous IR data", this entry has been, consequently, taken as the basis for GEISA-2015 update. A total revision of the $\mathrm{v}_{2}=0$ and $\mathrm{v}_{2}=1$ rotational transitions has been made, using data from the CDMS catalog. The spectroscopic data of two (as identified in the CDMS catalog) data files, i.e.: (i) W064502 (transition 000-000), 14754 entries; version 2; (ii) W064503 (transition 010-010), 9808 entries; version 2, have been implemented in GEISA-2015 and used to totally replace previous data, after unit conversion and line shape default value addition, i.e.:

- HWHM $\left(\gamma_{\text {air }}\right)$ default value $=0.1100 \mathrm{~cm}^{-1} \mathrm{~atm}^{-1}$

- HWHM self $\left(\gamma_{\text {self }}\right)$ default value $=0.400 \mathrm{~cm}^{-1} \mathrm{~atm}^{-1}$

A constant default value of 0.75 has been adopted for the temperature dependence coefficient $n$ of the air-broadening half width. The air pressure shift is set at the value $0.0 \mathrm{~cm}^{-1} \mathrm{~atm}^{-1}$ at $296 \mathrm{~K}$.

Besides new or updated transition frequencies from Ref. [175], important data sources in this new study on rotational transitions in the ground and $v_{2}=1$ states are those of Belov et al. [176] and Müller et al. [177] for the ground vibrational state as well as those of Mehrotra et al. [178,179], Helminger and DeLucia [180], and Alekseev et al. [181] $\mathrm{v}_{2}=0$ and 1.

In the CDMS catalog documentation, the transitions frequencies were deemed to be reliable with respect to the predicted uncertainties up to $3 K_{a}+J<110$ and 100 for $\mathrm{v}_{2}=0$ and 1 , 
respectively. Considering that the coverage in $K_{a}$ is good to reasonable up to 23 and 21, respectively, with only slight coverage up to $K_{a}=8$ for v=0, it may be safer to view transition with $4 K_{a}+J>110$ and 100, respectively, with some caution. The predictions should be accurate enough for observational purposes at temperatures up to about $300 \mathrm{~K}$ because uncertainties become noticeable only for very weak transitions. The data may have to be viewed with some caution at temperatures much higher than $300 \mathrm{~K}$.

Dipole moments were taken from Patel et al. [182]. Rotational corrections to the dipole moments are not known. This may lead to non-negligible intensity errors at rather high values of $J$ or $K_{a}$. The partition function values in the CDMS are fully converged in $J$ and $K_{a}$, but are restricted to $\mathrm{v}_{2}=0$ and $\mathrm{v}_{2}=1$ only. In the process of converting the intensities from $300 \mathrm{~K}$ (default in the CDMS) to $296 \mathrm{~K}$ (default in GEISA) and of changing intensity units, this small truncation error was considered for GEISA.

\subsection{7 $\mathrm{NH}_{3}$ (molecule 11)}

Down et al. [183] performed a thorough re-analysis of the available experimental data for ${ }^{14} \mathrm{NH}_{3}$. They generated a set of empirical energy levels and used the BYTe line list [184] to both make new assignments and to correct old ones. At the same time Down et al. [183] proposed a new and consistent set of quantum numbers which they applied to their data. Finally they used their empirical energy levels and BYTe intensities to generate new line lists for the $v_{2}+v_{4}-v_{4}, v_{4}-v_{2}, v_{4}-$ $v_{4}$, and $2 v_{2}-2 v_{2}$ hot bands. These data have been used to update the $\mathrm{NH}_{3}$ GEISA-2015 line list. This represents a total of 40,224 entries.

In the previous editions of GEISA, the $\mathrm{NH}_{3}$ archive ended near $5294 \mathrm{~cm}^{-1}$. In 2015 , it was extended to $7000 \mathrm{~cm}^{-1}$ using 5100 entries of the empirical line list from Sung et al. [185]. However, no compilations were created for missing ammonia bands between 5300 and $6300 \mathrm{~cm}^{-1}$, and no improved analyses were made for the existing ${ }^{15} \mathrm{NH}_{3}$ entries.

For the near-IR $\left(6300-7000 \mathrm{~cm}^{-1}\right)$, Sung et al. [185] reported an extensive empirical list of ${ }^{14} \mathrm{NH}_{3}$ lines containing 5078 features (positions, intensities, empirical lower state energies with some quantum assignments). This study used FTIR to characterize $99.7 \%$ of observed opacity in this region; a few line positions from Cacciani et al. [186] were also included. If the rotational quantum numbers $J$ and $K$ were known [185], the air- and self-broadening coefficients, $\gamma$, were computed as a function of the rotational quantum numbers, $J$ and $K$, using empirical expressions from Nemtchinov et al. [187], i.e.:

$$
\gamma(J, K)=\beta_{0}+\beta_{1} m+\beta_{2} K+\beta_{3} m^{2}+\beta_{4} K^{2}+\beta_{5} m K .
$$


Here $m=-J, J, J+1$ for $P, Q$, and $R$ branch, respectively, and $\beta_{i}$ are the polynomial coefficients of Ref. [187] derived from the $v_{2}$ measurements. Uncertainties for the widths of assigned transitions were assumed to be $10 \%$ by taking into account their measurement and modeling uncertainties. For unassigned (or partially assigned) transitions, the empirical lower state energy estimates were used to infer quantum numbers (i.e., $J, K$ ) for eq. (2). However, the uncertainties were assumed to be no better than $10 \%$. Finally, air- and self-broadening coefficients were set to 0.065 and $0.45 \mathrm{~cm}^{-1} / \mathrm{atm}$, respectively, for lines whose $E^{\prime \prime}$ were not obtained.

Temperature dependence exponents were also adopted from Nemtchinov et al. [187]. Taking their temperature dependence exponents for $\mathrm{N}_{2}$ and $\mathrm{O}_{2}$ broadening given at $J$ and $K$ less than 8 in the $v_{2}$ band, air-pressure broadening temperature exponents, $n_{\text {air }}$, were computed by

$$
n_{\text {air }}=0.79 \times n_{\mathrm{N} 2}+0.21 \times n_{\mathrm{O} 2}
$$

Pressure shifts were estimated (with an uncertainty no better than $0.005 \mathrm{~cm}^{-1} \mathrm{~atm}^{-1}$ ) using

$$
\delta_{\text {air }}(J, K)=-0.1 \times \gamma_{\text {air }}(J, K)
$$

The new consistent set of quantum numbers proposed by Down et al. [183] has been applied to the data of Sung et al. [185], as well. Similar description details could be also found in HITRAN-2012 [14].

For the future, several new studies are in progress which will improve the ammonia database. Recently Al-Derzi et al. [188] undertook a comprehensive MARVEL analysis of the empirical energy levels of ammonia. In the future these will be combined with intensities from BYTe and a new, more extensive and more accurate ammonia line list is being computed as part of the ExoMol project [189]. In two new studies of the far-IR region using Fourier Transform spectra recorded with the Synchrotron SOLEIL, Sung et al. [190] measured positions and intensities for more than $2840{ }^{14} \mathrm{NH}_{3}$ transitions observed from $50-660 \mathrm{~cm}^{-1}$ and determined, at the moment, quantum assignments of 2053 transitions involving eight bands, while Pearson et al. [191] performed a new Hamiltonian analysis to model 159 new transitions measured with microwave precision and assigned 1680 new ones. Finally Barton et al.[192] have recently assigned an FTS spectrum from the Kitt Peak archive providing assigned data for the first time above $8000 \mathrm{~cm}^{-1}$.

\subsection{8 $\mathrm{HNO}_{3}$ (molecule 13)}

GEISA-2015 includes, for the first time, a line list at $11.2 \mu \mathrm{m}$ for the second-most abundant isotopologue of nitric acid, $\mathrm{H}^{15} \mathrm{NO}_{3}$ with a ${ }^{15} \mathrm{~N} /{ }^{14} \mathrm{~N}$ natural isotopic ratio of approximately $0.00365(7)$. The $v_{5}$ and $2 v_{9}$ vibrational bands for this isotopologue were added using a high resolution Fourier transform investigation performed at $11 \mu \mathrm{m}$ by Perrin and Mbiaké [193]. As for 
$\mathrm{H}^{14} \mathrm{NO}_{3}$, the theoretical model used to compute the line positions and line intensities accounts for the very strong Fermi and C-type Coriolis resonances which couple together the $v_{5}$ and energy levels.

Using this model, the $v_{5}$ and $2 v_{9}$ line intensities for $\mathrm{H}^{15} \mathrm{NO}_{3}$ were computed satisfactorily using the value of the $v_{5}$ transition moment operator that was previously obtained during the investigation of the intensities for the $11 \mu \mathrm{m}$ bands for the ${ }^{14} \mathrm{~N}$ (main) isotopic species [194]. For this computation, the total partition sum, $Q_{\text {total }}(296 \mathrm{~K})=141872$ was taken from Ref. [193].

However since the resonance coupling the $v_{5}$ and $2 v_{9}$ energy levels is significantly weaker for $\mathrm{H}^{15} \mathrm{NO}_{3}$ than for $\mathrm{H}^{14} \mathrm{NO}_{3}$, the intensity transfer from the fundamental (and in principle strong) $v_{5}$ band to the overtone (and in principle weak) $2 v_{9}$ band is significantly weaker for $\mathrm{H}^{15} \mathrm{NO}_{3}$ than for $\mathrm{H}^{14} \mathrm{NO}_{3}$. Therefore in GEISA-2015 the $\mathrm{H}^{15} \mathrm{NO}_{3}$ and $\mathrm{H}^{14} \mathrm{NO}_{3} v_{5}$ bands are in an intensity ratio which is about $\sim 1.4$ larger than the expected value assumed from the ${ }^{15} \mathrm{~N} /{ }^{14} \mathrm{~N}$ natural isotopic ratio. Finally the air- and self-broadened half widths and temperature dependence were adopted from the work of Flaud et al. [195].

Fig. 9 gives an overview of the $v_{5}$ and $2 v_{9}$ bands of $\mathrm{H}^{14} \mathrm{NO}_{3}$ and $\mathrm{H}^{15} \mathrm{NO}_{3}$. One can see that the narrow $\mathrm{Q}$ branch structure of the $v_{5}$ band of $\mathrm{H}^{15} \mathrm{NO}_{3}$ is shifted to the low frequency range (at about $871 \mathrm{~cm}^{-1}$ ) compared to its $\mathrm{H}^{14} \mathrm{NO}_{3}$ counterpart (at about $879 \mathrm{~cm}^{-1}$ ).

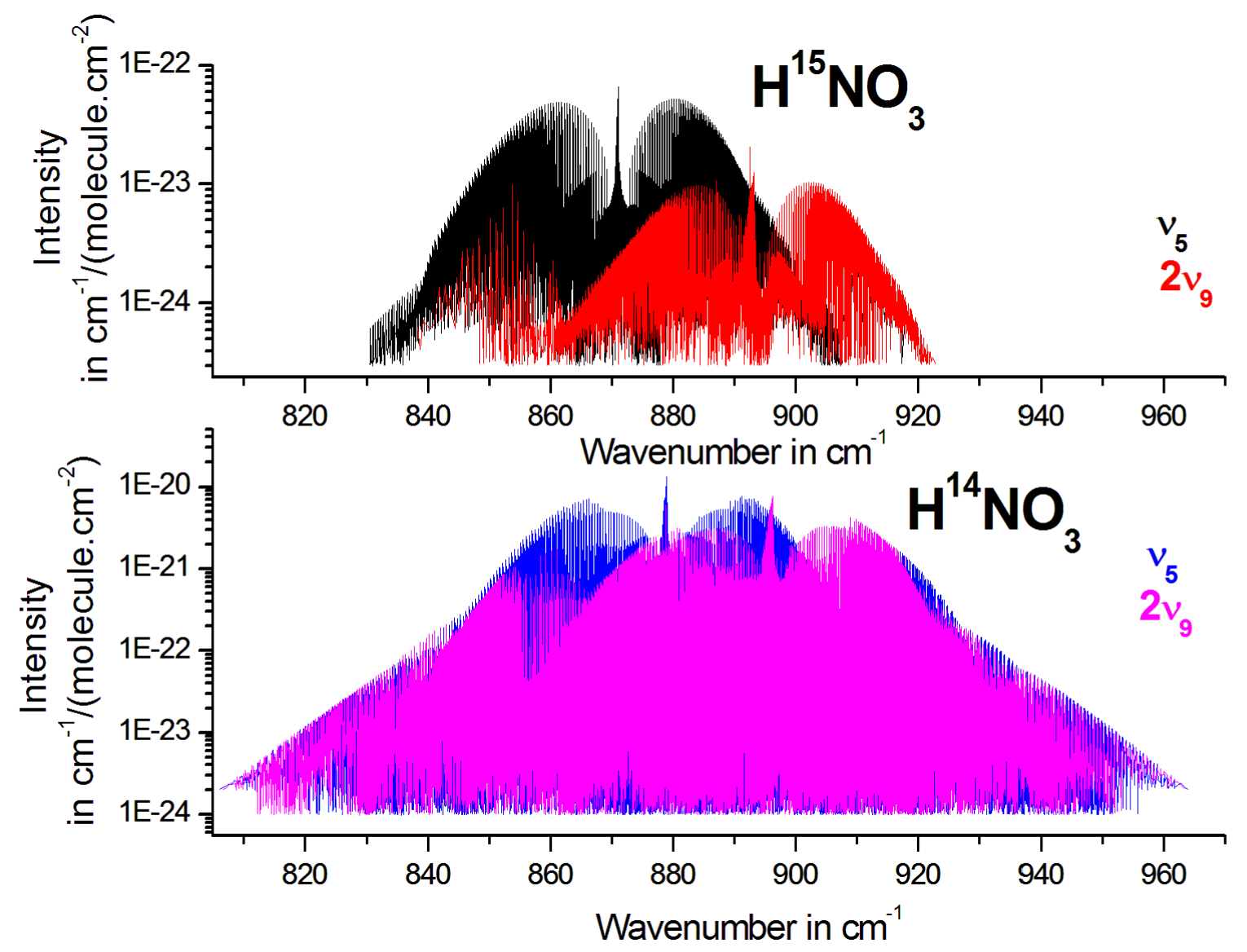


Fig. 9. Graphical overview of the $v_{5}$ and $2 v_{9}$ cold bands for $\mathrm{H}^{14} \mathrm{NO}_{3}$ and $\mathrm{H}^{15} \mathrm{NO}_{3}$.

Because of the favorable position of the $v_{5}$ band of $\mathrm{H}^{15} \mathrm{NO}_{3}$ (a shift of the band center and band intensity) relative to $\mathrm{H}^{14} \mathrm{NO}_{3}$, it was possible to search for the evidence of the $v_{5}$ spectral signature of $\mathrm{H}^{15} \mathrm{NO}_{3}$ in atmospheric limb-emission spectra measured by MIPAS [196]. Later, this signature was used to report the first measurement of the isotopic partitioning between stratospheric $\mathrm{H}^{14} \mathrm{NO}_{3}$ and $\mathrm{H}^{15} \mathrm{NO}_{3}$ [197].

Table 7 gives an overview of the GEISA-2015 entry for nitric acid in the $11 \mu \mathrm{m}$ region, for both isotopologues $\mathrm{H}^{14} \mathrm{NO}_{3}$ (Part $\mathrm{A}$ ) and $\mathrm{H}^{15} \mathrm{NO}_{3}$ (part B).

\section{Table7}

Overview of the GEISA-2015 entry for nitric acid in the $11 \mu \mathrm{m}$ region. The upper and lower vibrational identifications of actual transitions are given in columns 1 and 2 respectively; for each transition: the total number of lines, the total intensity (in $\mathrm{cm}$ molecule ${ }^{-1}$ at $296 \mathrm{~K}$ ), the minimum and maximum wavenumber of the lines, as well as the minimum and maximum intensity (in $\mathrm{cm}$ molecule $^{-1}$ at $296 \mathrm{~K}$ ), are in columns 3 to 8 , respectively.

\section{A) $\mathrm{H}^{14} \mathrm{NO}_{3}$}

\begin{tabular}{|c|c|c|c|c|c|c|c|}
\hline Vib' & Vib" & \# lines & $\begin{array}{c}\text { Total Int. } \\
\left(\mathrm{cm} \text { molecule }^{-1}\right) \\
\text { at } 296 \mathrm{~K}\end{array}$ & $\begin{array}{c}\text { Wavenumber } \\
\text { min } \\
\left(\mathrm{cm}^{-1}\right)\end{array}$ & $\begin{array}{c}\text { Wavenumber } \\
\underset{\max }{\left(\mathrm{cm}^{-1}\right)}\end{array}$ & $\begin{array}{l}\text { Int._min. } \\
\left(\text { cm molecule } \text { en }^{-1}\right) \\
\text { at } 296 \mathrm{~K}\end{array}$ & $\begin{array}{l}\text { Int._max. } \\
\left(\mathrm{cm} \text { molecule }^{-1}\right) \\
\text { at } 296 \mathrm{~K}\end{array}$ \\
\hline$v_{5}$ & GS & 57,108 & $0.1027 \times 10^{-16}$ & 806.207 & 963.995 & $0.983 \times 10^{-24}$ & $0.660 \times 10^{-20}$ \\
\hline $2 v_{9}$ & GS & 55,310 & $0.7503 \times 10^{-17}$ & 806.709 & 963.435 & $0.983 \times 10^{-24}$ & $0.388 \times 10^{-20}$ \\
\hline $3 v_{9}$ & $v_{9}$ & 17,720 & $0.5291 \times 10^{-18}$ & 769.687 & 884.438 & $0.384 \times 10^{-24}$ & $0.672 \times 10^{-21}$ \\
\hline$v_{5}+v_{6}$ & $v_{6}$ & 57,108 & $0.6179 \times 10^{-18}$ & 796.207 & 953.995 & $0.592 \times 10^{-25}$ & $0.397 \times 10^{-21}$ \\
\hline$v_{5}+v_{7}$ & $v_{7}$ & 57108 & $0.9761 \times 10^{-18}$ & 802.807 & 960.595 & $0.935 \times 10^{-25}$ & $0.627 \times 10^{-21}$ \\
\hline$v_{5}+v_{9}$ & $v_{9}$ & 14521 & $0.1068 \times 10^{-17}$ & 832.116 & 942.901 & $0.987 \times 10^{-24}$ & $0.700 \times 10^{-21}$ \\
\hline
\end{tabular}

B) $\mathrm{H}^{15} \mathrm{NO}_{3}$

\begin{tabular}{|c|c|c|c|c|c|c|c|}
\hline Vib' & Vib" & \# lines & $\begin{array}{c}\text { Total Int. } \\
\left(\mathrm{cm} \text { molecule }^{-1}\right) \\
\text { at } 296 \mathrm{~K}\end{array}$ & $\begin{array}{c}\text { Wavenumber } \\
\underset{\min }{\left(\mathrm{cm}^{-1}\right)}\end{array}$ & $\begin{array}{c}\text { Wavenumber } \\
\underset{\max }{\left(\mathbf{c m}^{-1}\right)}\end{array}$ & $\begin{array}{c}\text { Int._min. } \\
\left(\text { cm molecule }{ }^{-1}\right) \\
\text { at } 296 \mathrm{~K}\end{array}$ & $\begin{array}{c}\text { Int_max } \\
\left(\text { cm molecule }{ }^{-1}\right) \\
\text { at } 296 \mathrm{~K}\end{array}$ \\
\hline$v_{5}$ & GS & 12883 & $0.5023 \times 10^{-19}$ & 830.371 & 919.725 & $0.300 \times 10^{-24}$ & $0.330 \times 10^{-22}$ \\
\hline $2 v_{9}$ & GS & 8290 & $0.9917 \times 10^{-20}$ & 838.223 & 922.931 & $0.300 \times 10^{-24}$ & $0.625 \times 10^{-23}$ \\
\hline
\end{tabular}




\subsection{9 $\quad \mathrm{H}_{2} \mathrm{CO}$ (molecule 21)}

Formaldehyde has been completely revised in the microwave and far infrared using the line list of positions and intensities from the CDMS database $[18, \mathbf{1 9}]$ for the three isotopologues present in GEISA, namely $\mathrm{H}_{2}{ }^{12} \mathrm{C}^{16} \mathrm{O}, \mathrm{H}_{2}{ }^{12} \mathrm{C}^{18} \mathrm{O}$, and $\mathrm{H}_{2}{ }^{13} \mathrm{C}^{16} \mathrm{O}$. Whereas GEISA-2011 had 1541 lines for these isotopologues ranging from 0 to $100 \mathrm{~cm}^{-1}, 9102$ transitions are now present in GEISA-2015, between 0 and $508 \mathrm{~cm}^{-1}$.

Three $\mathrm{H}_{2} \mathrm{CO}$ isotopologue data implemented in GEISA-2015, i.e. (as identified in the CDMS (atalog) is:

$$
\begin{array}{ll}
\text { 30501.cat }\left(\mathrm{H}_{2} \mathrm{CO}-16\right) & 5171 \text { entries }\left(\mathrm{H}_{2}{ }^{12} \mathrm{C}^{16} \mathrm{O}\right) \\
\text { 32503.cat }\left(\mathrm{H}_{2} \mathrm{CO}-18\right) & 1622 \text { entries }\left(\mathrm{H}_{2}{ }^{12} \mathrm{C}^{18} \mathrm{O}\right) \\
\text { 31503.cat }\left(\mathrm{H}_{2} \mathrm{C}-13-\mathrm{O}\right) & 2309 \text { entries }\left(\mathrm{H}_{2}{ }^{13} \mathrm{C}^{16} \mathrm{O}\right)
\end{array}
$$

These new data totally replace the previous entries.

The self-widths, air-widths and temperature dependence of the air-widths have been updated using the calculated values of Jacquemart et al. [198] for the whole three isotopologue line lists. The self- and air-broadening coefficients correspond to empirical calculations that reproduced measurements in the 3.5 and $5.7 \mu \mathrm{m}$ spectral regions whereas the temperature dependence comes from theoretical calculation using the CRB formalism.

The evaluation of transition frequencies and their uncertainties is based on Brünen et al. [199], Müller et al. [200], and Müller et al. [201] for $\mathrm{H}_{2}{ }^{12} \mathrm{C}^{16} \mathrm{O}, \mathrm{H}_{2}{ }^{12} \mathrm{C}^{18} \mathrm{O}$, and $\mathrm{H}_{2}{ }^{13} \mathrm{C}^{16} \mathrm{O}$, respectively. Besides new or improved data from these publications, each data set includes transition frequencies from Cornet and Winnewisser [202] with some lower frequency data from earlier publications. An additional important source of $\mathrm{H}_{2}{ }^{12} \mathrm{C}^{16} \mathrm{O}$ transition frequencies is Bocquet et al. [203]. Furthermore, IR ground state combination differences used in Müller et al. [204] were also employed in Brünken et al. [199]. The strong $R$-branch transitions (with $\Delta K_{a}=0$ ) should be predicted reasonably well up to $\sim 100 \mathrm{~cm}^{-1}$ and $K_{a} \leq 15$ for $\mathrm{H}_{2}{ }^{12} \mathrm{C}^{16} \mathrm{O}$, up to $\sim 80 \mathrm{~cm}^{-1}$ and $K_{a} \leq 14$ for $\mathrm{H}_{2}{ }^{13} \mathrm{C}^{16} \mathrm{O}$, and up to $\sim 50 \mathrm{~cm}^{-1}$ and $K_{a} \leq 13$ for $\mathrm{H}_{2}{ }^{12} \mathrm{C}^{18} \mathrm{O}$. The weak $R$-branch transitions with $\Delta K_{a}=2$ should be predicted reasonably well up to $J$ of at least 30 and $K_{a}$ up to 10 or even 12 in the case of $\mathrm{H}_{2}{ }^{12} \mathrm{C}^{16} \mathrm{O}$. Uncertainty estimates are more difficult for $Q$ - or $P$-branch transitions or for the other two isotopologues. The predictions should be accurate enough for observational purposes at temperatures up to about $300 \mathrm{~K}$ because uncertainties become noticeable only for very weak transitions. The data should be viewed with some caution at temperatures much higher than $300 \mathrm{~K}$. 
Dipole moments for $\mathrm{H}_{2}{ }^{12} \mathrm{C}^{16} \mathrm{O}$ and $\mathrm{H}_{2}{ }^{13} \mathrm{C}^{16} \mathrm{O}$ were taken from Fabricant et al. [205], that of $\mathrm{H}_{2}{ }^{12} \mathrm{C}^{18} \mathrm{O}$ was assumed to take the $\mathrm{H}_{2}{ }^{12} \mathrm{C}^{16} \mathrm{O}$ value. Rotational corrections to the dipole moments are not known from experiment. The partition function values in the CDMS are fully converged in $J$ and $K_{a}$, but are restricted to the ground vibrational state only. It has to be noted that a fully converged partition function is available from Refaie et al. [206].

In the process of converting the intensities at $300 \mathrm{~K}$ (default in the CDMS) to $296 \mathrm{~K}$ (default in GEISA) and different intensity units, this small truncation error was considered for GEISA.

\subsubsection{0 $\mathrm{C}_{2} \mathrm{H}_{6}$ (molecule 22)}

Remote sensing of the Earth, outer planets, Titan and its satellites, and comets, as well, requires extensive knowledge of ethane spectroscopy covering both far and near-infrared wavelengths. In GEISA-2015, ${ }^{12} \mathrm{C}_{2} \mathrm{H}_{6}$ line parameters are available for three wavelengths: $12 \mu \mathrm{m}, 7$ $\mu \mathrm{m}$ and $3.3 \mu \mathrm{m},\left[\mathbf{1 3 , 2 0 7 , 2 0 8}\right.$, and the $v_{12}$ band of ${ }^{12} \mathrm{CH}_{3}{ }^{13} \mathrm{CH}_{3}$ at $12 \mu \mathrm{m}$ [209]. For astronomical applications future updates will consider recent studies of far-IR ${ }^{12} \mathrm{C}_{2} \mathrm{H}_{6}$ at $35 \mu \mathrm{m} \mathrm{[210]}$, ${ }^{112} \mathrm{CH}_{3}{ }^{13} \mathrm{CH}_{3}$ at $7 \mu \mathrm{m}$ [211],[212] and $\mathrm{C}_{2} \mathrm{H}_{5} \mathrm{D}$ [213] at $13 \mu \mathrm{m}$.

At $12 \mu \mathrm{m}$, previous calculated line parameters for the $v_{9}$ fundamental, the $3 v_{4}$ overtone and two hot bands were retained with adjustments to specific line parameters. New line shape measurements by Devi et al. [207,208] permitted derived empirical expressions for self- and $\mathrm{N}_{2^{-}}$ broadened line shapes and their temperature dependence to be applied assuming $\gamma_{\text {air }}=0.9 \times \gamma_{\mathrm{N} 2}$; the calculated line intensities [14] were reduced by $15 \%$ as well. Recent measurements of the isotopic band [209] will be included in the next GEISA edition.

At $7 \mu \mathrm{m}$, the ethane spectrum is dominated by the $v_{6}$ and $v_{8}$ fundamental bands, and these have proved useful for the analyses of the Titan atmosphere. Line parameters for ${ }^{12} \mathrm{C}_{2} \mathrm{H}_{6}$ were added [210] and those for ${ }^{12} \mathrm{CH}_{3}{ }^{13} \mathrm{CH}_{3}$ [211] are being considered. It has to be noted that the 2015 study of the ${ }^{12} \mathrm{C}_{2} \mathrm{H}_{6}$ torsional fundamental at $289 \mathrm{~cm}^{-1}$ [210] provides far-IR line parameters for remote sensing of the deeper portion of Titan's atmosphere but are not yet included.

At $3.3 \mu \mathrm{m}$, the highest ethane fundamental band $v_{7}$ is overlapped by numerous overtone and combination states, making it difficult to provide reliable ethane spectroscopy for remote sensing. Studies involving the earth's atmosphere have long used measurements of several prominent Q branches belonging to the $v_{7}$ fundamental (Pine and Rinsland [214] and Refs. therein). More recently, direct measurement of absorption cross sections at different temperatures have been reported by Harrison et al. [215], and Hargreaves et al. [216]. A few calculations also provide approximate line positions, intensities and lower state energies using the quantum mechanical models of Villanueva et al. [217] and Lattanzi et al. [218]. For GEISA-2015 the work of Lattanzi et 
al. [218] was used because it provides the most extensive modeling of direct measurements for this region.

\subsubsection{1 $\mathrm{CH}_{3} \mathrm{D}$ (molecule 23)}

The GEISA-2015 $\mathrm{CH}_{3} \mathrm{D}$ database been updated in 2 spectral regions:

- In the spectral region between $4000 \mathrm{~cm}^{-1}$ and $4550 \mathrm{~cm}^{-1}$, over 4000 lines of ${ }^{12} \mathrm{CH}_{3} \mathrm{D}$ were included for the first time [219]. Measured line positions and intensities for nine new bands of the Enneadecad polyad were obtained using high resolution FTIR spectra recorded using enriched gas samples $(98 \% \mathrm{D})$ at room and cold $(80 \mathrm{~K})$ temperatures. To construct a new line list, many lower state energies were determined from quantum assignments, and confirmed by effective Hamiltonian and dipole moment expansion models. For pressure broadening coefficients, empirical expressions based on measurements of $\mathrm{CH}_{3} \mathrm{D}$ bands near $7 \mu \mathrm{m}[\mathbf{2 2 0}, \mathbf{2 2 1}]$ and the references therein were applied as a function of known quantum numbers to approximately represent the air- and selfbroadened half widths and pressure-induced shifts. Additional details are given in Ref. [222].

-In the 6204.025190-6510.324200 $\mathrm{cm}^{-1}$ region, the position and intensity values of 5692 newly-included lines are taken from the supplementary material of Lu et al. [223].

\subsubsection{2 $\mathrm{C}_{2} \mathrm{H}_{2}$ (molecule 24)}

Acetylene has been identified in some of the giant planets and Titan since the mid-1940s, and recently has been quantified by the Galileo and Cassini-Huygens missions.

In the $7.7 \mu \mathrm{m}$ region, acetylene absorbs mainly at room temperature via the strong cold band $\left(v_{4}-v_{5}\right)_{+}^{0}$ for which spectroscopic parameters [224] were previously available in databases [12, 9]. This spectral region was used in 2006 [225] to observe acetylene signatures in carbon-rich asymptotic giant branch stars but the lack of spectroscopic data in this region did not allow the observation to be correctly reproduced. The temperature of interest for applications being around $500 \mathrm{~K}$ [225], the spectroscopic information for hot bands is also important. In the recent work from Gomez et al. [226,227], a complete line list of 2 cold bands (including the band $\left(v_{4}-v_{5}\right)_{+}^{0}$ ) and 15 hot bands has been generated and has been used to update the $7.7 \mu \mathrm{m}$ region of GEISA-2015. This line list of 1629 transitions between 1142 and $1451 \mathrm{~cm}^{-1}$ is replacing the previous 71 transitions of the $\left(v_{4}-v_{5}\right)_{+}^{0}$ band between 1248 and $1415 \mathrm{~cm}^{-1}$. 


\subsubsection{3 $\mathrm{C}_{2} \mathrm{H}_{4}$ (molecule 25)}

New spectroscopic line parameters for ethylene included in GEISA-2015 concern both the main isotopologue, ${ }^{12} \mathrm{C}^{12} \mathrm{CH}_{4}$ and the less abundant ${ }^{12} \mathrm{C}^{13} \mathrm{CH}_{4}$ isotopologue. More precisely the new line list contains 9 bands: $v_{8}+v_{10}, v_{7}+v_{8}, v_{4}+v_{8}, v_{8}+v_{12}, v_{6}+v_{10}, v_{6}+v_{7}, v_{4}+v_{6}, v_{3}+v_{10}, v_{3}+v_{7}$ of the main isotopologue ${ }^{12} \mathrm{C}^{12} \mathrm{CH}_{4}$ covering the spectral region 1656-2487 $\mathrm{cm}^{-1}$ [228, 229] and 5 bands: $v_{10}, v_{8}$, $v_{7}, v_{4}, v_{6}$ for ${ }^{12} \mathrm{C}^{13} \mathrm{CH}_{4}$ covering the spectral region $615-1339 \mathrm{~cm}^{-1}$ [230, 231]. These data, which were derived from high resolution Fourier transform spectra, are rather accurate: for the main isotopologue, the uncertainties can be estimated to be $\sim 10^{-3} \mathrm{~cm}^{-1}$ for the positions [228] and $\sim 5 \%$ for the intensities [229]; for ${ }^{12} \mathrm{C}^{13} \mathrm{CH}_{4}$ they can be estimated to be $\sim 0.6 \times 10^{-3} \mathrm{~cm}^{-1}$ for the positions [230] and $\sim 4 \%$ for the intensities [231].

In the absence of measurements or calculations for the line-shape parameters, default values were chosen, i.e.:

$\begin{array}{ll}\text { HWHM } & \gamma_{\text {air }}=0.0870 \mathrm{~cm}^{-1} \mathrm{~atm}^{-1} \text { at } 296 \mathrm{~K} \\ \text { HWHMself } & \gamma_{\text {self }}=0.1245 \mathrm{~cm}^{-1} \mathrm{~atm}^{-1} \text { at } 296 \mathrm{~K}\end{array}$

Temperature-dependence coefficient $n$ of the air broadening half width $\quad n_{\text {air }}=0.82$

We note that:

-the default values for $\gamma_{\text {air }}$ and $n_{\text {air }}$ are identical with those having similar quantum identification in GEISA-2011, without considering the isotopic composition;

-the selected value $0.1245 \mathrm{~cm}^{-1} \mathrm{~atm}^{-1}$ at $296 \mathrm{~K}$, attributed to the self-broadening pressure half width,

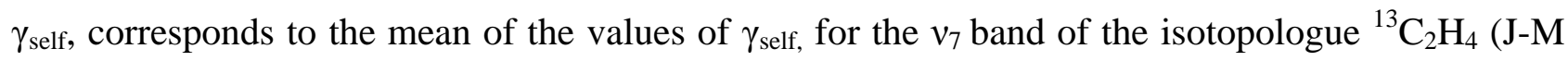
Flaud, private communication);

-the GEISA standard default value, $\delta_{\text {air }}=0.000000 \mathrm{~cm}^{-1} \mathrm{~atm}^{-1}$ at $296 \mathrm{~K}$, is used for the air pressure induced shift of the line transition.

The GEISA-2015 $\mathrm{C}_{2} \mathrm{H}_{4}$ updated file contains 53,227 entries (18,378 in GEISA-2011), corresponding to a total of 26 vibrational bands (12 in GEISA-2011).

\subsubsection{HCN (molecule 27)}

GEISA-2011 provided an HCN line list which relied extensively on the computed line lists of Harris et al. [232, 233]. Over the last few years Mellau [234,235] has performed emission experiments on hot HCN. Using Mellau's energy levels and the ab-initio line intensities computed by Harris et al.[232], Barber et al.[236] built up an extensive database of experimental HCN energy levels. This line list was designed for studies of hot astronomical problems and contains hundreds 
of millions of lines. For present purposes a $296 \mathrm{~K} \mathrm{H}^{12} \mathrm{C}^{14} \mathrm{~N}$ line list was generated and only the 131,139 lines stronger than $10^{-31}$ were retained to form the input for GEISA-2015. In the spectral range 9933.825951-17581.009367 $\mathrm{cm}^{-1}, 4871$ lines from Harris have been kept from GEISA-2011 [11]; 2085 experimentally-measured lines from Maki [11], in the region $2.415494-3550.842326 \mathrm{~cm}^{-}$ ${ }^{1}$, have been kept from GEISA-2011, alongside data for the 3 other isotopologues: $\mathrm{H}^{13} \mathrm{C}^{15} \mathrm{~N}$, $\mathrm{H}^{13} \mathrm{C}^{14} \mathrm{~N}, \mathrm{D}^{12} \mathrm{C}^{14} \mathrm{~N}$.

The update file provided by UCL contained no line shape parameters. The missing parameters were therefore created using the GEISA-2011 HCN ones for lines with a similar quantum identification. For the other lines, the default values were attributed as follows:

HWHM

HWHMself

$$
\begin{aligned}
& \gamma_{\text {air }}=0.1011 \mathrm{~cm}^{-1} \mathrm{~atm}^{-1} \text { at } 296 \mathrm{~K} \\
& \gamma_{\text {self }}=0.1245 \mathrm{~cm}^{-1} \mathrm{~atm}^{-1} \text { at } 296 \mathrm{~K}
\end{aligned}
$$

Temperature-dependence coefficient $n$ of the air broadening half width

$$
n_{\text {air }}=0.70
$$

The GEISA standard default value, $\delta_{\text {air }}=0.000000 \mathrm{~cm}^{-1} \mathrm{~atm}^{-1}$ at $296 \mathrm{~K}$, was used for the air pressure induced shift of the line transition.

The GEISA-2015 HCN line list contains a total of 138,103 entries (81,889 in GEISA-2011).

\subsubsection{5 $\mathrm{C}_{2} \mathrm{~N}_{2}$ (molecule 29)}

The ${ }^{12} \mathrm{C}_{2}{ }^{14} \mathrm{~N}_{2}$ (cyanogen) line list in GEISA-2011 included 2577 entries mainly belonging to the $v_{5}$ bending system centered at $234 \mathrm{~cm}^{-1}$ and also lines from the weak stretching $v_{2}$ mode around $2150 \mathrm{~cm}^{-1}$. In GEISA-2015, all the entries belonging to $v_{5}$ have been replaced by a new line list based on experimental and theoretical work by Fayt et al. [237]. This new study includes a recording of the high resolution spectrum and the first ro-vibrational global analysis for this molecule. The positions of about 13000 peaks were obtained experimentally and analyzed to determine very accurate molecular parameters. Transitions with upper states as high as $2100 \mathrm{~cm}^{-1}$ could be assigned. On the basis of the molecular parameters determined by the global analysis, a line list was generated with all lines with intensity above a cut-off chosen to ensure that $99.5 \%$ of the total band intensity is taken into account at room temperature (maximum intensity value: $2.478 \times 10^{-20} \mathrm{~cm} \mathrm{molecule}^{-1}$ at $296 \mathrm{~K}$ ). Note that the number of lines can be greatly diminished if used for cold environments such as Titan's atmosphere, which is the only object where cyanogen has been detected so far (Teanby et al. [238]).

Spectra of $\mathrm{C}_{2} \mathrm{~N}_{2}$ at low resolution were also recorded (Fayt et al. [237]) in order to determine the band system intensity. The measured intensities were found to be in very good agreement with 
earlier band intensity measurements by Kim et al. [239] and also with line intensities measured by Grecu et al. [240], and thus adopted in GEISA-2015.

The updated GEISA-2015 ${ }^{12} \mathrm{C}_{2}{ }^{14} \mathrm{~N}_{2}$ line list involves a total of 71,774 entries (only $181 \mathrm{kept}$ from the former editions).

\subsubsection{6 $\mathrm{C}_{4} \mathrm{H}_{2}$ (molecule 30)}

The line list of $\mathrm{C}_{4} \mathrm{H}_{2}$ in GEISA-2011 (119,480 entries) was based on preliminary results from the global ro-vibrational analysis of both bending modes $v_{8}\left(628.0 \mathrm{~cm}^{-1}\right)$ and $v_{9}\left(220.1 \mathrm{~cm}^{-1}\right)$ described in Jolly et al. [241]. GEISA-2015 includes the final version of this line list. The number of lines $(417,540)$ is much larger than in GEISA-2011 because the calculation includes the contribution of hot bands, up to the polyad containing $9 v_{9} \leftarrow 8 v_{9}$, corresponding to a maximum vibrational energy level of the lower state E"=1700 $\mathrm{cm}^{-1}$. The intensity of all the transitions belonging to the analyzed polyads are calculated and included in the line list if the intensity at room temperature is stronger than a cut-off value of about $10^{-7}$ times the band intensity. This ensures that the sum of the intensities of all the lines is equal to the measured band intensity, except for the contribution of the isotopologues. This method has been recently illustrated, for $\mathrm{C}_{4} \mathrm{~N}_{2}$, by Jolly et al. [242] where their Fig. 4 concerns the $\mathrm{C}_{4} \mathrm{~N}_{2} v_{9}$ band and shows for two different temperatures the individual intensities of the successive hot band systems as well as the progressively increasing overall band intensity. It demonstrates how the intensities of higher polyads eventually become negligible.

In addition to the lines from the two bending modes already present in GEISA-2011, new lines from the strong combination band $v_{6}+v_{8}$ at $1240.7 \mathrm{~cm}^{-1}$ have been included in GEISA-2015. The line list of $v_{6}+v_{8}$ was calculated based on the very accurate results of a global analysis which enables parameters for vibrational levels with high energies including combination levels to be determined. This band has already been detected astrophysically: first by Cernicharo et al. [243] in the proto planetary nebula CRL 618 and very recently in Titan's atmosphere thanks to the infrared spectrometer CIRS of the CASSINI spacecraft (Vinatier et al. [244]).

One major update in GEISA-2015 concerns the intensities of the $v_{8}$ and $v_{9}$ bands. While the band intensities in GEISA-2011 relied on measurements madeby Koops et al. [245], the new version relies on recent measurements by Jolly et al. [246], who find large differences compared to Koop et al.'s values, in particular for the $v_{9}$ band. Both bands, measured separately with different apparatus by Koops et al. [245], were found to have an intensity ratio as high as 28. Jolly et al. [246] were able to measure both bending modes in a single spectrum covering the region between 40 and 670 $\mathrm{cm}^{-1}$ and found the weak $v_{9}$ band to be 2.4 times stronger. Conversely, the strong $v_{8}$ band was found 
to be $20 \%$ weaker resulting in a band intensity ratio close to 9 . For the intensity of the $v_{6}+v_{8}$ combination band, the result obtained by Jolly et al. [246] confirmed the previous measurement by Khlifi et al. [247].

\subsubsection{7 $\mathrm{CH}_{3} \mathrm{Cl}$ (molecule 34)}

The methyl chloride line list is completely updated in GEISA-2015 on the basis of various works, depending on the spectral regions and on the line parameters.

Line positions and intensities from JPL catalog $\left[\mathbf{1 6 , 1 7 ]}\right.$ are used between 0.8 and $71 \mathrm{~cm}^{-1}$ $(12,824$ pure rotational transitions). Since the vibrational notation of this molecule is explicit, the vibrational notation in GEISA-2015 is identified as "GROUND” for the upper and lower states. All these pure rotational transitions have hyperfine structure, so that the quantum number $F$ is used in the rotational fields corresponding to the upper and lower states.

Between 644 and $2625 \mathrm{~cm}^{-1}$, a calculation by Nikitin based on effective Hamiltonian has been used for positions [248,249]. As this calculation provides absolute line positions but only approximate relative line intensities [249], a calibration based on measurements has been performed to retrieve absolute intensity values, as explained below. Comparisons of calculations with measurements from the literature concern only the fundamental bands lying in the spectral region studied theoretically: the $v_{3}$ band around $750 \mathrm{~cm}^{-1}$, the $v_{6}$ band around $1000 \mathrm{~cm}^{-1}$ as well as the $v_{2}$ and $v_{5}$ band around $1450 \mathrm{~cm}^{-1}$. The following studies were used:

- For the $v_{3}$ band, Bouanich et al. [250] for the $\mathrm{CH}_{3}{ }^{35} \mathrm{Cl}$ isotopologue (29 transitions), Blanquet et al. [251] for the $\mathrm{CH}_{3}{ }^{37} \mathrm{Cl}$ isotopologue (50 transitions).

- For the $v_{6}$ band: Blanquet et al. [252,253] for 96 and 58 transitions of $\mathrm{CH}_{3}{ }^{35} \mathrm{Cl}$ and $\mathrm{CH}_{3}{ }^{37} \mathrm{Cl}$, respectively.

- For the $v_{2}$ and $v_{5}$ bands, the recent measurements of Barbouchi et al. [254] show good consistency with the values of Chackerian et al. [255] (around 1\%) but present discrepancies (up to 15-20\%) when compared to the results of Cappeliani et al. [256]. Consequently, for comparison with Nikitin's calculations for the $v_{2}$ and $v_{5}$ bands, we only used the results from Barbouchi et al. [254] (1073/115 transitions of $\mathrm{CH}_{3}{ }^{35} \mathrm{Cl}$ and $135 / 28$ transitions of $\mathrm{CH}_{3}{ }^{37} \mathrm{Cl}$ for the $v_{2} / v_{5}$ band).

As an illustration, comparisons of intensities for the $v_{2}$ and $v_{5}$ bands are plotted in Fig. 10-a and Fig 10-b, respectively. As can be seen, the ratio Calc/Obs depends strongly on the band but also on the wavenumbers. To stay close to the measurements, a fitted wavenumber-dependent calibration factor has been applied to obtain absolute theoretical line intensities from the 
calculations [248]. No measurements are available for all the other hot, harmonic or combination bands from Nikitin's calculation, so that no accurate absolute theoretical intensities can be retrieved. Consequently, we chose not to put these weak bands in GEISA until absolute calibration can be performed. When comparing the measured line positions [249-254] to the calculated values of Nikitin [248], the averaged discrepancy between measurements and calculations does not exceed $0.001 \mathrm{~cm}^{-1}$. Therefore, 46,406 transitions calculated from Ref. [248] and belonging to the fundamental bands $v_{3}, v_{6}, v_{2}$ and $v_{5}$ are introduced in GEISA-2015.

Between 2920 and $3198 \mathrm{~cm}^{-1}$, line positions and intensities of 22,963 transitions in the $3 \mu \mathrm{m}$ region from Bray el al. [257] are used. These transitions mainly concern the strong fundamental band $v_{1}$, but some of them refer to the weaker $v_{4}$ band or other harmonic or combination bands.

Concerning the self- and air-broadened $\mathrm{CH}_{3} \mathrm{Cl}$ line widths, recent measurements on the $v_{5}$ $[254,258,259], v_{1}[260,261]$ and pure rotation [262,261] bands do not show any significant vibrational dependence for these parameters. Therefore, the semi-empirical calculations by Dudaryonok et al. [263] for the $\mathrm{CH}_{3}{ }^{35} \mathrm{Cl}$ self-broadening case and the semi-classical calculations of Buldyreva [264] for the $\mathrm{CH}_{3}{ }^{35} \mathrm{Cl}$ and $\mathrm{CH}_{3}{ }^{37} \mathrm{Cl}$ air-broadening case, providing the broadening coefficients for the reference temperature $296 \mathrm{~K}$ and the associated temperature exponents, are used for all transitions listed in the database.

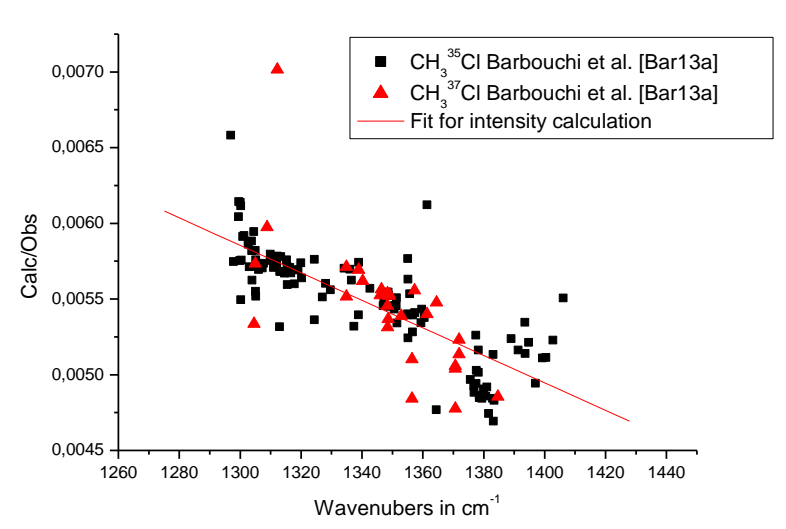

10-a

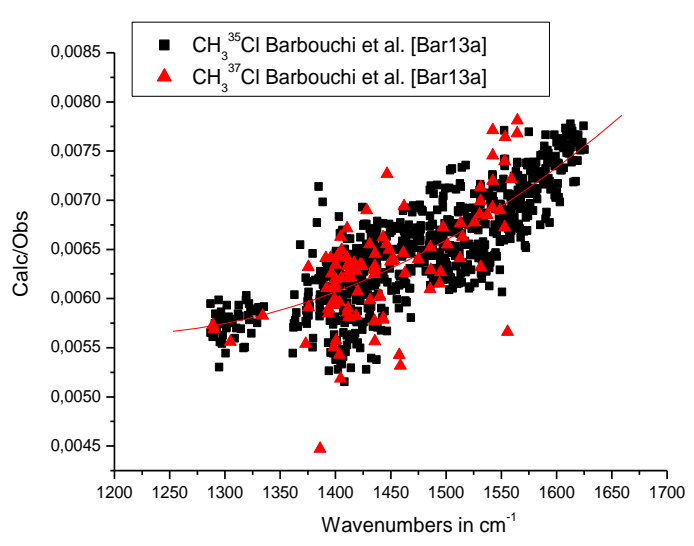

10-b

Fig. 10 Ratio of Calculated/Observed (Calc/Obs) for the $v_{2}$ band (figure 10-a) and for the $v_{5}$ band (figure 10b) of $\mathrm{CH}_{3} \mathrm{Cl}$. Calc comes from a calculation from Nikitin. Obs are Fourier transform measurements of Barbouchi et al. [254].

\subsubsection{8 $\mathrm{H}_{2} \mathrm{~S}$ (molecule 36)}


Better spectroscopic knowledge and extended database archive of $\mathrm{H}_{2} \mathrm{~S}$ are needed for two reasons:

- Hydrogen sulfide is a well-documented but little understood hazard because of its atmospheric release, for example, by the geothermal energy industry. This represents a very significant public health concern for air-quality and also because it is known to migrate into surface soils and groundwater [265].

- Hydrogen sulfide is also produced by organisms living in harsh environments; if a similar metabolism has evolved on an extra solar planet, the detection of sulfurous molecules in those atmospheres could reveal the presence of alien life [266].

A very significant update of the $\mathrm{H}_{2} \mathrm{~S}$ data is implemented in GEISA- 2015 to provide 58,650 transitions of the three isotopic species, $\mathrm{H}_{2}{ }^{32} \mathrm{~S}, \mathrm{H}_{2}{ }^{33} \mathrm{~S}, \mathrm{H}_{2}{ }^{34} \mathrm{~S}$. This represents an increase of 37,862 lines compared to GEISA-2011 [11] (20,788 lines). The new or updated transitions fall within four spectral ranges: $1.0-615 \mathrm{~cm}^{-1}, 994-1574 \mathrm{~cm}^{-1}, 2143-4257 \mathrm{~cm}^{-1}$, and $4472-113201 \mathrm{~cm}^{-1}$.

Pure rotational transitions of hydrogen sulfide in its ground and first excited vibrational states between 1.03056- $614.89397 \mathrm{~cm}^{-1}$ were recorded at room temperature by Azzam et al. [267]. The line positions given in their Supplementary data have been applied to 8430 transitions, formerly represented by 3396 lines in GEISA-2011.

Updated positions for the $v_{2}$ region (994.1296-1573.8098 $\mathrm{cm}^{-1}$ ): for the $010-000$ band, line positions of 653 transitions from GEISA-2011 were improved [268] using experimental upper energy levels for $\mathrm{H}_{2}{ }^{32} \mathrm{~S}, \mathrm{H}_{2}{ }^{33} \mathrm{~S}$, and $\mathrm{H}_{2}{ }^{34} \mathrm{~S}$ isotopologues reported by Ulenikov et al. [269]; the lower energy levels were calculated using the rotational constants of Flaud et al. [270].

Fig. 11 shows that, in GEISA-2015, the $v_{2}$ band positions are clearly shifted by $\sim 0.002 \mathrm{~cm}^{-1}$, with a maximum difference reaching to $0.055 \mathrm{~cm}^{-1}$, compared to HITRAN-2012 [14]. The precision obtained is estimated to be about $0.0002 \mathrm{~cm}^{-1}$. These corrections were not reported in HITRAN2012. The calculated transition intensities are the same as in GEISA-2011 and HITRAN-2012. 


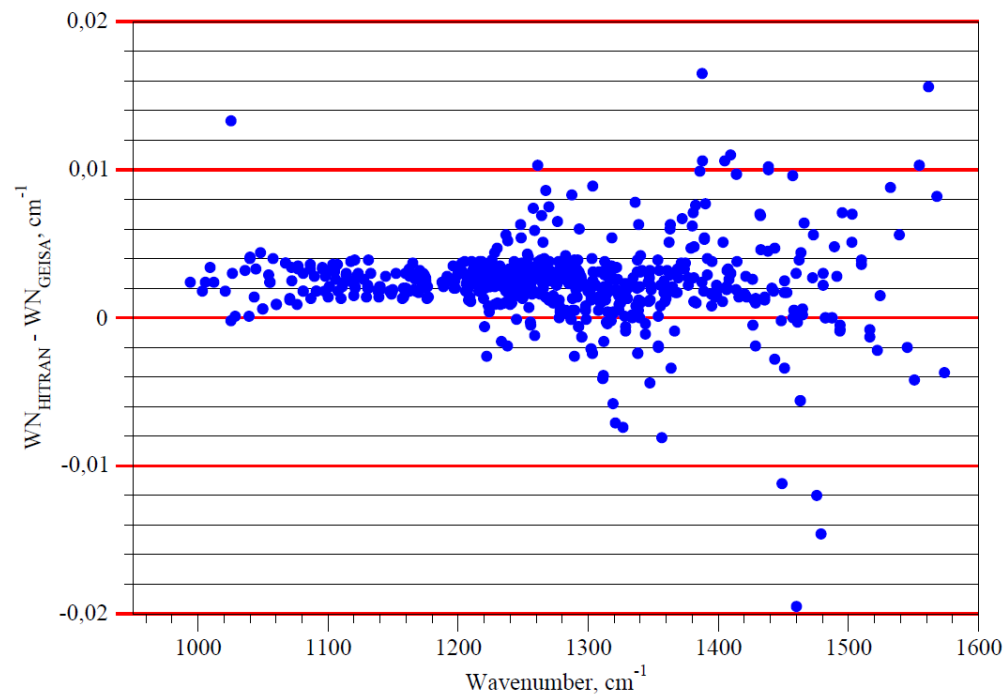

Fig. 11. Comparison of the 010-000 band updated lines in GEISA-2015 with those of HITRAN-2012. [14] illustrating differences in wavenumber $(\mathrm{WN})$ positions $\left(\mathrm{WN}_{\text {HITRAN }}-\mathrm{WN}_{\mathrm{GEISA}}\left(\mathrm{cm}^{-1}\right)\right)$.

Updates in the 2142.83505-4256.54681 $\mathrm{cm}^{-1}$ spectral region cover bands of the first and second triads. The data included in GEISA-2011 [11] showed errors in line positions and intensities, compared to their original source [271]. O. Naumenko generated a corrected file [268] including 16,731 entries which have replaced, in GEISA-2015, the former GEISA-2011 data. New parameters were added in the spectral region $4471.7721-11329.7799 \mathrm{~cm}^{-1}$, this spectral region covers the first and second hexads along part of the first decade of $\mathrm{H}_{2} \mathrm{~S}$. It is included for the first time in GEISA using 28,972 transitions of $\mathrm{H}_{2}{ }^{32} \mathrm{~S}, \mathrm{H}_{2}{ }^{33} \mathrm{~S}$, and $\mathrm{H}_{2}{ }^{34} \mathrm{~S}$ from Ref. [268]. The line positions and intensities are taken from both experimental and calculated data. Line positions are constructed from the experimental upper energy levels and calculated lower energies based on parameters provided in [270]. Line intensities are predicted using the transition moment parameters retrieved from the fitting to measured intensities, using an effective Hamiltonian approach. A detailed review of all published experimental rotation-vibration transitions and retrieved energy levels for the hydrogen sulfide can be found in Polotseva et al. [272].

The information newly included in GEISA-2015 relates to 30 vibrational bands of $\mathrm{H}_{2}{ }^{32} \mathrm{~S}$ and is summarized in the 8 columns of Table 8.

Experimental data from Fourier transform spectra in the range $4471.77211-8039.74431 \mathrm{~cm}^{-1}$ were obtained from the laboratory spectra recorded with the McMath Fourier transform spectrometer located at Kitt Peak National Solar Observatory [271,273]. The details of the experimental spectra assignment and modeling within the effective Hamiltonian approach can be found in [271,274-276]. The accuracy of experimental line positions varies from 0.001 (and better for stronger lines) up to $0.005 \mathrm{~cm}^{-1}$ and worse for blended or weak features. Similar accuracy applies to calculated line positions. 
Line intensities accurate within 1-7\% were measured for about 3000 lines in the 4578-6573 $\mathrm{cm}^{-1}$ spectral region, while the accuracy of the experimental intensities above $7000 \mathrm{~cm}^{-1}$ can be estimated around $10-15 \%$ at best. The experimental intensities were modeled, and the retrieved transition moment parameters were used to evaluate the intensities of additional pure calculated lines with the estimated accuracy of $10-20 \%$ and worse for weakest lines.

In total, 16284, 4087 and 1666 transitions of isotopologues $\mathrm{H}_{2}{ }^{32} \mathrm{~S}, \mathrm{H}_{2}{ }^{34} \mathrm{~S}$, and $\mathrm{H}_{2}{ }^{33} \mathrm{~S}$, respectively, have been newly implemented in GEISA-2015 between 4471.772110 and $8039.744310 \mathrm{~cm}^{-1}$. The line shape parameters are those reported in HITRAN-2012 [14]. 


\section{Table 8}

New vibrational bands of $\mathrm{H}_{2}{ }^{32} \mathrm{~S}$ included in GEISA-2015. For each vibrational band: the quantum identifications of the upper and lower levels of the transition, in the two first columns; the extension of the spectral region from WN min (minimum wave number in $\mathrm{cm}^{-1}$, ) to $\mathrm{WN} \max$ (maximum wave number in $\mathrm{cm}^{-}$ ${ }^{1}$ molecule ${ }^{-1}$ ), in columns 3 and 4 respectively; the summed transition intensities in $\mathrm{cm}$, in column 5; the maximum values of the rotational quantum numbers $J$ and $K_{a}$, in columns 7 and 8 respectively; the number of transitions is given in the last column.

\begin{tabular}{|c|c|c|c|c|c|c|c|}
\hline $\begin{array}{l}V_{1} V_{2} V_{3} \\
\text { Upper }\end{array}$ & $\begin{array}{l}V_{1} V_{2} V_{3} \\
\text { Lower }\end{array}$ & $\underset{\left(\mathbf{c m}^{-1}\right)}{\text { WN_min }}$ & $\begin{array}{c}\text { WN_max } \\
\left(\mathrm{cm}^{-1}\right)\end{array}$ & $\begin{array}{c}\sum_{\text {int }} \\
\left(\mathrm{cm} \text { molecule }^{-1}\right) \\
\text { at } 296 \mathrm{~K}\end{array}$ & $\begin{array}{l}\text { J_max } \\
\text { Upper }\end{array}$ & $\underset{\text { Upper }}{\text { Ka_max }_{\text {Uper }}}$ & \# lines \\
\hline 040 & 000 & 4471.7721 & 5094.0399 & $7.22 \times 10^{-23}$ & 16 & 8 & 535 \\
\hline 021 & 000 & 4555.7922 & 5392.1073 & $2.17 \times 10^{-21}$ & 19 & 12 & 1169 \\
\hline 101 & 000 & 4647.9645 & 5545.0965 & $2.59 \times 10^{-20}$ & 20 & 12 & 1886 \\
\hline 200 & 000 & 4676.6355 & 5548.5630 & $1.25 \times 10^{-20}$ & 19 & 14 & 1636 \\
\hline 120 & 000 & 4720.3837 & 5387.7404 & $7.41 \times 10^{-22}$ & 16 & 12 & 844 \\
\hline 002 & 000 & 4828.3805 & 5665.5575 & $2.51 \times 10^{-21}$ & 18 & 13 & 1220 \\
\hline 111 & 010 & 4877.2258 & 5240.4972 & $1.16 \times 10^{-22}$ & 15 & 10 & 403 \\
\hline 210 & 010 & 4889.8533 & 5249.6706 & $5.03 \times 10^{-23}$ & 15 & 9 & 326 \\
\hline 050 & 000 & 5671.4441 & 6029.4104 & $9.91 \times 10^{-24}$ & 12 & 5 & 203 \\
\hline 130 & 000 & 5840.1421 & 6579.5353 & $1.38 \times 10^{-22}$ & 15 & 9 & 566 \\
\hline 031 & 000 & 5844.5832 & 6582.2596 & $1.30 \times 10^{-22}$ & 16 & 10 & 541 \\
\hline 111 & 000 & 5887.1896 & 6695.2663 & $1.13 \times 10^{-20}$ & 18 & 13 & 1423 \\
\hline 210 & 000 & 5984.9635 & 6693.3914 & $2.95 \times 10^{-21}$ & 18 & 14 & 1484 \\
\hline 012 & 000 & 5989.3819 & 6664.1874 & $5.21 \times 10^{-23}$ & 13 & 9 & 126 \\
\hline 121 & 010 & 6051.8265 & 6489.7069 & $6.91 \times 10^{-23}$ & 14 & 8 & 380 \\
\hline 220 & 010 & 6071.8079 & 6477.5959 & $2.71 \times 10^{-23}$ & 12 & 7 & 198 \\
\hline 121 & 000 & 7053.2468 & 7738.0455 & $1.89 \times 10^{-22}$ & 14 & 8 & 539 \\
\hline 220 & 000 & 7128.4865 & 7672.2512 & $1.77 \times 10^{-23}$ & 12 & 7 & 248 \\
\hline 201 & 000 & 7170.3630 & 7868.6880 & $7.78 \times 10^{-22}$ & 17 & 10 & 794 \\
\hline 102 & 000 & 7191.1311 & 7766.3336 & $2.32 \times 10^{-22}$ & 13 & 10 & 601 \\
\hline 300 & 000 & 7400.1750 & 8039.7443 & $2.80 \times 10^{-22}$ & 14 & 9 & 601 \\
\hline 003 & 000 & 7496.6411 & 8031.1830 & $1.86 \times 10^{-22}$ & 14 & 9 & 560 \\
\hline 141 & 000 & 9385.1150 & 9991.9363 & $7.23 \times 10^{-25}$ & 12 & 8 & 385 \\
\hline 122 & 000 & 9470.6934 & 10157.4780 & $2.24 \times 10^{-24}$ & 15 & 8 & 492 \\
\hline 301 & 000 & 9477.0610 & 10241.6542 & $3.10 \times 10^{-23}$ & 16 & 11 & 1074 \\
\hline 221 & 000 & 9494.1657 & 10154.2523 & $4.97 \times 10^{-24}$ & 15 & 10 & 656 \\
\hline 202 & 000 & 9528.5303 & 10266.7543 & $9.98 \times 10^{-24}$ & 18 & 9 & 840 \\
\hline 212 & 000 & 10777.8636 & 11329.7798 & $1.49 \times 10^{-23}$ & 19 & 11 & 996 \\
\hline 311 & 000 & 10777.8636 & 11317.3960 & $2.26 \times 10^{-23}$ & 19 & 11 & 902 \\
\hline 330 & 000 & 10948.4353 & 11278.5380 & $3.82 \times 10^{-25}$ & 10 & 7 & 232 \\
\hline
\end{tabular}


ICLAS and ICLAS-VECSEL systems were used to probe the weak $\mathrm{H}_{2} \mathrm{~S}$ absorption spectrum in the $9385-10200 \mathrm{~cm}^{-1}$ [277] and $10780-11330 \mathrm{~cm}^{-1}$ [277] spectral regions. Spectra were obtained from transitions to the eight highly-excited upper vibrational states listed in Table 8. Line position accuracy was estimated to be better than 0.01 and about $0.005 \mathrm{~cm}^{-1}$ in the first and second region, respectively. Approximate relative intensities values were derived from the peak absorption and then scaled to the FTS data of Ref. [273]. The accuracy of measured intensities is estimated to be 25-30\% for stronger lines and up 100\% uncertainty for the weakest lines for the ICLAS-VECSEL data, and 15-20\% and worse for the ICLAS recordings. Similar accuracy can be assumed for the calculated intensities based on the transition moment parameters retrieved from the fitting to experimental data (see Refs. [277,278] for details of the intensity modeling). The resulting set of the $\mathrm{H}_{2}{ }^{32} \mathrm{~S}, \mathrm{H}_{2}{ }^{34} \mathrm{~S}$, and $\mathrm{H}_{2}{ }^{33} \mathrm{~S}$ transitions consists of 3385 measured and 3551 weaker pure predicted absorption lines.

In total, 5605, 1185 and 146 new transitions of isotopologues $\mathrm{H}_{2}{ }^{32} \mathrm{~S}, \mathrm{H}_{2}{ }^{34} \mathrm{~S}$, and $\mathrm{H}_{2}{ }^{33} \mathrm{~S}$, respectively, have been included in GEISA-2015 between 9385.115080 and $11329.779860 \mathrm{~cm}^{-1}$.

\subsubsection{9 $\mathrm{CH}_{3} \mathrm{Br}$ (molecule 43)}

The complete line list of $\mathrm{CH}_{3} \mathrm{Br}$ present in GEISA-2011 has been updated by adding the temperature dependence of both self- and $\mathrm{N}_{2}$-broadening coefficients for all transitions. Measurements performed for numerous transitions in the strong $v_{6}$ band led to a $J$-dependent model of the temperature exponents $n_{\text {self }}$ and $n_{N 2}$ [279]. The polynomial expansions of the temperature exponents $n_{\text {self }}$ and $n_{N 2}$ (see equations [4] and [5] from Ref. [279] respectively) were used to update all transitions in GEISA neglecting both the $K$-rotational dependence and the vibrational dependence. The approximation $n_{\text {air } ~} n_{\mathrm{N} 2}$ was made for the temperature-dependence coefficient $n$ of the air-broadening half-width.

\subsubsection{HNC (molecule 46)}

Barber et al. [236] actually performed a combined analysis of the HCN/HNC system. For this they used Mellau's empirical HNC energy levels [280,281], and the line intensities of Harris et al. [233]. The resulting $296 \mathrm{~K}$ HNC line list contains 75,554 transitions against 5619 in GEISA-2011. 


\subsubsection{HDO (molecule 51)}

\subsubsection{HDO update: line list parameters}

As already pointed out, for atmospheric applications, $\mathrm{H}_{2} \mathrm{O}$ and $\mathrm{HDO}$ need to be taken into account separately in radiative transfer models (as different vertical concentrations may occur), This, combined with their different symmetry properties, led us to decide to consider HDO as an independent molecular species in GEISA-2015. The 2015 update of the HDO entries has been very significant, giving a total of 63,641 lines, against 12,766 in GEISA-2011. This increase is mainly due to the inclusion of empirical line lists in GEISA-2015 HDO update.

Two isotopologues have been involved in the update: i.e.: $\mathrm{HD}^{16} \mathrm{O}$ and $\mathrm{HD}^{18} \mathrm{O}$, as summarized in Table 9. No update occurred for $\mathrm{HD}^{17} \mathrm{O}$ which retains the 175 entries from GEISA2011 The isotopologue formulas are listed in the first column with their associated identification codes in the GEISA management software (see Appendix C); for each species are provided, in columns 2 to 7 respectively: its line list spectral range minimum and maximum wave number $\left(\mathrm{cm}^{-}\right.$ ${ }^{1}$ ), the number of transitions, the mean and the maximum of the line intensities ( $\mathrm{cm}$ molecule ${ }^{-1}$ at $296 \mathrm{~K}$ ), and the origin of the data.

The new GEISA-2015 HDO line list has been built following the same process as for $\mathrm{H}_{2} \mathrm{O}$ (see above in 2.2.1).

\section{Table 9}

General overview of the HDO update in GEISA-2015

\begin{tabular}{|c|c|c|c|c|c|c|}
\hline $\begin{array}{l}\text { Isot. } \\
\text { ID }\end{array}$ & $\begin{array}{l}\text { Wavenb. min } \\
\qquad\left(\mathrm{cm}^{-1}\right)\end{array}$ & $\begin{array}{l}\text { Wavenb. max } \\
\qquad\left(\mathrm{cm}^{-1}\right)\end{array}$ & \#lines & $\begin{array}{c}\text { Moy. I } \\
\left(\mathrm{cm} \mathrm{molec}^{-1}\right) \\
\text { at } 296 \mathrm{~K}\end{array}$ & $\begin{array}{c}\text { Max. I } \\
\left(\mathrm{cm} \mathrm{molec}^{-1}\right) \\
\text { at } 296 \mathrm{~K}\end{array}$ & Origin \\
\hline $\begin{array}{c}\mathrm{HD}^{16} \mathrm{O} \\
162\end{array}$ & 0.007002 & 17080.098180 & 53706 & $3.175 \times 10^{-25}$ & $2.700 \times 10^{-22}$ & $\begin{array}{l}\text { IAO } \\
\text { LIPhy }\end{array}$ \\
\hline $\begin{array}{c}\mathrm{HD}^{17} \mathrm{O} \\
172\end{array}$ & 1234.234730 & 1598.765470 & 175 & $4.075 \times 10^{-27}$ & $9.319 \times 10^{-27}$ & GEISA-2011 \\
\hline $\begin{array}{c}\mathrm{HD}^{18} \mathrm{O} \\
182\end{array}$ & 0.196882 & 8748.128100 & 9760 & $3.694 \times 10^{-27}$ & $5.646 \times 10^{-25}$ & $\begin{array}{l}\text { IAO } \\
\text { LIPhy }\end{array}$ \\
\hline
\end{tabular}

The new $\mathrm{HD}^{16} \mathrm{O}$ set, in GEISA-2015, consists of 53,706 transitions in the $0-17104 \mathrm{~cm}^{-1}$ spectral region, compared to 11,932 transitions between 0 and $13900 \mathrm{~cm}^{-1}$ in GEISA-2011. The difference in contents, between the previous, GEISA-2011, and new enlarged GEISA-2015 $\mathrm{HD}^{16} \mathrm{O}$ 
line lists, is illustrated on Fig. 12 and Fig. 13. Coincident transitions in GEISA-2011 and GEISA2015 are plotted with the same (blue) color on both figures. In the new GEISA-2015 version, the previous data, in the $5850-7921 \mathrm{~cm}^{-1}$ region, are replaced by those from the exhaustive list of Mikhaïlenko et al. [27]. This list includes both observed lines from Refs. [30-32] (2730 lines) and 6095 empirical lines based on works on potential energy surface and dipole moment surface $[\mathbf{3 4}, \mathbf{3 5}, \mathbf{7 1}]$ and on the IUPAC TG energy levels [282].

After implementation of the new data, the whole $\mathrm{HD}^{16} \mathrm{O}$ set was checked against the empirical list generated in Ref. [283]; the resulting cleaned list was enlarged by inclusion of missing empirical lines. The empirical list [283] is based on the improved and enlarged IUPAC TG energy level set [282,284] and well known VTT variational list [285], which is recognized to be most accurate one available for the $\mathrm{HD}^{16} \mathrm{O}$ molecule. In total, 34181 pure empirical lines [283] are used. Inaccurate positions of about 900 lines between 5 and $7916 \mathrm{~cm}^{-1}$, from GEISA-2011, were replaced with those from the empirical list [283].

Obviously, the new $\mathrm{HD}^{16} \mathrm{O}$ list is about three times larger than the GEISA-2011 version. In particular, the majority of the $\mathrm{HD}^{16} \mathrm{O}$ lines above $7500 \mathrm{~cm}^{-1}$ are new. In the near infrared spectral region, an advantage of this list is that $\mathrm{HD}^{16} \mathrm{O}$ line parameters are provided in the 1.6 and $1.28 \mu \mathrm{m}$ atmospheric windows where this minor isotopologue in natural abundance has a major contribution. 


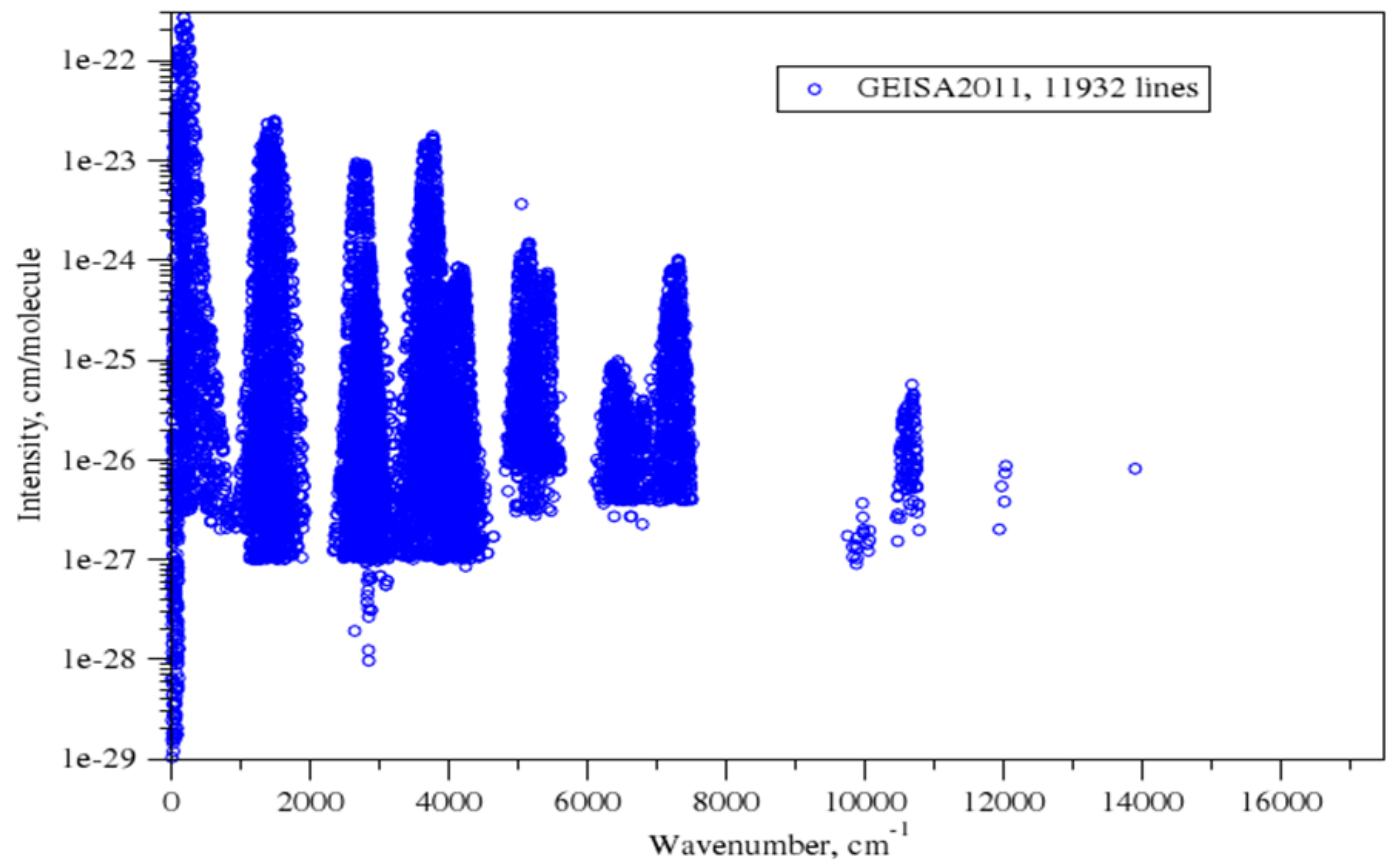

Fig.12. $\mathrm{HD}^{16} \mathrm{O}$ transitions in the GEISA-2011 database.

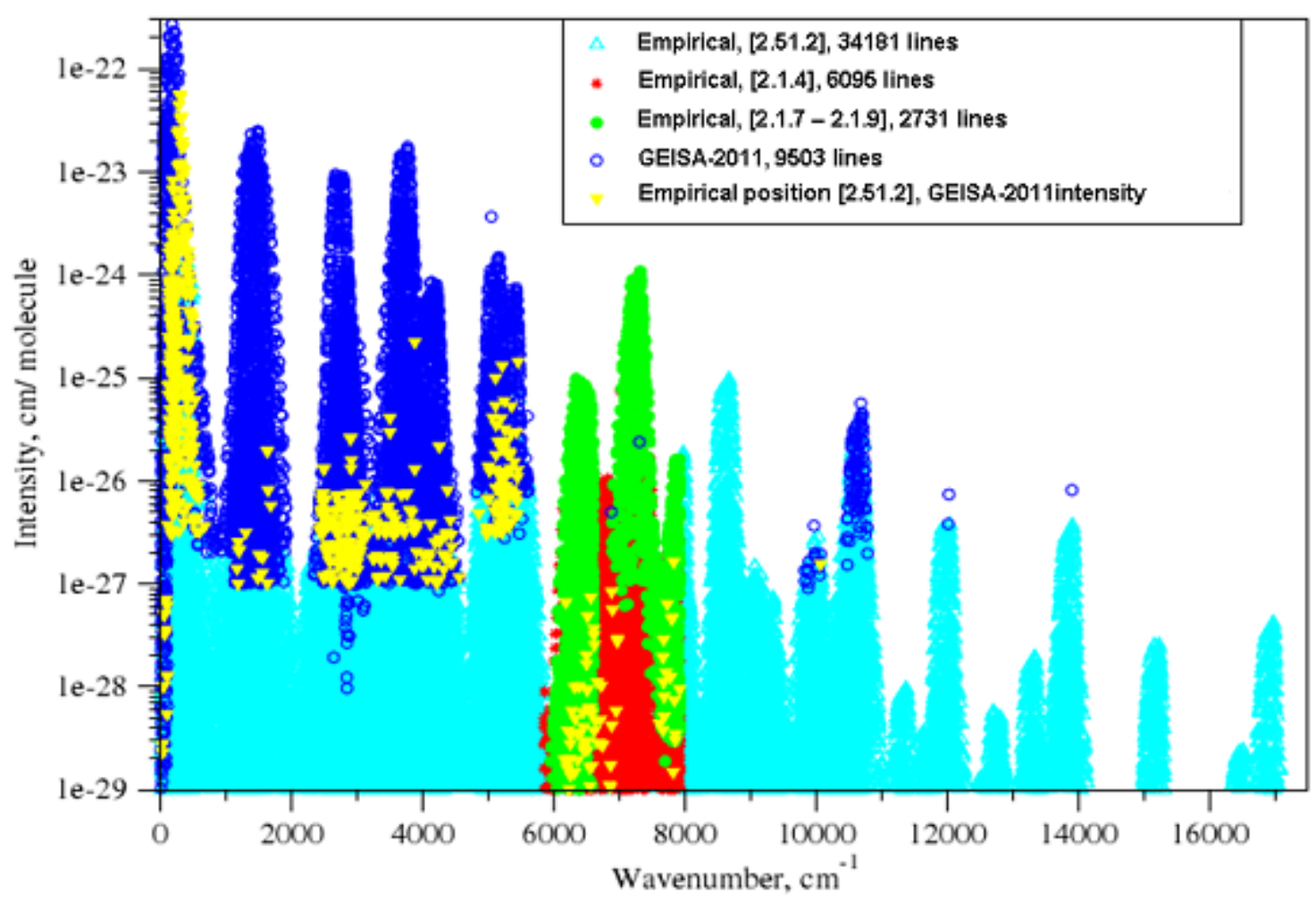

Fig. 13. Composition of the $\mathrm{HD}^{16} \mathrm{O}$ transition set in GEISA-2015. 
An important update has also been performed in GEISA-2015 for the $\mathrm{HD}^{18} \mathrm{O}$ isotopologue. The $\mathrm{HD}^{18} \mathrm{O}$ linelist includes now 9760 transitions in the 0.196882-8748.128100 $\mathrm{cm}^{-1}$ spectral range (compared to 659 transitions previously). The new $\mathrm{HD}^{18} \mathrm{O}$ line list was constructed in the following way: The highly accurate experimental microwave and far infrared lines of Refs. [59,286,287], 204 in total, are used in $0-200 \mathrm{~cm}^{-1}$ region. Positions of other lines are derived from the experimental energy levels obtained in Refs. $[\mathbf{5 6}, \mathbf{2 8 6}, \mathbf{2 8 8}, \mathbf{2 8 9}]$, while the intensities represent variational values based on Partridge and Schwenke potential and dipole moment surfaces $[34,35,290]$. $\mathrm{HD}^{18} \mathrm{O}$ line parameters for near infrared are included in GEISA region for the first time.

Fig. 14 presents a comparison between HITRAN-2012 and GEISA-2015, showing the importance of the added HDO data in GEISA-2015; HDO strongly impacts the absorption in the $1.6 \mu \mathrm{m}$ and $1.28 \mu \mathrm{m}$ atmospheric windows.
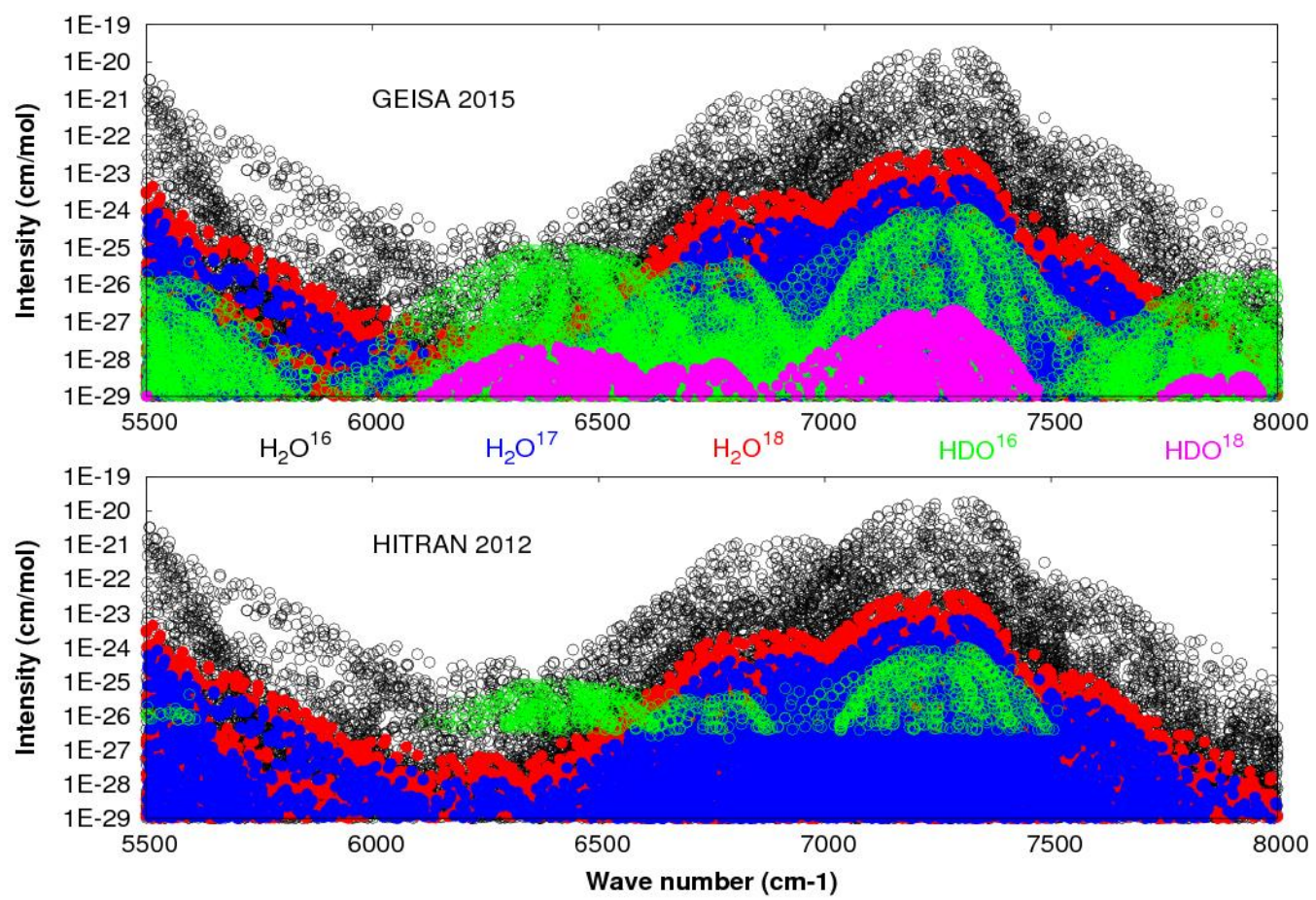

Fig. 14. Illustration of the difference between GEISA-2015 and HITRAN-2012 water vapor archives and of the importance of the impact of HDO in the 1.6 and $1.28 \mu \mathrm{m}$ atmospheric windows. The contribution of the different isotopologues is highlighted $\left(\mathrm{H}_{2}{ }^{16} \mathrm{O}\right.$-black, $\mathrm{H}_{2}{ }^{17} \mathrm{O}$-blue, $\mathrm{H}_{2}{ }^{18} \mathrm{O}$-red, $\mathrm{HD}^{16} \mathrm{O}$-green, $\mathrm{HD}^{18} \mathrm{O}$-pink).

\subsubsection{HDO update: line shape parameters}


For the deuterated isotopologues, $\mathrm{HD}^{16} \mathrm{O}, \mathrm{HD}^{18} \mathrm{O}, \mathrm{HD}^{17} \mathrm{O}$, the line shape parameters i.e.: the air-broadened half-widths, $\gamma_{\text {air }}$, its temperature dependence, $n_{\text {air }}$, the air-induced line shifts, $\delta_{\text {air }}$, and the self-broadened half-widths, $\gamma_{\text {self }}$, an algorithm similar to that used for the three most abundant water isotopologues, $\mathrm{H}_{2}{ }^{16} \mathrm{O}, \mathrm{H}_{2}{ }^{18} \mathrm{O}, \mathrm{H}_{2}{ }^{17} \mathrm{O}$ was developed using the measurement database of Gamache and Hartmann [291]. When measurement data are available for $\mathrm{HD}^{16} \mathrm{O}$ they are added as above, or theoretical values of Gamache and Fischer [292] are used. Because there are far fewer measurements for $\mathrm{HD}^{16} \mathrm{O}$ the following actions were taken to enhance the database. The measurement database was taken and the ratio $\gamma_{\text {air }}\left(\mathrm{H}_{2}{ }^{16} \mathrm{O}\right) / \gamma_{\text {air }}\left(\mathrm{HD}^{16} \mathrm{O}\right)$ determined for 992 transitions giving an average value of 0.9167 .

These data are shown in Fig. 15 where the ratio is plotted versus the $\mathrm{H}_{2} \mathrm{O}$ air-broadened half-width. The solid red line in the figure is the average ratio, which is used in the algorithm to scale $\mathrm{H}_{2}{ }^{16} \mathrm{O}$ half-widths to $\mathrm{HD}^{16} \mathrm{O}$ half-widths. Scaling was used to generate an additional 17,812 HDO-air half-widths that were added to the database. A similar scaling of the line shifts of $\mathrm{H}_{2} \mathrm{O}$ and $\mathrm{HDO}$ was made. Data were available for 392 transitions. Fig. 16 shows the ratios versus the $\mathrm{H}_{2} \mathrm{O}$ line shift; the solid red line is the average ratio of 0.7772 . Note, there are not enough data to repeat this procedure for $n_{\text {air }}$, or $\gamma_{\text {self. }}$.

Roughly 1500 measured HDO-air half-widths were compared with data from the semi-empirical $\gamma_{\text {air }}$ algorithm data scaled from $\mathrm{H}_{2}{ }^{16} \mathrm{O}$ to $\mathrm{HD}^{16} \mathrm{O}$ and with the smoothened HDO-air half-widths of Toth [293]. Overall the data of Toth gave better agreement; an average difference of $\sim 20 \%$. These data were used, neglecting vibrational dependence, to help complete data for transitions for which there were no measurements. Finally if there are no air-broadened HDO half-width data from the above procedure, the data are taken from a polynomial in J" fit to the J" averaged data from the database [291] extrapolated to J" $=50$.

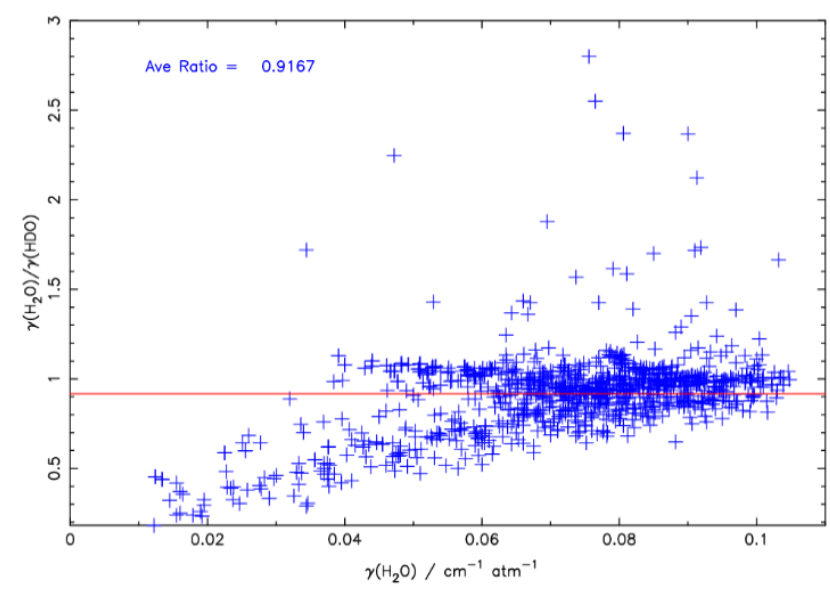

Fig. 15. Ratio $\gamma_{\text {air }}\left(\mathrm{H}_{2} \mathrm{O}\right) / \gamma_{\text {air }}(\mathrm{HDO})$ versus $\gamma_{\text {air }}\left(\mathrm{H}_{2} \mathrm{O}\right)$ in $\mathrm{cm}^{-1} \mathrm{~atm}^{-1}$; solid red line is the average ratio. 


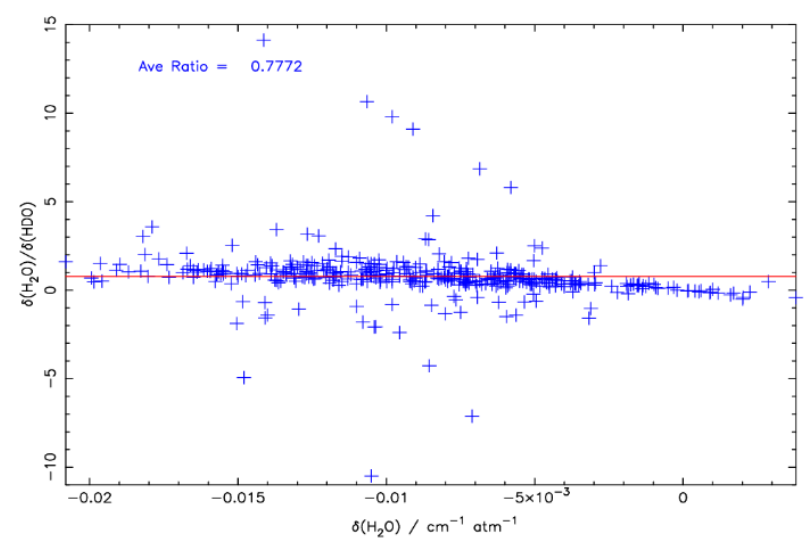

Fig. 16: Ratio $\delta_{\text {air }}\left(\mathrm{H}_{2} \mathrm{O}\right) / \delta_{\text {air }}(\mathrm{HDO})$ versus $\delta_{\text {air }}\left(\mathrm{H}_{2} \mathrm{O}\right) \mathrm{in}^{-1} \mathrm{~cm}^{-1}$; solid red line is the average ratio.

\subsubsection{2 $\mathrm{SO}_{3}$ (molecule 52, new in GEISA-2015)}

$\mathrm{SO}_{3}$, produced from smoke-stacks and other industrial exhausts, is, in its gaseous form, a significant pollutant, and the primary agent in acid rain. It is produced naturally on Earth (through volcanic emissions) and is thought to be a significant constituent of the atmosphere of Venus. It was absent for previous editions of GEISA in part because there were no absolute intensity measurements available for this molecules that placed severe limitations on the use of its infrared spectrum for remote sensing applications. However, thanks to the availability of a computed, complete, ab-initio, room-temperature line list by Underwood et al. [294], $\mathrm{SO}_{3}$ has been implemented as a new molecule in GEISA-2015.

This line list has been used to augment experimentally measured frequencies in two regions, i.e.: $0.477672-580.263263 \mathrm{~cm}^{-1}$ and $1353.104833-2824.347247 \mathrm{~cm}^{-1}$ to provide to GEISA2015 the input of 10,881 lines of the main ${ }^{32} \mathrm{~S}^{16} \mathrm{O}_{3}$ isotopologue, in the spectral range $0.477672-2824.347247 \mathrm{~cm}^{-1}$.

$\mathrm{SO}_{3}$ is a planar, symmetric top and therefore does not possess a permanent dipole moment. However, rotationally excited $\mathrm{SO}_{3}$ can distort, creating instantaneous dipoles and as a result undergo centrifugally-induced, pure rotational transitions. 25 such lines were observed by Meyer et al. [295]; these lines with ab-initio intensities are included in GEISA.

Maki and co-workers [296-300] performed a series of studies on the infrared spectrum of $\mathrm{SO}_{3}$, some of which contained relative but not absolute intensities.

Underwood et al. calibrated these intensities using their ab-initio calculations and the 10,881 lines included here have empirical frequencies and $a b$-initio or ab-initio calibrated intensities. 
Recently Underwood et al. have undertaken a much more extensive calculations on the rotational spectrum of $\mathrm{SO}_{3}$ [301], and its infrared spectrum [302]. These studies will be used to provide more extensive line lists for room-temperature $\mathrm{SO}_{3}$ in the future. Ref. [302] also provides new measurements of absolute cross sections which suggest that the ab intio dipole moment surface of Underwood et al. [294] may lead intensities that are about $20 \%$ too strong. This problem will also be considered in a future release.

In the absence of no measurements or calculations for the line-shape parameters, usual default were chosen, i.e.:

$$
\begin{array}{ll}
\text { HWHM } & \gamma_{\text {air }}=0.0700 \mathrm{~cm}^{-1} \mathrm{~atm}^{-1} \text { at } 296 \mathrm{~K} \\
\text { HWHM self } & \gamma_{\text {self }}=0.100 \mathrm{~cm}^{-1} \mathrm{~atm}^{-1}
\end{array}
$$

Temperature-dependence coefficient $n$ of the air broadening half width $\quad n_{\text {air }}=0.700$

The GEISA standard default value has been attributed to the air pressure induced shift of the line transition: $\delta_{\text {air }}=0.000000 \mathrm{~cm}^{-1} \mathrm{~atm}^{-1}$.

\section{GEISA-2015 Infrared absorption cross-sections sub-database}

This sub-database contains infrared absorption cross sections of molecules for which spectral line parameters are incomplete or unavailable; generally these are 'large' molecules for which the generation of line parameters is very difficult. Thirty-nine molecules were represented by cross sections in GEISA-2011. See Table 10 of Rosenkranz et al. [303] and Table 10 of Jacquinet-Husson et al. [11]. The GEISA-2015 compilation has been updated with additional cross-section datasets, consisting of multiple temperature-pressure combinations, for new and existing molecules.

This database has been significantly extended (more than about 50\% increase in information volume) with the introduction of some new molecular species originating mainly from two sources:

- a first cross-section set from the University of Oslo (Hodnebrog et al. [304,305]) and the University of Castilla-La Mancha [318,319,321]. These compounds (halocarbons, bromocarbons, bromofluorocarbons, bromochlorofluorocarbons, halogenated alcohols, halogenated, fluorinated ethers and perfluorinated compounds) contribute to the global warming;

- a second cross-sections set from the University of York (Harrison and Bernath $[\mathbf{3 0 6 , 3 0 7 ]})$. This set includes molecular species already present in GEISA-2011, i.e.: $\mathrm{C}_{2} \mathrm{H}_{6}$, 
$\mathrm{C}_{3} \mathrm{H}_{8}, \mathrm{CH}_{3} \mathrm{CN}, \mathrm{C}_{3} \mathrm{H}_{6} \mathrm{O}$, as well as the new species methanol $\left(\mathrm{CH}_{3} \mathrm{OH}\right)$ which was observed in IASI measurements of reactive trace species in biomass burning plumes (Coheur 2009 [308]), trifluoromethane $\left(\mathrm{CHF}_{3}\right)$ and acetaldehyde $\left(\mathrm{CH}_{3} \mathrm{CHO}\right)$.

\subsection{Universities of Oslo and Castilla-La Mancha cross sections}

The GEISA-2011 IR absorption cross-section sub-database contained data for 35 molecules in the spectral range from $200 \mathrm{~cm}^{-1}$ to $6500 \mathrm{~cm}^{-1}[\mathbf{3 0 3 , 1 1}$. Most of these species are chlorofluorocarbons (CFCs) and their first- and second-generation replacements, i.e. hydrochlorofluorocarbons (HCFCs) and hydrofluorocarbons (HFCs). HFCs do not have the ozone-damaging effects of CFCs and HCFCs, nevertheless they are potent greenhouse gases with high global warming potentials (GWPs). For that reason, in many applications (air conditioning refrigerants, foam expansion agents, fire protection fluids, etc) low-GWP alternatives have been suggested in recent years. Among these low-GWP substitutes, perfluorolefins (PFOs), hydrofluoroethers (HFEs), hydrofluoroalcohols (HFAs), and perfluoroalcohols (PFAs) are proposed as environmental friendly alternatives to HFCs.

Recently, Hodnebrog et al. [304] provided a complete new set of calculations of GWPs and radiative efficiencies (REs) of halocarbons, such as $\mathrm{CF}_{2} \mathrm{Cl}_{2}(\mathrm{CFC}-12)$, and related compounds. Consequently, the IR absorption cross-sections for CFC-12 and 31 fluorinated compounds, included in the recent review of Hodnebrog et al. [304] were added to GEISA2015. Among these compounds, hydrofluorinated aldehydes, $\mathrm{CF}_{3} \mathrm{CHO}, \mathrm{CF}_{3} \mathrm{CH}_{2} \mathrm{CHO}$ and $\mathrm{CF}_{3}\left(\mathrm{CH}_{2}\right)_{2} \mathrm{CHO}$, are also included since they are the major products of the atmospheric degradation of the corresponding HFA. The newly included molecular species are listed in Table 10, which provides for each compounds: its chemical formula, common name, CAS $\mathrm{RN}$ and spectral information, i.e.: spectral range, gas bath, foreign broadening pressure $(\mathrm{Pa})$, and references.

The IR absorption cross-sections for CFC-12 have been updated using the data reported by Myhre et al. [309] for pure CFC-12 and gas mixtures (1 atm of nitrogen) at $(295 \pm 1) \mathrm{K}$ in the spectral region $500-2000 \mathrm{~cm}^{-1}$ [309]. For the other fluorinated compound the spectral resolution was $1 \mathrm{~cm}^{-1}$ and the absorption cross-sections were determined in mixtures with non-absorbing molecules, such as $\mathrm{N}_{2}$ or He, or pure gases [310-321]. For RTM, the effect of pressure broadening must be considered. At the spectral resolution of the updated IR absorption cross sections, the structure is quite broad and the effect of the foreign 
perturbing gases has only a small effect on the broadening. For CFC-12, the spectral resolution of the updated absorption cross-sections is 0.5 and $1 \mathrm{~cm}^{-1}$, but the IR absorption cross section found by Myhre et al. [309] were in good agreement with the results obtained at high spectral resolution. Oyaro et al. [315] did not observe a discernible dependency in the IR absorption cross-sections for a series of fluorinated ethers by the addition of $\mathrm{N}_{2}$ to reach atmospheric pressure.

To model correctly in a RTM the correct atmospheric conditions (p, T, amount of gases, clouds, etc...), the IR absorption cross-sections should ideally be provided also as a function of temperature. However, for most of the larger molecules the temperature variation in absorption cross-section is negligible. For the small and important greenhouse gases, pressure broadening and temperature variation in the absorption cross sections become an issue. As an example, the temperature dependence of the absorption cross-section of the important greenhouse gas CFC-12 was reported by McDaniel et al. between 203 and $298 \mathrm{~K}$ [322]. The authors observed that the peak absorption cross-sections increased by up to $50 \%$ at the lowest temperature relative to their values at $298 \mathrm{~K}$, but the integrated band intensities only changed slightly in this temperature range. 
Table 10

Summary of GEISA-2015 infrared absorption cross-sections update. Data from University of Oslo [304, 305] and the University of Castilla-La Mancha $[318,319,321]$ at room temperature and spectral resolution of $1 \mathrm{~cm}^{-1}$.

\begin{tabular}{|c|c|c|c|c|c|c|}
\hline Molecule & $\begin{array}{c}\text { Common Name } \\
\text { or Chemical } \\
\text { Name }\end{array}$ & $\operatorname{CAS~RN}^{\mathrm{a}}$ & $\begin{array}{c}\text { Spectral } \\
\text { range }\left(\mathrm{cm}^{-1}\right)\end{array}$ & $\begin{array}{l}\text { Bath } \\
\text { Gas }\end{array}$ & $\begin{array}{l}\text { Foreign } \\
\text { broadening } \\
\text { pressure }(\mathbf{P a})\end{array}$ & Refs. ${ }^{c}$ \\
\hline \multirow[t]{2}{*}{$\mathrm{CCl}_{2} \mathrm{~F}_{2}$} & CFC-12 & $75-71-8$ & $800-1,300^{b}$ & $\mathrm{~N}_{2}$ & $101,325.72$ & [309] \\
\hline & & & & Pure & - & [309] \\
\hline $\mathrm{CF}_{2}=\mathrm{CF}_{2}$ & PFC-1114 & $116-14-3$ & $100-2,600$ & Pure & - & [310] \\
\hline $\mathrm{CF}_{3} \mathrm{CF}=\mathrm{CF}_{2}$ & PFC-1216 & $116-15-4$ & $100-2,600$ & Pure & - & [310] \\
\hline $\mathrm{CF}_{2}=\mathrm{CFCF}=\mathrm{CF}_{2}$ & Perfluorobut-2-ene & $685-63-2$ & $100-2,600$ & Pure & - & [310] \\
\hline $\mathrm{CHF}_{2} \mathrm{OCF}_{2} \mathrm{OCHF}_{2}$ & HFE-235ca12 & $78522-47-1$ & $25-3,250$ & Pure & - & [311] \\
\hline $\mathrm{CHF}_{2} \mathrm{OCF}_{2} \mathrm{CF}_{2} \mathrm{OCHF}_{2}$ & HFE-338pcc13 & $\begin{array}{l}188690-78- \\
0\end{array}$ & $25-3,250$ & Pure & - & [311] \\
\hline$\left(\mathrm{CF}_{3}\right)_{2} \mathrm{CHOCH}_{2} \mathrm{~F}$ & $\begin{array}{l}\text { HFE-347mmz1 } \\
\text { (Sevoflurane) }\end{array}$ & $28523-86-6$ & $400-4,000$ & Pure & - & [312] \\
\hline $\mathrm{CHF}_{2} \mathrm{OCHClCF}_{3}$ & $\begin{array}{l}\text { HCFE-235da2 } \\
\text { (Isoflurane) }\end{array}$ & $26675-46-7$ & $400-4,000$ & Pure & - & [312] \\
\hline$\left(\mathrm{CF}_{3}\right)_{2} \mathrm{CFC}(\mathrm{O}) \mathrm{CF}_{2} \mathrm{CF}_{3}$ & $\begin{array}{l}\text { Perfluoro(2- } \\
\text { methyl-3- } \\
\text { pentanone) }\end{array}$ & $756-13-8$ & $450-2,000$ & Pure & - & [313] \\
\hline $\mathrm{CHF}_{2} \mathrm{CF}_{2} \mathrm{CH}_{2} \mathrm{OCH}_{3}$ & HFE-374pcf & $60598-17-6$ & $450-3,200$ & Pure & - & [314] \\
\hline $\mathrm{CF}_{3} \mathrm{CF}_{2} \mathrm{CH}_{2} \mathrm{OCH}_{3}$ & HFE-365mcf & $378-16-5$ & $450-3,200$ & Pure & - & [314] \\
\hline $\mathrm{CF}_{3} \mathrm{CH}_{2} \mathrm{OCH}_{2} \mathrm{CF}_{3}$ & HFE-356mf-f & $333-36-8$ & $450-3,200$ & Pure & - & [314] \\
\hline$\left(\mathrm{CF}_{3}\right)_{2} \mathrm{CHOCH}_{3}$ & $356 \mathrm{mmzE} \beta \gamma$ & 13171-18-1 & $450-3,200$ & Pure & - & [314] \\
\hline $\mathrm{CHF}_{2} \mathrm{CHFOCF}_{3}$ & $\begin{array}{l}\text { 1,1,2-Trifluoro-2- } \\
\text { (trifluoromethoxy)- } \\
\text { ethane }\end{array}$ & $84011-06-3$ & $440-3,200$ & Pure & - & [315] \\
\hline $\mathrm{CF}_{3} \mathrm{CHFOCF}_{3}$ & HFE-227ea & $2356-62-9$ & $440-3,200$ & Pure & - & [315] \\
\hline
\end{tabular}




\begin{tabular}{|c|c|c|c|c|c|c|}
\hline Molecule & $\begin{array}{c}\text { Common Name } \\
\text { or Chemical } \\
\text { Name }\end{array}$ & CAS RN $^{\mathrm{a}}$ & $\begin{array}{c}\text { Spectral } \\
\text { range }\left(\mathrm{cm}^{-1}\right)\end{array}$ & $\begin{array}{c}\text { Bath } \\
\text { Gas }\end{array}$ & $\begin{array}{l}\text { Foreign } \\
\text { broadening } \\
\text { pressure }(\mathbf{P a})\end{array}$ & Refs. $^{c}$ \\
\hline $\mathrm{CHF}_{2} \mathrm{OCHFCF}_{3}$ & $\begin{array}{l}\text { HFE-236 } \\
\text { (Desflurane) }\end{array}$ & $57041-67-5$ & $440-3,200$ & Pure & - & [315] \\
\hline $\mathrm{CF}_{3} \mathrm{CHFCF}_{2} \mathrm{OCH}_{2} \mathrm{CH}_{3}$ & $\begin{array}{l}\text { 1-Ethoxy- } \\
1,1,2,3,3,3- \\
\text { hexafluoropropane }\end{array}$ & $380-34-7$ & $440-3,200$ & Pure & - & [315] \\
\hline $\mathrm{CF}_{3} \mathrm{CF}_{2} \mathrm{CF}_{2} \mathrm{OCHFCF}_{3}$ & $\begin{array}{l}1,1,1,2,2,3,3- \\
\text { Heptafluoro-3- } \\
(1,2,2,2- \\
\text { tetrafluoroethoxy)- } \\
\text { propane }\end{array}$ & $3330-15-2$ & $440-3,200$ & Pure & - & [315] \\
\hline $\mathrm{CHF}_{2} \mathrm{OCH}_{2} \mathrm{CF}_{3}$ & HFE-245fa2 & $1885-48-9$ & $440-3,200$ & Pure & - & [315] \\
\hline $\mathrm{CF}_{3} \mathrm{CH}_{2} \mathrm{OCH}_{3}$ & HFE-263fb2 & $460-43-5$ & $440-3,200$ & Pure & - & [315] \\
\hline $\mathrm{CH}_{2} \mathrm{FCH}_{2} \mathrm{OH}$ & 2-fluoroethanol & $371-62-0$ & $80-4,800$ & Pure & - & [316] \\
\hline $\mathrm{CHF}_{2} \mathrm{CH}_{2} \mathrm{OH}$ & 2,2-difluoroethanol & $359-13-7$ & $70-4,800$ & Pure & - & [316] \\
\hline $\mathrm{CF}_{3} \mathrm{CH}_{2} \mathrm{OH}$ & $\begin{array}{l}2,2,2- \\
\text { trifluoroethanol }\end{array}$ & $75-89-8$ & $70-4,800$ & Pure & - & [316] \\
\hline \multirow[t]{3}{*}{$\mathrm{CF}_{3} \mathrm{CF}_{2} \mathrm{CH}_{2} \mathrm{OH}$} & $\begin{array}{l}2,2,3,3,3- \\
\text { pentafluoropropan- } \\
1 \text {-ol }\end{array}$ & $422-05-9$ & $400-4,000$ & Pure & - & {$[317]$} \\
\hline & & & $500-4,000$ & $\mathrm{He}$ & $666.6-20,797.9$ & [319] \\
\hline & & & $500-4,000$ & Pure & - & [319] \\
\hline \multirow[t]{3}{*}{$\mathrm{CHF}_{2} \mathrm{CF}_{2} \mathrm{CH}_{2} \mathrm{OH}$} & $\begin{array}{l}\text { 2,2,3,3-tetrafluoro- } \\
\text { 1-propanol }\end{array}$ & $76-37-9$ & $400-4,000$ & Pure & - & [317] \\
\hline & & & $500-4,000$ & $\mathrm{He}$ & 746.6-12,798.7 & [319] \\
\hline & & & $500-4,000$ & Pure & - & [319] \\
\hline $\mathrm{CF}_{3} \mathrm{CF}_{2} \mathrm{CF}_{2} \mathrm{CH}_{2} \mathrm{OH}$ & $\begin{array}{l}2,2,3,3,4,4,4- \\
\text { Heptafluoro-1- } \\
\text { butanol }\end{array}$ & $375-01-9$ & $400-4,000$ & Pure & - & [317] \\
\hline
\end{tabular}




\begin{tabular}{|c|c|c|c|c|c|c|}
\hline Molecule & $\begin{array}{c}\text { Common Name } \\
\text { or Chemical } \\
\text { Name }\end{array}$ & CAS RN $^{a}$ & $\begin{array}{c}\text { Spectral } \\
\text { range }\left(\mathrm{cm}^{-1}\right)\end{array}$ & $\begin{array}{c}\text { Bath } \\
\text { Gas }\end{array}$ & $\begin{array}{l}\text { Foreign } \\
\text { broadening } \\
\text { pressure (Pa) }\end{array}$ & Refs. $^{c}$ \\
\hline $\mathrm{CF}_{3} \mathrm{CHFCF}_{2} \mathrm{CH}_{2} \mathrm{OH}$ & $\begin{array}{l}2,2,3,4,4,4- \\
\text { Hexafluoro-1- } \\
\text { butanol }\end{array}$ & $382-31-0$ & $400-4,000$ & Pure & - & [317] \\
\hline \multirow[t]{2}{*}{$\mathrm{CF}_{3} \mathrm{CH}_{2} \mathrm{CH}_{2} \mathrm{OH}$} & $\begin{array}{l}3,3,3- \\
\text { trifluoropropan-1- } \\
\text { ol }\end{array}$ & $2240-88-2$ & $400-4,000$ & Pure & - & [317] \\
\hline & & & $500-4,000$ & $\mathrm{He}$ & $666.6-20,797.9$ & [318] \\
\hline $\mathrm{CF}_{3}\left(\mathrm{CH}_{2}\right)_{2} \mathrm{CH}_{2} \mathrm{OH}$ & $\begin{array}{l}\text { 4,4,4-trifluoro-1- } \\
\text { butanol }\end{array}$ & $461-18-7$ & $500-4,000$ & $\mathrm{He}$ & $666.6-21,864.5$ & [318] \\
\hline $\mathrm{CF}_{3} \mathrm{CHO}$ & trifluoroethanal & $75-90-1$ & $400-2,500$ & Pure & - & [318] \\
\hline \multirow[t]{2}{*}{$\mathrm{CF}_{3} \mathrm{CH}_{2} \mathrm{CHO}$} & $\begin{array}{l}3,3,3- \\
\text { trifluoropropanal }\end{array}$ & $460-40-2$ & $400-3,500$ & Pure & - & {$[320]$} \\
\hline & & & $500-4,000$ & $\mathrm{He}$ & $626.6-7,999.2$ & [321] \\
\hline $\mathrm{CF}_{3}\left(\mathrm{CH}_{2}\right)_{2} \mathrm{CHO}$ & $\begin{array}{l}4,4,4- \\
\text { trifluorobutanal }\end{array}$ & $406-87-1$ & $500-4,000$ & $\mathrm{He}$ & $493.3-9,065.7$ & [321] \\
\hline
\end{tabular}

${ }^{\mathrm{a}}$ Abbreviation of Chemical Abstract Service Registry Number; ${ }^{\mathrm{b}}$ Also at a spectral resolution of $0.5 \mathrm{~cm}^{-1}$; ${ }^{\mathrm{c}}$ Each reference corresponds to a single $\mathrm{P}, \mathrm{T}$ dataset. 


\subsection{University of York cross-sections}

THE ABSORPTION CROSS SECTION (IN UNITS OF $\mathrm{CM}^{2}$ MOLECULE ${ }^{-1}$ ) PROVIDED BY YORK UNIVERSITY [307] FOR GEISA-2015 UPDATE ARE SUMMARIZED IN TABLE 11

The cross sections for $\mathrm{C}_{2} \mathrm{H}_{6}, \mathrm{C}_{3} \mathrm{H}_{8},\left(\mathrm{CH}_{3}\right)_{2} \mathrm{CO}, \mathrm{CH}_{3} \mathrm{CN}$ already included in GEISA-2011 [303,11] are extended. Three new molecular species have been added to GEISA-2015 i.e.: $\mathrm{CH}_{3} \mathrm{OH}, \mathrm{CHF}_{3}$, $\mathrm{CH}_{3} \mathrm{CHO}$.

\section{Table 11}

Absorption cross-sections provided by the University of York for GEISA-2015 update. For each molecular species listed are given: the temperature $(\mathrm{T})$ range $(\mathrm{K})$, the pressure $(\mathrm{P})$ range (Torr), the number of $\mathrm{P}, \mathrm{T}$ sets, and the spectral range $\left(\mathrm{cm}^{-1}\right)$.

\begin{tabular}{|l|c|c|c|c|}
\hline Molecule & $\begin{array}{c}\text { Temperature } \\
\text { range (K) }\end{array}$ & $\begin{array}{c}\text { Pressure range } \\
\text { (Torr) }\end{array}$ & $\begin{array}{c}\text { Number of P,T } \\
\text { sets }\end{array}$ & $\begin{array}{c}\text { Spectral range } \\
\left(\mathbf{c m}^{-1}\right)\end{array}$ \\
\hline $\begin{array}{l}\text { Ethane (update) } \\
\mathrm{C}_{2} \mathrm{H}_{6}\end{array}$ & $194-297$ & $49-763$ & 14 & $2545-3315$ \\
\hline $\begin{array}{l}\text { Propane (update) } \\
\mathrm{CH}_{3} \mathrm{CH}_{2} \mathrm{CH}_{3} \\
\left(\mathrm{C}_{3} \mathrm{H}_{8}\right)\end{array}$ & $195-296$ & $40-763$ & 12 & $2540-3300$ \\
\hline $\begin{array}{l}\text { Acetone (update) } \\
\left(\mathrm{CH}_{3}\right)_{2} \mathrm{CO}\end{array}$ & $194-298$ & $50-700$ & 19 & $830-1950$ \\
\cline { 2 - 5 } $\begin{array}{l}\text { Acetonitrile } \\
(\text { update) } \\
\mathrm{CH}_{3} \mathrm{CN}\end{array}$ & $195-296$ & $49-759$ & 12 & $2615-3300$ \\
\hline $\begin{array}{l}\text { Methanol } \\
\mathrm{CH}_{3} \mathrm{OH} \text { (new) }\end{array}$ & $203-297$ & $50-760$ & 12 & $880-1700$ \\
\cline { 2 - 5 } $\begin{array}{l}\text { Trifluoromethane } \\
\mathrm{CHF}_{3} \text { (New) }\end{array}$ & $208-296$ & $50-760$ & 11 & $2550-3300$ \\
\hline $\begin{array}{l}\text { Acetaldehyde } \\
\mathrm{CH}_{3} \mathrm{CHO} \text { (new) }\end{array}$ & $204-295$ & $50-761$ & 12 & $877-1167$ \\
\hline
\end{tabular}

\subsection{Complementary data for species already implemented in GEISA-2011}

\subsubsection{Ethane $\left(\mathrm{C}_{2} \mathrm{H}_{6}\right)$}

ETHANE IS THE MOST ABUNDANT NON-METHANE HYDROCARBON IN THE ATMOSPHERE. THE SPECTROSCOPIC PARAMETERS INFORMATION IN THE $3 \mu \mathrm{M}$ REGION $\left(v_{7}\right.$ band) IS INCOMPLETE, I.E. THERE ARE MANY MISSING P AND R BRANCH LINES. The $v_{7}$ band is particularly desirable for remote-sensing of ethane because it occurs in a reasonably uncongested 
spectral region and is associated with a C-H STRETCH VIBRATIONAL MODE. INFRARED ABSORPTION CROSS SECTIONS FOR ETHANE over the spectral range 2545-3315 $\mathrm{cm}^{-1}$ [323] HAVE been included in GEISA-2015. These cross sections provide a higher degree of accuracy for tropospheric sounding than can currently be obtained using the line list. Spectra of ethane / dry synthetic air mixtures inside a $26-\mathrm{cm}$ cell were recorded at fourteen pressure-temperature combinations using a high-resolution FTIR spectrometer (Bruker IFS $125 \mathrm{HR}$ ) at $0.015 \mathrm{~cm}^{-1}$ resolution (using the Bruker definition of 0.9/MOPD).

Additionally, these cross sections have been used to create a set of 'pseudo-lines', effective spectral lines that empirically reproduce the pressure and temperature-dependencies of spectral absorption without any recourse to quantum-mechanical assignments. As the derived absorption varies smoothly with temperature and pressure, this pseudo lines list provide a convenient way of interpolating (and extrapolating) cross sections. The pseudo-line list may be obtained from http://mark4sun.jpl.nasa.gov/pseudo.html.

\subsubsection{Propane $\left(\mathrm{CH}_{3} \mathrm{CH}_{2} \mathrm{CH}_{3}\left(\mathrm{C}_{3} \mathrm{H}_{8}\right)\right)$}

Propane is the second most abundant non-methane hydrocarbon in the atmosphere, however no global measurements using IR remote-sensing techniques have yet been undertaken. Absorption cross sections over the spectral range $2540-3300 \mathrm{~cm}^{-1}$ [324] have been included in GEISA-2015 for the first time. They cover the spectral region where propane has its strongest-intensity absorbance features (C-H stretch). Spectra of propane / dry synthetic air mixtures inside a 26-cm cell were recorded at twelve pressure-temperature combinations using a high-resolution FTIR spectrometer (Bruker IFS $125 \mathrm{HR})$ at $0.015 \mathrm{~cm}^{-1}$ resolution (=0.9/MOPD).

\subsubsection{Acetone $\left((\mathrm{CH3})_{2} \mathrm{O}\right)$}

ACETONE IS THE SIMPLEST MEMBER OF THE KETONE FAMILY, AND ONE OF THE MOST ABUNDANT VOCS IN THE FREE TROPOSPHERE; THE MAJORITY OF ITS EMISSIONS ARISE FROM OXIDATION OF ORGANIC PRECURSORS. INFRARED ABSORPTION CROSS SECTIONS FOR ACETONE WERE FIRST INTRODUCED IN GEISA-2009. TWO NEW DATASETS HAVE BEEN ADDED IN GEISA-2015; THESE COVER THE SPECTRAL RANGES 830-1950 CM${ }^{-1}$ [325] AND 2615-3300 $\mathrm{CM}^{-1}$ [326]; THE NEW MID-IR CROSS SECTIONS HAVE BEEN COMBINED WITH A RENORMALIZED SUBSET OF THOSE IN GEISA-2011 [11] TO CREATE A MORE OPTIMISED DATASET FOR THIS SPECTRAL REGION. For the new measurements, spectra of 
acetone / dry synthetic air AT A NUMBER OF PRESSURE-TEMPERATURE COMBINATIONS were recorded by a high spectral resolution FTIR spectrometer (Bruker IFS $125 \mathrm{HR}$ ) at $0.015 \mathrm{~cm}^{-1}$ RESOLUTION (=0.9/MOPD) USING A COOLEABLE WHITE CELL WITH A MAXIMUM PATH LENGTH OF $19.32 \mathrm{M}$.

\subsubsection{Acetonitrile $\left(\mathrm{CH}_{3} \mathrm{CN}\right)$}

ACETONITRILE IS A MINOR CONSTITUENT OF THE EARTH'S ATMOSPHERE, WITH THE MAJORITY OF EMISSIONS ARISING FROM BIOMASS BURNING. IN ADDITION TO LINE PARAMETERS FOR THE $\mathrm{V}_{4}$ BAND, GEISA-2011 CONTAINED THREE ACETONITRILE CROSS SECTIONS AT 276, 298 AND $323 \mathrm{~K}$ AND 760 TORR NITROGEN. DUE TO THEIR POOR COVERAGE OF ATMOSPHERIC TEMPERATURES AND PRESSURES, THESE WERE OF LIMITED USE FOR ATMOSPHERIC REMOTE SENSING. GEISA-2015 CONTAINS NEW INFRARED ABSORPTION CROSS SECTIONS, COVERING THE SPECTRAL RANGES 880-1700 $\mathrm{CM}^{-1}$ [306] AND 2550-3300 $\mathrm{CM}^{-1}$ [327]. Spectra of acetonitrile / dry synthetic air AT A NUMBER OF PRESSURETEMPERATURE COMBINATIONS were recorded by a high-resolution FTIR spectrometer (Bruker IFS $125 \mathrm{HR}$ ) at $0.015 \mathrm{~cm}^{-1}$ RESOLUTION (=0.9/MOPD) USING A COOLEABLE WHITE CELL WITH A MAXIMUM PATH LENGTH OF 19.32 M. THE CROSS SECTIONS IN THE MWIR REGION, IN PARTICULAR THE ${ }^{\mathrm{R}} \mathrm{Q}_{0}$ BRANCH OF THE $v_{6}$ BAND AT 1462.96-1463.60 $\mathrm{CM}^{-1}$, HAVE RECENTLY BEEN USED AS THE BASIS FOR AN ACE-FTS ACETONITRILE RESEARCH PRODUCT [328].

\subsection{Molecular species added to the GEISA-2011 edition}

\subsubsection{Methanol $\left(\mathrm{CH}_{3} \mathrm{OH}\right)$}

METHANOL IS THE SECOND MOST ABUNDANT ORGANIC MOLECULE IN THE EARTH'S ATMOSPHERE AFTER METHANE; THE MAJORITY OF ITS EMISSIONS ARISE FROM PLANT GROWTH AND DECAY. TWO NEW INFRARED ABSORPTION CROSS SECTION DATASETS HAVE BEEN ADDED TO THE DATABASE, COVERING THE SPECTRAL RANGES 877$1167 \mathrm{CM}^{-1}$ AND 2600-3250 $\mathrm{CM}^{-1}$ [329]. Spectra of methanol/dry synthetic air AT A NUMBER OF PRESSURE-TEMPERATURE COMBINATIONS were recorded by a high-resolution FTIR spectrometer (Bruker IFS $125 \mathrm{HR}$ ) at $0.015 \mathrm{~cm}^{-1}$ RESOLUTION (=0.9/MOPD) USING A COOLEABle White CELl With A MAXIMUM PATH LENGTH OF 19.32 M. MeThanOl DATA 
NEAR 3.4 $\mu \mathrm{M}$ ARE INCLUDED IN GEISA-2015 FOR THE FIRST TIME. LINE PARAMETERS NEAR $10 \mu \mathrm{M}$ ARE ALREADY INCLUDED IN GEISA; THIS BAND SYSTEM IS PRINCIPALLY ASSOCIATED WITH THE STRONG FUNDAMENTAL $v_{8}$ MODE AT $1033 \mathrm{CM}^{-1}$ (CO STRETCH). THE NEW CROSS SECTIONS NEAR $10 \mu \mathrm{M}$ PROVIDE A HIGHER LEVEL OF ACCURACY AT LOWER TEMPERATURES AND REVEAL A NUMBER OF PROBLEMS WITH THE LINE LIST, INCLUDING A SUBSTANTIAL TEMPERATURE DEPENDENCE OF THE INTEGRATED BAND INTENSITY WHICH IS NOT OBSERVED IN THE CROSS SECTIONS. AS FOR ETHANE (SECTION 3.3.1), THESE CROSS SECTIONS HAVE BEEN USED TO CREATE A SET OF 'PSEUDO-LINES' COVERING THE 877-1167 $\mathrm{CM}^{-1}$ AND 2600-3250 $\mathrm{CM}^{-1}$ SPECTRAL REGIONS. THE PSEUDO-LINE LIST MAY BE FOUND AT HTTP://MARK4SUN.JPL.NASA.GOV/PSEUDO.HTML.

\subsubsection{Trifluoromethane $\left(\mathrm{CHF}_{3}, \mathrm{HFC}-23\right)$}

THE PRIMARY EMISSIONS OF TRIFLUOROMETHANE ARISE AS A BYPRODUCT (FROM THE OVER-FLUORINATION OF CHLOROFORM) DURING THE PRODUCTION OF CHLORODIFLUOROMETHANE (HCFC-22; $\mathrm{CHCLF}_{2}$ ). TRIFLUOROMETHANE IS A VERY POWERFUL GREENHOUSE GAS WITH A 100-YR GWP OF 14,200, A LONG atmospheric lifetime of 222 years, and an increasing atmospheric abundance. Recently the first remote-sensing measurements of this molecule were taken by the balloon-borne MkIV interferometer [330] and the ACE-FTS [331], using less than ideal spectroscopy. New infrared absorption cross sections for trifluoromethane over the spectral range $950-1500 \mathrm{~cm}^{-1}$ [332] have recently been made available; these are included in GEISA for the first time. Spectra of trifluoromethane / dry synthetic air mixtures inside a $26-\mathrm{cm}$ cell were recorded at twenty-seven pressure-temperature combinations using a high-resolution FTIR spectrometer (Bruker IFS $125 \mathrm{HR}$ ) at $0.015 \mathrm{~cm}^{-1}$ resolution $(=0.9 / \mathrm{MOPD})$.

\subsubsection{Acetaldehyde $\left(\mathrm{CH}_{3} \mathrm{CHO}\right)$}

Acetaldehyde, a trace molecular species, found in the Earth's atmosphere, plays an important role as a source of ozone $\left(\mathrm{O}_{3}\right), \mathrm{PAN}$ and $\mathrm{HOx}$ radicals.

Infrared absorption cross-sections have been measured by Tereszchuk et al. [333] in the $3 \mu \mathrm{m}$ region (2400-3400 $\mathrm{cm}^{-1}$ ) from spectra obtained using a FTIR spectrometer at a resolution of 0.005 $\mathrm{cm}^{-1}$. See Ref. [333] for details. 


\subsubsection{Summary for the infrared cross-sections update}

Finally, 43 new molecular species have been added to GEISA-2015 infrared absorption cross-sections. On the basis of the description above, the evolution of the GEISA infrared absorption cross-sections since the 2011 edition is illustrated in Figs. 17 a), 17 b), and 17 c).

Fig. 17a) summarizes the evolution of the GEISA IR cross-sections sub-database, giving the percentages of new (43\%) and updated data (3\%) since GEISA-2011 (on the basis of the number of molecules), the remaining datasets represent $54 \%$ of the whole contents.

Fig.17b) illustrates the relative contribution from the University of Oslo and Castilla-La Mancha $[\mathbf{3 0 4}, 305]$, and from the University of York [306,307], in terms of percentage (on the basis of the number of molecules) of the total, new or updated, data provided for GEISA-2015 edition update. Note that there are more cross sections provided by York, in terms of number of P,T sets;

Fig. 17c) gives graphical display (in \%) of the relative contributions of the compounds from University of Oslo and Castilla-La Mancha [305] listed in Table 10. 


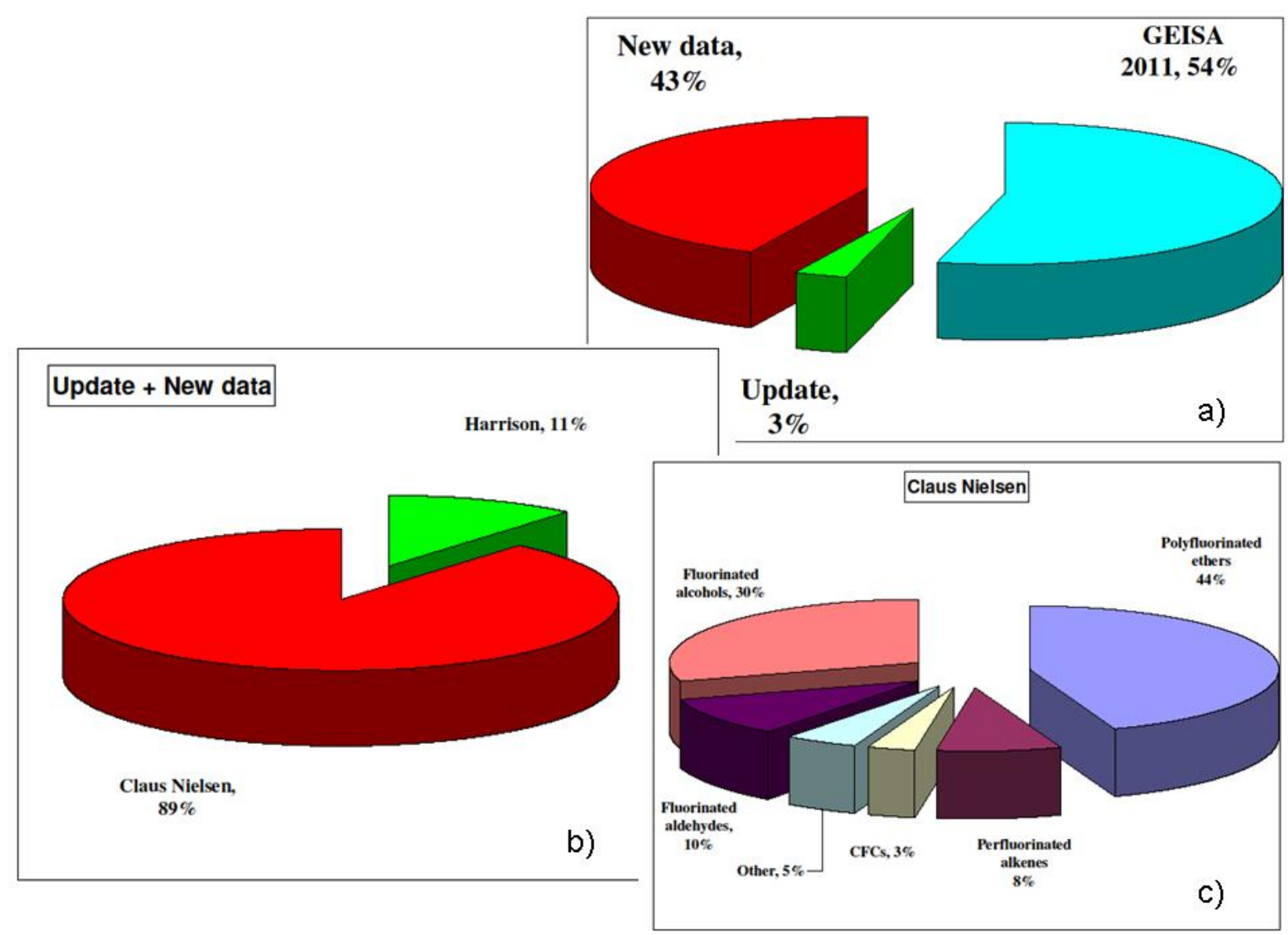

Figs. 17 a) b) c). Illustration of the evolution of the GEISA infrared absorption cross-sections archive since the GEISA-2011 edition. 


\subsubsection{GEISA-2015 new absorption cross-sections sub-database in the NIR region}

The 1-3 $\mu \mathrm{m}$ near-infrared spectral region is of great interest for atmospheric remotesensing and planetary science. Many experimental techniques have become available that are capable of measuring extremely weak absorptions or small photon numbers with great accuracy. This has led, on one hand, to an increasing demand for reference data in this spectral region when standard line parameters (such as line centers, intensities, lower state energies, etc.), based on line-by-line analysis and theoretical calculation of the spectra, are not (yet) available. On the other hand, an increasing amount of accurate experimental data is now available that may be used as a reference in the absence of theoretical calculations e.g. for modelling or calibration purposes. This situation is very similar to the ultraviolet-visible spectral region where most reference data are molecular absorption cross-sections based on laboratory measurements.

The sections below present and document a first set of seven high-resolution absorption crosssections as reference data in the near-infrared region, for molecules and bands where no theoretical prediction is available. This set of new data has been implemented in GEISA-2015 as a new section of the absorption cross-sections sub-database for GEISA in the NIR region an overview of which is given in Table 12.

The common names of the molecules and their formula are listed in the two first columns. The spectral regions covered $\left(\mathrm{cm}^{-1}\right)$, the spectral resolution $\left(\mathrm{cm}^{-1}\right)$, the maximal uncertainties of the spectral position $\left(\mathrm{cm}^{-1}\right)$ and absorption cross-sections (\%), are given in columns two to five, and references in the final column. Experimental conditions are detailed, below, in subsections 3.4.5.1 to 3.4.5.7. 


\section{Table 12}

Summary of the molecules whose experimental absorption cross-sections in the NIR are newly provided in the GEISA-2015 database.

\begin{tabular}{|c|c|c|c|c|c|c|}
\hline \multirow{2}{*}{\multicolumn{2}{|c|}{ Molecule }} & \multirow{3}{*}{$\begin{array}{c}\text { NIR range } \\
\left(\mathrm{cm}^{-1}\right)\end{array}$} & \multirow{3}{*}{$\begin{array}{c}\begin{array}{c}\text { Spectral } \\
\text { resolution } \\
\left(\mathrm{cm}^{-1}\right)\end{array} \\
0.001\end{array}$} & \multicolumn{2}{|c|}{ Uncertainty } & \multirow{3}{*}{$\begin{array}{r}\text { Refs. } \\
\text { [334] }\end{array}$} \\
\hline & & & & \multirow{2}{*}{$\begin{array}{c}\begin{array}{c}\text { position } \\
\left(\mathrm{cm}^{-1}\right)\end{array} \\
0.01\end{array}$} & \multirow{2}{*}{$\begin{array}{c}\text { cross-section } \\
(\%) \\
15\end{array}$} & \\
\hline Acetonitrile & $\mathrm{CH}_{3} \mathrm{CN}$ & & & & & \\
\hline Methyl iodide & $\mathrm{CH}_{3} \mathrm{I}$ & $7473-7497$ & 0.001 & 0.01 & 10 & [335] \\
\hline Methyldioxidany & $\mathrm{CH}_{3} \mathrm{O}_{2}$ & $7474-7497$ & 0.025 & 0.01 & 30 & [335] \\
\hline Formaldehyde & $\mathrm{H}_{2} \mathrm{CO}$ & $6547-7051$ & 0.001 & 0.005 & 20 & [338] \\
\hline $\begin{array}{l}\text { Hydroperoxy } \\
\text { radical }\end{array}$ & $\mathrm{HO}_{2}$ & $6604-6696$ & 0.003 & 0.01 & 15 & $\begin{array}{l}{[339]} \\
{[340]}\end{array}$ \\
\hline Nitrous acid & HONO & $6624-6645$ & 0.005 & 0.01 & 40 & [343] \\
\hline Ammonia & $\mathrm{NH}_{3}$ & $6880-6997$ & 0.001 & 0.005 & 20 & [344] \\
\hline
\end{tabular}

\subsubsection{Acetonitrile $\left(\mathrm{CH}_{3} \mathrm{CN}\right)$}

Absorption cross-sections of Acetonitrile between 6814 and $7067 \mathrm{~cm}^{-1}$ were measured, by O'Leary et al. [334], with off-axis CW-CEAS at 5 mbar with a resolution of about 0.001 $\mathrm{cm}^{-1}$. There are about 4630 absorption lines in this spectrum. Absorption features of $\mathrm{H}_{2} \mathrm{O}$ in this region have been removed from the spectrum. Approximately 200 individual overlapping spectral segments have been concatenated to cover the entire spectral range. The uncertainty inthe absolute line positions was estimated to be between $0.005 \mathrm{~cm}^{-1}$ and $0.01 \mathrm{~cm}^{-1}$. The uncertainty inthe absolute absorption cross-sections is $\sim 15 \%$. For one isolated line at $7034.171 \mathrm{~cm}^{-1}$ a value for the self-broadening coefficient was determined to be $(3.3 \pm 0.2) \times 10^{-}$ ${ }^{3} \mathrm{~cm}^{-1} \mathrm{mbar}^{-1}$ in [334].

\subsubsection{Methyl iodide, also called iodomethane $\left(\mathrm{CH}_{3} \mathrm{I}\right)$}

Measurements, by Farag $\notin$ et al. [335], of methyl iodide were made using CW-CRDS in the wavenumber range $7473-7497 \mathrm{~cm}^{-1}$ at a total pressure of 50 Torr and a resolution of $0.001 \mathrm{~cm}^{-1}$. $\mathrm{CH}_{3} \mathrm{I}$ was prepared as a diluted mixture in helium, and its concentration was determined from calibrated flowmeters. The spectrum was measured in several small portions in order to minimize a shift in the baseline between measurement of the spectrum with and without $\mathrm{CH}_{3} \mathrm{I}$. There are small gaps in the spectrum at wavelength ranges corresponding to absorption lines of water where data have been erased because water was present in the cell. Three sharp, characteristic peaks were found in this wavenumber range at 7473.92, 7481.13 
and $7484.42 \mathrm{~cm}^{-1}$ with absorption cross-sections of $7.41,17.3$ and $19.0 \times 10^{-22} \mathrm{~cm}^{2}$, respectively. The error in these peak absorption cross-sections is estimated to be $10 \%$, mostly due to uncertainties in the concentration of $\mathrm{CH}_{3} \mathrm{I}$. The error in other regions of the spectrum is probably higher, small baseline shifts will lead to larger errors due to weak, overall absorption.

\subsubsection{Methyldioxidanyl $\left(\mathrm{CH}_{3} \mathrm{O}_{2}\right)$}

Measurements, by Farag $\varnothing$ et al. [335], of methyldioxidanyl were made using CWCRDS coupled to laser photolysis. The wavenumber range $7474-7493 \mathrm{~cm}^{-1}$ was scanned at a resolution of $0.025 \mathrm{~cm}^{-1}$. $\mathrm{CH}_{3} \mathrm{O}_{2}$ was generated by pulsed photolysis of $\mathrm{CH}_{3} \mathrm{I}$ in the presence of $\mathrm{O}_{2}$. Absolute $\mathrm{CH}_{3} \mathrm{O}_{2}$ concentrations have been deduced by measuring the time-resolved absorbance following the photolysis pulse and adjusting the decay rate to the well-known rate constant of the self-reaction of $\mathrm{CH}_{3} \mathrm{O}_{2}$ radicals [335]. Calibration of $\mathrm{CH}_{3} \mathrm{O}_{2}$ concentration was obtained by measuring the time-resolved evolution of the $\mathrm{CH}_{3} \mathrm{O}_{2}$ concentration and fitting the kinetic decay traces of $\mathrm{CH}_{3} \mathrm{O}_{2}$ to a bimolecular reaction. Using the well-known rate constant of the self-reaction allows retrieval of the initial $\mathrm{CH}_{3} \mathrm{O}_{2}$ concentrations. A generally broad absorption spectrum was obtained containing three striking absorption features located at $7748.18,7489.16$ and $7493.33 \mathrm{~cm}^{-1}$. For these three characteristic lines absolute absorption cross-sections of $3.41 \times 10^{-20}, 3.40 \times 10^{-20}$ and $2.11 \times 10^{-20} \mathrm{~cm}^{2}$ were established, respectively. The remainder of the broad spectrum was scaled according to these cross-sections. Within the error limit of the measurement the cross-sections were not affected by changes of the pressure between 50 and 100 Torr. The error is estimated to be $30 \%$, mostly due to uncertainty in the rate constant for the self-reaction.

\subsubsection{Formaldehyde $\left(\mathrm{H}_{2} \mathrm{CO}\right)$}

Absorption cross-sections for formaldehyde were measured, by Staak et al. [336], with CW-CEAS at 2 mbar in the range $6547-7051 \mathrm{~cm}^{-1}$ with a resolution of about $0.001 \mathrm{~cm}^{-1}$. The absorption cross-sections were evaluated by comparison with the known measured lineintensities of $\mathrm{CO}_{2}$ and $\mathrm{H}_{2} \mathrm{O} . \mathrm{H}_{2} \mathrm{CO}$ was prepared by pyrolysis of paraformaldehyde under vacuum. The gaseous $\mathrm{H}_{2} \mathrm{CO}$ was first passed through a cooling trap below $200 \mathrm{~K}$ to remove water vapor and polymerization products of $\mathrm{H}_{2} \mathrm{CO}$. The monomeric $\mathrm{H}_{2} \mathrm{CO}$ was trapped and stored at $77 \mathrm{~K}$ under vacuum. The sample cavity was evacuated to approximately $10^{-6} \mathrm{mbar}$, ensuring that it was virtually free of gaseous water. $\mathrm{H}_{2} \mathrm{CO}$ gas was introduced into the cavity 
by slowly heating the solid $\mathrm{H}_{2} \mathrm{CO}$ from the cooling trap; the temperature of the system was $291 \pm 2$ K. Later, the absorption cross sections of 2 selected lines were measured by Morajkar et al. [337]. For determining the $\mathrm{H}_{2} \mathrm{CO}$ concentration present in the absorption cell, $\mathrm{OH}$ radicals were generated by laser photolysis in presence of excess $\mathrm{H}_{2} \mathrm{CO}$. The well-known rate constant of the $\mathrm{OH}+\mathrm{CH}_{2} \mathrm{O}$ reaction was then be used to determine the $\mathrm{H}_{2} \mathrm{CO}$ concentration from the pseudo-first-order decay of $\mathrm{OH}$ radicals. It was found that the absorption crosssections from Staak et al. [336] were systematically a factor of 2 too large. Several other experiments using NIR absorption to quantify $\mathrm{H}_{2} \mathrm{CO}$ seemed to confirm the result of Morajkar et al. [337]; a summary is given in Ruth et al. [338] together with new absorption data on $\mathrm{H}_{2} \mathrm{CO}$ between 6804 and $7051 \mathrm{~cm}^{-1}$. GEISA-2015 contains the data from Ruth et al. [338] and those of Staak et al. [336] corrected by a factor of 2 in the spectral range $6547-7051 \mathrm{~cm}^{-1}$; see Table 12.

\subsubsection{Hydroperoxy radical $\left(\mathrm{HO}_{2}\right)$}

Measurements of the $\mathrm{HO}_{2}$ radical were made by Thiebaud et al. [339] and Ibrahim et al. [340] at a total pressure of 50 Torr. $\mathrm{HO}_{2}$ radicals were generated by reaction of $\mathrm{Cl}$-atoms with $\mathrm{CH}_{3} \mathrm{OH}$ in the presence of $\mathrm{O}_{2}$. Cl-atoms were generated either by photolysis of $\mathrm{SOCl}_{2}$ at $248 \mathrm{~nm}$ or by photolysis of $\mathrm{Cl}_{2}$ at $351 \mathrm{~nm}$. The spectrum was measured in the 6604-6696 $\mathrm{cm}^{-1}$ wavenumber range with a resolution of better than $0.003 \mathrm{~cm}^{-1}$. A few selected lines werecalibrated by determining the absolute, initial $\mathrm{HO}_{2}$ concentration in the same way as $\mathrm{CH}_{3} \mathrm{O}_{2}$ : time resolved $\mathrm{HO}_{2}$ absorption decays were measured following their pulsed photolysis. As the decay is governed by a bimolecular reaction, the initial $\mathrm{HO}_{2}$ radical concentration can be deduced from the shape of the decay. The most important absorption feature in this wavelength range was found at $6638.20 \mathrm{~cm}^{-1}$, exhibiting an absorption crosssection of $\mathrm{s}=2.72 \times 10^{-19} \mathrm{~cm}^{2}$ in the buffer gas of helium at 50 Torr. The pressure dependence of a few lines were obtained in [339-341], more details on the pressure broadening in $\mathrm{HO}_{2}$ can be found in [342].

\subsubsection{Nitrous Acid (HONO)}

Measurements of nitrous acid were made, by Jain et al. [343], in the range 6623.6$6645.6 \mathrm{~cm}^{-1}$ with a resolution of $0.005 \mathrm{~cm}^{-1}$, using CW-CRDS coupled to laser photolysis. HONO was generated in situ by photolysis of $\mathrm{H}_{2} \mathrm{O}_{2}$ in the presence of NO. Calibration of the HONO concentration (and hence the cross-sections) was achieved through modelling the 
kinetics of the time resolved concentrations of the $\mathrm{OH}$ and $\mathrm{HO}_{2}$ radicals, which are generated in the $\mathrm{H}_{2} \mathrm{O}_{2}$ photolysis. A very dense $\mathrm{HONO}$ spectrum was observed with the strongest line in this wavenumber range at $6642.51 \mathrm{~cm}^{-1}$ with $\sigma=(5.8 \pm 2.2) \times 10^{-21} \mathrm{~cm}^{2}$, the error being mostly due to uncertainties in the reaction mechanism used to model the $\mathrm{OH}$ and $\mathrm{HO}_{2}$ decays necessary to deduce the initial HONO concentration. The pressure broadening of the line at $6642.51 \mathrm{~cm}^{-1}$ was determined in the pressure range 10-74 Torr with $\mathrm{He}$ and $\mathrm{N}_{2}$ as bath gas.

\subsubsection{Ammonia $\left(\mathrm{NH}_{3}\right)$}

Absorption cross-sections as a function of wavelength for $\mathrm{NH}_{3}$ were measured, by O'Leary et al. [344], with off-axis CW-CEAS at $0.2 \mathrm{mbar}\left(6880-6997 \mathrm{~cm}^{-1}\right)$ and at $11.5 \mathrm{mbar}$ $\left(6850-6997 \mathrm{~cm}^{-1}\right)$. A total of $1117 \mathrm{NH}_{3}$ lines are contained in the spectrum. The $2 \sigma \mathrm{rms}$ value of the absolute wavenumber calibration was approximately $0.001 \mathrm{~cm}^{-1}$. Absorption features due to $\mathrm{H}_{2} \mathrm{O}$ in this region were removed from the spectrum. The uncertainty in the absolute absorption cross-sections is less than $20 \%$.

There are two $\mathrm{NH}_{3}$ spectra recorded at different pressures. In the spectrum measured at 11.5 mbar cross-sections larger than $4 \times 10^{-22} \mathrm{~cm}^{2}$ molecule ${ }^{-1}$ are affected by saturation. All corresponding strong lines are unaffected by saturation in the spectrum measured at 0.2 mbar. The spectrum at higher pressure is provided to show weak $\mathrm{NH}_{3}$ lines with $\sigma$ less than $4 \times 10^{-22}$ $\mathrm{cm}^{2}$ molecule ${ }^{-1}$.

It should be noted that 262 lines of the $\mathrm{NH}_{3}$ line-by-line sub-database are present in this cross-sections spectral region (see above in $\S 2.2 .7$ ). Among these lines, only 49 have been assigned. We retain the unassigned lines, which are useful for many purposes, and we have implemented the cross-sections, in addition, to provide the total absorption in that region.

\section{5 sub-database on microphysical and optical properties of atmospheric aerosols}

With the importance of the aerosol contribution to the infrared RTM of the earth's atmosphere, a sub-database, containing microphysical and optical properties of atmospheric aerosols, here after GEISA/aerosols, was first added to GEISA in the 2003 edition [9].

GEISA/aerosols gathers the micro-physical and optical properties of atmospheric aerosols and complementary information on other public aerosols dedicated databases. See Ref. [11] for detailed information. No updates have occurred since the sub-database creation. 
For GEISA-2015, a significant update has been made thanks to the implementation of complementary data of two origins: from Massie [345,346] at $\underline{\text { NCAR and from the ARIA }}$ archive developed at Oxford University.

\subsection{The NCAR contribution to GEISA-2015/aerosols}

Refractive indices from Massie and Hervig [345,346] as described in Rothman et al. [14] are archived in GEISA-2015, corresponding to molecular species already implemented, or to new ones for GEISA-2015. The real and imaginary refractive indices of over three dozen liquid and solid aerosols present in the Earth's atmosphere are specified from the ultraviolet through the infrared (and the microwave for water and ice).

The indices date from and correspond chronologically to a variety of scientific themes investigated during the last 100 years. Water and ice indices have a long historical interest due to the ubiquitous presence of clouds in the Earth's atmosphere.

Measurements of liquid binary $\mathrm{H}_{2} \mathrm{SO}_{4} / \mathrm{H}_{2} \mathrm{O}$, ternary $\mathrm{H}_{2} \mathrm{SO}_{4} / \mathrm{H}_{2} \mathrm{O} / \mathrm{HNO}_{3}$, and solid nitric acid trihydrate (NAT) indices, at a variety of concentrations, dates to ongoing interest in studies of the interaction between the PSC's and ozone hole heterogeneous chemistry. Today, more recent additions to the GEISA-2015 database are traced to interest in tropospheric vegetative fires, brown carbon aerosols, organic haze particles, particles associated with desert dusts of varying iron content, and surface minerals of different compositions.

As satellite and other remote sensing measurements become more demanding in terms of the accuracy of gas species retrievals, knowledge of the optical properties of aerosols (e.g. aerosol extinction and absorption coefficients, single scattering albedo, asymmetry parameter) also becomes increasingly important since total optical depths are dependent upon both gases and aerosols in a planetary atmosphere. Since these properties are dependent upon composition (i.e. the refractive indices), the sensed wavelength(s), and the particle size and spatial distributions, Mie [347] and other codes (for non-spherical particles) are used to calculate the aerosol optical properties. The codes of Hess et al. [348] and Massie and Hervig [346] are convenient to calculate these properties, and can be used to compare in graphical form the refractive indices of different materials (and different physical settings).

Figure 18 shows an illustration of the real and imaginary refractive index differences for the two new GEISA-2015 entries: flame soot [349] (pertaining to high temperatures) and brown carbon [350] (measured at ambient temperatures). 
Chang flame soot

Alexander brown carbon
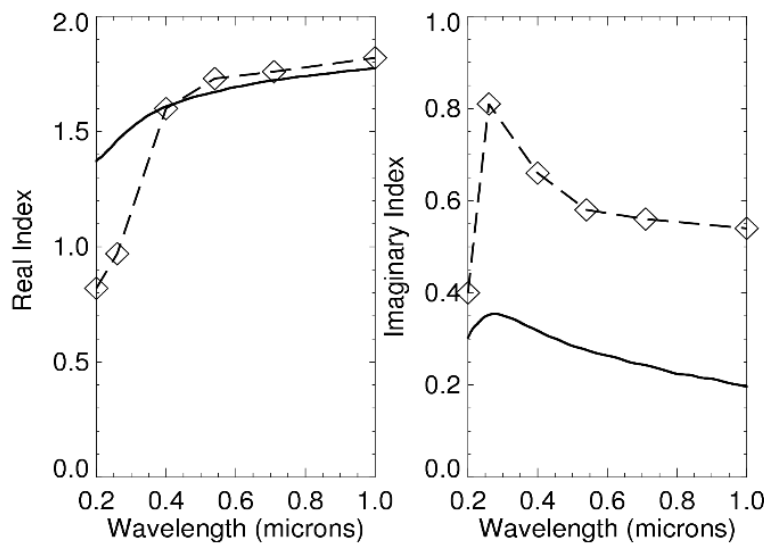

Fig. 18. Illustration of flame soot [349] and brown carbon [350] refractive index differences. The Yaxis gives the real index (left)) and the imaginary index (right).

Table 13 gives the list of refractive indices [349-376], representing a contribution from NCAR of more than 40 aerosol molecular species. They are distributed in "material classes" according to the GEISA classification. 


\section{Table 13}

Refractive indices from NCAR included in GEISA-2015. Data already existing in GEISA are indicated by an ' $A$ ' in the last column. New data are marked by an '*'.

\begin{tabular}{lll}
\hline Material Class/Material & Measurement Details & Reference
\end{tabular}

$\underline{\text { Acids }}$

Sulfuric acid $\left(\mathrm{H}_{2} \mathrm{SO}_{4} / \mathrm{H}_{2} \mathrm{O}\right)$

$215 \mathrm{~K}, 499-6996 \mathrm{~cm}^{-1}$

200-300 K, 825-4700 $\mathrm{cm}^{-1}$

Sulfuric acid $\left(\mathrm{H}_{2} \mathrm{SO}_{4} / \mathrm{H}_{2} \mathrm{O}\right)$

Room temp, $0.2-40 \mu \mathrm{m}$

[351]A

Sulfuric acid $\left(\mathrm{H}_{2} \mathrm{SO}_{4} / \mathrm{H}_{2} \mathrm{O}\right)$

Room temp, 25-96\% $\mathrm{H}_{2} \mathrm{SO}_{4}$

[355]A

Sulfuric acid $\left(\mathrm{H}_{2} \mathrm{SO}_{4} / \mathrm{H}_{2} \mathrm{O}\right)$

Room temp, 75 and $90 \% \mathrm{H}_{2} \mathrm{SO}_{4}$

[356]A

Sulfuric acid $\left(\mathrm{H}_{2} \mathrm{SO}_{4} / \mathrm{H}_{2} \mathrm{O}\right)$

213-293 K, 432-5028 cm $\mathrm{cm}^{-1}$

Nitric acid $\left(\mathrm{H}_{2} \mathrm{SO}_{4} / \mathrm{HNO}_{3}\right)$

Room temp, $250-2987 \mathrm{~cm}^{-1}$

[359]A

Nitric acid $\left(\mathrm{H}_{2} \mathrm{SO}_{4} / \mathrm{HNO}_{3}\right)$

$220 \mathrm{~K}, 754-4700 \mathrm{~cm}^{-1}$

[360]

Nitric acid $\left(\mathrm{H}_{2} \mathrm{SO}_{4} / \mathrm{HNO}_{3}\right)$

Amorphous nitric acid

NAM (nitric acid monohydrate)

213-293 K, 432-5028 cm

$153 \mathrm{~K}, 482-7000 \mathrm{~cm}^{-1}$

$179 \mathrm{~K}, 482-6002 \mathrm{~cm}^{-1}$

NAD (nitric acid dihydrate)

$184 \mathrm{~K}, 482-6981 \mathrm{~cm}^{-1}$

NAD

$160-190 \mathrm{~K}, 700-4700 \mathrm{~cm}^{-1}$

[362]

[359]A

[362]

[362]

[362]

$181 \mathrm{~K}, 482-6989 \mathrm{~cm}^{-1}$

[363]

$\alpha$ NAT (nitric acid trihydrate)

$196 \mathrm{~K}, 482-6364 \mathrm{~cm}^{-1}$

[362]

$\beta N A T$

$160 \mathrm{~K}, 711-4004 \mathrm{~cm}^{-1}$

[362]

NAT

$0.25-1.1 \mu \mathrm{m}$

[364]

[368]*

Organic acids

pyruvic, phthalic

Organic haze

$0.525 \mathrm{~nm}$

[369]*

SOA (proxy)

$0.525 \mathrm{~nm}$

[370]*

Ash/Soot/Carbonaceous

Burning vegetation

$525-5000 \mathrm{~cm}^{-1}$

[365]

Burning vegetation

$0.35-1.5 \mu \mathrm{m}$

[366]*

Carbon flame

$0.4-0.7 \mu \mathrm{m}, 25-600^{\circ} \mathrm{C}$

[367]*

Flame soot

$0.2-38 \mu \mathrm{m}$

[349]*

Brown carbon

Carbonaceous aerosol

$0.2-1.2 \mu \mathrm{m}$

[350]*

Room temp, 0.2-40 $\mu \mathrm{m}$

[351]A

\section{Water/Ice}

Water

$27^{\circ} \mathrm{C}, 10-5000 \mathrm{~cm}^{-1}$

Water

$0.67-2.5 \mu \mathrm{m}$

[352]

Ice

$266 \mathrm{~K}, 0.04 \mu \mathrm{m}-2 \mathrm{~m}$

[353]

Ice

$0.67-2.5 \mu \mathrm{m}$

Water, ice

Room temp, 0.2-40 $\mu \mathrm{m}$ 
$\underline{\text { Solids/Salts }}$

Ammonium sulfate

Sodium chloride, sea salt

Minerals

clay, illite, kaolin, montmorillonite

Minerals

granite, montmorillonite

Saharan dust

Saharan dust

Saharan dust

Volcanic ash

Volcanic dust

Ammonium sulfate

Sodium chloride, sea salt

Meteoric dust

Quartz, hematite, sand
Room temp, 0.2-40 $\mu \mathrm{m}$

[351]A

Room temp, 0.2-40 $\mu \mathrm{m}$

$2.5-200 \mu \mathrm{m}$

[351]A

[371]*

$5-40 \mu \mathrm{m}$

[372]*

$0.30-0.95 \mu \mathrm{m}$

[373]*

$0.35-0.65 \mu \mathrm{m}$

$0.35-0.65 \mu \mathrm{m}$

[374]*

$0.45-25 \mu \mathrm{m}$

Room temp, $0.2-40 \mu \mathrm{m}$

Room temp, 0.2-40 $\mu \mathrm{m}$

Room temp, $0.2-40 \mu \mathrm{m}$

Room temp, $0.2-40 \mu \mathrm{m}$

[375]*

[376]*

[351]A

[351]A

[351]A

[351]A

Room temp, 0.2-40 $\mu \mathrm{m}$

[351]A 


\subsection{The Oxford University contribution to GEISA-2015/aerosols}

More than 20 molecular species (identified in red), including minerals, dusts, soots, water particles, etc...) from the ARIA archive developed at Oxford University

Table 14 summarizes the total contents of the GEISA-2015 aerosols sub-database; the Table reflects the material classes used by the GEISA-2011 and GEISA-2015 distribution web site

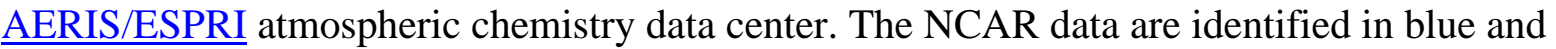
the ARIA archive ones in red. 


\section{Conclusion}

Its 2015 edition implements important updates and additions are in the three sub-databases of GEISA:

The line parameters sub-database contains 52 molecular species (113 isotopologues) with transitions in the spectral range from $10^{-6}$ to $35,877.031 \mathrm{~cm}^{-1} ; 5,059,777$ entries are listed compared to 3,794,297 in GEISA-2011. This corresponds to an increase of 33\%. $\mathrm{SO}_{3}$ appears for the first time in GEISA. HDO is now considered as an independent species: as explained above, this choice is becauseits symmetry properties differ from $\mathrm{H}_{2} \mathrm{O}$ and for a more flexibly taking it into account in forward radiative transfer modelling. Updates of 20 molecules, already included in GEISA-2011, involve species of significant importance in terrestrial or planetary atmospheres and for astrophysical research (i.e.: $\mathrm{C}_{2} \mathrm{H}_{6}, \mathrm{C}_{2} \mathrm{H}_{2}, \mathrm{C}_{4} \mathrm{H}_{2}, \mathrm{C}_{2} \mathrm{H}_{4}, \mathrm{H}_{2} \mathrm{~S}$, $\mathrm{HCN}, \mathrm{HNC} . .$.$) . With reference to the Earth's atmosphere, noticeable effort has been made to$ upgrade entries for $\mathrm{H}_{2} \mathrm{O}, \mathrm{HDO}, \mathrm{CH}_{4}$ and $\mathrm{CH}_{3} \mathrm{D}$ : the spectroscopic parameters of these molecules are updated and validated, leading to a significant increase in the number of entries.

The cross section sub-database is enriched by 43 new molecular species in its infrared part which is also updated for four previously considered molecules (ethane, propane, acetone, acetonitrile). $43 \%$ of the content is new and $3 \%$ of it is updated. A new section has been added, covering the near-infrared region, involving 7 molecular species, i.e.: $\mathrm{CH}_{3} \mathrm{CN}$, $\mathrm{CH}_{3} \mathrm{I}, \mathrm{CH}_{3} \mathrm{O}_{2}, \mathrm{H}_{2} \mathrm{CO}, \mathrm{HO}_{2}, \mathrm{HONO}, \mathrm{NH}_{3}$.

The sub-database on microphysical and optical properties of atmospheric aerosols is updated, for the first time since the 2003 edition of GEISA. It contains more than 40 species originating from NCAR and 20 species originating from the ARIA archive of Oxford University. A specific classification of the species has been adopted, corresponding to 8 sections associated with their nature, i.e.: Minerals, Organic acids, Acids, Water ice and sea salt, Dusts and sands, Ash, soots and burning aerosols, Carbonaceous, Other.

This new release of GEISA and associated management software facilities are presently being implemented and will be distributed via AERIS/ESPRI atmospheric chemistry data center website. As for the previous versions, all the spectroscopic data (spectroscopic parameters, cross-sections sub-databases) and related information can be handled through the user-friendly associated management software facilities. It is used on-line by more than 350 laboratories working in various sectors including atmospheric physics, planetary science, astronomy, astrophysics. 
Thanks to its involvement in various space missions, GEISA has been used for more than 40 years for forward and, hence, inverse radiative transfer modelling. It is regularly used in the processing of current hyperspectral sounders (AIRS/Aqua, IASI/Metop, etc.), GEISA is

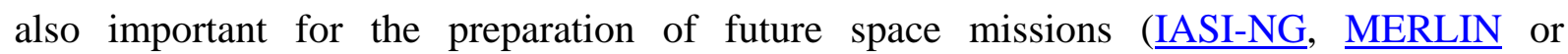

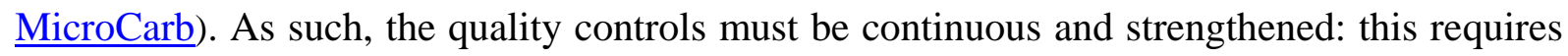
constant effort, as described in Armante et al. ([22], this issue). One of our main aims is to make available the results of these quality controls to help to improve the planning, acquisition and delivery processes of new, eventually more targeted, spectroscopic data.

Thanks to the possibility of giving faster feedback to the contributing laboratories on the accuracy of the data they provide, we now anticipate that a new release of GEISA will be produced annually. 


\section{Acknowledgements.}

This study is supported by CNES and CNRS/INSU with associated encouragements of EUMETSAT.

We thank the AERIS data infrastructure for providing access to the data used in this study.

Pr. R.R. Gamache is pleased to acknowledge support of this research by the National Science Foundation through Grant No. AGS-1156862.

Dr. Shanshan $\mathrm{Yu}$ would like to thank Dr. Iouli Gordon for helpful discussions on the comparison of the updated O2 Positions to those of HITRAN-2012. Part of the research described in this paper was performed at the Jet Propulsion Laboratory, California Institute of Technology, under contract with the National Aeronautics and Space Administration.

The work of Reims, Tomsk and Grenoble groups on ozone and a part of the methane studies were is jointly supported by CNRS (France) and RFBR (Russia) in the frame of the International Associated Laboratory SAMIA. The latter one was performed in the frame of the Labex OSUG@2020 (ANR10LABX56).

The $\mathrm{CH}_{4}$ work of Dr. A. Campargue is jointly supported by CNRS (France) and RFBR (Russia) in the frame of the International Associated Laboratory SAMIA. This work was performed in the frame of the Labex OSUG@2020 (ANR10 LABX56)

The near infrared measurements from Physics Department and Environmental Research Institute, University College Cork, were supported by Science Foundation Ireland (contract 14/TIDA/2415). The financial support, through the ACTRIS Research Infrastructure Project by the European Union's Horizon 2020 research and innovation program under grant agreement n. 654169 is also gratefully acknowledged.

Dr. U. Heitmann (DLR Berlin) and Dr. E. Heinecke, (FU Berlin) are acknowledged for their participation in the Near Infrared new data

E. Jiménez thanks the national and regional Spanish projects GASSOL (CGL2013-43227-R) and FOTOCINE (PEII-2014-043-P) for supporting her work

Dr. André Fayt thanks the supercomputing facilities of the Université Catholique de Louvain (CISM/UCL) for the provided computational resources, as well as the Consortium des Equipements de Calcul Intensif en Fédération Wallonie Bruxelles (CECI) funded by the Fond de la Recherche Scientifique de Belgique (FRS-FNRS), for his C2N2 and $\mathrm{C} 4 \mathrm{H} 2$ contributions.

The research carried out by Dr. A. Predoi-Cross at University of Lethbridge has been funded by the Natural Sciences and Engineering Research Council of Canada through the Discovery and CREATE grant programs.

Dr. N. Lavrentieva is pleased to acknowledge the support of the Russian Fund for Basic Research (grant 16-52-16016 NCNIL_a) in this research. 


\section{Appendix A. List of acronyms}

$4 \mathrm{~A}$

4A/OP

ACE

AERIS

AFGL

AIRS

ARIA

ARA/ABC(t)

BEAMCAT

CAL/VAL

CAS RN

CDMS

CDSD

CIRS

CNRS

CNES

CRB

CRDS

DAS

DMS

CW-CEAS

CW-CRDS

ENVISAT

ESPRI

EUMETSAT

FTIR

FTS

GEISA

GOSAT

GS

GSMA

GWP

HITRAN

HULIS

HWHM

ICLAS

IASI

IASI/NG

ICB

ID

INSU

IPSL

IAO

IR
Atlas Automatisé des Absorptions Atmosphériques;

Automatized Atmospheric Absorption Atlas

4A/OPerational release

Atmospheric Chemistry Experiment

Atmosphere and service data pole (CNES, CNRS), France

Air Force Geophysics Laboratory

Atmospheric Infrared Sounder

Aerosol Refractive Index Archive/University of Oxford (UK)

Atmospheric Radiation Analysis/Atmosphère-Biosphère-Climat

(télédétection)

BErnese Atmospheric Meta Catalog Access Tool

Calibration/Validation

Chemical Abstract Service Registry Number

Cologne Database for Molecular Spectroscopy

Carbon Dioxide Spectroscopic Databank

Composite InfraRed Spectrometer

Centre National de la Recherche Scientifique (France)

Centre National d'Etudes Spatiales (France)

Complex Robert-Bonamy

Cavity ring-down spectroscopy

Differential laser Absorption Spectroscopy

Dipole Moment Surface

Continuous Wave-Cavity Absorption Spectroscopy

Continuous Wave-Cavity Ring Down Spectroscopy

ENVIronmental SATellite

Ensemble de Services pour la Recherche à l'IPSL (Centre for Data and

Services belonging to IPSL), CNRS, France

European Organisation for the Exploitation of Meteorological

Satellites

Fourier Transformed InfraRed spectroscopy

Fourier Transform Spectrometer

Gestion et Etude des Informations Spectroscopiques Atmosphériques;

Management and study of Atmospheric Spectroscopic Information

Greenhouse Observing SATellite project

Ground State

Groupe de Spectroscopie Moléculaire et Atmosphérique (France)

Global Warming Potential

HIgh-resolution TRANsmission molecular absorption database

HUmic-LIke Substances

Half Width at Half Maximum

Intra Cavity Laser Absorption Spectroscopy

Infrared Atmospheric Sounder Interferometer

Infrared Atmospheric Sounder Interferometer/New Generation

Institut Carnot de Bourgogne

Identification code

Institut National des Sciences de l'Univers (France)

Institut Pierre Simon Laplace

Institute of Atmospheric Optics (Russia)

InfraRed 
ISSWG

IUPAC

IUPAC TG

JPL

KIT

LIPhy

LISA

LMD

Non-LTE

MARVEL

MCRB

MERLIN

MIPAS

Metop

MOPD

MWIR

NASA

NCAR

NIR

PAN

PSC

PES

RTM

SCIAMACHY

SRON

S\&MPO

UCC

UCL

UV

VAMDC

VECSEL

VOC

VTT

WKLMC

WN
IASI Sounding Science Working Group

International Union of Pure and Applied Chemistry

IUPAC Task Group

Jet Propulsion Laboratory (USA)

Institute for Meteorology and Climate Research Centre Karlsruhe, (Germany)

Laboratoire Interdisciplinaire de Physique (France)

Laboratoire Inter-Universitaire des Systèmes Atmosphériques

(France)

Laboratoire de Météorologie Dynamique (France)

non-Local Thermodynamic Equilibrium

Measured Active Rotational-Vibrational

Modified Complex Robert-Bonamy

Methane Remote Sensing Lidar Mission

Michelson Interferometer for Passive Atmospheric Sounding

Meteorological operational satellite

Maximum Optical Path Difference

Mid-wavelength infrared

National Aeronautics and Space Administration (USA)

National Center for Atmospheric research (USA)

Near-InfraRed

PeroxyAcetyl Nitrate

Polar Sratospheric Cloud

Potential Energy Surface

Radiative Transfer Modeling

SCanning Imaging Absorption spectroMeter for Atmospheric

ChartograpHY

Netherlands Institute for Space Research, The Netherlands

Spectroscopy \& molecular properties of Ozone

University College Cork, Ireland

University College, London (UK)

Ultra Violet

Virtual Atomic and Molecular Data Centre

Vertical External Cavity Surface Emitting Laser

Volatile organic compounds

Voronin, Tolchenov, Tennyson

Wang, Kassi, Leshchishina, Mondelain, Campargue

Wave Number $\left(\mathrm{cm}^{-1}\right)$ 


\section{Appendix B. Description of the format used for the line parameters stored in the 2015 edition of GEISA:}

The format of each entry is described in the following Table 15.

Each entry is a 252 character record to describe the 31 spectroscopic line parameters.

First line of Table 14: the 31 Spectroscopic line parameters are listed in the 31 columns and their description is given below.

Line 2 and line 3 display the field length and the FORTAN format descriptor, respectively.

Line 4 displays the standard_default values associated to each parameter.

Line 5 displays a cumulative index indicating the position of the last character of the record associated to each of the 31 spectroscopic line parameters.

The standard default values for fields «O'», « $\mathrm{T} »$ and « $\mathrm{T}$ ' », have been changed and set to "zero". This modification was made to avoid potential misunderstanding and thus improper use of these parameters in some applications especially related to forward radiative transfer.- Value in field "M" is documented in GEISA only if it is directly provided by the author of the spectroscopic line entry.

Table 15

Format of each entry in GEISA-2015

\begin{tabular}{|c|c|c|c|c|c|c|c|c|c|c|c|c|c|}
\hline Parameter & A & B & C & D & E1 & E2 & E3 & E4 & F & G & I & J \\
\hline Field length & $\mathbf{1 2}$ & $\mathbf{1 1}$ & $\mathbf{6}$ & $\mathbf{1 0}$ & $\mathbf{2 5}$ & $\mathbf{2 5}$ & $\mathbf{1 5}$ & $\mathbf{1 5}$ & $\mathbf{4}$ & $\mathbf{3}$ & $\mathbf{3}$ & $\mathbf{3}$ \\
\hline Fortran descriptor & F12.6 & $\mathbf{1 P D 1 1 . 4}$ & $\mathbf{0 P F 6 . 4}$ & $\mathbf{F 1 0 . 4}$ & $\mathbf{A 2 5}$ & $\mathbf{A 2 5}$ & $\mathbf{A 1 5}$ & $\mathbf{A 1 5}$ & $\mathbf{F 4 . 2}$ & $\mathbf{I 3}$ & $\mathbf{I 3}$ & $\mathbf{A 3}$ \\
\hline Undefined values & NR & $\mathbf{- 9 . 9 9 9 9 D - 0 1}$ & $-\mathbf{- 9 9 9 9}$ & $-\mathbf{0 . 9 9 9 9}$ & $*$ & $*$ & $*$ & $*$ & $\mathbf{- . 9 9}$ & $\mathbf{- 9 9}$ & $-\mathbf{- 9 9}$ & $*$ \\
\hline Record counting & $\mathbf{1 2}$ & $\mathbf{2 3}$ & $\mathbf{2 9}$ & $\mathbf{3 9}$ & $\mathbf{6 4}$ & $\mathbf{8 9}$ & $\mathbf{1 0 4}$ & $\mathbf{1 1 9}$ & $\mathbf{1 2 3}$ & $\mathbf{1 2 6}$ & $\mathbf{1 2 9}$ & $\mathbf{1 3 2}$ \\
\hline
\end{tabular}

\begin{tabular}{|c|c|c|c|c|c|c|c|c|c|}
\hline $\mathbf{K}$ & $\mathbf{L}$ & $\mathbf{M}$ & $\mathbf{N}$ & $\mathbf{O}$ & $\mathbf{R}$ & $\mathbf{A}^{\prime}$ & $\mathbf{B}^{\prime}$ & $\mathbf{C}^{\prime}$ & $F^{\prime}$ \\
\hline 2 & 1 & 10 & 7 & 9 & 6 & 10 & 11 & 6 & 4 \\
\hline I2 & I1 & 1PE10.3 & OPF7.4 & F9.6 & F6.4 & F10.6 & 1PD11.4 & 0PF6.4 & F4.2 \\
\hline-9 & $\mathbf{0}$ & $-9.999 \mathrm{E}-01$ & \begin{tabular}{|l|}
-9.9999 \\
\end{tabular} & 0.000000 & \begin{tabular}{|l|}
-.9999 \\
\end{tabular} & -0.999999 & -9.9999D-01 & -.9999 & -.99 \\
\hline 134 & 135 & 145 & 152 & 161 & 167 & 177 & 188 & 194 & 198 \\
\hline
\end{tabular}

\begin{tabular}{|c|c|c|c|c|c|c|c|c|}
\hline $\mathbf{O}^{\prime}$ & $\mathbf{R}^{\prime}$ & $\mathbf{N}^{\prime}$ & $\mathbf{S}$ & $\mathbf{S}^{\prime}$ & $\mathbf{T}$ & $\mathbf{T}^{\prime}$ & $\mathbf{U}$ & $\mathbf{U}^{\prime}$ \\
\hline 9 & 6 & 7 & 4 & 4 & 8 & 8 & 4 & 4 \\
\hline F9.6 & F6.4 & F7.4 & F4.2 & F4.2 & F8.6 & F8.6 & F4.2 & F4.2 \\
\hline 0.000000 & -.9999 & -9.9999 & -.99 & -.99 & 0.000000 & 0.000000 & -.99 & -.99 \\
\hline 207 & 213 & 220 & 224 & 228 & 236 & 244 & 248 & 252 \\
\hline
\end{tabular}

A : wave number $\left(\mathrm{cm}^{-1}\right)$ of the line

B : intensity of the line in $\left(\mathrm{cm}^{-1} /\left(\right.\right.$ molecule. $\left.\mathrm{cm}^{-2}\right)$ at $296 \mathrm{~K}$

C : Air broadening pressure halfwidth $(\mathrm{HWHM})\left(\mathrm{cm}^{-1} \mathrm{~atm}^{-1}\right)$ at $296 \mathrm{~K}$

$\mathrm{D}$ : Energy of the lower transition level $\left(\mathrm{cm}^{-1}\right)$

Ei $(i=1,2,3,4)$ : Transition quantum identifications for the lower and upper state of the transition

E1 : upper state vibrational identification $\quad$ E2 : lower state vibrational identification

E3 : upper state rotationnal identification $\quad$ E4 : lower state rotationnal identification

$\mathrm{F}$ : temperature dependence coefficient $n$ of the air broadening halfwidth 
$\mathrm{G}$ : identification code for isotopologue as in GEISA

I : identification code for molecule as in GEISA

$\mathrm{J}$ : Internal GEISA code for the data identification

$\mathrm{K}$ : Molecule number as in HITRAN

$\mathrm{L}$ : isotopologue number ( $1=$ most abundant, $2=$ second...etc $)$ as in HITRAN

$\mathrm{M}$ : Einstein A-coefficient

$\mathrm{N}$ : self broadening pressure halfwidth (HWHMself) $\left(\mathrm{cm}^{-1} \mathrm{~atm}^{-1}\right)$ at $296 \mathrm{~K}$

$\mathrm{O}$ : air pressure shift of the line transition $\left(\mathrm{cm}^{-1}\right)$ at $296 \mathrm{~K}$

$\mathrm{R}$ : temperature dependence coefficient of the air pressure shift

$\mathrm{A}^{\prime}$ : estimated accuracy $\left(\mathrm{cm}^{-1}\right)$ on the line position

$\mathrm{B}^{\prime}$ : estimated accuracy on the intensity of the line in $\left(\mathrm{cm}^{-1} /\left(\right.\right.$ molecule. $\left.\mathrm{cm}^{-2}\right)$

$\mathrm{C}^{\prime}$ : estimated accuracy on the air collision halfwidth (HWHM) $\left(\mathrm{cm}^{-1} \mathrm{~atm}^{-1}\right)$

$\mathrm{F}^{\prime}$ : estimated accuracy on the temperature dependence coefficient of the air broadening halfwidth

$\mathrm{O}^{\prime}$ : estimated accuracy on the air pressure shift of the line transition $\left(\mathrm{cm}^{-1}\right)$ at $296 \mathrm{~K}$

$\mathrm{R}^{\prime}$ : estimated accuracy on the temperature dependence coefficient of the air pressure shift

$\mathrm{N}^{\prime}$ : estimated accuracy on the self broadened (HWHM) $\left(\mathrm{cm}^{-1} \mathrm{~atm}^{-1}\right)$ at $296 \mathrm{~K}$

$\mathrm{S}$ : temperature dependence coefficient of the self broadening halfwidth

$S^{\prime}$ : estimated accuracy on the temperature dependence coefficient of the self broadening halfwidth

$\mathrm{T}$ : self pressure shift of the line transition $\left(\mathrm{cm}^{-1}\right)$ at $296 \mathrm{~K}$

$\mathrm{T}^{\prime}$ : estimated accuracy on the self pressure shift of the line transition $\left(\mathrm{cm}^{-1}\right)$ at $296 \mathrm{~K}$

$\mathrm{U}$ : temperature dependence coefficient of the self pressure shift

$\mathrm{U}^{\prime}$ : estimated accuracy on the temperature dependence coefficient of the self pressure shift

As shown in line 4 of Table 15 GEISA undefined values are attributed to the line parameter entries when no value is available from the data provider (missing data).

\section{Appendix C. Molecules and isotopologues in GEISA-2015}

Description of molecule and isotopologue codes in GEISA-2015 are given in Table 16. The molecule names and associated codes are in the two first columns; for each molecule, the isotopologue codes and the corresponding detailed formula are in columns 3 and 4 respectively. New molecules are in red and new isotopologues are in purple.

Table 16 Description of molecule and isotopologue codes in GEISA-2015

\begin{tabular}{|c|c|c|c|}
\hline Molecule & $\begin{array}{c}\text { Molecule } \\
\text { Code }\end{array}$ & $\begin{array}{c}\text { Isotope } \\
\text { Code }\end{array}$ & Formula \\
\hline \hline \multirow{4}{*}{$\mathbf{H}_{2} \mathbf{O}$} & & 161 & $\mathrm{H}^{16} \mathrm{OH}$ \\
\cline { 3 - 4 } & \multirow{3}{*}{1} & 171 & $\mathrm{H}^{17} \mathrm{OH}$ \\
\cline { 3 - 4 } & & 181 & $\mathrm{H}^{18} \mathrm{OH}$ \\
\cline { 3 - 4 } & & 262 & $\mathrm{D}_{2}{ }^{16} \mathrm{O}$ \\
\hline & & 282 & $\mathrm{D}_{2}{ }^{18} \mathrm{O}$ \\
\hline \multirow{3}{*}{} & & 626 & ${ }^{16} \mathrm{O}^{12} \mathrm{C}^{16} \mathrm{O}$ \\
\hline & & 636 & ${ }^{16} \mathrm{O}^{13} \mathrm{C}^{16} \mathrm{O}$ \\
\hline & & 628 & ${ }^{16} \mathrm{O}^{12} \mathrm{C}^{18} \mathrm{O}$ \\
\hline
\end{tabular}




\begin{tabular}{|c|c|c|c|}
\hline Molecule & $\begin{array}{c}\text { Molecule } \\
\text { Code }\end{array}$ & $\begin{array}{l}\text { Isotope } \\
\text { Code }\end{array}$ & Formula \\
\hline \multirow{9}{*}{$\mathrm{CO}_{2}$} & \multirow{9}{*}{2} & 627 & ${ }^{16} \mathrm{O}^{12} \mathrm{C}^{17} \mathrm{O}$ \\
\hline & & 638 & ${ }^{16} \mathrm{O}^{13} \mathrm{C}^{18} \mathrm{O}$ \\
\hline & & 637 & ${ }^{16} \mathrm{O}^{13} \mathrm{C}^{17} \mathrm{O}$ \\
\hline & & 828 & ${ }^{18} \mathrm{O}^{12} \mathrm{C}^{18} \mathrm{O}$ \\
\hline & & 728 & ${ }^{17} \mathrm{O}^{12} \mathrm{C}^{18} \mathrm{O}$ \\
\hline & & 727 & 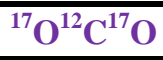 \\
\hline & & 838 & ${ }^{18} \mathrm{O}^{13} \mathrm{C}^{18} \mathrm{O}$ \\
\hline & & 738 & ${ }^{17} \mathrm{O}^{13} \mathrm{C}^{18} \mathrm{O}$ \\
\hline & & 737 & ${ }^{17} \mathrm{O}^{13} \mathrm{C}^{17} \mathrm{O}$ \\
\hline \multirow{5}{*}{$\mathbf{O}_{3}$} & \multirow{5}{*}{3} & 666 & ${ }^{16} \mathrm{O}^{16} \mathrm{O}^{16} \mathrm{O}$ \\
\hline & & 668 & ${ }^{16} \mathrm{O}^{16} \mathrm{O}^{18} \mathrm{O}$ \\
\hline & & 686 & ${ }^{16} \mathrm{O}^{18} \mathrm{O}^{16} \mathrm{O}$ \\
\hline & & 667 & ${ }^{16} \mathrm{O}^{16} \mathrm{O}^{17} \mathrm{O}$ \\
\hline & & 676 & ${ }^{16} \mathrm{O}^{17} \mathrm{O}^{16} \mathrm{O}$ \\
\hline \multirow{8}{*}{$\mathbf{N}_{2} \mathbf{O}$} & \multirow{8}{*}{4} & 446 & ${ }^{14} \mathrm{~N}^{14} \mathrm{~N}^{16} \mathrm{O}$ \\
\hline & & 447 & ${ }^{14} \mathrm{~N}^{14} \mathrm{~N}^{17} \mathrm{O}$ \\
\hline & & 4448 & ${ }^{114} \mathrm{~N}^{14} \mathrm{~N}^{18} \mathrm{O}$ \\
\hline & & 456 & 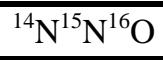 \\
\hline & & 546 & ${ }^{15} \mathrm{~N}^{14} \mathrm{~N}^{16} \mathrm{O}$ \\
\hline & & 458 & ${ }^{114} \mathrm{~N}^{14} \mathrm{~N}^{18} \mathrm{O}$ \\
\hline & & 548 & ${ }^{15} \mathrm{~N}^{14} \mathrm{~N}^{18} \mathrm{O}$ \\
\hline & & 556 & ${ }^{15} \mathrm{~N}^{15} \mathrm{~N}^{16} \mathrm{O}$ \\
\hline \multirow{6}{*}{$\mathrm{CO}$} & \multirow{6}{*}{5} & 26 & ${ }^{12} \mathrm{C}^{16} \mathrm{O}$ \\
\hline & & 27 & ${ }^{12} \mathrm{C}^{17} \mathrm{O}$ \\
\hline & & 28 & ${ }^{12} \mathrm{C}^{18} \mathrm{O}$ \\
\hline & & 36 & ${ }^{13} \mathrm{C}^{16} \mathrm{O}$ \\
\hline & & 37 & ${ }^{13} \mathrm{C}^{17} \mathrm{O}$ \\
\hline & & 38 & ${ }^{13} \mathrm{C}^{18} \mathrm{O}$ \\
\hline \multirow[b]{2}{*}{$\mathrm{CH}_{4}$} & \multirow{2}{*}{6} & 211 & ${ }^{12} \mathrm{CH}_{4}$ \\
\hline & & 311 & ${ }^{13} \mathrm{CH}_{4}$ \\
\hline \multirow{3}{*}{$\mathbf{O}_{2}$} & \multirow{3}{*}{7} & 66 & ${ }^{16} \mathrm{O}^{16} \mathrm{O}$ \\
\hline & & 67 & ${ }^{16} \mathrm{O}^{17} \mathrm{O}$ \\
\hline & & 68 & ${ }^{16} \mathrm{O}^{18} \mathrm{O}$ \\
\hline \multirow{3}{*}{ NO } & \multirow{3}{*}{8} & 46 & ${ }^{14} \mathrm{~N}^{16} \mathrm{O}$ \\
\hline & & 48 & ${ }^{14} \mathrm{~N}^{18} \mathrm{O}$ \\
\hline & & 56 & ${ }^{15} \mathrm{~N}^{16} \mathrm{O}$ \\
\hline \multirow[b]{2}{*}{$\mathrm{SO}_{2}$} & \multirow[b]{2}{*}{9} & 626 & ${ }^{32} \mathrm{~S}^{16} \mathrm{O}_{2}$ \\
\hline & & 646 & ${ }^{34} \mathrm{~S}^{16} \mathrm{O}_{2}$ \\
\hline $\mathrm{NO}_{2}$ & 10 & 646 & ${ }^{14} \mathrm{~N}^{16} \mathrm{O}_{2}$ \\
\hline \multirow[t]{2}{*}{$\mathbf{N H}_{3}$} & \multirow[t]{2}{*}{11} & 4411 & ${ }^{1{ }^{14} \mathrm{NH}_{3}}$ \\
\hline & & 511 & ${ }^{15} \mathrm{NH}_{3}$ \\
\hline \multirow[t]{2}{*}{$\mathrm{PH}_{3}$} & 12 & 131 & ${ }^{31} \mathrm{PH}_{3}$ \\
\hline & & 146 & $\mathrm{H}^{14} \mathrm{~N}^{16} \mathrm{O}$ \\
\hline
\end{tabular}




\begin{tabular}{|c|c|c|c|}
\hline Molecule & $\begin{array}{c}\text { Molecule } \\
\text { Code }\end{array}$ & $\begin{array}{c}\text { Isotope } \\
\text { Code }\end{array}$ & Formula \\
\hline $\mathrm{HNO}_{3}$ & 13 & 156 & $\mathrm{H}^{15} \mathrm{~N}^{16} \mathrm{O}$ \\
\hline \multirow{3}{*}{$\mathbf{O H}$} & \multirow{3}{*}{14} & 61 & ${ }^{2}{ }^{16} \mathrm{OH}$ \\
\hline & & 62 & ${ }^{16} \mathrm{OD}$ \\
\hline & & 81 & 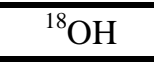 \\
\hline HF & 15 & 19 & $\mathrm{H}^{19} \mathrm{~F}$ \\
\hline \multirow[b]{2}{*}{ HCl } & \multirow[b]{2}{*}{16} & 15 & $\mathrm{H}^{35} \mathrm{Cl}$ \\
\hline & & 17 & $\mathrm{H}^{37} \mathrm{Cl}$ \\
\hline \multirow[t]{2}{*}{$\mathrm{HBr}$} & \multirow[t]{2}{*}{17} & 11 & $\mathrm{H}^{81} \mathrm{Br}$ \\
\hline & & 19 & $\mathrm{H}^{79} \mathrm{Br}$ \\
\hline HI & 18 & 17 & $\mathrm{H}^{127} \mathrm{I}$ \\
\hline \multirow[b]{2}{*}{$\mathrm{ClO}$} & \multirow[b]{2}{*}{19} & 56 & ${ }^{35} \mathrm{Cl}^{16} \mathrm{O}$ \\
\hline & & 76 & ${ }^{37} \mathrm{Cl}^{16} \mathrm{O}$ \\
\hline \multirow{6}{*}{ OCS } & \multirow{6}{*}{20} & 622 & ${ }^{16} \mathrm{O}^{12} \mathrm{C}^{32} \mathrm{~S}$ \\
\hline & & 623 & ${ }^{16} \mathrm{O}^{12} \mathrm{C}^{33} \mathrm{~S}$ \\
\hline & & 624 & ${ }^{16} \mathrm{O}^{12} \mathrm{C}^{34} \mathrm{~S}$ \\
\hline & & 632 & ${ }^{16} \mathrm{O}^{13} \mathrm{C}^{32} \mathrm{~S}$ \\
\hline & & 634 & ${ }^{16} \mathrm{O}^{13} \mathrm{C}^{34} \mathrm{~S}$ \\
\hline & & 822 & ${ }^{18} \mathrm{O}^{12} \mathrm{C}^{32} \mathrm{~S}$ \\
\hline \multirow{3}{*}{$\mathrm{H}_{2} \mathrm{CO}$} & \multirow{3}{*}{21} & 126 & $\mathrm{H}_{2}{ }^{12} \mathrm{C}^{16} \mathrm{O}$ \\
\hline & & 128 & $\mathrm{H}_{2}{ }^{12} \mathrm{C}^{18} \mathrm{O}$ \\
\hline & & 136 & $\mathrm{H}_{2}{ }^{13} \mathrm{C}^{16} \mathrm{O}$ \\
\hline \multirow[b]{2}{*}{$\mathbf{C}_{2} \mathbf{H}_{6}$} & \multirow[b]{2}{*}{22} & 226 & ${ }^{12} \mathrm{C}_{2} \mathrm{H}_{6}$ \\
\hline & & 236 & ${ }^{12} \mathrm{C}^{13} \mathrm{CH}_{6}$ \\
\hline \multirow[t]{2}{*}{$\mathrm{CH}_{3} \mathrm{D}$} & \multirow[t]{2}{*}{23} & 212 & 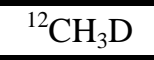 \\
\hline & & 312 & ${ }^{13} \mathrm{CH}_{3} \mathrm{D}$ \\
\hline \multirow[b]{2}{*}{$\mathbf{C}_{2} \mathbf{H}_{2}$} & \multirow[b]{2}{*}{24} & 221 & ${ }^{12} \mathrm{C}_{2} \mathrm{H}_{2}$ \\
\hline & & 231 & ${ }^{12} \mathrm{C}^{13} \mathrm{CH}_{2}$ \\
\hline \multirow[b]{2}{*}{$\mathrm{C}_{2} \mathbf{H}_{4}$} & \multirow[b]{2}{*}{25} & 211 & ${ }^{12} \mathrm{C}_{2} \mathrm{H}_{4}$ \\
\hline & & 311 & ${ }^{12} \mathrm{C}^{13} \mathrm{CH}_{4}$ \\
\hline $\mathrm{GeH}_{4}$ & 26 & 411 & ${ }^{74} \mathrm{GeH}_{4}$ \\
\hline \multirow{4}{*}{ HCN } & \multirow{4}{*}{27} & 124 & $\mathrm{H}^{12} \mathrm{C}^{14} \mathrm{~N}$ \\
\hline & & 125 & $\mathrm{H}^{13} \mathrm{C}^{15} \mathrm{~N}$ \\
\hline & & 134 & $\mathrm{H}^{13} \mathrm{C}^{14} \mathrm{~N}$ \\
\hline & & 224 & $\mathrm{D}^{12} \mathrm{C}^{14} \mathrm{~N}$ \\
\hline $\mathrm{C}_{3} \mathrm{H}_{8}$ & 28 & 221 & ${ }^{12} \mathrm{C}_{3} \mathrm{H}_{8}$ \\
\hline $\mathrm{C}_{2} \mathrm{~N}_{2}$ & 29 & 224 & ${ }^{12} \mathrm{C}_{2}{ }^{14} \mathrm{~N}_{2}$ \\
\hline $\mathrm{C}_{4} \mathrm{H}_{2}$ & 30 & 211 & ${ }^{12} \mathrm{C}_{4} \mathrm{H}_{2}$ \\
\hline $\mathrm{HC}_{3} \mathrm{~N}$ & 31 & 124 & $\mathrm{H}^{12} \mathrm{C}_{3}{ }^{14} \mathrm{~N}$ \\
\hline \multirow[b]{2}{*}{ HOCl } & \multirow[b]{2}{*}{32} & 165 & $\mathrm{H}^{16} \mathrm{O}^{35} \mathrm{Cl}$ \\
\hline & & 167 & $\mathrm{H}^{16} \mathrm{O}^{37} \mathrm{Cl}$ \\
\hline $\mathbf{N}_{2}$ & 33 & 44 & ${ }^{14} \mathrm{~N}^{14} \mathrm{~N}$ \\
\hline \multirow[b]{2}{*}{$\mathrm{CH}_{3} \mathrm{Cl}$} & & 215 & ${ }^{12} \mathrm{CH}_{3}{ }^{35} \mathrm{Cl}$ \\
\hline & 34 & 217 & ${ }^{12} \mathrm{CH}_{3}{ }^{37} \mathrm{Cl}$ \\
\hline
\end{tabular}




\begin{tabular}{|c|c|c|c|}
\hline Molecule & $\begin{array}{c}\text { Molecule } \\
\text { Code }\end{array}$ & $\begin{array}{l}\text { Isotope } \\
\text { Code }\end{array}$ & Formula \\
\hline $\mathrm{H}_{2} \mathrm{O}_{2}$ & 35 & 166 & $\mathrm{H}_{2}{ }^{16} \mathrm{O}^{16} \mathrm{O}$ \\
\hline \multirow{3}{*}{$\mathrm{H}_{2} \mathrm{~S}$} & \multirow{3}{*}{36} & 121 & $\mathrm{H}_{2}{ }^{32} \mathrm{~S}$ \\
\hline & & 131 & $\mathrm{H}_{2}{ }^{33} \mathrm{~S}$ \\
\hline & & $\overline{141}$ & $\overline{\mathrm{H}} \mathrm{H}_{2}{ }^{34} \mathrm{~S}$ \\
\hline $\mathrm{HCOOH}$ & 37 & 261 & $\mathrm{H}^{12} \mathrm{C}^{16} \mathrm{O}^{16} \mathrm{OH}$ \\
\hline 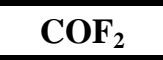 & 38 & 269 & ${ }^{12} \mathrm{C}^{16} \mathrm{O}^{19} \mathrm{~F}_{2}$ \\
\hline $\mathrm{SF}_{6}$ & 39 & 29 & ${ }^{32} \mathrm{~S}^{19} \mathrm{~F}_{6}$ \\
\hline $\mathrm{C}_{3} \mathrm{H}_{4}$ & 40 & 341 & ${ }^{12} \mathrm{C}_{3} \mathrm{H}_{6}$ \\
\hline $\mathrm{HO}_{2}$ & 41 & 166 & $\mathrm{H}^{16} \mathrm{O}_{2}$ \\
\hline \multirow[b]{2}{*}{$\mathrm{ClONO}_{2}$} & \multirow[b]{2}{*}{42} & $\begin{array}{c}564 \\
\end{array}$ & ${ }^{15} \mathrm{Cl}^{16} \mathrm{O}^{14} \mathrm{~N}^{16} \mathrm{O}_{2}$ \\
\hline & & 764 & ${ }^{17} \mathrm{Cl}^{16} \mathrm{O}^{14} \mathrm{~N}^{16} \mathrm{O}_{2}$ \\
\hline \multirow[b]{2}{*}{$\mathrm{CH}_{3} \mathrm{Br}$} & \multirow[b]{2}{*}{43} & 79 & ${ }^{12} \mathrm{CH}_{3}{ }^{79} \mathrm{Br}$ \\
\hline & & 81 & ${ }^{12} \mathrm{CH}_{3}{ }^{81} \mathrm{Br}$ \\
\hline $\mathrm{CH}_{3} \mathrm{OH}$ & 44 & 216 & ${ }^{12} \mathrm{CH}_{3}{ }^{16} \mathrm{OH}$ \\
\hline $\mathrm{NO}+$ & 45 & 46 & ${ }^{14} \mathrm{~N}^{16} \mathrm{O}+$ \\
\hline HNC & 46 & 142 & $\mathrm{H}^{14} \mathrm{~N}^{12} \mathrm{C}$ \\
\hline $\mathrm{C}_{6} \mathrm{H}_{6}$ & 47 & 266 & ${ }^{12} \mathrm{C}_{6} \mathrm{H}_{6}$ \\
\hline $\mathrm{C}_{2} \mathrm{HD}$ & 48 & 122 & ${ }^{12} \mathrm{C}_{2} \mathrm{HD}$ \\
\hline$\overline{\mathrm{CF}_{4}}$ & 49 & 291 & $\overline{{ }^{12} \mathrm{C}^{15} \mathrm{~F}_{4}}$ \\
\hline$\overline{\mathrm{CH}_{3} \mathrm{CN}}$ & 50 & 234 & ${ }^{12} \mathrm{CH}_{3}{ }^{12} \mathrm{C}^{14} \mathrm{~N}$ \\
\hline \multirow[t]{2}{*}{ HDO } & \multirow[t]{2}{*}{51} & 162 & $\mathrm{H}^{16} \mathrm{OD}$ \\
\hline & & 182 & $\mathrm{H}^{18} \mathrm{OD}$ \\
\hline $\mathrm{SO}_{3}$ & 52 & 26 & ${ }^{32} \mathrm{~S}^{16} \mathrm{O}_{3}$ \\
\hline
\end{tabular}




\section{References}

[1] J. Connes, P. Connes, and J.-P Maillard, Atlas des spectres dans le proche infrarouge de Venus, Mars, Jupiter et Saturne, CNRS, Paris, 1969.

[2] R.A. McClatchey, W.S. Benedict, S.A. Clough, D.E. Burch, R.F. Calfee, K. Fox, L.S. Rothman, J.S. Garing, AFCRL Atmospheric Absorption Line Parameters Compilation, AFCRL-Technical Report-0096, 1973.

[3] J.S. Garing and R.A. McClatchey, Atmospheric Absorption Line Compilation. Appl. Opt. 12 (1973) 2545-2545, doi: 10.1364/AO.12.002545.

[4] A. Chédin, N. Husson, N.A. Scott, I. Jobard, I. Cohen-Hallaleh, A. Berroir, La banque de données GEISA. Description et logiciel d'utilisation. In : Laboratoire de Météorologie Dynamique du CNRS, Internal Note 108, Ecole Polytechnique, Palaiseau, France, 1980.

[5] A. Chédin, N. Husson, N.A. Scott, Une banque de données pour l'étude des phénomènes de transfert radiatif dans les atmosphères planétaires: la banque GEISA. In : Bulletin d'Information du Centre de Données Stellaires, France, 1982, Vol. 22, pp. 21-121.

[6] N. Husson, A. Chédin, N.A. Scott. The GEISA spectroscopic line parameters data bank in 1984, Annales Geophysicae 4 (1986)185-190.

[7] N. Husson, B. Bonnet, N.A. Scott, A. Chédin, Management and study of spectroscopic information: the GEISA program, J. Quant. Spectrosc. Radiat. Transfer 48 (1992) 509-518.

[8] N. Jacquinet-Husson, E. Arié, J. Ballard, A. Barbe, G. Bjoraker, B. Bonnet, et al., The 1997 spectroscopic GEISA databank, J. Quant. Spectrosc. Radiat. Transfer 62 (1999) 205-254.

[9] N. Jacquinet-Husson, N.A. Scott, A. Chédin, K. Garceran, R. Armante, A.A. Chursin et al., The 2003 Edition of the GEISA/IASI spectroscopic database, J. Quant. Spectrosc. Radiat. Transfer 95 (2005) 429-467.

[10] N. Jacquinet-Husson, NA. Scott, A. Chédin, L. Crépeau, R. Armante, V. Capelle at al., The GEISA spectroscopic database: Current and future archive for Earth and planetary atmosphere studies, J. Quant. Spectrosc. Radiat. Transfer 109 (2008)1043-1059.

[11] N. Jacquinet-Husson, L. Crepeau, R. Armante, C. Boutammine, A. Chédin, N.A. Scott, C. Crevoisier, V. Capelle, C. Boone, N. Poulet-Crovisier, A. Barbe, A. Campargue, D. Chris Benner, Y. Benilan, B. Bézard, V. Boudon, L.R. Brown, L.H. Coudert, A. Coustenis, V. Dana, V.M. Devi, S. Fally, A. Fayt, J.-M Flaud, A. Goldman, M. Herman, G.J. Harris, D. Jacquemart, A. Jolly, I. Kleiner, A. Kleinböhl, F. Kwabia-Tchana, N. Lavrentieva, N. Lacome, Li-Hong Xu, O.M. Lyulin, J.-Y. Mandin, A. Maki, S. Mikhailenko, C.E. Miller, T. Mishina, N. Moazzen-Ahmadi, H.S.P. Müller, A. Nikitin, J. Orphal, V. Perevalov, A. Perrin, D.T. Petkie, A. Predoi-Cross, C.P. Rinsland, J.J. Remedios, M. Rotger, M.A.H. Smith, K. Sung, S. Tashkun, J. Tennyson, R.A. Toth, A.-C. Vandaele, J. Vander Auwera, The 2009 edition of the GEISA spectroscopic database. J. Quant. Spectrosc. Radiat. Transfer 112 (2011) 2395-2445. doi: 10.1016/j.jqsrt. 2011.06.004.

[12] L.S. Rothman et al., The HITRAN 2004 molecular spectroscopic database. J. Quant. Spectrosc. Radiat. Transfer 96 (2005)139-204.

[13] L.S. Rothman et al. (2009). The HITRAN 2008 molecular spectroscopic database. J. Quant. Spectrosc. Radiat. Transfer, Vol. 110, pp. 533-572. doi: 10.1016/j.jqsrt.2009.02.013.

[14] L.S. Rothman, I.E. Gordon, Y. Babikov, A. Barbe, D. Chris Benner, P.F. Bernath, M. Birk, L. Bizzocchi, V. Boudon, L.R. Brown, A. Campargue, K. Chance, E.A. Cohen, L.H. Coudert, V.M. Devi, B.J. Drouin, A. Fayt, J.-M. Flaud, R.R. Gamache, J.J. Harrison, J.-M. Hartmann, C. Hill, J.T. 
Hodges, D. Jacquemart, A. Jolly, J. Lamouroux, R.J. Le Roy, G. Li, D.A. Long, O.M. Lyulin, C.J. Mackie, S.T. Massie, S. Mikhailenko, H.S.P. Müller, O.V. Naumenko, A.V. Nikitin, J. Orphal, V. Perevalov, A. Perrin, E.R. Polovtseva, C. Richard, M.A.H. Smith, E. Starikova, K. Sung, S. Tashkun, J. Tennyson, G.C. Toon, Vl.G. Tyuterev, G. Wagner (2013). The HITRAN 2012 molecular spectroscopic database. J. Quant. Spectrosc. Radiat. Transfer Vol. 130, 4-50. doi: 10.1016/j.jqsrt.2013.07.002.

[15] J.-M Flaud, C. Piccolo, B. Carli, A spectroscopic database for MIPAS. Proc. of ENVISAT Validation Workshop, Frascati, Italy, 9-13 December 2002, ESA (2003) SP-531.

[16] H.M. Pickett, R.L. Poynter, E.A. Cohen, M.L. Delitsky, J.C. Pearson H.S.P. Müller, Submillimeter, millimeter, and microwave spectral line catalog, J. Quant. Spectrosc. Radiat. Transfer 60 (1998) 883-890.

[17] J.C. Pearson, H.S.P. Müller, H.M. Pickett, E.A. Cohen B.J. Drouin, Introduction to submillimeter, millimeter and microwave spectral line catalog, J. Quant. Spectrosc. Radiat. Transfer 111 (2010) 1614-1616.

[18] H.S.P. Müller, S. Thorwirth, D.A. Roth, G. Winnewisser, The Cologne Database for molecular spectroscopy, CDMS, Astron. Astrophys. 370 (2001) L49-L52.

[19] H.S.P. Müller, F. Schlöder, J. Stutzki, G. Winnewisser, The Cologne Database for Molecular Spectroscopy, CDMS: a useful tool for astronomers and spectroscopists, J. Mol. Struct. 742 (2005) 215-227.

[20] N.A. Scott, N., A direct method of computation of transmission function of an inhomogeneous gaseous medium: description of the method and influence of various factors. J. Quant. Spectrosc. Radiat. Transfer 14 (1974) 691-707.

[21] Scott N. and A. Chédin, A fast line-by-line method for atmospheric absorption computations: The Automatized Atmospheric Absorption Atlas, J. Appl. Meteor. 20 (1981) 802-812.

[22] R. Armante, N.A. Scott, C. Crevoisier, V. Capelle, L. Crépeau, N. Jacquinet, A. Chédin, Evaluation of spectroscopic databases through radiative transfer simulations compared to observations. Application to the validation of GEISA-2015 with IASI and TCCON, J. Molec. Spectrosc. (this issue), 2016, 10.1016/j.jms.2016.04.004.

[23] C. Crevoisier, C. Clerbaux, V. Guidard, T. Phulpin, R. Armante, B. Barret, C. Camy-Peyret, J.P. Chaboureau, P.-F. Coheur, L. Crépeau, G. Dufour, L. Labonnote, L. Lavanant, J. Hadji-Lazaro, H. Herbin, N. Jacquinet-Husson, S. Payan, E. Péquignot, C. Pierangelo, P. Sellitto, and C. Stubenrauch, Towards IASI-New Generation (IASI-NG): impact of improved spectral resolution and radiometric noise on the retrieval of thermodynamic, chemistry and climate variables, Atmos. Meas. Tech. 7 (2014) 4367-4385, doi:10.5194/amt-7-4367-2014

[24] O.V. Naumenko. Institute of Atmospheric Optics. Private communication. (2015).

[25] L.H. Coudert, M.-A. Martin-Drumell, O. Pirali, Analysis of the high-resolution water spectrum up to the Second Triad and to J=30, J. Mol. Spectrosc. 303 (2014) 36-41.

[26] L.H. Coudert, G. Wagner, M. Birk M, Yu.I. Baranov, W.J. Lafferty, J.-M. Flaud, The $\mathrm{H}_{2}{ }^{16} \mathrm{O}$ molecule: line position and line intensity analyses up to the second triad, J. Mol. Spectrosc. 251 (2008) 339-357.

[27] S. Mikhailenko, D. Mondelain, S. Kassi, A. Campargue, An accurate and complete empirical line list for water vapor between 5850 and $7920 \mathrm{~cm}^{-1}$, J. Quant. Spectrosc. Radiat. Trans. 140 (2014) 48-57. 
[28] P. Macko, D. Romanini, S.N. Mikhailenko, O.V. Naumenko, S. Kassi, A. Jenouvrier, Vl.G. Tyuterev, A. Campargue, High sensitivity $\mathrm{CW}$-cavity ring down spectroscopy of water in the region of the $1.5 \mu \mathrm{m}$ atmospheric window, J. Mol. Spectrosc. 227 (2004) 90-108.

[29] S.N. Mikhailenko, L. Wang, S. Kassi, A. Campargue, Weak water absorption lines around 1.455 and $1.66 \mu \mathrm{m}$ by CW-CRDS, J. Mol. Spectrosc. 244 (2007) 170-178.

[30] S. Mikhailenko, S. Kassi, L. Wang, A. Campargue, The absorption spectrum of water in the $1.25 \mu \mathrm{m}$ transparency window $\left(7408-7920 \mathrm{~cm}^{-1}\right)$, J. Mol. Spectrosc. 269 (2011) 92-103.

[31] O. Leshchishina, S. Mikhailenko, D. Mondelain, S. Kassi, A. Campargue, CRDS of water vapor at 0.1 Torr between 6886 and $7406 \mathrm{~cm}^{-1}$, J. Quant. Spectrosc. Radiat. Trans. 113 (2012) 2155-2166.

[32] O. Leshchishina, S. Mikhailenko, D. Mondelain, S. Kassi, A. Campargue, An improved line list for water vapor in the $1.5 \mu \mathrm{m}$ transparency window by highly sensitive CRDS between 5852 and $6607 \mathrm{~cm}^{-1}$, J. Quant. Spectrosc. Radiat. Trans. 130 (2013) 69-80.

[33] R.A. Toth, Measurements of positions, strengths and self-broadened widths of $\mathrm{H}_{2} \mathrm{O}$ from 2900 to $8000 \mathrm{~cm}^{-1}$ : Line strength analysis of the $2^{\text {nd }}$ triad bands, J. Quant. Spectrosc. Radiat. Trans. 94 (2005) 51-107.

\section{[34] http://spectra.iao.ru}

[35] D.W. Schwenke, H. Partridge, Convergence testing of the analytic representation of an ab initio dipole moment function for water: Improved fitting yields improved intensities, J. Chem. Phys. 113 (2000) 6592-6597.

[36] L. Régalia, C. Oudot, S. Mikhailenko, L. Wang, X. Thomas, A. Jenouvrier, P. Von der Heyden, Water vapor line parameters from 6450 to $9400 \mathrm{~cm}^{-1}$, J. Quant. Spectrosc. Radiat. Trans. 136 (2014) 119-136.

[37] R. Tolchenov, J. Tennyson, Water line parameters from refitted spectra constrained by empirical upper state levels: Study of the $9500-14500 \mathrm{~cm}^{-1}$ region, J. Quant. Spectrosc. Radiat. Trans. 109 (2008) 559-568.

[38] J. Tennyson, P.F. Bernath, L.R. Brown, A. Campargue, A.G. Császár, L. Daumont, R.R. Gamache, J.T. Hodges, O.V. Naumenko, O.L. Polyansky, L.S. Rothman, A.C. Vandaele, N.F. Zobov, A.R. Al Derzi, C. Fábri, A.Z. Fazliev, T. Furtenbacher, I.E. Gordon, L. Lodi, I.I. Mizus, IUPAC critical evaluation of the rotational-vibrational spectra of water vapor. Part III: Energy levels and transition wavenumbers for $\mathrm{H}_{2}{ }^{16} \mathrm{O}$, J. Quant. Spectrosc. Radiat. Trans. 117 (2013) 29-58.

[39] R.J. Barber, J. Tennyson, G.J. Harris, R.N. Tolchenov, A high - accuracy computed water line list, Mon. Not. R. Astron. Soc. 368 (2006) 1087-1094.

[40] R.A. Toth, Line list of water vapor parameters from 500 to $8000 \mathrm{~cm}^{-1}$, http://mark4sun.jpl.nasa.gov/h2o.html

[41] R.N. Tolchenov, O. Naumenko, N.F. Zobov, S.V. Shirin, O. L. Polyansky, J. Tennyson, M. Carleer, P.-F. Coheur, S. Fally, A. Jenouyrier, A.C. Vandaele, Water vapour line assignments in the $9250-26000 \mathrm{~cm}^{-1}$ frequency range, J. Mol. Spectrosc. 233 (2005) 68-76.

[42] L. Lodi, J. Tennyson, Line lists for $\mathrm{H}_{2}{ }^{18} \mathrm{O}$ and $\mathrm{H}_{2}{ }^{17} \mathrm{O}$ based on empirical line positions and $a b$ initio intensities, J. Quant. Spectrosc. Radiat. Trans. 113 (2012) 850-858.

[43] J. Tennyson, P.F. Bernath, L.R. Brown, A. Campargue, A.G. Császár, L. Daumont, R.R. Gamache, J.T. Hodges, O.V. Naumenko, O.L. Polyansky, L.S. Rothman, A.C. Vandaele, N.F. Zobov, A database of water transitions from experiment and theory (IUPAC Technical Report), Pure Appl. Chem. 86 (2014) 71-83. 
[44] T. Furtenbacher, A.G. Csaszar and J. Tennyson, MARVEL: measured active rotationalvibrational energy levels, J. Molec. Spectrosc. 245 (2007) 115-125.

[45] T. Furtenbacher, A.G. Császár, MARVEL: Measured active rotational-vibrational energy levels. II. Algorithmic improvements, J. Quant. Spectrosc. Radiat. Trans. 113 (2012) 929-935.

[46] J. Tennyson, P.F. Bernath, L.R. Brown, A. Campargue, M.R. Carleer, A.G. Császár, R.R. Gamache, J.T. Hodges, A. Jenouvrier, O.V. Naumenko, O.L. Polyansky, L.S. Rothman, R.A. Toth, A.C. Vandaele, N.F. Zobov, L. Daumont, A.Z. Fazliev, T. Furtenbacher, I.E. Gordon, S.N. Mikhailenko, S.V. Shirin, IUPAC critical evaluation of the rotational-vibrational spectra of water vapor. Part I. Energy levels and transition wavenumbers for $\mathrm{H}_{2}{ }^{17} \mathrm{O}$ and $\mathrm{H}_{2}{ }^{18} \mathrm{O}$, J. Quant. Spectrosc. Radiat. Trans. 110 (2009) 573-596.

[47] L. Lodi, J. Tennyson, O.L. Polyansky, A global, high accuracy ab initio dipole moment surface for the electronic ground state of the water molecule, J. Chem. Phys. 135 (2011) 034113.

[48] S.V. Shirin, N.F. Zobov, R.I. Ovsyannikov, O.L. Polyansky, J. Tennyson, Water line lists close to experimental accuracy using a spectroscopically determined potential energy surface for $\mathrm{H}_{2}{ }^{16} \mathrm{O}$, $\mathrm{H}_{2}{ }^{17} \mathrm{O}$ and $\mathrm{H}_{2}{ }^{17} \mathrm{O}$, J. Chem. Phys. 128 (2008) 224306.

[49] O.L. Polyansky, A.A. Kyuberis, L. Lodi, J. Tennyson, R.I. Ovsyanniko, N.F. Zobov, ExoMol molecular line lists. VII: high accuracy computed line lists for $\mathrm{H}_{2}{ }^{18} \mathrm{O}$ and $\mathrm{H}_{2}{ }^{17} \mathrm{O}$, Mon. Not. Roy. Astron. Soc. (submitted).

[50] R.A. Scheepmaker, C. Frankenberg, A. Galli, A. Butz, H. Schrijver, N.M. Deutscher, D. Wunch, T. Warneke, S. Fally, I. Aben, Improved water vapour spectroscopy in the $4174-4300 \mathrm{~cm}^{-1}$ region and its impact on SCIAMACHY HDO/ $\mathrm{H}_{2} \mathrm{O}$ measurements, Atmos. Meas. Tech. 6 (2013) 879-894. doi:10.5194/amt-6-879-2013.

[51] A. Jenouvrier, L. Daumont, L. Régalia-Jarlot, Vl.G. Tyuterev, M. Carleer, A.C. Vandaele, S. Mikhailenko, S. Fally, Fourier transform measurements of water vapor line parameters in the 4200 - $6600 \mathrm{~cm}^{-1}$ region, J. Quant. Spectrosc. Radiat. Trans. 105 (2007) 326-355. doi:10.1016/j.jqsrt.2006.11.007.

[52] L.H. Coudert, P. Chelin, Line position and line intensity analyses of the high-resolution spectrum of $\mathrm{H}_{2}{ }^{18} \mathrm{O}$ up to the First Triad and $J=17$, J. Mol. Spectrosc. This issue (2016). doi:10.1016/j.jms.2016.01.012.

[53] J. Orphal, A.A. Ruth, High-resolution Fourier-transform cavity-enhanced absorption spectroscopy in the near-infrared using an incoherent broad-band light source, Opt. Express 16 (2008) 19232-19243.

[54] R.A. Toth, Transition frequencies and absolute strengths of $\mathrm{H}_{2}{ }^{17} \mathrm{O}$ and $\mathrm{H}_{2}{ }^{18} \mathrm{O}$ in the 6.2- $\mu \mathrm{m}$ region, J. Opt. Soc. Am. B 9 (1992) 462-482.

[55] S.N. Mikhailenko, Vl.G. Tyuterev, G.Ch. Mellau, (000) and (010) States of $\mathrm{H}_{2}{ }^{18} \mathrm{O}$ : analysis of rotational transitions in hot emission spectrum in the $400-850 \mathrm{~cm}^{-1}$ region, J. Mol. Spectrosc. 217 (2003) 195-211.

[56] A.-W. Liu, J.-H. Du, K.-F. Song, L. Wang, L. Wan, S.-M. Hu, High-resolution Fouriertransform spectroscopy of ${ }^{18} \mathrm{O}$-enriched water molecule in the $1080-7800 \mathrm{~cm}^{-1}$ region, J. Mol. Spectrosc. 237 (2006) 149-162.

[57] E. Kyrö, Centrifugal distortion analysis of pure rotational spectra of $\mathrm{H}_{2}{ }^{16} \mathrm{O}, \mathrm{H}_{2}{ }^{17} \mathrm{O}$, and $\mathrm{H}_{2}{ }^{18} \mathrm{O}$, J. Mol. Spectrosc. 88 (1981) 167-174. 
[58] F. Matsushima, H. Nagase, T. Nakauchi, H. Odashima, K. Takagi, Frequency measurement of pure rotational transitions of $\mathrm{H}_{2}{ }^{17} \mathrm{O}$ and $\mathrm{H}_{2}{ }^{18} \mathrm{O}$ from 0.5 to $5 \mathrm{THz}, \mathrm{J}$. Mol. Spectrosc. 193 (1999) 217-223.

[59] J.W.C. Johns, High-resolution far-infrared $\left(20-350 \mathrm{~cm}^{-1}\right)$ spectra of several isotopic species of $\mathrm{H}_{2} \mathrm{O}$, J. Opt. Soc. Am. B 2 (1985) 1340-1354.

[60] C. Oudot, L. Régalia, S. Mikhailenko, X. Thomas, P. Von der Heyden, D. Décatoire, Fourier transform measurements of $\mathrm{H}_{2}{ }^{18} \mathrm{O}$ and $\mathrm{HD}^{18} \mathrm{O}$ in the spectral range $1000-2300 \mathrm{~cm}^{-1}$, J. Quant. Spectrosc. Radiat. Trans. 113 (2012) 859-869.

[61] R.A. Toth, Water vapor measurements between 590 and $2582 \mathrm{~cm}^{-1}$ : Line positions and strengths, J. Mol. Spectrosc. 190 (1998) 379-396.

[62] M.J. Down, J. Tennyson, J. Orphal, P. Chelin, A.A. Ruth, Analysis of an ${ }^{18} \mathrm{O}$ and D enhanced water spectrum and new assignments for $\mathrm{HD}^{18} \mathrm{O}$ and $\mathrm{D}_{2}{ }^{18} \mathrm{O}$ in the near-infrared region $(6000-7000$ $\mathrm{cm}^{-1}$ ) using newly calculated variational lists, J. Quant. Spectrosc. Radiat. Trans. 282 (2012) 1-8.

[63] S.N. Mikhailenko, S.A. Tashkun, L. Daumont, A. Jenouvrier, M. Carleer, S. Fally, A.C. Vandaele, Line positions and energy levels of the ${ }^{18} \mathrm{O}$ substitutions from the HDO/ $\mathrm{D}_{2} \mathrm{O}$ spectra between 5600 and $8800 \mathrm{~cm}^{-1}$, J. Quant. Spectrosc. Radiat. Trans. 111 (2010) 2185-2196.

[64] P.S. Ormsby, K.N. Rao, M. Winnewisser, B.P. Winnewisser, O.V. Naumenko, A.D. Bykov, L.N. Sinitsa, The $3 v_{2}+v_{3}, v_{1}+v_{2}+v_{3}, v_{1}+3 v_{2}, 2 v_{1}+v_{2}$, and $v_{2}+2 v_{3}$ bands of $\mathrm{D}_{2}{ }^{16} \mathrm{O}$ : The second hexade of interacting states, J. Mol. Spectrosc. 158 (1993) 109-130.

[65] G.Ch. Mellau, S.N. Mikhailenko, E.N. Starikova, S.A. Tashkun, H. Over, Vl.G. Tyuterev, Rotational levels of the (000) and (010) states of $\mathrm{D}_{2}{ }^{16} \mathrm{O}$ from hot emission spectra in the 320-860 $\mathrm{cm}^{-1}$ region, J. Mol. Spectrosc. 224 (2004) 32-60.

[66] S.V. Shirin, N.F. Zobov, O.L. Polyansky, Theoretical line list of $\mathrm{D}_{2}{ }^{16} \mathrm{O}$ up to $16,000 \mathrm{~cm}^{-1}$ with an accuracy close to experimental, J. Quant. Spectrosc. Radiat. Trans. 109 (2008) 549-558.

[67] http://spectra.iao.ru, Tomsk, 2012.

[68] A.-W. Liu, K.-F. Song, H.-Y. Ni, S.-M. Hu, O.V. Naumenko, I.A.Vasilenko, S.N. Mikhailenko, (000) and (010) energy levels of the $\mathrm{HD}^{18} \mathrm{O}$ and $\mathrm{D}_{2}{ }^{18} \mathrm{O}$ molecules from analysis of their $v_{2}$ bands, J. Mol. Spectrosc. 265 (2011) 26-38.

[69] H.-Y. Ni, A.-W. Liu, K.-F. Song, S.-M. Hu, O.V. Naumenko, T.V. Kruglova, S.A. Tashkun. High-resolution spectroscopy of the triple-substituted isotopologue of water $\mathrm{D}_{2}{ }^{18} \mathrm{O}$ : the first triad, Mol. Phys. 106 (2008) 1793-1801.

[70] J. Tennyson, P.F. Bernath, L.R. Brown, A. Campargue, A.G. Császár, L. Daumont, R.R. Gamache, J.T. Hodges, O.V. Naumenko, O.L. Polyansky, L.S. Rothman, A.C. Vandaele, N.F. Zobov, N. Dénes, A.Z. Fazliev, T. Furtenbacher, I.E. Gordon, S.-M. Hu, T. Szidarovszky, I.A. Vasilenko, IUPAC critical evaluation of the rotational-vibrational spectra of water vapor. Part IV: Energy levels and transition wavenumbers for $\mathrm{D}_{2}{ }^{16} \mathrm{O}, \mathrm{D}_{2}{ }^{17} \mathrm{O}$, and $\mathrm{D}_{2}{ }^{18} \mathrm{O}$, J. Quant. Spectrosc. Radiat. Trans. 142 (2014) 93-108.

[71] H. Partridge, D.W. Schwenke, The determination of an accurate isotope dependent potential energy surface for water from extensive ab initio calculations and experimental data, J. Chem. Phys. 106 (1997) 4618-4639.

[72] I.E. Gordon, L.S. Rothman, R.R. Gamache, D. Jacquemart, C. Boone, P.F. Bernath, M.W. Shephard, J.S. Delamere, S.A. Clough, Current updates of the water-vapor line list in HITRAN: A new "Diet" for air-broadened half-widths, J. Quant. Spectrosc. Radiat. Trans. 108 (2007) 389-402. doi:10.1016/j.jqsrt.2007.06.009. 
[73] R.R. Gamache, A.L. Laraia, $\mathrm{N}_{2^{-}}, \mathrm{O}_{2^{-}}$, and air-broadened half-widths, their temperature dependence, and line shifts for the rotation band of $\mathrm{H}_{2}{ }^{16} \mathrm{O}$, J. Mol. Spectrosc. 257 (2009) 116-127. doi:10.1016/j.jms.2009.07.004.

[74] R.R. Gamache, Line shape parameters for water vapor in the 3.2 to $17.76 \mu \mathrm{m}$ region for atmospheric applications, J. Mol. Spectrosc. 229 (2005) 9-18. doi:10.1016/j.jms.2004.08.004.

[75] D. Jacquemart, R. Gamache, L.S. Rothman, Semi-empirical calculation of air-broadened halfwidths and air pressure-induced frequency shifts of water-vapor absorption lines, J. Quant. Spectrosc. Radiat. Trans. 96 (2005) 205-239. doi:10.1016/j.jqsrt.2004.11.018.

[76] L.S. Rothman, I.E. Gordon, R.J. Barber, H. Dothe, R.R. Gamache, A. Goldman, V.I. Perevalov, S.A. Tashkun, J. Tennyson, HITEMP, the high-temperature molecular spectroscopic database, J. Quant. Spectrosc. Radiat. Trans. $111 \quad$ (2010) 2139-2150. doi:10.1016/j.jqsrt.2010.05.001.

[77] R.R. Gamache. University of Massachusetts Lowell. Unpublished results. (2014).

[78] M. Birk, G. Wagner, Temperatue-dependent air broadening of water in the $1250-1750 \mathrm{~cm}^{-1}$ range, J. Quant. Spectrosc. Radiat. Trans. 113 (2012) 889-928. doi:10.1016/j.jqsrt.2011.12.013.

[79] C.P. Rinsland, M.A.H. Smith, V. Malathy Devi, D. Chris Benner, Measurements of Lorentzbroadening coefficients and pressure-induced line shift coefficients in the $v_{2}$ band of $\mathrm{D}_{2}{ }^{16} \mathrm{O}, \mathrm{J}$. Mol. Spectrosc. 150 (1991) 173-183.

[80] V. Malathy Devi, C.P. Rinsland, D. Chris Benner, M.A.H. Smith, Tunable diode laser measurements of air and $\mathrm{N}_{2}$ broadened half-widths in the $v_{2}$ band of $\mathrm{D}_{2} \mathrm{O}$, Appl. Opt. 25 (1986) 336-338.

[81] C.P. Rinsland, M.A.H. Smith, V. Malathy Devi, D. Chris Benner, Measurements of Lorentzbroadening coefficients and pressure-induced line shift coefficients in the $v_{1}$ band of $\mathrm{HD}^{16} \mathrm{O}$ and the $v_{3}$ band of $\mathrm{D}_{2}{ }^{16} \mathrm{O}$, J. Mol. Spectrosc. 156 (1992) 507-511.

[82] R.A. Toth, Air- and $\mathrm{N}_{2}$-broadening parameters of $\mathrm{HDO}$ and $\mathrm{D}_{2} \mathrm{O}, 709$ to $1931 \mathrm{~cm}^{-1}$, J. Mol. Spectrosc. 198 (1999) 358-370.

[83] R.R. Gamache, M. Farese, C.L. Renaud, A spectral line list for water isotopologues in the $1100-4100 \mathrm{~cm}^{-1}$ region for application to $\mathrm{CO}_{2}$-rich planetary atmospheres, J. Mol. Spectrosc. (in press). doi:10.1016/j.jms.2015.09.001.

[84] S.A. Tashkun, V.I. Perevalov, R.R. Gamache, J. Lamouroux, CDSD-296, high resolution carbon dioxide spectroscopic databank: Version for atmospheric applications, J. Quant. Spectrosc. Radiat. Transfer 152 (2015) 45-73.

[85] D. Jacquemart, F. Gueye, O.M. Lyulin, E.V. Karlovets, D. Baron, V.I. Perevalov, Infrared spectroscopy of $\mathrm{CO}_{2}$ isotopologues from 2200 to $7000 \mathrm{~cm}^{-1}$ : I-Characterizing experimental uncertainties of positions and intensities, Quant. Spectrosc. Radiat. Transfer 113 (2012) 961-975.

[86] O.M. Lyulin, E.V. Karlovets, D. Jacquemart, Y. Lu, A.W. Liu, V.I. Perevalov, Infrared spectroscopy of ${ }^{17} \mathrm{O}$ - and ${ }^{18} \mathrm{O}$-enriched carbon dioxide in the $1700-8300 \mathrm{~cm}^{-1}$ wavenumber region, Quant. Spectrosc. Radiat. Transfer 113 (2012) 2167-2181.

[87] Yu.G. Borkov, D. Jacquemart, O.M. Lyulin, S.A. Tashkun, V.I. Perevalov, Infrared spectroscopy of ${ }^{17} \mathrm{O}$ - and ${ }^{18} \mathrm{O}$-enriched carbon dioxide: Line positions and intensities in the 3200$4700 \mathrm{~cm}^{-1}$ region. Global modeling of the line positions of ${ }^{16} \mathrm{O}^{12} \mathrm{C}^{17} \mathrm{O}$ and ${ }^{17} \mathrm{O}^{12} \mathrm{C}^{17} \mathrm{O}$, Quant. Spectrosc. Radiat. Transfer 137 (2014) 967-975. 
[88] Yu.G. Borkov, D. Jacquemart, O.M. Lyulin, S.A. Tashkun, V.I. Perevalov, Infrared spectroscopy of ${ }^{17} \mathrm{O}$ - and ${ }^{18} \mathrm{O}$-enriched carbon dioxide: Line positions and intensities in the 4681$5337 \mathrm{~cm}^{-1}$ region, Quant. Spectrosc. Radiat. Transfer 159 (2015) 1-10.

[89] E.V. Karlovets, A. Campargue, D.Mondelain, S.Beguier, S. Kassi, S.A. Tashkun, V.I. Perevalov, High sensitivity Cavity Ring Down spectroscopy of ${ }^{18} \mathrm{O}$ enriched carbon dioxide between 5850 and $7000 \mathrm{~cm}^{-1}$ : I. Analysis and theoretical modeling of the ${ }^{16} \mathrm{O}^{12} \mathrm{C}^{18} \mathrm{O}$ spectrum, J. Quant. Spectrosc. Radiat. Transfer 130 (2013) 116-133.

[90] E.V. Karlovets, A. Campargue, D.Mondelain, S. Kassi, S.A. Tashkun, V.I. Perevalov, High sensitivity Cavity Ring Down spectroscopy of ${ }^{18} \mathrm{O}$ enriched carbon dioxide between 5850 and 7000 $\mathrm{cm}^{-1}$ : Part II-Analysis and theoretical modeling of the ${ }^{12} \mathrm{C}^{18} \mathrm{O}_{2},{ }^{13} \mathrm{C}^{18} \mathrm{O}_{2}$ and ${ }^{16} \mathrm{O}^{13} \mathrm{C}^{18} \mathrm{O}$ spectra, J. Quant. Spectrosc. Radiat. Transfer 136 (2014) 71-88.

[91] E.V. Karlovets, A. Campargue, D.Mondelain, S. Kassi, S.A. Tashkun, V.I. Perevalov, High sensitivity Cavity Ring Down spectroscopy of ${ }^{18} \mathrm{O}$ enriched carbon dioxide between 5850 and 7000 $\mathrm{cm}^{-1}$ : Part III-Analysis and theoretical modeling of the ${ }^{12} \mathrm{C}^{17} \mathrm{O}_{2},{ }^{16} \mathrm{O}^{12} \mathrm{C}^{17} \mathrm{O},{ }^{17} \mathrm{O}^{12} \mathrm{C}^{18} \mathrm{O},{ }^{16} \mathrm{O}^{13} \mathrm{C}^{17} \mathrm{O}$ and ${ }^{17} \mathrm{O}^{13} \mathrm{C}^{18} \mathrm{O}$ spectra, J. Quant. Spectrosc. Radiat. Transfer 136 (2014) 89-107.

[92] K.-F. Song, Y. Lu, Y. Tan, B. Gao, A.-W. Liu, S.-M. Hu, High sensitivity cavity ring down spectroscopy of CO overtone bands near 790 nm, J. Quant. Spectrosc. Radiat. Transfer 112 (2011) 761-768.

[93] Y. Lu, A.-W. Liu, H. Pan, X.-F. Li, V.I. Perevalov, S.A. Tashkun, S.-M. Hu, High sensitivity cavity ring down spectroscopy of ${ }^{13} \mathrm{C}^{16} \mathrm{O}_{2}$ overtone bands near $806 \mathrm{~nm}$, J. Quant. Spectrosc. Radiat. Transfer 113 (2012) 2197-2204.

[94] H. Pan, X.-F. Li, Y. Lu, A.-W. Liu, V.I. Perevalov, S.A. Tashkun, S.-M. Hu, Cavity ring down spectroscopy of ${ }^{18} \mathrm{O}$ and ${ }^{17} \mathrm{O}$ enriched carbon dioxide near $795 \mathrm{~nm}$, J. Quant. Spectrosc. Radiat. Transfer 114 (2013) 42-44.

[95] D. Golebiowski, M. Herman, O.M. Lyulin, ${ }^{16} \mathrm{O}^{12} \mathrm{C}^{17} \mathrm{O}$ and ${ }^{18} \mathrm{O}^{12} \mathrm{C}^{17} \mathrm{O}$ spectroscopy in the $1.2-$ 1.25 mm region, Can. J. Phys. 91 (2013) 963-965.

[96] O.L. Polyansky, K. Bielska, M. Ghysels, L. Lodi, N.F. Zobov, J.T. Hodges and J. Tennyson, High accuracy $\mathrm{CO}_{2}$ line intensities determined from theory and experiment, Phys. Rev. Lett. 114 (2015) 243001.

[97] E. Zak, J. Tennyson, O.L. Polyansky, L. Lodi, S.A. Tashkun and V.I. Perevalov, A room temperature $\mathrm{CO}_{2}$ line list with ab initio computed intensities, J. Quant. Spectrosc. Rad. Transfer 177 (2016) 31-42.

[98] R.R. Gamache, J. Lamouroux, V. Blot-Lafon, E. Lopes, An intercomparison of measured pressure-broadening, pressure shifting parameters of carbon dioxide and their temperature dependence, J. Quant. Spectrosc. Radiat. Transfer 135 (2014) 30-43.

[99] R.R. Gamache, J. Lamouroux, A.L. Laraia, J.-M. Hartmann, C. Boulet, Semiclassical calculations of half-widths and line shifts for transitions in the $30012 \longleftarrow 00001$ and $30013 \leftarrow 00001$ bands of $\mathrm{CO}_{2}$ I: Collisions with $\mathrm{N}_{2}$, J. Quant. Spectrosc. Radiat. Transfer 113 (2012) 976-990.

[100] J. Lamouroux, R.R. Gamache, A.L. Laraia, J.-M. Hartmann, C. Boulet, Semiclassical calculations of half-widths and line shifts for transitions in the $30012 \leftarrow 00001$ and $30013 \leftarrow 00001$ bands of $\mathrm{CO}_{2}$ II: collisions with $\mathrm{O}_{2}$ and Air, J. Quant. Spectrosc. Radiat. Transfer 113 (2012) 9911003.

[101] J. Lamouroux, R.R. Gamache, A.L. Laraia, J.-M. Hartmann, C. Boulet, Semiclassical calculations of half-widths and line shifts for transitions in the $30012 \leftarrow 00001$ and $30013 \leftarrow 00001$ bands of $\mathrm{CO}_{2}$ III: self collisions, J. Quant. Spectrosc. Radiat. Transfer 113 (2012) 1536-1546. 
[102] R.R. Gamache, J. Lamouroux, The vibrational dependence of half-widths of $\mathrm{CO}_{2}$ transitions broadened by $\mathrm{N}_{2}, \mathrm{O}_{2}$, air, and $\mathrm{CO}_{2}$, J. Quant. Spectrosc. Radiat. Transfer 117 (2012) 93-103.

[103] R.R. Gamache, J.-M. Hartmann, Collisional parameters of $\mathrm{H}_{2} \mathrm{O}$ lines: effects of vibration, J. Quant. Spectrosc. Radiat. Transfer 83 (2004) 119-147.

[104] R.R Gamache, J. Lamouroux, Predicting accurate line shape parameters for CO2 transitions, J. Quant. Spectrosc. Radiat. Transfer 130 (2013) 158-171.

[105] X. Huang, R.R. Gamache, R.S. Freedman, D.W. Schwenke, T.J. Lee, Reliable InfraRed Line Lists for ${ }^{13} \mathrm{CO}_{2}$ Isotopologues up to $\mathrm{E}^{\prime}=18,000 \mathrm{~cm}-1$ and $1500 \mathrm{~K}$, with Line Shape Parameters, J. Quant. Spectrosc. Radiat. Transfer 147 (2014) 134-144.

[106] A. Barbe, M.-R. De Backer, E. Starikova, S.A. Tashkun, X. Thomas, Vl.G. Tyuterev, FTS high resolution spectra of ${ }^{16} \mathrm{O}_{3}$ in 3500 and $5500 \mathrm{~cm}^{-1}$ regions. First example of new theoretical modelling for a polyad of strongly coupled states, J. Quant. Spectrosc. Radiat. Transfer 113 (2012) 829-839.

[107] A. Barbe. Université de Reims Champagne-Ardenne. Private communication. (2011).

[108] A. Barbe, J.J. Plateaux, S.N. Mikhailenko, Vl.G. Tyuterev, Infrared spectrum of ozone in the 4600 and $5300 \mathrm{~cm}^{-1}$ regions: High order accidental resonances through the analysis of the $v_{1}+2 v_{2}+3 v_{3}-v_{2}, v_{1}+2 v_{2}+3 v_{3}$, and $4 v_{1}+v_{3}$ bands, J. Molec. Spectrosc. 185 (1997) 408-416.

[109] A. Barbe, J.J. Plateaux, Vl.G. Tyuterev, S.N. Mikhailenko, Analysis of high resolution measurements of the $2 v_{1}+3 v_{3}$ band of ozone: Coriolis interaction with the $v_{1}+3 v_{2}+2 v_{3}$ band, J. Quant. Spectrosc. Radiat. Transfer 59 (1998) 185-194.

[110] A. Barbe, A. Chichery, The $2 v_{1}+v_{2}+3 v_{3}$ band of ${ }^{16} \mathrm{O}_{3}$. Line positions and intensities, J. Molec.Spectrosc. 192 (1998) 102-110.

[111] A. Barbe, A. Chichery, Vl.G. Tyuterev, J.J. Plateaux, Analysis of high resolution measurements of the $v_{1}+5 v_{3}$ band of ozone: Coriolis interactions with the $6 v_{3}$ and $3 v_{1}+v_{2}+2 v_{3}$ bands, Molec.Phys. 94 (1998) 751-757.

[112] A. Barbe, M.-R. De Backer, Vl.G. Tyuterev, A. Campargue, D. Romanini, S. Kassi, CWcavity ring down spectroscopy of ozone molecule in the $5980-6220 \mathrm{~cm}^{-1}$ region, J. Molec.Spectrosc. 242 (2007) 156-175.

[113] A. Barbe, M.-R. De Backer, Vl.G. Tyuterev, S. Kassi, A. Campargue, CW-cavity ring down spectroscopy of ozone molecule in the $6220-6400 \mathrm{~cm}^{-1}$ region, J. Molec.Spectrosc. 246 (2007) 2238.

[114] A. Campargue, M.-R. De Backer-Barilly, A. Barbe, Vl.G. Tyuterev, S. Kassi, The near infrared spectrum of ozone by CW-cavity ring down spectroscopy between 5850 and $7000 \mathrm{~cm}^{-1}$ : New observations and exhaustive review, Phys. Chem. Chem. Phys. 10 (2008) 2925-2946.

[115] A. Campargue, S. Kassi, D. Romanini, A. Barbe, M.-R. De Backer, Vl.G. Tyuterev, CWcavity ring down spectroscopy of ozone molecule in the $6625-6830 \mathrm{~cm}^{-1}$ region, J. Molec.Spectrosc. 240 (2006) 1-13.

[116] Y.L. Babikov, S.N. Mikhailenko, A. Barbe, Vl.G. Tyuterev, S\&MPO - an information system for ozone spectroscopy on the WEB, J. Quant. Spectrosc. Radiat. Transfer 145 (2014) 169196.

[117] S.N. Mikhailenko, A. Barbe, M.-R. De Backer-Barilly, Vl.G. Tyuterev, Update of line parameters of ozone in the 2550-2900 cm $\mathrm{cm}^{-1}$ region, Appl. Opt. 47 (2008) 4612-4618.

[118] A. Barbe, S. Mikhailenko, E. Starikova, M.-R. De Backer, Vl.G. Tyuterev, D. Mondelain, S. Kassi, A. Campargue, C. Janssen, S. Tashkun, R. Kochanov, R. Gamache. Ozone spectroscopy in 
the electronic ground state: High resolution spectra analyses and update of line parameters since 2003. J. Quant. Spectrosc. Radiat.Transfer 130 (2013) 172-190.

[119] A. Barbe, S.N. Mikhailenko, Vl.G. Tyuterev, A. Hamdouni, J.J. Plateaux, Analysis of the $2 v_{1}+2 v_{2}+v_{3}$ band of ozone, J. Molec.Spectrosc. 171 (1995) 538-588.

[120] S. Mikhailenko, A. Barbe, Vl.G. Tyuterev, L. Régalia L, J.J. Plateaux, Line positions and intensities of the $v_{1}+v_{2}+3 v_{3}, v_{2}+4 v_{3}$, and $3 v_{1}+2 v_{2}$ bands of ozone, J. Molec.Spectrosc. 180 (1996) 227-235.

[121] J.-M. Flaud, A. Barbe, C. Camy-Peyret, J.J. Plateaux, High resolution analysis of the $5 v_{3}$, $3 v_{1}+v_{2}+v_{3}$, and $v_{1}+4 v_{3}$ bands of ${ }^{16} \mathrm{O}_{3}$ : Line positions and intensities, J. Molec.Spectrosc. 177 (1996) 34-39.

[122] Vl.G. Tyuterev, R. Kochanov, A. Campargue, S. Kassi, D. Mondelain, A. Barbe, E. Starikova, M.R. De Backer, P.G. Szalay, S. Tashkun, Does the "reef structure" at the ozone transition state towards the dissociation exist? New insight from calculations and ultrasensitive spectroscopy experiments, Phys. Rev. Lett. 113 (2014) 143002.

[123] R.O. Manuilova, O.A. Gusev, A.A. Kutepov, T. von Clarmann, H. Oelhaf, G.P. Stiller, A. Wegner, M. López-Puertas, F.J. Martin-Torres, G. Zaragoza, J.-M. Flaud, Modelling of non-LTE limb spectra of i.r. ozone bands for the MIPAS space experiment, J. Quant. Spectrosc. Radiat. Transfer 59 (1998) 405-422.

[124] G. Funke, M. López-Puerta, M. García-Comas, M. Kaufmann, M. Höpfner, G.P. Stiller, GRANADA: A Generic RAdiative traNsfer AnD non-LTE population algorithm, J. Quant. Spectrosc. Radiat. Transfer 113 (2012) 1771-1817.

[125] C. Clerbaux, J. Drummond, J.M. Flaud, J. Orphal. Thermal infrared: absorption and emission - trace gases and parameters. The Remote Sensing of Tropospheric Composition from Space, J.P. Burrows, U. Platt, and P. Borrell (eds.), ISBN 978-3-642-14790-6, Springer Verlag, Heidelberg and New York, 2011, Chapter 3, pp. 123-152.

[126] Vl.G. Tyuterev, S. Tashkun, M. Rey, R. Kochanov, A. Nikitin, T. Delahaye. Accurate spectroscopic models for methane polyads derived from a potential energy surface using high-order contact transformations. J. Phys. Chem. A 117 (2013) 13779-13805.

[127] Vl.G. Tyuterev, R.V. Kochanov, S.A. Tashkun, F. Holka, P. Szalay, New analytical model for the ozone electronic ground state potential surface and accurate ab initio vibrational predictions at high energy range, J. Chem. Phys. 139 (2013) 134307.

[128] J.J. Plateaux, L. Régalia, C. Boussin, A. Barbe, Multispectrum fitting technique for data recorded by Fourier transform spectrometer: Application to $\mathrm{N}_{2} \mathrm{O}$ and $\mathrm{CH}_{3} \mathrm{D}$, J. Quant. Spectrosc. Radiat.Transfer 68 (2001) 507-520.

[129] J.M. Flaud, G. Wagner, M. Birk, C. Camy-Peyret, C. Claveau, M.R. De Backer-Barilly, A. Barbe, C. Piccolo, Ozone absorption around $10 \mu \mathrm{m}$, J. Geophys. Res. 108D (2003) 4269. doi:10.1029/2002JD002755

[130] M.A.H. Smith, V. Malathy Devi, D. Chris Benner, The quest for ozone intensities in the 9-11 mm region: A retrospective, J. Quant. Spectrosc. Radiat. Transfer 113 (2012) 825-828.

[131] F. Holka, P.G. Szalay, T. Muller, Vl.G. Tyuterev, Toward an improved ground state potential energy surface of ozone, J. Phys.Chem. A 114 (2010) 9927-9935.

[132] A. Nikitin, V. Boudon, Ch. Wenger, S. Albert, L. R. Brown, S. Bauerecker, M. Quack, High Resolution Spectroscopy and First Global Analysis of the Tetradecad Region of Methane ${ }^{12} \mathrm{CH}_{4}$. Phys. Chem. Chem. Phys, 15 (2013) 10071-10093. 
[133] H.-M. Niederer, X.-G. Wang, T. Carrington Jr., S. Albert, S. Bauerecker, V. Boudon, Analysis of the rovibrational spectrum of methane ${ }^{13} \mathrm{CH}_{4}$ in the infrared, J. Molec. Spectrosc. 291 (2013) 33-47.

[134] L. R. Brown, K. Sung, D. C. Benner, V. M. Devi, V. Boudon, T. Gabard, Ch. Wenger, A. Campargue, O. Leshchishina, S. Kassi, D. Mondelain, L. Wang, L. Daumont, L. Régalia, M. Rey, X. Thomas, Vl. G. Tyuterev, O. M. Lyulin, A. V. Nikitin, H. M. Niederer, S. Albert, S. Bauerecker, M. Quack, J. J. O’Brien, I. E. Gordon, L. S. Rothman, H. Sassada, A. Coustenis, M. A. H. Smith, T. Carrington Jr., X. G. Wang, A. W. Manz, P. T. Spickler, Methane Line Parameters in the HITRAN Database, J. Quant. Spectrosc. Radiat. Transf. 130 (2013) 201-219.

[135] R. Checa-Garcia, J. Landgraf, A. Galli, F. Hase, V. A. Velazco, H. Tran. V. Boudon, F. Alkemade, A. Butz, Mapping spectroscopic uncertainties into prospective methane retrieval errors from Sentinel-5 and its precursor, 8 (2015) 3617-3629.

[136] B. Amyay, M. Louviot, O. Pirali, R. Georges, J. Vander Auwera, V. Boudon, Global Analysis of the High Temperature Infrared Emission Spectrum of ${ }^{12} \mathrm{CH}_{4}$ in the Dyad $\left(v_{2} / v_{4}\right)$ Region, J. Chem. Phys. 144 (2016) 024312.

[137] V. M. Devi, D. C. Benner, K. Sung, T. J. Crawford, S. Yu, L. R. Brown, M. A. H. Smith, A. Mantz, V. Boudon, S. Ismail, Self- and Air-broadened Line Shapes in the $2 v_{3} P$ and $R$ Branches of ${ }^{12} \mathrm{CH}_{4}$, J. Molec. Spectrosc. 315 (2015) 114-136.

[138] V. M. Devi, D. C. Benner, K. Sung, L. R. Brown, T. J. Crawford, S. Yu, M. A. H. Smith, A. W. Mantz, V. Boudon, S. Ismail, Spectral Line Parameters Including Line Shapes in the $2 v_{3}$ Q Branch of ${ }^{12} \mathrm{CH}_{4}$, J. Quant. Spectrosc. Radiat. Transf. 177 (2016) 152-169.

[139] L. Brown, Empirical line parameters of methane from 1.1 to $2.1 \mu \mathrm{m}, \mathrm{J}$. Quant. Spectrosc. Radiat. Transf. 96 (2005) 251-270.

[140] A. Campargue (Private communication 2014)

[141] A. Campargue, O. Leshchishina, L. Wang, D. Mondelain, S. Kassi, The WKLMC empirical line lists $\left(5852-7919 \mathrm{~cm}^{-1}\right)$ for methane between $80 \mathrm{~K}$ and 296K: "final" lists in HITRAN format for atmospheric and planetary applications, J. Molec. Spectrosc. 291 (2013) 16-22.

[142] A. Campargue, O. Leshchishina, L. Wang, D. Mondelain, S. Kassi, A.V. Nikitin, Refinements of the WKMC empirical line lists $\left(5852-7919 \mathrm{~cm}^{-1}\right)$ for methane between $80 \mathrm{~K}$ and 296 K, J. Quant. Spectrosc. Radiat. Transf. 113 (2012) 1855-1873.

[143] L. Wang, S. Kassi, A. Campargue, Temperature dependence of the absorption spectrum of $\mathrm{CH}_{4}$ by high resolution spectroscopy at $81 \mathrm{~K}$ : (I) The region of the $2 v_{3}$ band at $1.66 \mu \mathrm{m}$, J. Quant. Spectrosc. Radiat. Transf. 111 (2010) 1130-1140.

[144] A. Campargue, L. Wang, D. Mondelain, S.Kassi, B. Bézard, E. Lellouch, M. Hirtzig, A Coustenis, C. de Bergh, P. Drossart, A complete empirical line list for methane at $80 \mathrm{~K}$ and $296 \mathrm{~K}$ (1.26-1.71 $\mu \mathrm{m})$ for planetary applications. Icarus. 219 (2012) 110-128.

[145] A. Campargue, O. Leshchishina, D. Mondelain, S. Kassi, A. Coustenis, An improved empirical line list for methane in the region of the $2 v_{3}$ band at $1.66 \mu \mathrm{m}$. J. Quant. Spectrosc. Radiat. Transf. 118 (2013) 49-59.

[146] A. Campargue, L. Wang, S. Kassi, M. Mašát, O. Votava, Temperature dependence of the absorption spectrum of $\mathrm{CH}_{4}$ by high resolution spectroscopy at $81 \mathrm{~K}$ : (II) The icosad region (1.49$1.30 \mu \mathrm{m})$. J. Quant. Spectrosc. Radiat, Transf. 111 (2010) 1141-1151. 
[147] O. Votava, M. Mašát, P. Pracna, S. Kassi, A. Campargue, Accurate determination of low state rotational quantum numbers $(J<4)$ from planar-jet and liquid nitrogen cell absorption spectra of methane near 1.4 micron, Phys. Chem. Chem. Phys. 12 (2010) 3145-3155.

[148] L. Wang, D. Mondelain, S. Kassi, A. Campargue, The absorption spectrum of methane at 80 $\mathrm{K}$ and $294 \mathrm{~K}$ in the icosad $\left(6717-7589 \mathrm{~cm}^{-1}\right)$ : improved empirical line lists, isotopologue identification and temperature dependence, J. Quant. Spectrosc. Radiat. Transf. 113 (2012) 47-57.

[149] A. Campargue, L. Wang, A. W. Liu, S. M. Hu, S. Kassi, Empirical line parameters of methane in the 1.63-1.48 $\mu \mathrm{m}$ transparency window by high sensitivity Cavity Ring Down Spectroscopy, Chem. Phys. 373 (2010) 203-210.

[150] A.V. Nikitin, X. Thomas, L. Régalia, L.Daumont, P. Von der Heyden,Vl.G. Tyuterev, L. Wang, S. Kassi, A. Campargue, Assignment of the $5 v_{4}$ and $v_{2}+4 v_{4}$ band systems of ${ }^{12} \mathrm{CH}_{4}$ in the 6287-6550 $\mathrm{cm}^{-1}$ region, J. Quant. Spectrosc. Radiat. Transf. 112 (2011) 28-40.

[151] L. Wang, S. Kassi, A. Liu, S. Hu, A. Campargue, The $1.58 \mu \mathrm{m}$ transparency window of methane $\left(6165-6750 \mathrm{~cm}^{-1}\right)$ : empirical line list and temperature dependence between $80 \mathrm{~K}$ and 296 K, J. Quant. Spectrosc. Radiat. Transf. 112 (2011) 937-951.

[152] D. Mondelain, S. Kassi, L. Wang, A. Campargue, The $1.28 \mu \mathrm{m}$ transparency window of methane (6165-6750 $\left.\mathrm{cm}^{-1}\right)$ : empirical line list and temperature dependence between $80 \mathrm{~K}$ and 296 K, Phys. Chem. Chem. Phys. 17 (2011) 7985-7996.

[153] L.A. Sromovsky, P.M. Fry, V. Boudon, A. Campargue, A. Nikitin, Comparison of line-byline and band models of near-IR methane absorption applied to outer planet atmospheres, Icarus 218 (2012) 1-23.

[154] P.G.J. Irwin, C. de Bergh, R. Courtin, B. Bézard, N.A. Teanby, G.R. Davis, L.N. Fletcher, G.S. Orton, S.B. Calcutt, D. Tice, J. Hurley, The application of new methane line absorption data to Gemini-N/NIFS and KPNO/FTS observations of Uranus' near- infrared spectrum, Icarus 220 (2012) 369-382.

[155] E. Lellouch, B. Sicardy, C. De Bergh, H.-U. Kaufl, S. Kassi, A. Campargue, Pluto’s lower atmosphere structure and methane abundance from high-resolution spectroscopy and stellar occultations, Astron. Astrophys. 495 (2009) L17-L21.

[156] C.de Bergh, R.Courtin, B. Bézard, A. Coustenis, E.Lellouch, M.Hirtzig, P. Rannou, P. Drossart, A. Campargue, S. Kassi, L. Wang, V. Boudon, A. Nikitin, V. Tyuterev, Applications of a new set of methane line parameters to the modeling of Titan's spectrum in the 1.58 micron window, Planetary and Space Science 61 (2012) 85-99.

[157] L. Wang, S. Kassi, A. Liu, S. Hu, A. Campargue, High sensitivity absorption spectroscopy of methane at $80 \mathrm{~K}$ in the $1.58 \mu \mathrm{m}$ transparency window: Temperature dependence and importance of the $\mathrm{CH}_{3} \mathrm{D}$ contribution, J. Molec. Spectrosc. 261 (2010) 41-52.

[158] S. Kassi, B. Gao, D. Romanini, A. Campargue, The near infrared (1.30 - $1.70 \mu \mathrm{m})$ absorption spectrum of methane down to 77 K, Phys. Chem. Chem. Phys. 10 (2008) 4410-4419.

[159] A.V. Nikitin, O.M. Lyulin, S. N. Mikhailenko, V. I. Perevalov, N.N. Filippov, I.M. Grigoriev, I. Morino, T. Yokota, R. Kumazawa, T. Watanabe, GOSAT-2009 methane spectral line list in the 5550-6236 cm $\mathrm{cm}^{-1}$ range, J. Quant Spectrosc Radiat Transf. 111 (2010) 2211-2224.

[160] S. Béguier, S. Kassi, A. Campargue, An empirical line list for methane in the $1.25 \mu \mathrm{m}$ transparency window, J. Molec. Spectrosc. 308-309 (2015) 1-5.

[161] S. Béguier, A. W. Liu, A. Campargue, An empirical line list for methane near $1 \mu \mathrm{m}(9028$ $10435 \mathrm{~cm}^{-1}$ ), J. Quant. Spectrosc. Radiat. Transf. 166 (2015) 6-12. 
[162] D. Chris Benner, V. Malathy Devi, J.J. O’Brien, S. Shaji, P.T. Spickler, C.P. Houck, J.A. Coakley, J. Dolph, K. Rankin, Empirical line parameters of $\mathrm{CH}_{4}$ from 10923 to $11502 \mathrm{~cm}^{-1}$, in preparation. Private communication 2015.

[163] I. E. Gordon, S. Kassi, A. Campargue, G. C. Toon, First identification of the electric quadrupole transitions of oxygen in solar and laboratory spectra, J. Quant. Spectrosc. Radiat. Transfer 111 (2010), $1174-1183$.

[164] I. E. Gordon, L. S. Rothman, G. C. Toon, Revision of spectral parameters for the B- and $\gamma-$ bands of oxygen and their validation against atmospheric spectra, J. Quant. Spectrosc. Radiat. Transfer 112 (2011), 2310 - 2322.

[165] O. Leshchishina, S. Kassi, I. E. Gordon, L. S. Rothman, L. Wang, A. Campargue, High sensitivity CRDS of the $a^{1} \Delta_{g}-X^{3} \Sigma_{g}^{-}$band of oxygen near $1.27 \mu \mathrm{m}$ : Extended observations, quadrupole transitions, hot bands and minor isotopologues, J. Quant. Spectrosc. Radiat. Transfer 111 (2010), $2236-2245$.

[166] O. Leshchishina, S. Kassi, I. E. Gordon, S. Yu, A. Campargue, The ${ }^{a^{\mathbf{1}} \Delta_{g}-X^{\mathbf{3}} \Sigma_{g}^{-}}$band of ${ }^{16} \mathrm{O}^{17} \mathrm{O},{ }^{17} \mathrm{O}^{18} \mathrm{O}$ and ${ }^{17} \mathrm{O}_{2}$ by high sensitivity CRDS near $1.27 \mu \mathrm{m}$, J. Quant. Spectrosc. Radiat. Transfer 112 (2011), 1257 - 1265.

[167] D. A. Long, D. K. Havey, M. Okumura, H. M. Pickett, C. E. Miller and J. T. HODGES, Laboratory measurements and theoretical calculations of $\mathrm{O}_{2}$ A-band electric quadrupole transitions, Phys. Rev. A 80 (2009), 042513.

[168] D. A. Long, D. K. Havey, M. Okumura, C. E. Miller and J. T. Hodges, $\mathrm{O}_{2}$ A-band line parameters to support atmospheric remote sensing, J. Quant. Spectrosc. Radiat. Transfer 111 (2010), $2021-2036$.

[169] D. A. Long, D. K. Havey, S. Yu, M. Okumura, C. E. Miller, J. T. Hodges, $\mathrm{O}_{2}$ A-band line parameters to support atmospheric remote sensing. Part II: The rare isotopologues, J. Quant. Spectrosc. Radiat. Transfer 112 (2011), 2527 - 2541.

[170] S. Yu, B. Drouin, and C. Miller, High resolution spectral analysis of oxygen IV. Energy levels, partition sums, band constants, RKR potentials, Franck-Condon factors involving the $X_{g}^{3}, a_{g}^{1}$, and $b_{g}^{1}{ }_{g}^{+}$states, J. Chem. Phys. 141 (2014), 174302.

[171] B. Drouin, H. Gupta, S. Yu, C. Miller, and H. Muller, High resolution spectral analysis of oxygen II. rotational spectra of $a^{1}{ }_{g} \mathrm{O}_{2}$ isotopologues, J. Chem. Phys. 137 (2012), 024305.

[172] B. Drouin, S. Yu, B. Elliott, T. Crawford, and C. Miller, High resolution spectral analysis of oxygen III. Laboratory investigation of the airglow bands, J. Chem. Phys. 139 (2013), 144301.

[173] S. Yu, C. Miller, B. Drouin, and H. Muller, High resolution spectral analysis of oxygen I. isotopically invariant Dunham fit for the $X_{g}^{3}, a_{g}^{1}, b_{g}^{1}{ }_{g}^{+}$states, J. Chem. Phys. 137 (2012), 024304.

[174] H. Edwards, D. Long, and K. Najm, The pure rotation Raman spectrum of ${ }^{17} \mathrm{O}^{18} \mathrm{O}$, J. Raman Spectrosc. 17 (1986), $431-432$.

[175] H.S.P. Müller, S. Brünken, Accurate rotational spectroscopy of sulfur dioxide, $\mathrm{SO}_{2}$, in its ground vibrational and first excited bending states, $\mathrm{v}_{2}=0,1$, up to $2 \mathrm{THz}, \mathrm{J}$. Mol. Spectrosc. 232 (2005) 213-222.

[176] S.P. Belov, M.Yu. Tretyakov, I.N. Kozin, E. Klisch, G. Winnewisser, W.J. Lafferty, J.-M. Flaud, High Frequency Transitions in the Rotational Spectrum of $\mathrm{SO}_{2}$, J. Mol. Spectrosc. 191 (1998) 17-27. 
[177] H.S.P. Müller, J. Farhoomand, E.A. Cohen, B. Brupbacher-Gatehouse, M. Schäfer, A. Bauder, G. Winnewisser, The Rotational Spectrum of $\mathrm{SO}_{2}$ and the Determination of the Hyperfine Constants and Nuclear Magnetic Shielding Tensors of ${ }^{33} \mathrm{SO}_{2}$ and $\mathrm{SO}^{17} \mathrm{O}$, J. Mol. Spectrosc. 201 (2000) 1-8.

[178] S.C. Mehrotra, G. Bestmann, H. Dreizler, H. Mäder, Contribution to the investigation of $T_{2^{-}}$ relaxation: rotational transitions of OCS and $\mathrm{SO}_{2}$, Z. Naturforsch. 39a (1984) 633-636.

[179] S.C. Mehrotra, H. Dreizler, H. Mäder, J-Dependence of $T_{2}$-parameters for rotational transitions of $\mathrm{SO}_{2}$ and $\mathrm{CH}_{3} \mathrm{OH}$ in $K$-band, Z. Naturforsch. 40a (1985) 683-685.

[180] P.A. Helminger, F. DeLucia, The submillimeter wave spectrum of ${ }^{32} \mathrm{~S}^{16} \mathrm{O}_{2},{ }^{32} \mathrm{~S}^{16} \mathrm{O}_{2}\left(v_{2}\right)$, and ${ }^{34} \mathrm{~S}^{16} \mathrm{O}_{2}$, J. Mol. Spectrosc. 111 (1985) 66-72.

[181] E.A. Alekseev, S.F. Dyubko, V.V. Ilyushin, S.V. Podnos, The High-Precision MillimeterWave Spectrum of ${ }^{32} \mathrm{SO}_{2},{ }^{32} \mathrm{SO}_{2}\left(v_{2}\right)$, and ${ }^{34} \mathrm{SO}_{2}$. J. Mol. Spectrosc. 176 (1996) 316-320.

[182] D. Patel, D. Margolese, T.R. Dyke. Electric dipole moment of $\mathrm{SO}_{2}$ in ground and excited vibrational states, J. Chem. Phys. 70 (1979) 2740-2747.

[183] M.J. Down, C. Hill, S.N. Yurchenko, J. Tennyson, L.R. Brown, I. Kleiner, Re-analysis of ammonia spectra: Updating the HITRAN ${ }^{14} \mathrm{NH}_{3}$ database, J. Quant. Spectrosc. Radiat. Transfer 130 (2013) 260-272.

[184] N. Yurchenko, R.J. Barber, J. Tennyson, A variationally computed hot line list for $\mathrm{NH}_{3}$, Mon. Not. R. astron. Soc. 413 (2011) 1828-1834.

[185] K. Sung, L. R. Brown, X. Huang, D. W. Schwenke, T. J. Lee, S. L. Coy, K. K. Lehmann, Extended line positions, intensities, empirical lower state energies and quantum assignments of $\mathrm{NH}_{3}$ from 6300 to $7000 \mathrm{~cm}^{-1}$, J. Quant. Spectrosc. Radiat. Transfer 113 (2012) 1066-1083.

[186] P. Cacciani, P. Cermak, J. Cosleou, M. Khelkhal, New progress in spectroscopy of ammonia in the infrared $1.5 \mu \mathrm{m}$ range using evolution of spectra from $300 \mathrm{~K}$ down to $122 \mathrm{~K}$, J. Quant. Spectrosc. Radiat. Transfer 113 (2012) 1084-1091.

[187] V. Nemtchinov, K. Sung, P. Varanasi, Measurements of line intensities and half-widths in the 10 um bands of ${ }^{14} \mathrm{NH}_{3}$, J. Quant Spectrosc. Radiat. Transfer 243 (2004) 243- 265.

[188] A.R. Al-Derzi, T. Furtenbacher, J. Tennyson, S.N. Yurchenko, A.G. Császár, MARVEL analysis of the measured high-resolution spectra of ${ }^{14} \mathrm{NH}_{3}$, J. Quant. Spectrosc. Radiat. Transfer 161 (2015) 117-130.

[189] J. Tennyson, S.N. Yurchenko, ExoMol: molecular line lists for exoplanet and other atmospheres, Mon. Not. R. astr. Soc., 425 (2012) 21-33.

[190] K. Sung, S. Yu, J. Pearson, F. Kwabia Tchana, L. Manceron, O. Pirali, Far-infrared ${ }^{14} \mathrm{NH}_{3}$ line positions and intensities measured with an FT-IR and AILES beam line, Synchrotron SOLEIL (submitted to J. Molec.Spectrosc.)

[191] J. C. Pearson, S. Yu, O. Pirali, Modeling the spectrum of the $2 v_{2}$ and $v_{4}$ states of ammonia to experimental accuracy (submitted to J. Molec.Spectrosc.)

[192] E.J. Barton, S.N. Yurchenko, J. Tennyson, S. Beguier, A. Campargue, A near infrared line list for $\mathrm{NH}_{3}$ : Analysis of a Kitt Peak spectrum after 35 years, J. Molec.Spectrosc. 325 (2016) 7-12.

[193] A. Perrin and R. Mbiaké, The $v_{5}$ and $2 v_{9}$ bands of the ${ }^{15} \mathrm{~N}$ isotopic species of nitric acid $\left(\mathrm{H}^{15} \mathrm{NO}_{3}\right)$ : Line positions and intensities, J. Molec. Spectrosc. 237 (2006) 27-35

[194] A. Perrin, J. Orphal, J.-M.Flaud, S.Klee, G.Mellau, H. Mäder, D. Walbrodt, M. Winnewisser, New analysis of the $v_{5}$ and $2 v_{9}$ bands of $\mathrm{HNO}_{3}$ by infrared and millimeter wave techniques: line positions and intensities, J. Molec.Spectrosc. 228 (2004) 375-391. 
[195] J-M. Flaud, G. Brizzi, M. Carlotti, A. Perrin, M. Ridolfi, MIPAS database: validation of $\mathrm{HNO}_{3}$ line parameters using MIPAS satellite measurements, Atmos. Chem. Phys. 6 (2006) 50375048.

[196] G. Brizzi, M. Carlotti, J-M. Flaud, A. Perrin and M. Ridolfi. First observation of $\mathrm{H}^{15} \mathrm{NO}_{3}$ in atmospheric spectra, Geophys. Res. Lett. 34 (2007) L038025.

[197] G. Brizzi, E. Arnone, M. Carlotti, B.M. Dinelli, J.-M. Flaud, E. Papandrea, A. Perrin and M. Ridolfi. Retrieval of atmospheric $\mathrm{H}^{15} \mathrm{NO}_{3} / \mathrm{H}^{14} \mathrm{NO}_{3}$ isotope ratio profile from MIPAS/ENVISAT limb measurements, J. Geophys. Res. 114 (2009) doi:10.1029/2008JD011504.

[198] D. Jacquemart, F. Kwabia Tchana, N. Lacome, A. Perrin, A. Laraia, R.R. Gamache, Formaldehyde around 3.5 and 5.7- $\mu \mathrm{m}$ : measurement and calculation of broadening coefficients, J. Quant. Spectrosc. Radiat. Transfer 111 (2010) 1209-1222.

[199] S. Brünken, H.S.P. Müller, F. Lewen, G. Winnewisser, High accuracy measurements on the ground state rotational spectrum of formaldehyde $\left(\mathrm{H}_{2} \mathrm{CO}\right)$ up to $2 \mathrm{THz}$, Phys. Chem. Chem. Phys. 5 (2003) 1515-1518.

[200] H.S.P. Müller, R. Gendriesch, F. Lewen, G. Winnewisser, The Submillimeter-wave Spectrum of the Formaldehyde Isotopomer $\mathrm{H}_{2} \mathrm{C}^{18} \mathrm{O}$ in its Ground Vibrational State, Z. Naturforsch. 55a (2000) 486-490.

[201] H.S.P. Müller, R. Gendriesch, L. Margulès, F. Lewen, G. Winnewisser, R. Bocquet, J. Demaison, U. Wötzel, H. Mäder, Spectroscopy of the formaldehyde isotopomer $\mathrm{H}_{2}{ }^{13} \mathrm{CO}$ in the microwave to terahertz region, Phys. Chem. Chem. Phys. 2 (2000) 3401-3404.

[202] R. Cornet, G. Winnewisser, A precise study of the rotational spectrum of formaldehyde $\mathrm{H}_{2}{ }^{12} \mathrm{C}^{16} \mathrm{O}, \mathrm{H}_{2}{ }^{13} \mathrm{C}^{16} \mathrm{O}, \mathrm{H}_{2}{ }^{12} \mathrm{C}^{18} \mathrm{O}, \mathrm{H}_{2}{ }^{13} \mathrm{C}^{18} \mathrm{O}$, J. Mol. Spectrosc. 80 (1980) $438-452$.

[203] R. Bocquet, J. Demaison, L. Poteau, M. Liedtke, S. Belov, K.M.T. Yamada, G. Winnewisser, C. Gerke, J. Gripp, Th. Köhler, The Ground State Rotational Spectrum of Formaldehyde, J. Mol. Spectrosc. 177 (1996) 154-159.

[204] H.S.P. Müller, G. Winnewisser, J. Demaison, A. Perrin, A. Valentin, The Ground State Spectroscopic Constants of Formaldehyde, J. Mol. Spectrosc. 200 (2000) 143-144.

[205] B. Fabricant, D. Krieger, S. Muenter, Molecular beam electric resonance study of formaldehyde, thioformaldehyde, and ketene, J. Chem. Phys. 67 (1977) 1576-1586.

[206] A.F. Al-Refaie, S.N. Yurchenko, A. Yachmenev and J. Tennyson, ExoMol line lists VIII: A variationally computed line-list for hot formaldehyde It is published in Mon. Not. R. astr. Soc., 448, 1704-1714 (2015)

[207] V.M. Devi, C.P. Rinsland D.C. Benner, R. L. Sams, T. A. Blake, Multispectrum analysis of the $v_{9}$ band of ${ }^{12} \mathrm{C}_{2} \mathrm{H}_{6}$ : Positions, intensities, self- and $\mathrm{N}_{2}$-broadened half-width coefficients, J. Quant. Spectrosc. Radiat. Transfer 111 (2010) 1234-51.

[208] V.M. Devi, D.C. Benner, C.P. Rinsland, M. A. H. Smith, R. L. Sams, T. A. Blake, J.-M. Flaud, K. Sung, L.R. Brown, A.W. Mantz, Multispectrum measurements of spectral line parameters including temperature dependences of $\mathrm{N}_{2}$ - and self-broadened half-width coefficients in the region of the $v_{9}$ band of ${ }^{12} \mathrm{C}_{2} \mathrm{H}_{6}$, J. Quant. Spectrosc. Radiat. Transfer 111 (2010) 2481-2504.

[209] V.M. Devi, D.C. Benner, K. Sung, T.J. Crawford, A.W. Mantz, Line positions and intensities for the $v_{12}$ band of ${ }^{13} \mathrm{C}^{12} \mathrm{CH}_{6}$, J. Molec.Spectrosc. 301 (2014) 28-38.

[210] N. Moazzen-Ahmadi, J. Norooz Oliaee, I. Ozier, E. H. Wishnow, K. Sung, T. Crawford, L. R. Brown, V. M. Devi, An intensity study of the torsional bands of ethane at $35 \mu \mathrm{m}$, J. Quant. Spectrosc. Radiat. Transfer 151 (2015) 123-132. 
[211] C. di Lauro, F. Lattanzi, L.R. Brown, K. Sung, J. Vander-Auwera, A.W. Mantz, M.A.H. Smith, High resolution investigation of the $7 \mu \mathrm{m}$ region of the ethane spectrum. Planetary and Space Science for the Titan, Through Time Workshop (Special Issue) 60 (2012) 93-101, doi:10.1016/j.pss.2011.01.008.

[212] C. di Lauro, F. Lattanzi, L. R. Brown, K. Sung, A. W. Mantz, M. A. H. Smith, The $v_{4}, v_{9}, v_{10}$ and $v_{6}+v_{11}$ bands of ${ }^{12} \mathrm{CH}_{3}{ }^{13} \mathrm{CH}_{3}$ between 1245 and $1550 \mathrm{~cm}^{-1}$, J. Molec. Spectrosc. 304 (2014) 1224.

[213] A.M. Daly, B.J. Drouin, J.C. Pearson, K. Sung, L.R. Brown, A.W. Mantz, M.A.H. Smith, The $\mathrm{v}_{17}$ band of $\mathrm{C}_{2} \mathrm{H}_{5} \mathrm{D}$ from 770 to $880 \mathrm{~cm}^{-1}$, J. Molec.Spectrosc. 316 (2015) 1-10.

[214] AS Pine, C.P. Rinsland, The role of torsional hot bands in modeling atmospheric ethane, J. Quant. Spectrosc. Radiat. Transfer 62 (1999) 445-458.

[215] J.J. Harrison, N. D. C. Allen, P. F. Bernath, Infrared absorption cross sections for ethane $\left(\mathrm{C}_{2} \mathrm{H}_{6}\right)$ in the $3 \mu \mathrm{m}$ region, J. Quant. Spectrosc. Radiat. Transfer 111 (2010) 357-363.

[216] R. J. Hargreaves, P. F. Bernath, D. R. T Appadoo, Relative high-resolution absorption cross sections of $\mathrm{C}_{2} \mathrm{H}_{6}$ at low temperatures, J. Molec.Spectrosc.315 (2015) 102-106.

[217] G. L. Villanueva, M. J. Mumma, K. Magee-Sauer, Ethane in planetary and cometary atmospheres: Transmittance and fluorescence models of the $v_{7}$ band at $3.3 \mu \mathrm{m}$, J. Geophys. Res. 116 (2011) E08012, doi:10.1029/2010JE003794.

[218] F. Lattanzi, C. di Lauro, J. Vander Auwera, Toward the understanding of the high resolution infrared spectrum of $\mathrm{C}_{2} \mathrm{H}_{6}$ near $3.3 \mu \mathrm{m}$, J. Molec.Spectrosc. 267 (2011) 71-79.

[219] A.V. Nikitin, L. R. Brown, M. Rey, Vl. G. Tyuterev, K. Sung, M. A. H. Smith, A.W. Mantz. Preliminary modeling of $\mathrm{CH}_{3} \mathrm{D}$ from 4000 to $4550 \mathrm{~cm}^{-1}$. J. Quant. Spectrosc. Radiat. Transfer 114 (2013) 1-12.

[220] V.M. Devi, D.C. Benner, MAH Smith, C.P. Rinsland, Measurements of air broadened width and air induced shift coefficients and line mixing in the $\mathrm{v}_{5}$ band of ${ }^{12} \mathrm{CH}_{3} \mathrm{D}$, J. Quant. Spectrosc. Radiat. Transfer 68 (2001) 135-161.

[221] V.M. Devi, D.C. Benner, MAH Smith, C.P. Rinsland, L.R. Brown, Self- and nitrogenbroadening, pressure induced shift and line mixing coefficients in the $\mathrm{v}_{5}$ of ${ }^{12} \mathrm{CH}_{3} \mathrm{D}$ using a multispectrum fitting procedure, J. Quant. Spectrosc. Radiat. Transfer 74 (2002)1-41.

[222] L. R. Brown, K. Sung, D. C. Benner, V. M. Devi, V. Boudon, T. Gabard, C. Wenger, A. Campargue, O. Leshchishina, S. Kassi, D. Mondelain, L. Wang, L. Daumont, L. Régalia, M. Rey, X. Thomas, Vl. G. Tyuterev, O. M. Lyulin, A. V. Nikitin, H. M. Niederer, S. Albert, S. Bauerecker, M. Quack, I. E. Gordon, L. S. Rothman, H. Sasada, A. Coustenis, M. A. H. Smith, T. Carrington Jr., X. G. Wang, A. W. Mantz, P. T. Spickler, Methane line parameters in the HITRAN 2012 database, J. Quant. Spectrosc. Radiat. Transfer 130 (2013) 201-219.

[223] Y.Lu, D. Mondelain, S. Kassi and A.Campargue, The CH3D absorption spectrum in the 1.58 micron transparency window of methane :empirical line lists and temperature dependence between 81K and 294K, J. Quant. Spectrosc. Radiat. Transfer 112 (2011) 2683-2697.

[224] J. Vander Auwera, Absolute intensities measurements in the $\left(v_{4}-v_{5}\right)$ band of ${ }^{12} \mathrm{C}_{2} \mathrm{H}_{2}$ : analysis of Herman-Wallis effects and forbidden transitions, J. Mol. Spectrosc. 201 (2000) 143150.

[225] M. Matsuura, P.R. Wood, G.C. Sloan, A.A. Zijlstra, J.T. van Loon, M.A.T. Groenewegen, et al., Spitzer observations of acetylene bands in carbon-rich asymptotic giant branch stars in the Large Magellanic Cloud, Mon. Not. Roy. Astron. Soc. 371 (2006) 415-420. 
[226] L. Gomez, D. Jacquemart, N. Lacome, J.-Y. Mandin, Line intensities of ${ }^{12} \mathrm{C}_{2} \mathrm{H}_{2}$ in the7.7 $\mu \mathrm{m}$ spectral region, J. Quant. Spectrosc. Radiat. Transfer 110 (2009) 2102-2114.

[227] L. Gomez, D. Jacquemart, N. Lacome, J.-Y. Mandin, New line intensity measurements for ${ }^{12} \mathrm{C}_{2} \mathrm{H}_{2}$ around $7.7 \mu \mathrm{m}$ and HITRAN format line list for applications, J. Quant. Spectrosc. Radiat. Transfer 111 (2010) 2256-2264.

[228] W.J. Lafferty, J.-M. Flaud, F. Kwabia Tchana, The high-resolution infrared spectrum of ethylene in the 1800-2350 $\mathrm{cm}^{-1}$ spectral region, Molec. Phys.. 109:21(2011) 2501-2510.

[229] A. Ben Hassen, F. Kwabia Tchana, J.-M. Flaud, W.J. Lafferty, X. Landsheere , H. Aroui, Absolute line intensities for ethylene from 1800 to $2350 \mathrm{~cm}^{-1}$, J. Molec. Spectrosc. 282 (2012) 3033.

[230] J.-M. Flaud, W.J. Lafferty, Robert Sams, V. Malathy Devi, High resolution analysis of the ethylene-1- ${ }^{13} \mathrm{C}$ spectrum in the 8.4-14.3- $\mu \mathrm{m}$ region, J. Molec. Spectrosc. 259 (2010) 39-45.

[231] J.-M. Flaud, W.J. Laffert, V. Malathy Devi, R.L. Sams, D. Chris Benner, Absolute line intensities and self-broadened half-width coefficients in the ethylene- $1-{ }^{13} \mathrm{C}$ bands in the $700-1190$ $\mathrm{cm}^{-1}$ region, J. Molec. Spectrosc. 267 (2011) 3-12.

[232] G.J. Harris, O.L. Polyansky and J. Tennyson, Opacity data for HCN and HNC from a new ab initio linelist, Astrophys. J. 578 (2002) 657-663.

[233] G.J. Harris, J. Tennyson, B.M. Kaminsky, Ya.V. Pavlenko, and H.R.A. Jones, Improved HCN/HNC linelist, model atmospheres synthetic spectra for WZ Cas, Mon. Not. R. astron. Soc. 367 (2006) 400-406.

[234] G.C. Mellau, Complete experimental rovibrational eigen energies of HCN up to $6880 \mathrm{~cm}^{-1}$ above the ground state, J. Chem. Phys. 134 (2011), 234-303.

[235] G.C. Mellau, Rovibrational eigen energy structure of the H,C,N molecular system, J. Chem. Phys. 134 (2011) 194-302.

[236] R.J. Barber, J. Strange, C. Hill, O.L. Polyansky, G. Mellau, S.N. Yurchenko and J. Tennyson, ExoMol Molecular linelists: III An improved hot rotation-vibration line list for HCN and HNC, Mon. Not. Roy. Astron. Soc. 437 (2014) 1828-1835.

[237] A. Fayt, A. Jolly, Y. Benilan, L. Manceron, F. Kwabia-Tchana, J.-C. Guillemin, Frequency and intensity analysis of the far infrared $v_{5}$ band complex of cyanogen $\left(\mathrm{C}_{2} \mathrm{~N}_{2}\right)$ and applications to Titan, J. Quant. Spectrosc. Radiat. Transfer 113 (2012) 1195-1219.

[238] N.A. Teanby, P.G.J. Irwin, R. deKok, A. Jolly, B. Bézard, C.A. Nixon, S.B. Calcutt, Titan's stratospheric $\mathrm{C}_{2} \mathrm{~N}_{2}, \mathrm{C}_{3} \mathrm{H}_{4}$, and $\mathrm{C}_{4} \mathrm{H}_{2}$ abundance from Cassini/CIRS far-infrared spectra, Icarus 220 (2009) 620-631.

[239] K.K. Kim, W.T. King, Integrated infrared intensities in cyanogen, J. Chem. Phys 80 (1984) 974-977.

[240] J.C. Grecu, B.P. Winnewisser, M. Winnewisser, Absolute rovibrational line- intensities in the $v_{5}$ band system of cyanogen NCCN, J. Molec. Spectrosc. 159(2) (1993) 551-571.

[241] A. Jolly, A. Fayt, Y. Benilan, D. Jacquemart, C.A. Nixon, D.E. Jennings, The $v_{8}$ bending mode of diacetylene: from laboratory spectroscopy to the detection of ${ }^{13} \mathrm{C}$ isotopologues in Titan's atmosphere, Astrophys. J. 714 (2010) 852-859.

[242] A. Jolly, V. Cottini, A. Fayt, L. Manceron, F. Kwabia-Tchana, Y. Benilan, J-C. Guillemin, C. Nixon, P. Irwin, Gas phase dicyanoacetylene $\left(\mathrm{C}_{4} \mathrm{~N}_{2}\right)$ on Titan: new experimental and theoretical spectroscopy results applied to Cassini CIRS data, Icarus 248 (2015) 340-348. 
[243] J. Cernicharo, A. Heras, J. Pardo, A. Tielens, M. Guelin, E. Dartois, R. Neri, L. Water, Methylpolyynes and Small Hydrocarbons in CRL 618, Astrophys. J. 546 (2001) 127-130.

[244] S. Vinatier, B. Bezard, S. Lebonnois, N.A. Teanby, R.K. Achterberg, N. Gorius, A. Mamoutkine, E. Guandique, A. Jolly, D.E. Jennings, Seasonal variation in Titan's middle atmosphere during the northern spring derived from Cassini/CIRS observations, Icarus 250 (2015) 95-115.

[245] T. Koops, T. Visser, W.M.A. Smit, The harmonic force field and absolute infrared intensities of diacetylene, J. Molec. Struct. 125 (1984) 179-196.

[246] A. Jolly, L. Manceron, F. Kwabia-Tchana, Y. Benilan, M-C. Gazeau, Revised infrared bending mode intensities for diacetylene $\left(\mathrm{C}_{4} \mathrm{H}_{2}\right)$ : application to Titan, Planetary and Space Sciences 97 (2014) 60-64.

[247] M. Khlifi, P. Paillous, C. Delpech, M. Nishio, P. Bruston, F. Raulin, Absolute IR band intensities of diacetylene in the $250-4300 \mathrm{~cm}^{-1}$ region - implications for Titan's atmosphere, J. Molec. Spectrosc. 174 (1995) 116-122.

[248] A.V. Nikitin, J.-P. Champion, New ground state constants of ${ }^{12} \mathrm{CH}_{3}{ }^{35} \mathrm{Cl}$ and ${ }^{12} \mathrm{CH}_{3}{ }^{37} \mathrm{Cl}$ from global polyad analysis, J. Molec. Spectrosc. 230 (2005) 168-173.

[249] A.V. Nikitin, J.-P. Champion, H. Bürger, Global analysis of ${ }^{12} \mathrm{CH}_{3}{ }^{35} \mathrm{Cl}$ and ${ }^{12} \mathrm{CH}_{3}{ }^{37} \mathrm{Cl}$ : simultaneous fit of the lower five polyads $\left(0-2600 \mathrm{~cm}^{-1}\right)$, J. Molec. Spectrosc. 230 (2005) 174-184.

[250] J.P. Bouanich, G. Blanquet, J. Walrand. Diode-laser measurements of self-broadening coefficients and line strengths in the $\mathrm{v}_{3}$ band of $\mathrm{CH}_{3}{ }^{35} \mathrm{C} 1$. J. Quant. Spectrosc. Radiat. Transfer 51 (1994) 573-578.

[251] G. Blanquet, J. Walrand, Spectral intensities in the $\square_{3}$ band of ${ }^{12} \mathrm{CH}_{3}{ }^{37} \mathrm{CI}$, J. Molec. Spectrosc. 133 (1989) 471-474.

[252] G. Blanquet, J. Walrand, M. Dang-Nhu, Absolute line intensities of the $\square_{6}$ band of $\mathrm{CH}_{3}{ }^{35} \mathrm{Cl}$ at $10 \mu \mathrm{m}$, J. Molec. Spectrosc. 159 (1993) 156-160.

[253] G. Blanquet, J. Walrand, Intensities of the $\square_{6}$ band of $\mathrm{CH}_{3}{ }^{37} \mathrm{Cl}$ at $10 \mu \mathrm{m}$, J. Molec. Spectrosc. 162 (1993) 513-515.

[254] A. Barbouchi Ramchani, D. Jacquemart, M. Dhib, H. Aroui, Line positions, intensities and self-broadening coefficients for the $v_{5}$ band of methyl chloride, J. Quant. Spectrosc. Radiat. Transfer 120 (2013) 1-15.

[255] C. Chackerian, Jr, L.R. Brown, N. Lacome, G. Tarrago, Methyl chloride $v_{5}$ region lineshape parameters and rotational constants for the $v_{2}, v_{5}$ and $2 v_{3}$ vibrational bands, J. Mol. Spectrosc. 191 (1998) 148-157.

[256] F. Cappellani, G. Restelli, G. Tarrago, Absolute infrared intensities in the fundamentals $v_{2}$ and $v_{5}$ of ${ }^{12} \mathrm{CH}_{3}{ }^{35} \mathrm{Cl}$, J. Molec. Spectrosc. 146 (1991) 326-333.

[257] C. Bray, A. Perrin, D. Jacquemart, N. Lacome, The $v_{1}, v_{4}$ and $3 v_{6}$ bands of methyl chloride in the $3.4 \mu \mathrm{m}$ region: Line positions and intensities, J. Quant. Spectrosc. Radiat. Transfer 112 (2011) 2446-2462.

[258] A. Barbouchi Ramchani, D. Jacquemart, M. Dhib, H. Aroui, Theoretical calculation of selfbroadening coefficients for the $v_{5}$ band of methyl chloride at various temperatures, J. Quant. Spectrosc. Radiat. Transfer 134 (2014) 1-8.

[259] A. Barbouchi Ramchani, D. Jacquemart, M. Dhib, H. Aroui, $\mathrm{N}_{2}$-broadening coefficients of methyl chloride at various temperatures, J. Quant. Spectrosc. Radiat. Transfer 148 (2014) 186-196. 
[260] C. Bray, D. Jacquemart, J. Buldyreva, N. Lacome, A. Perrin, $\mathrm{N}_{2}$-broadening coefficients of methyl chloride at room temperature, J. Quant. Spectrosc. Radiat. Transfer 113 (2012) 1102-1112.

[261] C. Bray, D. Jacquemart, N. Lacome, M. Guinet, A. Cuisset, S. Eliet, F. Hindle, G. Mouret, F. Rohart, J. Buldyreva, Analysis of self-broadened pure rotational and rovibrational lines of methyl chloride at room temperature, J. Quant. Spectrosc. Radiat. Transfer 116 (2013) 87-100.

[262] M. Guinet, F. Rohart, J. Buldyreva, V. Gupta, S. Eliet, R. Motiyenko, L. Margulès, A. Cuisset, F. Hindle, G. Mouret, Experimental studies by complementary terahertz techniques and semi-classical calculations of $\mathrm{N}_{2}$-broadening coefficients of $\mathrm{CH}_{3} \mathrm{Cl}$, J. Quant. Spectrosc. Radiat. Transfer 113 (2012) 1113-1126.

[263] A.S. Dudaryonok, N.N. Lavrentieva, J. Buldyreva, $\mathrm{CH}_{3} \mathrm{Cl}$ self-broadening coefficients and their temperature dependences, J. Quant. Spectrosc. Radiat. Transfer 130 (2013) 321-326.

[264] J. Buldyreva, Air-broadening coefficients of $\mathrm{CH}_{3}{ }^{35} \mathrm{Cl}$ and $\mathrm{CH}_{3}{ }^{37} \mathrm{Cl}$ rovibrational lines and their temperature dependence by a semi-classical approach, J. Quant. Spectrosc. Radiat. Transfer 130 (2013) 315-320.

[265] C. C. Travis, E. L. Etnier, Health Risks of Energy Technologies, Westview Press for the American Association for the Advancement of Science, 1983, 278 pages.

[266] S. Seager, Exoplanet Atmospheres: Physical Processes, Princeton University Press, 2010, 264 pages.

[267] Al. A.A. Azzam, S.N. Yurchenko, J. Tennyson, M.-Al. Martin-Drumel, O. Pirali, Terahertz spectroscopy of hydrogen sulfide, J. Quant. Spectrosc. Radiat. Transfer. 130 (2013) 341-351.

[268] O.V. Naumenko. Private communication (2013).

[269] O.N. Ulenikov, A.B. Malikova, M. Koivusaari, S. Alanko, R. Anttila, High resolution vibrational-rotational spectrum of $\mathrm{H}_{2} \mathrm{~S}$ in the region of the $v_{2}$ fundamental band, $J$. Molec.Spectrosc. 176 (1996) 229-235.

[270] J-M. Flaud, C. Camy-Peyret, J.W.C. Johns, The far-infrared spectrum of hydrogen sulphide. The (000) rotational constants of $\mathrm{H}_{2}{ }^{32} \mathrm{~S}, \mathrm{H}_{2}{ }^{33} \mathrm{~S}$ and $\mathrm{H}_{2}{ }^{34} \mathrm{~S}$, Can. J. Phys. 61 (1983) 1462-1473.

[271] L. R. Brown, J. Crisp, D. Crisp, O.V. Naumenko, M. A. Smirnov, L. N. Sinitsa, A. Perrin, The absorption spectrum of $\mathrm{H}_{2} \mathrm{~S}$ between 2150 and $4260 \mathrm{~cm}^{-1}$ : Analysis of the position and intensities in the first $\left(2 v_{2}, v_{1}\right.$ and $\left.v_{3}\right)$ and second $\left(3 v_{2}, v_{1}+v_{2}\right.$ and $\left.v_{2}+v_{3}\right)$ triad regions, $\mathrm{J}$. Molec.Spectrosc. 188 (1998) 148-174.

[272] E.R. Polovtseva, N.A. Lavrentieva, S.S. Voronina, O.V. Naumenko, A.Z. Fazliev, Information system for molecular spectroscopy. Ro-vibrational transitions and energy levels of the hydrogen sulfide molecule, Atmos. Ocean. Opt. 251 (2012) 57-65.

[273] A. D. Bykov, O.V. Naumenko, M. A. Smirnov, L. N. Sinitsa L. R. Brown, J. Crisp, D. Crisp, The infrared spectrum of $\mathrm{H}_{2} \mathrm{~S}$ from 1 to $5 \mu \mathrm{m}$, Can. J. Phys. 72 (1994) 989-999.

[274] L.R. Brown, O.V. Naumenko, E.R. Polovtseva, L.N. Sinitsa, Hydrogen sulfide absorption spectrum in the 5700-6600 $\mathrm{cm}^{-1}$ spectral region. Proc. of SPIE 14th Symposium on High-Resolution Molecular Spectroscopy, Editors L.N. Sinitsa, S.N. Mikhailenko 5311 (2003) 59-67.

[275] L.R. Brown, O.V. Naumenko, E.R. Polovtseva, L. N. Sinitsa, Absorption spectrum of $\mathrm{H}_{2} \mathrm{~S}$ between 7200 and $7890 \mathrm{~cm}^{-1}$, Proc. of SPIE Tenth Joint International Symposium on Atmospheric and Ocean Optics. Atmospheric Physics. Part I: Radiation Propagation in the Atmosphere and Ocean, V. 5396, pp. 42-48. Editors G.G. Matvienko, G. M. Krekov, Krasnoyarsk, Russia, 2004.

[276] O.V. Naumenko, E.R. Polovtseva, Database of the hydrogen sulfide absorption in the 4400$11400 \mathrm{~cm}^{-1}$ region, Atmos. Ocean. Opt. 16 (2003) 900-906. 
[277] Y. Ding, O.V. Naumenko, S.-M. Hu, Q. Zhu, E. Bertseva, A. Campargue, The absorption spectrum of $\mathrm{H}_{2} \mathrm{~S}$ between 9540 and $10000 \mathrm{~cm}^{-1}$ by intracavity laser absorption spectroscopy with a vertical external cavity surface emitting laser, J. Molec. Spectrosc. 217 (2003) 222-223.

[278] O.V. Naumenko, A. Campargue, Local mode effects in the absorption spectrum of $\mathrm{H}_{2} \mathrm{~S}$ between 10780 and $11330 \mathrm{~cm}^{-1}$, J. Molec. Spectrosc. 209 (2001) 242-253.

[279] D. Jacquemart, H. Tran, Temperature dependence of self- and $\mathrm{N}_{2}$-broadening coefficients for $\mathrm{CH}_{3} \mathrm{Br}$ in the 10- $\mu \mathrm{m}$ spectral region, J. Quant. Spectrosc. Radiat. Transfer. 109 (2008) 569-579.

[280] G.C. Mellau, Complete experimental rovibrational eigenenergies of HNC up to $3743 \mathrm{~cm}^{-1}$ above the ground state, J. Chem. Phys., 133. (2010) 164303.

[281] G.C. Mellau, Highly excited rovibrational states of HNC, J. Molec. Spectrosc. 269 (2011) 77 85.

[282] J. Tennyson, P.F. Bernath, L.R. Brown. A. Campargue, M.R. Carleer, A.G. Császár, et al., IUPAC critical evaluation of the rotational-vibrational spectra of water vapor. Part II. Energy levels and transition wavenumbers for $\mathrm{HD}^{16} \mathrm{O}, \mathrm{HD}^{17} \mathrm{O}$, and $\mathrm{HD}^{18} \mathrm{O}$, J. Quant. Spectrosc. Radiat. Transfer 110 (2010) 2160-2184.

[283] N.N. Lavrentieva, B.A. Voronin, O.V. Naumenko, A.D. Bykov, A.A. Fedorova, Line list of $\mathrm{HD}^{16} \mathrm{O}$ for study of atmosphere of terrestrial planets (Earth, Venus and Mars), Icarus, 236 (2014) 38-47.

[284] A.-W. Liu, O.V. Naumenko, S. Kassi, A. Campargue, CW-Cavity Ring Down Spectroscopy of deuterated water in the $1.58 \mu \mathrm{m}$ atmospheric transparency window, J. Quant. Spectrosc. Radiat. Transfer 138 (2014) 97-106.

[285] B.A. Voronin, J. Tennyson, R.N. Tolchenov, A.A. Lugovskoy, S.N. Yurchenko, A high accuracy computed line list for the HDO molecule, Mon. Not. Roy. Astr. Soc. 402 (2009) 492-496.

[286] A.-W. Liu, K.-F. Song, H.-Y. Ni, S.-M. Hu, O.V. Naumenko, I.A. Vasilenko, S.N. Mikhailenko, (000) and (010) energy levels of the $\mathrm{HD}^{18} \mathrm{O}$ and $\mathrm{D}_{2}{ }^{18} \mathrm{O}$ molecules from analysis of their $v_{2}$ bands, J. Molec. Spectrosc. 265 (2011) 26-38.

[287] G. Steenbeckeliers, Private communication (July 1971). These data have been reproduced by Lovas at F.J. Lovas, Microwave spectral Tables. II. Triatomic molecules, J. Phys. Chem. Ref. Data, 7 (1978) 1445-1750

[288] I.A. Vasilenko, E.R. Polovtseva, O.V. Naumenko, A.P. Scherbakov, A.D. Bykov, A.-W. Liu. K.-F. Song, H.-Y. Ni, S.-M. Hu, Fourier transform absorption spectrum of deuterated water vapor enriched by ${ }^{18} \mathrm{O}$ between 2080 and $4600 \mathrm{~cm}^{-1}$, J. Quant. Spectrosc. Radiat. Transfer, to be submitted (2015).

[289] S.N. Mikhailenko, O.V. Naumenko, A.V. Nikitin, I.A. Vasilenko, A.-W. Liu, K.-F. Song, H.Y. Ni, S.-M. Hu, Absorption spectrum of deuterated water vapor enriched by ${ }^{18} \mathrm{O}$ between 6000 and $9200 \mathrm{~cm}^{-1}$, J. Quant. Spectrosc. Radiat. Transfer, 113 (2012) 653-669.

[290] H. Partridge, D.W. Schwenke, The determination of an accurate isotope dependent potential energy surface for water from extensive ab initio calculations and experimental data, J. Chem. Phys. 106 (1997) 4618-4639

[291] R.R. Gamache, J-M. Hartmann, An intercomparison of measured pressur x 10-broadening and pressur x 10-shifting parameters of water vapor, Can. J. Chem.; 82 (2004) 1013-1027.

[292] R.R. Gamache, J. Fischer, Half-widths of $\mathrm{H}_{2}{ }^{16} \mathrm{O}, \mathrm{H}_{2}{ }^{18} \mathrm{O}, \mathrm{H}_{2}{ }^{17} \mathrm{O}, \mathrm{HD}^{16} \mathrm{O}$, and $\mathrm{D}_{2}{ }^{16} \mathrm{O}$ : I Comparison between Isotopomers, J. Quant. Spectrosc. Radiat. Transfer 78 (2003) 289-304. 10.1016/S0022-4073(02)00217-0. 
[293] R.A. Toth, Smoothened HDO half-width data - Line lists of water vapor parameters for $v_{2}$; Files HDOWID.AIR and HDOSHFT.AIR, available from: http://mark4sun.jplnasa.go.v/data/spec/H2O/RAToth_H2O.tar

[294] D.S. Underwood, J. Tennyson, S.N. Yurchenko, An ab initio variationally computed roomtemperature line list for $\mathrm{SO}_{3}$, Phys. Chem. Chem. Phys. 15(2013) 10118-10125.

[295] V. Meyer, D.H. Sutter, H. Dreizler, The centrifugally-induced pure rotational spectrum and the structure of sulfur-trioxide: a microwave Fourier-transform study of a nonpolar molecule, $\mathrm{Z}$ Naturforsch A 46 (1991) 710-714.

[296] A. Kaldor, A.G. Maki, A.J. Dorney, I.M. Mills, Assignment of $v_{2}$ and $v_{4}$ of $\mathrm{SO}_{3}$, J. Molec. Spectrosc. 45 (1973) 247-252.

[297] J. Ortigoso, R. Escribano, A.G. Maki, The $v_{2}$ and $v_{4}$ IR bands of $\mathrm{SO}_{3}$, J. Molec. Spectrosc. 138 (1989) 602-613.

[298] A. Maki, T.A. Blake, R.L. Sams, N. Vulpanovici, J. Barber, E.T.H. Chrysostom, et al. High resolution infrared spectra of the $v_{2}, v_{3}, v_{4}$ and $2 v_{3}$ bands of ${ }^{32} \mathrm{~S}^{16} \mathrm{O}_{3}$, J. Molec. Spectrosc. 210 (2001) 240-249.

[299] S.W. Sharpe, T.A. Blake, R.L. Sams, A. Maki, T. Masiello, J. Barber, et al., The $v_{3}$ and $2 v_{3}$ bands of ${ }^{32} \mathrm{~S}^{16} \mathrm{O}_{3},{ }^{32} \mathrm{~S}^{18} \mathrm{O}_{3},{ }^{34} \mathrm{~S}^{16} \mathrm{O}_{3}$ and ${ }^{34} \mathrm{~S}^{18} \mathrm{O}_{3}$, J. Molec. Spectrosc. 222 (2003) 142-152.

[300] A. Maki, T.A. Blake, R.L. Sams, J. Frieh, J. Barber, T. Masiello, et al., Analysis of some combination-overtone infrared bands of ${ }^{32} \mathrm{~S}^{16} \mathrm{O}_{3}$, J. Molec. Spectrosc. 225 (2004) 109-122.

[301] D.S. Underwood, S.N. Yurchenko, J. Tennyson, P. Jensen, Rotational spectrum of $\mathrm{SO}_{3}$ and a theoretical evidence for the formation of rotational energy level clusters in its vibrational ground state, J. Chem. Phys. 140 (2014) 244316.

[302] D.S. Underwood, S.N. Yurchenko, J. Tennyson, S. Claessen, A. Fateev, ExoMol line lists XVII: The rotation-vibration spectrum of $\mathrm{SO}_{3}$, Mon. Not. Roy. Astron. Soc. (in press).

[303] Ph. Rosenkranz, S. Bühler, D. Feist, T. Hewison, N. Jacquinet-Husson, J.R. Pardo, et al., Thermal Microwave Radiation-Applications for Remote Sensing, Chap. 2: Emission and spectroscopy of the clear atmosphere, IEE Electromagnetic Waves Series, London, UK, 2006, pp. 25-99.

[304] Ø. Hodnebrog, M. Etminan, J.S. Fuglestvedt, G. Marston, G. Myhre, C.J. Nielsen, K.P. Shine, T.J. Wallington, Global warming potentials and radiative efficiencies of halocarbons and related compounds: A comprehensive review, Reviews of Geophysics. 51 (2013) 300-378.

[305] C.J. Nielsen, Private communication, 2014

[306] J.J. Harrison, P.F. Bernath, Mid- and long-wave infrared absorption cross sections for acetonitrile, J. Quant. Spectrosc. Radiat. Transfer 113 (2012) 221-225.

[307] J.J. Harrison, Private communication, 2013.

[308] P.-F. Coheur, L. Clarisse, S. Turquety, D. Hurtmans, C. Clerbaux, IASI measurements of reactive trace species in biomass burning plumes, Atmos. Chem. Phys. 9 (2009) 5655-5667

[309] G. Myhre, F. Stordal, I. Gausemel, C.J. Nielsen, E. Mahieu, Line-by-line calculations of thermal infrared radiation representative for global condition: CFC-12 as an example, J. Quant. Spectrosc. Radiat. Transfer 97 (2006) 317-331.

[310] G. Acerboni, J.A. Beukes, N.R. Jensen, J. Hjorth, G. Myhre, C.J. Nielsen, J.K. Sundet, Atmospheric degradation and global warming potentials of three perfluoroalkenes, Atmos. Environ. 35 (2001) 4113-4123. 
[311] G. Myhre, C.J. Nielsen, D.L. Powell, F. Stordal, Infrared absorption cross section, radiative forcing, and GWP of four hydrofluoro(poly)ethers, Atmos. Environ. 93 (1999) 4447-4458.

[312] S.M. Ryan, C.J. Nielsen, Global Warming Potential of Inhaled Anesthetics: Application to Clinical Use, Anesth. Analg. 111 (2010) 92-98.

[313] B. D'Anna, S.R. Sellevag, K. Wirtz, C.J. Nielsen, Photolysis study of perfluoro-2-methyl-3pentanone under natural sunlight conditions, Environ. Sci. Technol. 39 (2005) 8708-8711.

[314] N. Oyaro, S.R. Sellevag, C.J. Nielsen, Study of the $\mathrm{OH}$ and Cl-initiated oxidation, IR absorption cross-section, radiative forcing, and global warming potential of four C-4hydrofluoroethers, Environ. Sci. Technol. 38 (2004) 5567-5576.

[315] N. Oyaro, S.R. Sellevag, C.J. Nielsen, Atmospheric chemistry of hydrofluoroethers: Reaction of a series of hydrofluoro ethers with $\mathrm{OH}$ radicals and $\mathrm{Cl}$ atoms, atmospheric lifetimes, and global warming potentials, J. Phys. Chem. A. 109 (2005) 337-346.

[316] S.R. Sellevag, C.J. Nielsen, O.A. Sovde, G. Myhre, J.K. Sundet, F. Stordal, I.S.A. Isaksen, Atmospheric gas-phase degradation and global warming potentials of 2-fluoro ethanol, 2,2difluoroethanol, and 2,2,2-trifluoroethanol, Atmos. Environ. 38 (2004) 6725-6735.

[317] S.R. Sellevåg, B. D'Anna, C.J. Nielsen, Infrared Absorption Cross-Sections and Estimated Global Warming Potentials of $\mathrm{CF}_{3} \mathrm{CH}_{2} \mathrm{CH}_{2} \mathrm{OH}, \quad \mathrm{CHF}_{2} \mathrm{CF}_{2} \mathrm{CH}_{2} \mathrm{OH}, \quad \mathrm{CF}_{3} \mathrm{CF}_{2} \mathrm{CH}_{2} \mathrm{OH}$, $\mathrm{CF}_{3} \mathrm{CHFCF}_{2} \mathrm{CH}_{2} \mathrm{OH}$, and $\mathrm{CF}_{3} \mathrm{CF}_{2} \mathrm{CF}_{2} \mathrm{CH}_{2} \mathrm{OH}$, Asian Chemistry Letters. (2007) 33-40.

[318] E. Jiménez, M. Antinolo, B. Ballesteros, E. Martinez, J. Albaladejo, Atmospheric Lifetimes and Global Warming Potentials of $\mathrm{CF}_{3} \mathrm{CH}_{2} \mathrm{CH}_{2} \mathrm{OH}$ and $\mathrm{CF}_{3}\left(\mathrm{CH}_{2}\right)_{2} \mathrm{CH}_{2} \mathrm{OH}$, Phys. Chem. Chem. Phys. 11 (2010) 4079-4087.

[319] M. Antiñolo, S. González, B. Ballesteros, J. Albaladejo, E. Jiménez, Laboratory Studies of $\mathrm{CHF}_{2} \mathrm{CF}_{2} \mathrm{CH}_{2} \mathrm{OH}$ and $\mathrm{CF}_{3} \mathrm{CF}_{2} \mathrm{CH}_{2} \mathrm{OH}$ : UV and IR Absorption Cross Sections and $\mathrm{OH}$ Rate Coefficients between 263 and 358 K, J. Phys. Chem. A. 116 (2012) 6041-6050.

[320] S.R. Sellevåg, T. Kelly, H. Sidebottom, C.J. Nielsen, A study of the IR and UV-Vis absorption cross-sections, photolysis and $\mathrm{OH}$-initiated oxidation of $\mathrm{CF}_{3} \mathrm{CHO}$ and $\mathrm{CF}_{3} \mathrm{CH}_{2} \mathrm{CHO}_{\text {, }}$ Phys. Chem. Chem. Phys. 6 (2004) 1243-1252.

[321] M. Antiñolo, Fluoroalcohols and Fluoroaldehydes in the Troposphere: Kinetics and Photochemistry in the Gas Phase sutdied by Pulsed Laser Techniques, PhD Thesis, University of Castilla-La Mancha. 2011.

[322] A.H. McDaniel, C.A. Cantrell, J.A. Davidson, R.E. Shetter, J.G. Calvert, The Temperature Dependent, Infrared Absorption Cross-Sections for the Chlorofluorocarbons: CFC-11, CFC-12, CFC-13, CFC-14, CFC-22, CFC-113, CFC-114, and CFC-115, J. Atmos. Chem. 12 (1991) 211227.

[323] J.J. Harrison, N.D.C Allen, P.F. Bernath, Infrared absorption cross sections for ethane $\left(\mathrm{C}_{2} \mathrm{H}_{6}\right)$ in the $3 \mu \mathrm{m}$ region, J. Quant. Spectrosc. Radiat. Transfer 111 (2010) 357-363.

[324] J.J. Harrison, P.F. Bernath, Infrared absorption cross sections for propane $\left(\mathrm{C}_{3} \mathrm{H}_{8}\right)$ in the $3 \mu \mathrm{m}$ region, J. Quant. Spectrosc. Radiat. Transfer 111 (2010) 1282-1288.

[325] J.J. Harrison, N. Humpage, N.D.C. Allen, A.M. Waterfall, P.F. Bernath, J.J. Remedios, Midinfrared absorption cross sections for acetone (propanone), J. Quant. Spectrosc. Radiat. Transfer 112 (2011) 457-464.

[326] J.J. Harrison, N.D.C. Allen, P.F. Bernath, Infrared absorption cross sections for acetone (propanone) in the $3 \mu \mathrm{m}$ region, J. Quant. Spectrosc. Radiat. Transfer 112 (2011) 53-58. 
[327] N.D.C. Allen, J.J. Harrison, P.F. Bernath, Acetonitrile $\left(\mathrm{CH}_{3} \mathrm{CN}\right)$ infrared absorption cross sections in the $3 \mu \mathrm{m}$ region, J. Quant. Spectrosc. Radiat. Transfer 112 (2011) 1961-1966.

[328] J.J. Harrison, P.F. Bernath, ACE-FTS observations of acetonitrile in the lower stratosphere, Atmos. Chem. Phys. 13 (2013) 7405-7413.

[329] J.J. Harrison, N.D.C. Allen, P.F. Bernath, Infrared absorption cross sections for methanol, J. Quant Spectrosc Radiat Transfer 113 (2012) 2189-2196.

[330] G.C. Toon. The JPL MkIV Interferometer, Optics and Photonics News, 2 (1991) 19-21.

[331] J.J. Harrison, C.D. Boone, A.T. Brown, N.D.C Allen, G.C. Toon, P.F. Bernath, First remote sensing observations of trifluoromethane (HFC-23) in the upper troposphere and lower stratosphere, J. Geophys. Res. 117 (2012) D05308.

[332] J.J. Harrison, Infrared absorption cross sections for trifluoromethane, J. Quant. Spectrosc. Radiat. Transfer 130 (2013) 359-364.

[333] K.A. Tereszchuk, P.F. Bernath, Infrared absorption cross-sections for acetaldehyde $\left(\mathrm{CH}_{3} \mathrm{CHO}\right)$ in the $3 \mu \mathrm{m}$ region, J. Quant. Spectrosc. Radiat. Transfer 112 (2011) 990-993

[334] D.M. O’Leary, A.A. Ruth, S. Dixneuf, J. Orphal, R. Varma, The near infrared cavityenhanced absorption spectrum of methylcyanide, J. Quant. Spectrosc. Radiat. Transfer 113 (2012) 1138-1147.

[335] E.P. Faragó, B. Viskolcz, C. Schoemaecker, C. Fittschen, Measurement of the absorption spectrum and of absolute absorption cross-sections of $\mathrm{CH}_{3} \mathrm{O}_{2}$ Radicals and $\mathrm{CH}_{3} \mathrm{I}$ in the near IR Region, J. Phys. Chem. A 117 (2013) 12802-12811.

[336] M. Staak, E.W. Gash, D.S. Venables, A.A. Ruth, The rotationally-resolved absorption spectrum of formaldehyde from 6547 to $6804 \mathrm{~cm}^{-1}$, J. Molec. Spectrosc. 229 (2005) 115-121.

[337] P. Morajkar, C. Schoemaecker, C. Fittschen, Absolute absorption cross sections of selected lines of formaldehyde, $\mathrm{CH}_{2} \mathrm{O}$, around $6625 \mathrm{~cm}^{-1}$. J. Molec. Spectrosc. 281 (2012) 18-23.

[338] A.A. Ruth, U. Heitmann, E. Heinecke, C. Fittschen, The rotationally-resolved absorption spectrum of formaldehyde from 6550 to $7050 \mathrm{~cm}^{-1}$, Z. Phys. Chem. 229 (2015) 1609-1624.

[339] J. Thiebaud, S. Crunaire, C. Fittschen, Measurements of line strengths in the $2 v_{1}$ band of the $\mathrm{HO}_{2}$ radical using laser photolysis/continuous wave cavity ring-down spectroscopy (cw-CRDS), J. Phys. Chem. A 111 (2007) 6959-6966.

[340] N. Ibrahim, J. Thiebaud, J. Orphal, C. Fittschen, Air-broadening coefficients of the $\mathrm{HO}_{2}$ radical in the $2 v_{1}$ band measured using cw-CRDS, J. Mol. Spectrosc. 242 (2007) 64-69.

[341] P. Morajkar, A. Bossolasco, C. Schoemaecker, C. Fittschen, Photolysis of $\mathrm{CH}_{3} \mathrm{CHO}$ at 248 $\mathrm{nm}$ : Evidence of triple fragmentation from primary quantum yield of $\mathrm{CH}_{3}$ and $\mathrm{HCO}$ radicals and $\mathrm{H}$ atoms, J. Chem. Phys. 140 (2014) 214308.

[342] H. Bouzidi, M. Djehiche, T. Gierczak, P. Morajkar, C. Fittschen, P. Coddeville, A. Tomas, Low pressure photolysis of 2,3-pentanedione: quantum yields and reaction mechanism, J. Phys. Chem. A 119 (2015) 12781-12789.

[343] C. Jain, P. Morajkar, C. Schoemaecker, B. Viskolcz, C. Fittschen, Measurement of absolute absorption cross-sections for nitrous acid (HONO) in the near-infrared region by the continuous wave cavity ring-down spectroscopy (cw-CRDS) technique coupled to laser photolysis, J. Phys. Chem. A 115 (2011) 10720-10728.

[344] D.M. O'Leary, J. Orphal, A.A. Ruth, U. Heitmann, P. Chelin, C.E. Fellows, The cavityenhanced absorption spectrum of $\mathrm{NH}_{3}$ in the near-infrared region between 6850 and $7000 \mathrm{~cm}^{-1}, \mathrm{~J}$. Quant. Spectrosc. Radiat. Transfer 109 (2008) 1004-1015. 
[345] S. T. Massie, Private communication (2014).

[346] S. T. Massie, M. Hervig, HITRAN 2012 refractive indices, J. Quant. Spectrosc. Radiat. Transfer 130 (2013) 373-380.

[347] C. F. Bohren, D. R. Huffman, Absorption and scattering of light by small particles, John Wiley and Sons, New York, 1983.

[348] H. Hess, P. Koepke, I. Schult, Optical properties of aerosols and clouds: the software package OPAC, Bull. Am. Meteorol. Soc., 79 (1998) 831-844.

[349] H. Chang, T. T. Charalampopoulos, Determination of the Wavelength Dependence of Refractive Indices of Flame Soot, Proc. R. Soc. Lond. A 430 (1990) 577-591.

[350] D. T. Alexander, P. A. Crozier, J. R. Anderson, Brown carbon spheres in East Asian Outflow and Their Optical Properties, Science 321 (2008) 833-836.

[351] R. W. Fenn, S. A. Clough, W. O. Gallery, R. E. Good, F. X. Kneizys, J. D. Mill, L. S. Rothman, E. P. Shettle, Optical and infrared properties of the atmosphere [Chapter 18], A. S. Jursa, editor, In: Handbook of geophysics and the space environment, National Technical Information Service, Springfield, 1985.

[352] H. D. Downing, D. Williams, Optical constants of water in the infrared, J. Geophys. Res. 80 (1975) 1656-1661.

[353] L. Kou, D. Labrie, P. Chylek, Refractive indices of water and ice in the 0.65 to 2.5 micron range, Appl. Opt. 32 (1993) 3531-3540.

[354] S. G. Warren, R. E. Brandt, Optical constants of ice from the ultraviolet to the microwave: A revised compilation, J. Geophys. Res. 113 (2008) doi10.1029/2007JD009744.

[355] K. F. Palmer, D. Williams, Optical constants of sulfuric acid; application to the clouds of Venus, Appl. Opt. 14 (1975) 208-219.

[356] E. E. Remsberg, D. Lavery, B. Crawford, Optical constants for sulfuric and nitric acids, J. Chem. Eng. Data 19 (1974) 263-265.

[357] R. T. Tisdale, D. L. Glandorf, M. A. Tolbert, O. B. Toon, Infrared optical constants of lowtemperature $\mathrm{H}_{2} \mathrm{SO}_{4}$ solutions representative of stratospheric sulfate aerosols, J. Geophys. Res. 103 (1998) 25353-25370.

[358] R. F. Niedziela, M. L. Norman, C. L. Deforest, R. E. Miller, D. R. Worsnop, A temperature and composition-dependent study of $\mathrm{H}_{2} \mathrm{SO}_{4}$ aerosol optical constants using Fourier transform and tunable diode laser infrared spectroscopy, J. Phys. Chem. A. 103 (1999) 8030-8040.

[359] U. M. Biermann, B. P. Luo, T. Peter, Absorption spectra and optical constants of binary and ternary solutions of $\mathrm{H}_{2} \mathrm{SO}_{4}, \mathrm{HNO}_{3}$, and $\mathrm{H}_{2} \mathrm{O}$ in the mid infrared at atmospheric temperatures, J. Phys. Chem. A 104 (2000) 783-793.

[360] M. R. Querry, I. L. Tyler, Reflectance and complex refractive indices in the infrared of aqueous solutions of nitric acid, J. Chem. Phys. 72 (1980) 2495-2499.

[361] M. L. Norman, J. Qian, R. E. Miller, D. R. Worsnop, Infrared complex refractive indices of supercooled liquid $\mathrm{HNO}_{3} / \mathrm{H}_{2} \mathrm{O}$ aerosols, J. Geophys. Res. 104 (1999) 30571-30584.

[362] O. B. Toon, M. A. Tolbert, B. G. Koehler, A. M. Middlebrook, J. Jordan, Infrared optical constants of $\mathrm{H}_{2} \mathrm{O}$ ice, amorphous nitric acid solutions, and nitric acid hydrates, J. Geophys. Res. 99 (1994) 25631-25654. 
[363] R. F. Niedziela, R. E. Miller, D. R. Worsnop, Temperature and Frequency-Dependent Optical Constants for Nitric Acid Dihydrate from Aerosol Spectroscopy, J. Phys. Chem. A 102 (1998) 6477-6484.

[364] L. J. Richwine, M. L. Clapp, R. E. Miller, D. R. Worsnop, Complex refractive indices in the infrared of nitric acid trihydrate aerosols, Geophys. Res. Lett. 22 (1995) 2625-2628.

[365] R. A. Sutherland, R. K. Khanna, Optical properties of organic-based aerosols produced by burning vegetation, Aerosol Sci. Technol. 14 (1991) 331-342.

[366] B. I. Magi, Q. Fu, J. Redemann, A methodology to retrieve self-consistent aerosol optical properties using common aircraft measurements, J. Geophys. Res. 112 (2007) D24S12 doi10.1029/2006JD008312.

[367] B. J. Stagg, T. T. Charalampopoulos, Refractive Indices of Pyropytic Graphite, Amorphous Carbon, and Flame Soot in the Temperature Range $25^{\circ}$ to $600^{\circ}$ C., Comb. Flame 94 (199) 381-396.

[368] C. E. L. Myhre, C. J. Nielsen, Optical properties in the UV and visible spectral region of organic acids relevant to tropospheric aerosols, Atmos. Chem. Phys. 4 (2004) 1759-1769.

[369] C. Hasenkopf, M. Beaver, M. Trainer, H. L. Dewitt, M. A. Freedman, O. B. Toon, C. P. McKay, M. A. Tolbert, Optical properties of Titan and early earth haze laboratory analogs in the mid-visible, Icarus 207 (2010) 903-913.

[370] K. J. Zarzana, D. O. De-Hann, M. A. Freedman, C. A. Hasenkopf, M. A. Tolbert, Optical Properties of the Products of $\alpha$-Dicarbonyl and Amine Reactions in Simulated Cloud Droplet, Env. Sci. Tech. 46 (2012) 4845-4851.

[371] M. R. Querry, Optical constants of minerals and other materials from the millimeter to the ultraviolet, Chemical Research, Development Engineering Center, Aberdeen, CRDEC-CR-88009, 1987.

[372] O. B. Toon, J. B. Pollack, C. Sagan, Physical Properties of the Particles Composing the Martian Dust Storm of 1971-1972, Icarus 30 (1977) 663-696.

[373] R. Wagner, T. Ajtai, K. Kandler, K. Lieke, C. Linke, T. Müller, M. Schnaiter, M. Vragel, Complex refractive indices of Saharan dust samples at visible and near UV wavelengths: a laboratory study, Atmos. Chem. Phys 12 (2012) 2491-2512.

[374] A. Sinyuk, O. Torres, O. Dubovik, Combined use of satellite and surface observations to infer the imaginary part of refractive index of Saharan dust, Geophys. Res. Lett. 30 (2003) 1081, doi10.1029/2002GL016189.

[375] E. M. Patterson, D. A. Gillette, B. H. Stockton, Complex Index of Refraction Between 300 and $700 \mathrm{~nm}$ for Saharan Aerosols, J. Geophys. Res. 82 (1977) 3153-3160.

[376] R. G. Grainger, D. M. Peters, G. E. Thomas, A. J. A. Smith, R. Siddans, E. Carboni, A. Dudhia, Measuring Volcanic Plume and Ash Properties from Space, Pyle D, T. Mather, edit., In: Remote Sensing of Volcanoes and Volcanic Processes: Integrating Observation and Modeling, Special Publ. Geo. Soc., London, 2013. 
GEISA 2015

\section{LINE PARAMETERS SUB-DATABASE}

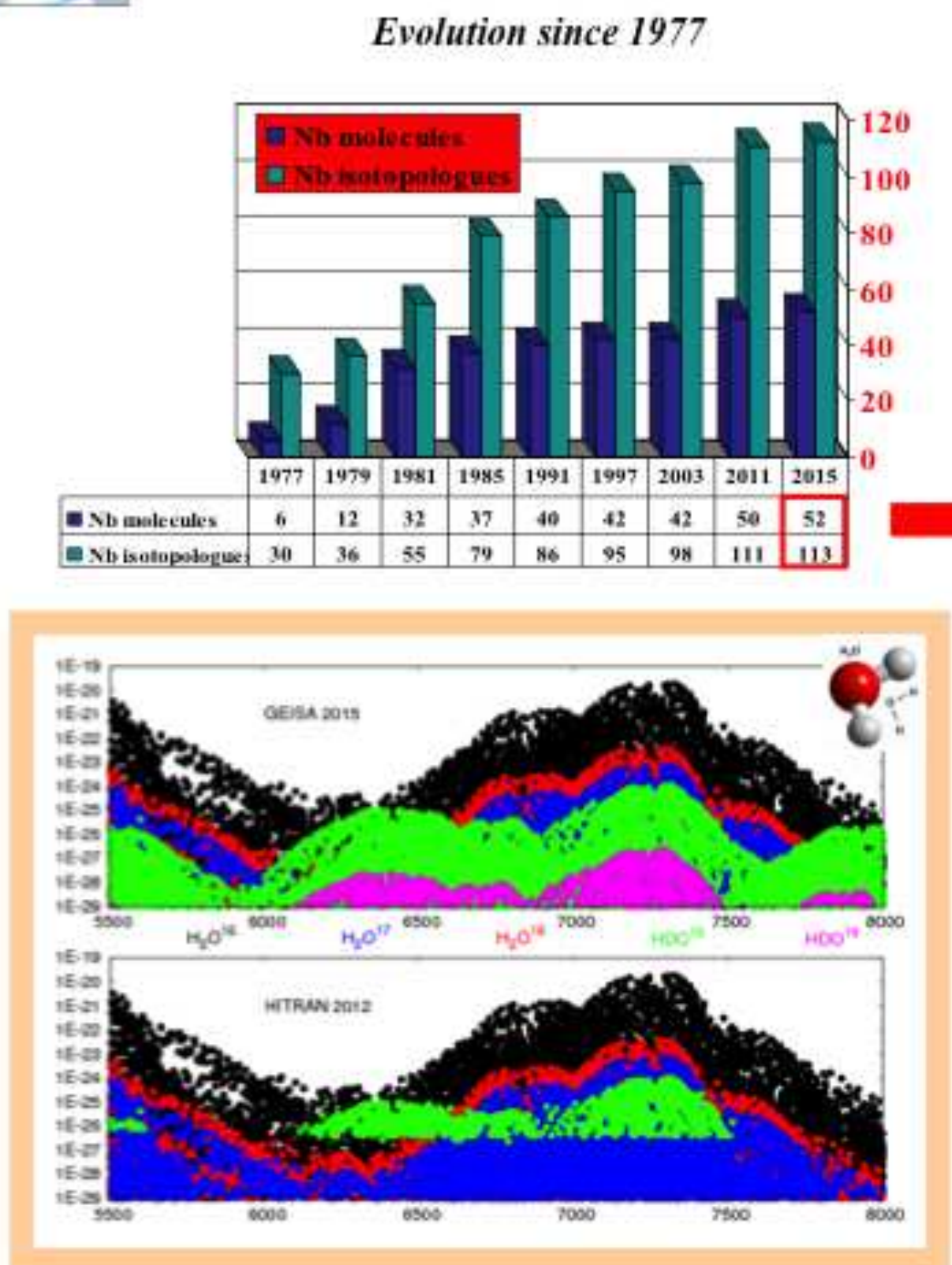

\begin{tabular}{|c|c|c|}
\hline $\begin{array}{l}\text { Molecular } \\
\text { Species }\end{array}$ & ID & Contributars \\
\hline $\mathrm{H}_{2} \mathrm{O}$ & 1 & $\begin{array}{l}\text { L. Coudert, } \\
\text { J. Tennysan, } \\
\text { A. Campargos, S. Mikhailenko, } \\
\text { O.V. Neumenko, L. Orphal, A. Ruth, } \\
\text { R.R. Gamactso }\end{array}$ \\
\hline $\mathrm{CO}_{2}$ & 2 & VI, Petevalor, S. Tobthun, R.R. Gamache \\
\hline 0 & 3 & A. Baute, S. Mikhailembo, VI.G. Tyutcrev \\
\hline $\mathrm{CH}_{4}$ & 6 & $\begin{array}{l}\text { V. Bondon, L.R. Bcown, A.Campargoe, } \\
\text { D.C. Bemer }\end{array}$ \\
\hline $0_{2}$ & 7 & S, Yu, B. Drouin \\
\hline $\mathrm{SO}_{1}$ & 9 & D. Jacquemart, H.S.P. Mullef \\
\hline $\mathrm{NH}_{3}$ & 11 & M. Down, J. Teneyson, L R. Brown \\
\hline HNO, & 13 & A.Peria \\
\hline $\mathrm{H}_{2} \mathrm{CO}$ & 21 & D. Jacyuemart, H. S.P. Maller \\
\hline $\mathrm{C}_{2} \mathrm{H}_{4}$ & 22 & LR. Beown, K.Y. Sung \\
\hline $\mathrm{CH}_{3} \mathrm{D}$ & 23 & L.R. Bronn, A. Campargue. \\
\hline $\mathrm{C}_{2} \mathrm{H}_{2}$ & 24 & D. Jacquenant \\
\hline $\mathrm{C}_{2} \mathrm{H}_{4}$ & 25 & J-M. Flaval \\
\hline $\mathrm{HCN}$ & 27 & J. Tennysos \\
\hline $\mathrm{C}_{2} \mathrm{~N}_{2}$ & 29 & A. Jolly, A. Fayt \\
\hline $\mathrm{C}_{4} \mathrm{H}_{2}$ & 30 & A. Jolly, A. Fayt \\
\hline $\mathrm{CH}_{5} \mathrm{Cl}$ & 34 & D. Jacquemart, A Nikitin, ], Beldyreva, N. Lavrenticra \\
\hline $\mathrm{H} / \mathrm{S}$ & 36 & O.Y. Naussukn, L.R. Bromt \\
\hline $\mathrm{CH}_{3} \mathrm{Br}$ & 43 & D. Jacqucmart. \\
\hline HNC & 46 & J. Tennysan \\
\hline HDO (NEW) & 51 & $\begin{array}{l}\text { A. Campargue, S. Mikhailenko, 0.V. Naumenko, } \\
\text { R.R. Gamache }\end{array}$ \\
\hline $\mathrm{SO}_{5}(\mathrm{NEW})$ & 52 & J. Tennysen, D.S. Linderwood \\
\hline
\end{tabular}

